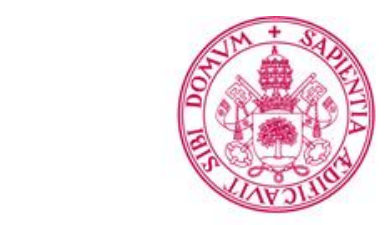

Universidad deValladolid

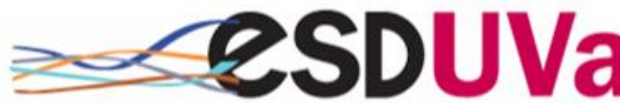

Escuela de Doctorado Universidad de Valladolid

PROGRAMA DE DOCTORADO EN ECONOMÍA

TESIS DOCTORAL:

\title{
LAS TRANSICIONES JUVENILES EN ESPAÑA: UN ANÁLISIS DE LA DESIGUALDAD Y LA DIFERENCIACIÓN
}

Presentada por Fco. Javier Sánchez Galán para optar al grado de

Doctor por la Universidad de Valladolid

Dirigida por:

Dra. Almudena Moreno Mínguez 


\section{AGRADECIMIENTOS}

En algún momento, pero solo en algún momento, me he dejado llevar por la soberbia al pensar que poco tenía que agradecer a nadie en el proceso de elaboración de un trabajo que, aunque modesto, tanto esfuerzo y horas de dedicación me ha costado. Muchas veces he reflexionado (internamente y también en voz alta ante mis alumnos) acerca de cuánto de propietarios somos de nuestras creaciones y cuánto corresponde a la sociedad y al contexto más inmediato al que pertenecemos. Lo cierto es que nada de lo que soy o de lo que tengo en estos momentos sería posible ni tendría el mismo sentido sin mi familia: mis padres, mis hermanos, mis hijos y mi esposa, Eva, quien más creyó en mí en momentos de incertidumbre en mi vida intelectual y profesional. A todos, mi agradecimiento. También destino mi agradecimiento a la UNED, una institución imprescindible que me dio la oportunidad de orientar mi vida y abrir nuevas expectativas. Gracias también a las personas que representaban a esta institución, como Pablo de Francisco, quien siempre se ha mostrado interesado por mi trabajo y, cómo no, gracias a mi directora de tesis, Almudena Moreno, que es mucho más que eso; ella me introdujo en un mundo apasionante y desconocido para mí y del que estoy firmemente convencido de que nunca saldré: la universidad.

Gracias a todos. 


\section{ÍNDICE DE CONTENIDOS}

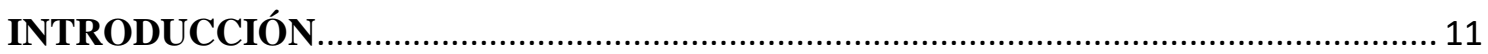

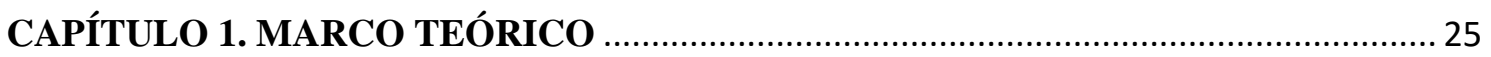

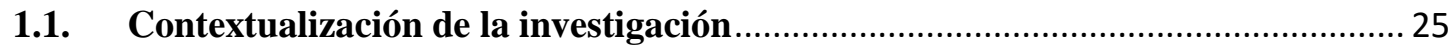

1.1.1. Las características demográficas como elementos básicos de contextualización

1.1.2. El contexto económico como elemento estructuralal. El riesgo de pobreza como factor en las diferencias y desigualdad. 28

1.2. Los conceptos de diferenciación y desigualdad ........................................................ 33

1.3. Debates en torno al concepto de juventud............................................................ 38

1.4. La perspectiva transicional o life course como enfoque adecuado en el estudio de la transición hacia la adultez.

1.4.1. Orígenes y desarrollo del life course …….......................................................... 45

1.4.2. La estructura social en la base de las diferencias y las desigualdades................ 48

1.5. Las diferentes transiciones juveniles hacia la adultez........................................... 50

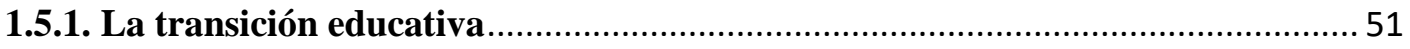

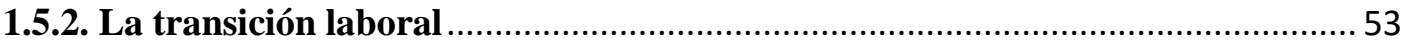

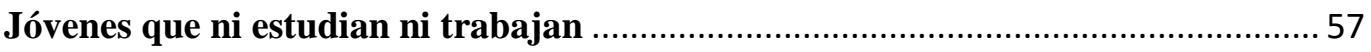

1.5.3. La transición residencial o emancipación ........................................................... 59

1.5.3.1. El cambio familiar en España ……........................................................ 59

1.5.3.2. La emancipación residencial. El apoyo intergeneracional y reproducción

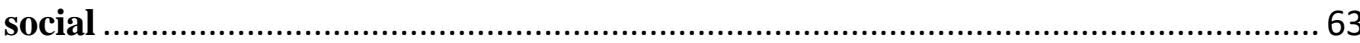

1.6. Estado de la cuestión sobre la heterogeneidad en la transición hacia la vida adulta69

CAPÍTULO 2. METODOLOGÍA Y BASES DE DATOS UTILIZADOS EN LA

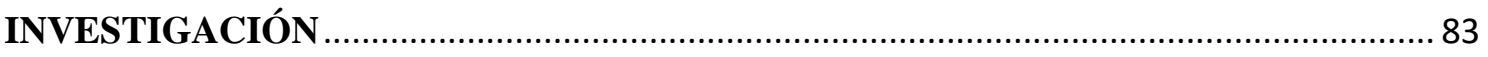

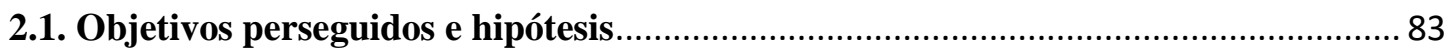

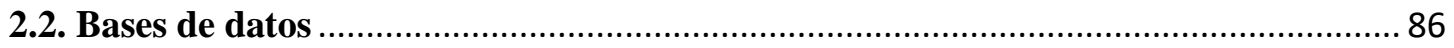

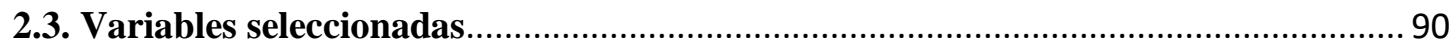

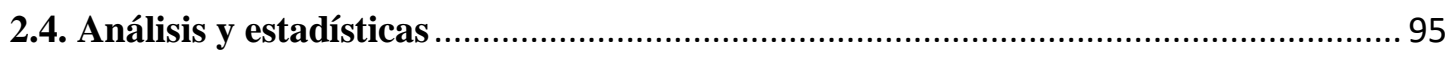

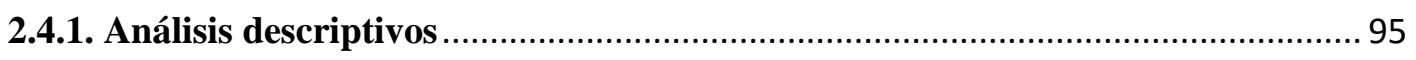

2.4.2. Análisis multivariante. Regresión logística binaria........................................... 96

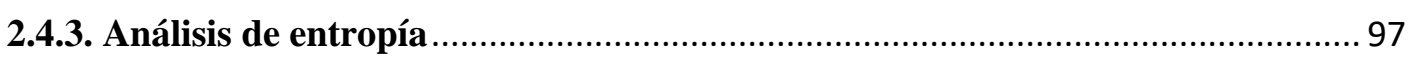

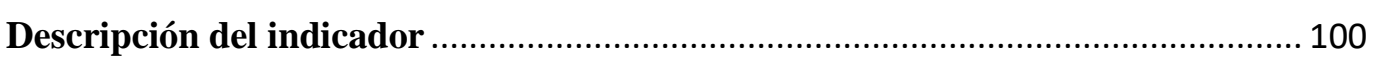

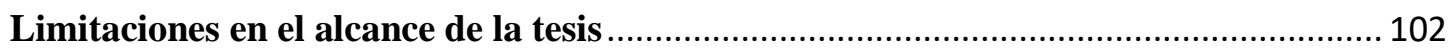


CAPÍTULO 3. Desigualdad y diferencias entre los jóvenes desde la estructura y el contexto familiar.

CAPÍTULO 4. Diferencias en las transiciones hacia la adultez.

CAPÍTULO 5. Las diferencias entre los jóvenes en la probabilidad de la ocurrencia de un evento de transición desde un modelo multivariante.

CAPÍTULO 6. La heterogeneidad en los procesos de transición vistos desde el índice de entropía.

CAPÍTULO 3. DESIGUALDAD Y DIFERENCIAS ENTRE LOS JÓVENES DESDE LA

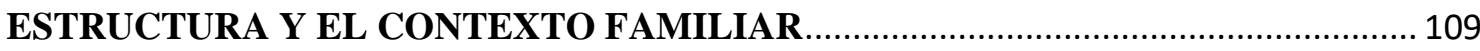

3.1. El sistema educativo. Los estudios terminados entre los jóvenes............................ 109

Estudios terminados según edad, sexo, ocupación, hábitat y renta ........................... 111

3.2. Los condicionantes económicos. Tipo de ocupación con relación a la actividad y tipo de hábitat entre los jóvenes ............................................................................................ 115

3.2.1. La actual crisis económica como elemento diferenciador................................. 115

3.2.2. Diferencias entre los jóvenes ocupados ......................................................... 119

3.3. El aporte de la educación a la empleabilidad....................................................... 124

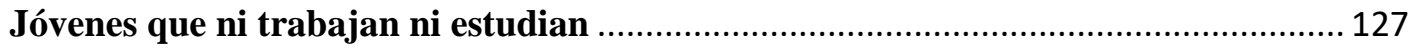

3.4. Estructura de la población española por ocupación y clase social. La influencia de la institución familiar. Reproducción sociocultural y socioeconómica ............................... 130

3.4.1. Evolución de la estructura de la población española por ocupación y clase social 130

3.4.2. Reproducción de las condiciones socioculturales 133

3.4.3. Reproducción en los jóvenes de las condiciones económicas del hogar de origen

4.1. Diversidad en los jóvenes que han experimentado los eventos de transición .......... 154

4.1.1. Jóvenes cursando algún tipo de estudios............................................................ 154

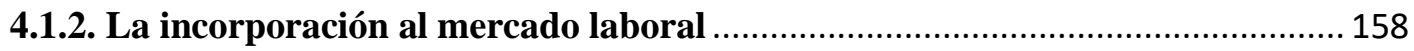

4.1.3. El abandono del hogar de origen o transición residencial ................................. 162

4.1.4. La vida en pareja y diferencias entre los jóvenes que han experimentado este

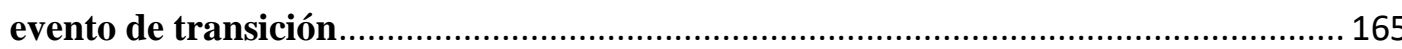

4.1.5. La maternidad/paternidad en los jóvenes como evento de transición ............... 168

4.2. La duración de los eventos de transición en diferentes periodos ............................. 171

4.3. Los cambios en la edad media a la que se experimenta cada transición .................. 175

Edad media a la que se producen las transiciones por comunidades autónomas...... 182 
5.1. Los factores que más influencia tienen en estar o no estar estudiando 188

5.2. Los factores que influyen en la incorporación al mercado laboral 189

5.3. Las causas que influyen en el abandono del hogar de origen o emancipación residencial .

5.4. Los factores que influyen en la probabilidad de vivir en pareja entre los jóvenes. 193

5.5. La experiencia en la maternidad/paternidad en los jóvenes. Los elementos que más influencia tienen

CAPÍTULO 6. LA HETEROGENEIDAD EN LOS PROCESOS DE TRANSICIÓN A TRAVÉS DEL ÍNDICE DE ENTROPÍA

6.1. La heterogeneidad de la transición antes y en la salida de la crisis 201

6.2. Diferencias por sexo. Los varones, más tiempo jóvenes que las mujeres 203

6.3. El riesgo de pobreza y las diferencias en la transición hacia la adultez 204

6.4. Heterogeneidad hacia la adultez según el grado de urbanización del hábitat donde se reside

6.5. Las causas de la heterogeneidad. El peso o influencia de cada estado (estudiando, activo, emancipado, en pareja y padre/madre) en el índice de entropía.

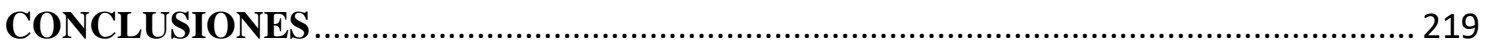

Diferencias formativas, laborales y familiares......................................................... 221

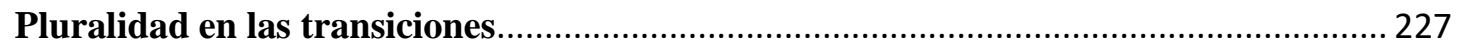

Momento de ocurrencia, duración y edad media a la que se producen los eventos de

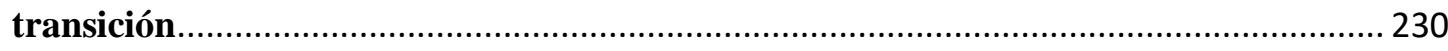

Factores determinantes de la transición.................................................................... 235

La heterogeneidad en la transición y el índice de entropía ............................................ 237

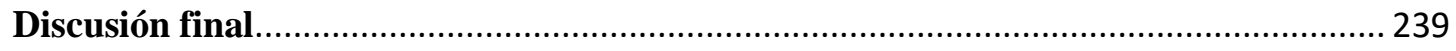

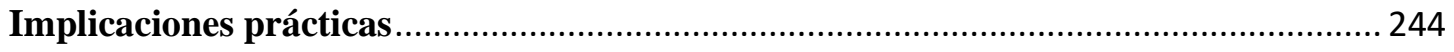

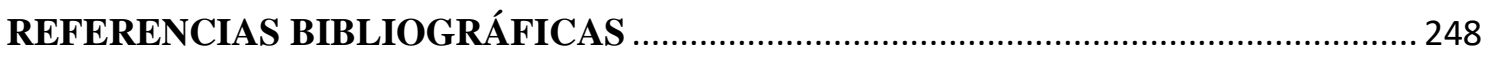

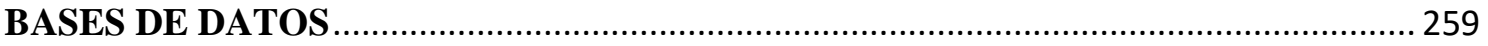




\section{INTRODUCCIÓN}

El ciclo vital de cualquier persona aparece jalonado por acontecimientos que marcan un antes y un después en su relación con el entorno y el contexto que le rodea. Son situaciones o procesos que definen nuestra identidad cultural y determinan las relaciones con la sociedad a la que pertenecemos. Es lo que en términos antropológicos se denominan ritos de paso. Celebraciones religiosas o civiles identifican buena parte de estos ritos, diferentes en cada cultura, pero en todas ellas se comparte el sentido de pertenencia a una sociedad determinada. Los procesos de transición hacia la vida adulta de los jóvenes pueden considerarse parte de esos ritos de paso, tal vez con la diferencia de que no se producen en un momento puntual, sino que es un proceso que se desarrolla en un continuo: el término del periodo formativo, la incorporación al mercado laboral, la emancipación residencial o la creación de nuevos núcleos familiares pueden considerarse elementos de ese continuo que terminaría con la obtención de la condición de persona adulta. Esta transición no se presenta exenta de dificultades y difiere sustancialmente según el momento histórico y los propios individuos, pero en buena medida se repite la secuencia (Torres y Lapa, 2010; Leccardi, 2010; Toulemon, 2010; Vieira y Miret, 2010).

Esta tesis nace con el convencimiento de que, en una realidad tan compleja como es la sociedad contemporánea, la sociedad de las tecnologías de la información, de los cambios en los procesos productivos cada vez más robotizados y en un contexto de crisis económica global que comenzó en el año 2008, los procesos de transición se complican especialmente para los jóvenes y favorecen diferentes formas de afrontarlos. El mercado laboral exige mayores niveles formativos para poder acceder a empleos cada vez más precarios que dificultan la emancipación residencial y la creación de nuevos núcleos familiares. En el caso de España, la baja competitividad, la escasa productividad, el insuficiente nivel tecnológico y la deficiente formación son elementos que contribuyen a 
acentuar las consecuencias de la crisis, en especial entre los colectivos más desfavorecidos, como son los jóvenes y las mujeres, si bien algunas situaciones no han sido causadas por la actual crisis económica, sino que son situaciones endémicas de la economía española; es el caso de la temporalidad y la precariedad en el empleo, además de altas tasas de abandono y fracaso escolar (Pérez et al., 2010); el escenario es una población joven que retrasa la edad de emancipación y la formación de nuevas familias. Por tanto, aunque la crisis ha empeorado las perspectivas de los jóvenes en cuanto a su proceso de emancipación y de transición ocupacional, relacional, etc., no es una novedad en España. En Garrido y González (2006) se analiza el mercado de trabajo, la ocupación y las clases sociales en las últimas décadas del siglo pasado, y aunque lo hacen con un cierto grado de optimismo, pues el periodo de referencia termina con unos niveles de desarrollo y de desempleo desconocidos hasta el momento y que podrían hacer pensar en el abandono de esa maldición secular que suponía en nuestro país el desempleo, no ocultan ciertos desajustes que, vistos en perspectiva, auguraban los problemas laborales que padece España en la actualidad. Es el caso de una dependencia excesiva de actividades económicas como la hostelería y la construcción y el crecimiento de la temporalidad, en especial entre la población joven. Uno de los motivos por los que estos autores mostraban su optimismo en el mercado laboral estaba fundamentado en el peso que el sector público ha mantenido, a pesar de los procesos de liberalización económica. Obviamente, esta situación ha cambiado mucho en un escenario actual donde los ajustes en los presupuestos públicos son continuos: amortización de puestos de trabajo, escasísima contratación, etc.

No corresponde en este trabajo el analizar los motivos de la crisis económica, lo que interesa en este estudio son las consecuencias, en especial en lo referente a los jóvenes y sus expectativas de futuro. No obstante, y por contextualizar el momento de los 
comienzos de la crisis, recordaré a Hessel (2011) en su alegato sobre la indiferencia, y a José Luis Sampedro, en el prólogo del citado alegato, cuestionando el modelo económico mundial que ha conducido a esta crisis e insta, junto a Hessel, a la juventud a indignarse y a tomar posiciones ante los que consideran verdaderos causantes de esta situación: sistemas financieros, mercados, gobernantes ineficaces, etc. El documental Inside Job, de Ferguson (2010), refleja la secuencia de los hechos, su origen en Estados Unidos y su rápida repercusión en el resto del mundo, especialmente en Europa; hipotecas subprime, quiebra de Lehman Brothers, etc., son cuestiones que se abordan en este documento. Nos encontramos en una sociedad globalizada donde las consecuencias de cualquier tipo de catástrofe tiene una dimensión internacional; los riesgos modernos no tienen limitaciones en el espacio y el tiempo, la era de la información y la sociedad tecnológicamente avanzada representan una nueva sociedad, una nueva cultura y una nueva economía al abrigo de las tecnologías de la información, el conocimiento y un nuevo capitalismo (Giddens, 1979; Castells, 1997; Beck, 1998; Tezanos, 2001). La juventud es uno de los colectivos más sensibles al proceso de globalización en las sociedades contemporáneas, los jóvenes sufren las consecuencias de los grandes movimientos económicos, como la deslocalización de empresas, los procesos migratorios en ambas direcciones, oportunidades de formación y empleo en otros países y la competencia de los inmigrantes en cuanto a empleo, servicios demandados, etc.

El término de los estudios y la transición laboral representan los primeros pasos en la transición hacia la adultez. El modelo del mercado de trabajo típico de los países desarrollados, o al menos el deseado, es un estado de pleno empleo con unos puestos de trabajo muy estables que aporten una seguridad financiera a los ciudadanos a medio y largo plazo. Este modelo ha triunfado en momentos de bonanza económica en países como Estados Unidos, el Reino Unido o Alemania, con unos niveles de desempleo muy 
bajos y empleos estables y relativamente bien remunerados. Por el contrario, en los países subdesarrollados o en vías de desarrollo el mercado de trabajo se caracteriza por todo lo contrario: empleo escaso, inseguro y mal remunerado, como es el caso de Brasil o China. Beck (2003) pronostica un modelo de mercado laboral para todos los países desarrollados similar al existente en los menos desarrollados, lo que denomina como la brasileñización de Occidente; apunta que esta situación no se debe asociar necesariamente a los cambios de ciclos económicos, es más bien fruto del capitalismo tecnológicamente avanzado y de la utopía neoliberal que apuesta por la desregularización y la flexibilización en exceso de las relaciones laborales. Estas reflexiones de Beck se producen varios años antes de la actual recesión económica mundial, por lo que tiene mucho sentido recordarlo. En algunos países, como es el caso de España, vemos claramente cómo este cambio en la estructura laboral se está produciendo; más desempleo, empleos precarios, temporalidad, etc., afectando a toda la población activa, pero en especial a los jóvenes. Este autor apunta la necesidad de nuevos marcos teóricos en los que apoyarse y una nueva visión de la realidad con otros ojos, no se trata de salir simplemente de la recesión económica para volver a una situación del pasado donde los empleos estables y bien remunerados sean la norma, pues esta situación es discutible que se pueda volver a producir. Ulrich Beck plantea un modelo donde la sociedad civil y la democracia directa tengan un peso decisivo en un nuevo orden institucional donde los Estados puedan descargar parte de sus responsabilidades asistenciales en la sociedad civil; es lo que Beck denomina el trabajo cívico, que conviviría con el trabajo convencional.

Este escenario, y sus consecuencias entre la población joven, representa uno de los principales motivos por los que se decide poner en marcha este estudio. Esta tesis nace de las inquietudes hacia un colectivo especialmente vulnerable en un contexto de crisis económica como el actual; tasas de desempleo que duplican a las de la población activa 
en su conjunto, dificultades para acceder a una vivienda, retraso en la formación de nuevos núcleos familiares, etc., son algunas de las principales circunstancias por las que trascurre la transición de los jóvenes hacia la vida adulta y que serán objeto de valoración. Los jóvenes y su transición hacia la vida adulta serán el objeto de estudio, pero, como se comprobará en el apartado teórico, la controversia en cuanto a este concepto es tan grande que será necesario matizarlo. Referirse a joven como una categoría social autónoma perfectamente diferenciada no es una cuestión que esté exenta de ambigüedades; el rango de edad es un elemento demasiado simple para determinar quién es joven y quién no lo es. Es cierto que desde un punto de vista operativo es la edad la variable que se utiliza en los estudios de juventud, en las políticas de discriminación positiva hacia la juventud, en la determinación de los derechos como ciudadanos, etc., pero no es menos cierto que, como se pondrá de manifiesto en esta tesis, las diferencias son tan acusadas entre los distintos rangos de edad para algunas de las cuestiones que se tratan, que hacen pensar en la necesidad de que la definición de joven incluya otras variables directamente relacionadas con los procesos de transición, como el momento de la salida del hogar de origen, el emparejamiento, la incorporación al mercado laboral, la creación de un nuevo núcleo familiar, etc. Autores como Brunet y Pizzia (2013) alertan sobre el riesgo que se corre en los estudios de juventud al no dedicar el suficiente esfuerzo a conceptualizar adecuadamente el objeto de estudio. Se hace necesario, según estos autores, una definición sociológica de la juventud cuestionando, cuando menos, las nociones demográficas, biológicas o administrativas. ¿Qué es ser joven?, ¿hasta cuándo se es joven?, ¿cuál es el intervalo de edad que comprende a las personas jóvenes?, ¿cuáles son las circunstancias que definen la juventud?, ¿cuáles las actitudes y valores de los jóvenes? Resulta complejo responder a estas preguntas; si se es joven mientras se reside en el hogar de origen, alguien con 20 años que decide emanciparse dejaría de ser joven, mientras que 
una persona con 40 años que sigue viviendo con los padres sería considerado como un joven; si optamos por delimitar la juventud con el momento del matrimonio o cualquier otro modelo de unión, nos encontraríamos en una situación igualmente contradictoria, personas con relativamente poca edad que deciden emparejarse y formar nuevos núcleos familiares y otras que deciden prolongar un modelo residencial en solitario de manera indefinida; y si nos referimos a la autonomía económica, la situación no se aclara mucho más, pues sujetos que se incorporan al mercado laboral prematuramente por necesidad o por haber sufrido fracaso escolar con 16 o 18 años no serían jóvenes, mientras que estudiantes de largo recorrido que se incorporan tardíamente a la vida laboral rondando los 30 años sí serían considerados jóvenes.

Se trata de circunstancias claramente ambiguas y contradictorias que dificultan la definición del objeto de estudio cuando nos referimos a la juventud; tal vez lo relativo a estilos de vida, pautas de comportamiento, escalas de valores, actitudes ante la realidad, unidas a otras variables ya mencionadas, como el trabajo, la emancipación, el emparejamiento o la reproducción, puedan dar una idea más clara de lo que es ser joven. Estas cuestiones se valoran en los estudios de juventud, si bien, apelando a un sentido práctico y operativo, es la edad lo que, aun cayendo en un obvio simplismo, constituye la variable que con todas las limitaciones que se han mencionado anteriormente, se utiliza para determinar cuándo un individuo es calificado como joven. Las instituciones públicas y otras de carácter privado, al elaborar datos estadísticos de diferente naturaleza, establecen a priori un intervalo de edad que contiene a las personas consideradas jóvenes dependiendo del tema de estudio de que se trate; intervalos entre 16 y 29 años, o incluso hasta los 30 o 34 años, son habituales.

En una situación de crisis económica como la actual, los jóvenes representan un colectivo especialmente vulnerable en lo que se refiere a afrontar las diferentes transiciones en su 
ciclo vital: formativa, ocupacional, residencial, relacional y parental; el objetivo general de esta tesis es valorar el grado de heterogeneidad, desigualdad y diferenciación de los jóvenes con relación a los procesos de transición hacia la adultez y a las variables que les definen (estudiar, ser activo, estar emancipado, vivir en pareja y ser padres), entendiendo esta heterogeneidad como la diversidad y multiplicidad en las maneras de afrontar los cambios en los diversos procesos que incluye la transición, como el proceso formativo, la incorporación al mercado laboral o asumir las responsabilidades de un nuevo núcleo familiar. Las formas de afrontar estos procesos se ven condicionadas por los componentes estructurales de la sociedad. A este respecto, Parsons y Merton son dos de los autores más relevantes en la defensa del funcionalismo estructural. Esta teoría se fundamenta básicamente en el constreñimiento de los hechos sociales sobre los actores. Para estos autores, los componentes estructurales son básicos en los análisis sociales, dejando un papel muy secundario a las características propias de los individuos. Estos postulados hicieron surgir críticas entre los teóricos sociales de mediados del siglo pasado, ya que se trata de una teoría muy conservadora y que acepta la legitimidad del orden social establecido por las élites. Estas críticas condujeron al desarrollo de la teoría del conflicto, inspirada en el pensamiento marxiano, pues se fija más en el cambio que en el equilibrio propio de los funcionalistas, en el conflicto más que en el orden y en los actores más que en las estructuras sociales, si bien la realidad es que las estructuras sociales son en ambas teorías la base del estudio de los hechos sociales por encima de los comportamientos individuales (Ritzer, 2001). Los procesos de transición hacia la adultez estarían condicionados por las estructuras sociales: aspectos de tipo económico, político, ideológico o religioso a una escala macro tienen influencia entre los jóvenes, por lo que esta perspectiva es adecuada para el análisis de los estudios de juventud. Por otra parte, una perspectiva individualista es complementaria: variables personales, como el nivel de 
estudios, el sexo, el origen, la renta disponible o las interacciones a un nivel micro, son válidas para determinar el grado de desigualdad y diferenciación entre los individuos, y estas características condicionan las diferentes estrategias para hacer frente a la coerción que suponen los elementos estructurales. Con estas premisas, los objetivos de esta tesis se resumen a continuación.

Como se ha comentado, el objetivo general será el valorar el grado de heterogeneidad de los jóvenes en los procesos de transición. Para ello se plantean los siguientes objetivos secundarios que en el apartado correspondiente se desarrollan con detalle: describir y valorar el grado de diferenciación en los jóvenes teniendo en cuenta las variables que más influyen en las diferentes transiciones (escolar, laboral, residencial, vida en pareja y parental) y según variables independientes, como edad, sexo, estudios terminados, relación con la actividad, etc. Igualmente, describir, valorar y comparar la edad media en la que se producen las transiciones, así como la duración de estas, también según diversas variables independientes como las comentadas. Valorar la probabilidad con la que se producen los eventos según las variables independientes seleccionadas y la significación estadísticas de estas. Valorar las consecuencias de las diferencias descritas en cuanto al comienzo y término de los procesos de transición en diferentes situaciones con coyunturas económicas distintas, por sexo, tipo de hábitat donde se reside, nivel de estudios terminados o renta del hogar de origen a través del índice de entropía.

El propósito de la tesis no es el análisis en profundidad de cada una de las cuestiones planteadas: formación, empleo, emancipación residencial, etc. Es servirse de estas variables para constatar las diferencias y la desigualdad entre los jóvenes en los procesos de transición. Es posible percibir en cada uno de los capítulos en los que se abordan los diversos problemas sociales que afectan a los jóvenes las consecuencias de la desigualdad, no los motivos ni el concepto de desigualdad propiamente, que pertenece a la esfera de lo 
filosófico en tanto construcción social subjetiva dependiendo de quién y qué se considera relevante a la hora de determinar el desigual acceso a los bienes y recursos que la sociedad valora. En este sentido, un desigual acceso a la educación condicionaría los resultados académicos; un desigual acceso a las rentas condicionaría el disfrute de los bienes y servicios; un desigual acceso al trabajo condicionaría los recursos, formas y estilos de vida; un desigual acceso a las nuevas tecnologías dificulta el acceso a la información y el conocimiento a los individuos que lo padecen, mermando su derecho como ciudadanos. Las causas de la desigualdad habría que buscarlas en el estudio de las constricciones sociales que lo determinan, tanto en el ámbito individual como en el interrelacional y en el estructural. En este sentido, es posible pensar en cómo, por ejemplo, el nivel educativo depende de factores individuales como el esfuerzo, pero ese esfuerzo puede estar condicionado por las expectativas familiares, por las condiciones económicas, por cuestiones de procedencia o etnicidad, etc. Estos condicionantes, entre otras consideraciones, obligan a definir los sujetos, los grupos sociales o las categorías sociales en su pluralidad y no encorsetados en definiciones simples, por muy operativas que sean desde el punto de vista administrativo o político, como puede ser la edad o rango de edad al que se pertenece.

Esta tesis no es un estudio atemporal, no es extrapolable ni en el espacio ni en el tiempo, tiene sentido en un contexto y momento histórico determinado; tiene como objeto de estudio la situación de un sector de la población en España, en una coyuntura económica condicionada por la actual crisis económica y la evolución de unos procesos demográficos que determinan una sociedad en continuo envejecimiento. Por último, el sentido práctico que se pretende alcanzar con este estudio es poner de manifiesto las diferencias y desigualdades en los procesos de transición desde la juventud hacia la adultez de tal manera que las dificultades que tienen que hacer frente las personas no deberían 
encorsetarse en cohortes de edad. Es necesario tener en cuenta otros factores para poder evaluar con objetividad estas necesidades. Desde las administraciones públicas se deberían valorar estas diferencias a la hora de la aplicación de políticas de discriminación positiva hacia un colectivo determinado, pues basar estas políticas únicamente en la edad resultaría injusto a tenor de las grandes diferencias que en adelante se evidenciarán. Por haber nacido un día antes o después es posible tener o no acceso a una ayuda a la emancipación residencial, por haber nacido un día antes o después es posible acceder, o no, a un plan de empleo o de formación, por haber nacido un día antes o después se permite, o no, consumir bebidas alcohólicas, acceder a determinados locales, consentir relaciones sexuales, tener responsabilidades penales o no tenerlas, etc.; por muy operativo que sea el hecho de determinar una edad para este tipo de decisiones legales o administrativas, no se debería caer en el simplismo que esto supone. Es necesario articular otros mecanismos que aporten una mayor coherencia y justicia, deberían ser las necesidades reales las que den acceso a determinados derechos, ayudas o cualquier otra atribución que los Estados, a través de las administraciones públicas, consideren adecuadas para hacer efectiva la igualdad de derechos y obligaciones de todos los ciudadanos con independencia de la edad.

La estructura de esta tesis sigue las normas establecidas para cualquier trabajo de investigación en las ciencias sociales. Las tres etapas en las que puede dividirse el complejo proceso que supone emprender una investigación social son: las condiciones antecedentes de la investigación, la observación, experimentación y medición, y el análisis y la interpretación de los datos (Gómez, 2003; Corbetta, 2007). Siguiendo básicamente este itinerario, la distribución es la siguiente:

En la introducción se contextualiza y fundamenta el interés que tiene el tema que se va a investigar, se ha planteado cuál ha sido la motivación para seleccionar el tema de estudio 
y se ha descrito una realidad económica compleja, donde la población joven tiene especiales dificultades para afrontar las diversas etapas en su ciclo vital. Se ha comentado la controversia del concepto de joven y se continuará haciendo con más detenimiento en el apartado teórico. En este apartado también se han avanzado los objetivos que se persiguen.

En el capítulo que corresponde al apoyo teórico de esta tesis, se clarifican algunos de los conceptos más utilizados en la misma, como son la heterogeneidad o diferenciación, la desigualdad o el concepto de joven, y se describe el enfoque teórico del life course o curso de vida, así como aquellas interpretaciones y estudios relacionados con la transición de los jóvenes hacia la adultez que ha sido posible consultar.

En el apartado metodológico se presenta la hipótesis, los modelos de análisis y las fuentes y bases de datos utilizadas en la investigación, así como las variables y los parámetros estadísticos que se han seleccionado. Se trata de una investigación cuantitativa con datos secundarios obtenidos básicamente de la ECV (Encuesta de Condiciones de Vida) que el INE (Instituto Nacional de Estadística) realiza anualmente. Para ello, se han descargado los ficheros de microdatos que el INE ofrece y se ha utilizado el programa estadístico SPSS para la obtención de los diferentes indicadores.

El bloque que corresponde al análisis de datos está formado por cuatro capítulos. El primero, que correspondería con el capítulo tres, se ocupa del análisis de los condicionantes estructurales en las transiciones de los jóvenes. En él se recuerda la coyuntura económica en la que nos encontramos actualmente y su influencia con el desempleo, el nivel de estudios de los jóvenes, la relación entre la formación y el desempleo, etc., cuestiones que pondrán de manifiesto el alto grado de diferenciación y desigualdad para estas variables. En este capítulo también se describen elementos relacionados con la familia, como es la reproducción de las condiciones socioeconómicas 
y socioculturales de padres a hijos, donde se mostrará la influencia que tiene el hogar de origen en las condiciones socioeconómicas y socioculturales de los jóvenes de más de 25 años en lo que se refiere a los estudios terminados y su situación económica. En el segundo de los capítulos del bloque de análisis de resultado, y que correspondería al capítulo cuatro de la tesis, se describen las diferentes transiciones hacia la adultez, la transición escolar, la transición laboral, residencial, conyugal o cualquier modelo de vida en pareja y parental en función de distintas variables independientes. Estas transiciones estarían definidas por cada una de las variables dicotómicas que en la parte metodológica se describirán: estudia, activo, emancipado, cónyuge o vida en pareja y padre. En el capítulo cinco se ofrece un análisis de regresión logística para estas variables y en él se observará la influencia que tienen las variables independientes, que serán habituales en toda la tesis como, la edad, el sexo, la coyuntura económica, el riesgo de pobreza, etc. Por último, en el capítulo sexto se analizan las diferencias a través de los índices de entropía para la distribución de posibles combinaciones de estatus de entre los que se van a considerar en el tránsito hacia la adultez (ser estudiante o no serlo, ser activo o no activo, estar emancipado o no estarlo, tener cónyuge o pareja de hecho o no tenerlo y ser o no ser padres). Se trata de un indicador utilizado originalmente en física para medir el grado de complejidad en un sistema y que es posible utilizar en ciencias sociales, como en el caso que nos ocupa, para medir la heterogeneidad en el tránsito hacia la vida adulta a través de la combinación de estados que se ha considerado. El objetivo de este análisis es valorar la mayor o menor complejidad en la combinación de estatus elegida por intervalos de edad, con el fin de vislumbrar nuevamente las diferencias halladas en el colectivo estudiado en función de diferentes variables como el sexo, la renta del hogar de origen, la edad, etc., además de comparar la entropía en dos periodos de distinta coyuntura 
económica, con el fin de detectar hipotéticos retrasos en el comienzo y en el final del proceso de transición.

Si bien en los capítulos correspondientes ya se adelantan conclusiones parciales, la tesis termina con el apartado relativo a las conclusiones finales, las referencias bibliográficas citadas y las bases de datos. 


\section{CAPÍTULO 1. MARCO TEÓRICO}

\subsection{Contextualización de la investigación}

La importancia del contexto está presente en los diferentes enfoques o perspectivas teóricas que fijan la atención en los procesos de transición; desde el life course y la perspectiva estructural es una cuestión clara la importancia que se presta a este tipo de factores, como se comprobará más adelante, pero también desde postulados más psicologistas y biográficos, ya que los comportamientos y las decisiones personales no se producen en un vacío social; por este motivo, lo primero que se presenta en este marco teórico son algunas consideraciones sobre los aspectos estructurales que mejor podrían definir el contexto: la demografía y las cuestiones económicas.

\subsubsection{Las características demográficas como elementos básicos de contextualización}

La demografía previa a los procesos industriales de las sociedades modernas se caracterizaba por una tasa de natalidad muy elevada, pero igualmente una tasa de mortalidad elevada; las deficientes condiciones sanitarias y de nutrición, las epidemias, las guerras, etc., además de los escasos conocimientos médicos, propiciaban un crecimiento de la población muy pequeño y una esperanza de vida nada comparable a la de la actualidad (Livi Bacci, 2001). La transición demográfica en el periodo de los grandes avances tecnológicos de la Revolución Industrial tuvo repercusión en las condiciones sanitarias, mejoras en la nutrición y avances en medicina, lo que favoreció una disminución de la tasa de mortalidad que, con el mantenimiento de los índices de fecundidad, propició un aumento de la población y de la esperanza de vida. En la sociedad contemporánea, los avances en medicina, las mejoras sanitarias y una nutrición adecuada 
son factores que influyen en una esperanza de vida elevada de la población que, junto a un descenso en la tasa de fecundidad también muy acusado, favorecen unas sociedades, como es el caso de los países occidentales, que se encuentran en continuo proceso de envejecimiento, pero estables en número o incluso aumentando.

Para MacInnes y Pérez (2005) es más correcto hablar de revolución reproductiva frente a transición demográfica, pues consideran que el cambio que ha experimentado la eficiencia en la reproducción humana es comparable a las revoluciones industrial y política, hasta el punto de observar que la población crece aun con índices de fecundidad a priori por debajo del nivel de remplazo. El nuevo concepto sería más adecuado para valorar desde una perspectiva longitudinal las cuestiones demográficas más allá de la influencia de acontecimientos sociales y económicos trasversales, y su repercusión en los hechos e instituciones sociales como la familia, los diferentes ciclos vitales, la fecundidad o el envejecimiento. La demografía tiene claves explicativas fundamentales para el resto de las ciencias sociales, porque su núcleo temático, a saber, la vida, la muerte y su resultado, la reproducción, atraviesan e impregnan cualquier ámbito de la vida individual y social (MacInnes y Pérez, 2008). Discernir si son los ciclos demográficos los que condicionan aspectos de tipo social, económico o político, o si son estos últimos elementos los que condicionan los ciclos demográficos, son cuestiones que han merecido la atención de los científicos sociales desde diferentes planteamientos, tanto sociológicos como económicos. Estas cuestiones son tratadas ampliamente por Rodríguez (1994) en Ciclos demográficos, una perspectiva socioeconómica, donde, a través de las aportaciones teóricas de Richard A. Easterlin, aporta explicaciones sociológicas y económicas a los ciclos demográficos desde dos planteamientos complementarios y no enfrentados: un modelo micro basado en condicionantes socioeconómicos y un modelo 
macro que denomina la hipótesis de la renta relativa, donde los aspectos demográficos estarían influenciados por la renta potencial prevista a medio plazo por las familias.

Los diferentes indicadores demográficos, y en especial el índice de fecundidad y la esperanza de vida, están condicionando el cambio de las pirámides de población en los países occidentales. Unos índices de fecundidad muy bajos, claramente por debajo del nivel de remplazo, y una esperanza de vida elevada están suponiendo un progresivo envejecimiento de la población. Así lo constata Moreno (2013) en Informe 2012, Juventud en España, donde se hace eco de la preocupación en los países europeos, pues unas cohortes de personas en edad de trabajar cada vez menores dificultarían el mantenimiento del actual sistema de seguridad social, con una población dependiente muy numerosa con relación a la población activa. En este sentido, igualmente Macunovich (2012) constata empíricamente la importancia que supondría en la economía un aumento de las cohortes jóvenes con efectos positivos en el producto interior bruto, mientras que una disminución de estas tendría efectos negativos.

El envejecimiento demográfico presenta diferentes puntos de vista más allá de los catastrofistas, que auguran un desmantelamiento progresivo de los estados de bienestar en lo referente a la prestación de recursos y servicios a los mayores por la llamada relación de dependencia. En este sentido, MacInnes y Pérez (2008) se refieren a un planteamiento tendencioso tanto en el léxico, «envejecimiento demográfico», como en sus consecuencias, pues según estos autores no está justificado este punto de vista, pues existen evidencias empíricas que demostrarían más bien todo lo contrario. El fundamento de estas posturas apocalípticas por el aumento de la media de la edad de la población estaría motivado por esa relación de dependencia, según la cual cada vez hay menos personas en edad productiva y más en edad de dependencia. Los autores contrarrestan este argumento indicando que no se tienen en cuenta factores como la productividad, en 
continuo aumento en la sociedad moderna, de tal manera que estudios longitudinales entre generaciones muestran unos resultados favorables continuados a favor del colectivo productivo con independencia de su número. Garrido et al. (2005) estiman una disminución del 40 \% en la relación de dependencia entre 1985 y 2030, y consideraciones similares se encuentran en Blanes et al. (1996). El debate sobre el futuro de las prestaciones sociales y, en especial, las pensiones, no ha concluido y posturas enfrentadas en el terreno político y académico tendrán que aportar argumentos basados en investigaciones que proporcionen una mayor claridad a esta cuestión.

Según las proyecciones ofrecidas por el INE (Instituto Nacional de Estadística), la población total no experimentaría un cambio significativo a medio plazo y, de ser así, la tendencia sería hacia un aumento de población, por lo que, teniendo en cuenta la disminución continuada de los jóvenes, la población en España está abocada a un envejecimiento progresivo. No existe un consenso unánime, como ya se ha comentado, con relación a considerar este hecho como un problema, pero es evidente que, si la población no activa crece y no lo hace la activa, debería implicar una mayor productividad por activo para mantener el actual modelo de bienestar; obviamente, esta circunstancia tiene relación con las futuras ocupaciones y niveles formativos de la generación de jóvenes actuales y, cómo no, de las desigualdades y diferencias que existen en el acceso a estas ocupaciones y planes formativos. Estas cuestiones se tratan con detenimiento más adelante.

\subsubsection{El contexto económico como elemento estructuralal. El riesgo de pobreza como factor en las diferencias y desigualdad.}

A demás de la demografía como factor básico de contextualización, como se ha señalado en el epígrafe anterior, el sistema económico y los ciclos económicos que se suceden 
provocan desigualdades en la distribución de los recursos en la sociedad que suponen igualmente un factor a tener en cuenta en el contexto en el que se producen los hecho sociales y en concreto los procesos de transición hacia la vida adulta. Las carencias económicas están detrás de los procesos de exclusión social, con relación a la educación, trabajo, acceso a una vivienda, etc. Si bien el concepto de pobreza es ambiguo, ¿quién es pobre? ¿cuál sería la medida de la pobreza? ¿se puede medir igual en todas las comunidades? Diferentes indicadores y definiciones se utilizan en las investigaciones que tienen como objeto de estudio la pobreza, a continuación se ofrecen algunos apuntes sobre este debate.

El concepto de pobreza se podría abordar básicamente desde dos perspectivas: la pobreza relativa, que hace referencia a la privación de recursos que experimentan algunas personas en relación con el resto de la sociedad a la que pertenece; y pobreza absoluta, que se refiere a una privación de recursos tal que pone en peligro la misma supervivencia de las personas (Macionis y Plummer, 1999). Se trata de dos perspectivas que no dejan de ser controvertidas en tanto no responden a qué entiende una sociedad determinada por un nivel de vida digno y cómo contabilizar a quienes no lo disfrutan. Desde un punto de vista operativo existen una serie de indicadores homologados sobre los que hay un cierto consenso en la comunidad internacional con el fin de poder calcular y valorar las situaciones de privación de recursos. Con independencia del enfoque que se quiera dar al concepto de pobreza y exclusión social, más centrado en la pobreza, en la formación, en la participación social, política, etc., lo cierto es que es un enfoque multidimensional de una situación de precariedad de las personas o grupos de personas. Silver (2007), en una reseña de estudios sobre exclusión social, apunta claramente cómo la pobreza crónica y la exclusión social son fenómenos distintos y que no existe una correlación empírica entre indicadores de exclusión y pobreza; exclusión social es un concepto más rico que el de 
pobreza, pues se puede no ser pobre y sufrir algún tipo de exclusión social, si bien en los últimos años en los documentos, acuerdos, estudios, etc., dentro de la UE se utiliza habitualmente como sinónimo de pobreza, apareciendo los dos términos indistintamente.

El componente subjetivo que tienen los conceptos de pobreza y exclusión social hace que diferentes investigadores elaboren enfoques propios dependiendo el tipo de variables que se tienen en cuenta. En este sentido, Albert y Davia (2011) presentan un estudio sobre pobreza y exclusión social de los jóvenes con carácter multivariable atendiendo a tres enfoques: el monetario, la privación material y la exclusión educativa. Así, los diferentes perfiles de pobreza afectan de diferente manera a los jóvenes; los jóvenes emancipados tendrían un mayor riesgo de pobreza monetaria, con independencia del sexo, y la exclusión educativa está muy directamente relacionada con la renta del hogar. Con la excepción de los problemas de vivienda, los mayores logros educativos protegen en buena medida de la pobreza monetaria y la privación material de bienes. En el mismo sentido, se ha observado una mayor pobreza entre los jóvenes en el momento de la emancipación, con especial incidencia en los países del norte de Europa. Esta situación se acentúa cuando se está en desempleo y hay hijos de por medio; la vida en pareja suaviza en parte los riesgos de pobreza frente a la emancipación individual (Aassve et al. 2005; Fahmy 2007).

Los jóvenes españoles se sienten ajenos e incomprendidos con la sociedad que les ha tocado vivir, pues a pesar de haber incorporado a su ideario moral y ético elementos novedosos, como la tolerancia, la flexibilidad, la apertura a diferentes grupos y clases sociales, etc., la sociedad no les aporta los elementos necesarios para poder afrontar un proyecto de vida con garantías; rechazan la desigualdad y creen en una sociedad justa y solidaria, pero ven cómo sus problemas centrales, como la vivienda o el empleo, no se solucionan (Sánchez y Sotomayor, 2009). Las mismas autoras identifican algunas características según las cuales los jóvenes piensan que debe ser la sociedad quien 
solucione sus problemas, pero donde parece que no tienen sitio estas nuevas generaciones es precisamente en la sociedad; consideran que ser joven es dinamismo y acción, pero los jóvenes apenas actúan, tienen voluntad de participación, pero participan poco, tienen opinión sobre los problemas, pero no se implican y sienten la necesidad de cambio, pero tampoco se comprometen políticamente. Sin embargo en el análisis realizado por Merino (2006) sobre participación y asociacionismo en los jóvenes europeos y a pesar de constatar una menor incidencia en los países mediterráneos en lo que se refiere a afiliación frente a los países nórdicos sí que ha observado convergencia en temas de difusión teórica y política. Más recientemente los datos ofrecidos por el eurobarómetro de la primavera de 2014 («European Youth in 2014») sobre jóvenes europeos, en el que se ofrecen los resultados de una encuesta realizada en la UE-28 a jóvenes de entre 16 y 30 años a quienes se preguntó sobre empleo, educación, revolución digital, valores europeos, participación de los jóvenes, etc., con resultados que, a pesar de las diferencias por edad, formación, sexo o procedencia, muestran claramente cómo los jóvenes europeos sí tienen interés, les preocupan y participan de las cuestiones públicas y opinan sobre todo los que les rodea y, lógicamente, afecta. Remitiéndonos a esta encuesta, un $18 \%$ de estos jóvenes tienen un fuerte sentimiento de exclusión, sin diferencias notables por sexos, pero sí por edades; son las cohortes de mayor edad los que se sienten en mayor medida excluidos, con un $22 \%$, que se manifiesta de esta manera: la preocupación por el desempleo en general es la cuestión que más inquieta a los jóvenes, con un $45 \%$ de respuestas, seguido del desempleo juvenil, con un $27 \%$, desigualdades sociales, inmigración, deuda de los Estados, etc. Curiosamente, en el desglose por países, España no es uno de los países donde más preocupa el desempleo juvenil. Siendo uno de los que mayores tasas de desempleo presenta en este colectivo, está justo en la media, con ese $27 \%$, pero muy por debajo de la preocupación que tienen los jóvenes italianos, con el 37\%, el $33 \%$ los 
franceses o el $29 \%$ de los jóvenes del Reino Unido. En cuanto a la participación en la vida pública, no se limita al voto en los periodos electorales, donde dicen participar el $44 \%$. También les parece importante la ayuda a los más necesitados, con un $35 \%$; colaboración en ONG, partidos políticos, sindicatos, etc., son actividades de la vida pública en las que los jóvenes dicen participar. En la pregunta: «En su opinión, ¿cuál de los siguientes valores debería defender prioritariamente el Parlamento Europeo?», lo más significativo es la mayor concienciación sobre la igualdad entre hombre y mujeres, con 14 puntos por encima de la media en cuanto a las diferencias que presenta España frente al conjunto de la UE. En otros países de la UE se observan diferencias por sexo, siendo significativas las que corresponden a la prioridad por el respeto a los derechos humanos y a la igualdad entre sexos, que es significativamente mayor entre las mujeres que entre los varones. Por intervalos de edad también se observan diferentes grados de prioridad para la misma cuestión, los de más edad son más sensibles a cuestiones como el diálogo entre culturas, mientras que los de menor edad apuestan más por la abolición de la pena de muerte en el mundo que los de mayor edad. Esta encuesta aporta suficiente información como para afirmar que los jóvenes europeos no se muestran pasivos ante los problemas propios o ajenos, además de mostrar un fuerte sentimiento de sensibilización ante la exclusión social. En cualquier caso una de las características de los jóvenes con relación a su compromiso social y político es la pluralidad de significados que confluyen en sus universos políticos (Benedicto, 2008) este autor revisa algunos de los presupuestos teóricos de orientación negativa con relación al compromiso político de los jóvenes, constatando evidencias empíricas que ponen de manifiesto la complejidad del compromiso político entre los jóvenes españoles y del resto de Europa. Constata la necesidad de abandonar esa visión negativa de los jóvenes en cuanto a su compromiso político y social, pues se produce este hecho y el contrario (apatía, desinterés ...) al igual 
que sucede en los adultos. A tenor de esta complejidad y diversidad Benedicto recomienda huir del debate simplista de jóvenes comprometidos o no comprometidos en lo público, en favor de la aceptación de diferentes culturas políticas. La juventud post moderna estaría caracterizada por la ausencia de certezas y un carácter híbrido e inestable del compromiso con lo social que fomentaría la pluralidad.

\subsection{Los conceptos de diferenciación y desigualdad}

El objetivo general de esta tesis es el análisis de las diferencias y desigualdad de los jóvenes en los procesos de transición hacia la vida adulta. Estas diferencias determinarían el grado de heterogeneidad en el momento de afrontar estos procesos. Las personas somos diferentes no solo por nuestras características de tipo biológico, también por nuestras distintas ocupaciones, nuestro origen, los papeles que desempeñamos, etc.; las diferencias entre individuos o grupos de individuos es algo consustancial al ser humano, desde cuestiones culturales, valores sociales, características psicológicas, hasta aspectos más individuales como la edad, el sexo, la nacionalidad o la raza, que representan elementos de diferenciación entre los individuos. La diferenciación social suele ser la antesala de la desigualdad; ser hombre o mujer, europeo o africano, joven o adulto, no tendría por qué tener consecuencias en cuanto al acceso a los bienes y servicios que una sociedad valora, o en el acceso a la educación o al mercado laboral y, sin embargo, las mujeres tienen más dificultad para encontrar un empleo y cobran por término medio menos salario desempeñando una igual ocupación; de la misma manera, el origen tampoco debería ser causa de desigualdad a priori. Sin embargo, en sociedades donde conviven diferentes razas no todas tienen igual acceso a la riqueza y a los bienes, pudiendo en este caso producirse problemas de desintegración y exclusión social. Por tanto, sí es posible afirmar 
que la diferenciación social es la antesala a la desigualdad o, lo que es lo mismo, al diferente acceso a los bienes y servicios que la sociedad valora. Hablar de estratificación social es decir que las desigualdades se han institucionalizado, que dentro de una sociedad se admite que existen diferentes estratos o capas sociales con desigual acceso a los bienes y servicios (Báñez, 1991; Kerbo, 2004).

Desde los diferentes paradigmas o perspectivas sociológicas se han aportado respuestas al porqué de esta desigual distribución de la riqueza en la sociedad. Para la escuela funcionalista la estratificación social desempeña un papel crucial en el correcto funcionamiento de las sociedades. La estratificación social tiene resultados positivos para la sociedad en su conjunto, existen muchas ocupaciones diferentes en las sociedades modernas, unas más sencillas de realizar y otras más complejas; estas últimas suelen ser más necesarias para el buen funcionamiento de la sociedad, por lo que hay que recompensar a quienes las realizan con mayores ingresos, más poder, prestigio, etc., lo que causa como resultado la desigual distribución de los recursos (Macionis y Plummer, 1999; Ritzer y Casado, 2001). Este planteamiento desemboca necesariamente en una sociedad meritocrática, en el sentido de que solo deben existir desigualdades en función de los esfuerzos y méritos personales, pero no explica la desigualdad cuando las ocupaciones de alta cualificación e influencia en la sociedad tienen menos ingresos que ocupaciones de baja cualificación y menos relevantes para la sociedad, y tampoco por qué están peor remuneradas las ocupaciones tradicionalmente femeninas, por ejemplo. Desde la perspectiva de las teorías del conflicto, la estratificación social no beneficia al conjunto de la población, sino que favorece a unos sectores frente a otros; la disparidad de riqueza y poder entre quienes poseen los medios de producción y los trabajadores caracteriza a los sistemas capitalistas; para esta perspectiva, esta situación provoca una mayoría cada vez más pobre y una minoría cada vez más rica. Por otra parte, las 
instituciones políticas, el derecho, las leyes, el sistema educativo o el sistema religioso, garantizarían y legitimarían que las desigualdades sociales se reproduzcan de generación en generación (Macionis y Plummer, 1999; Ritzer y Casado, 2001).

Las teorías clásicas sobre la desigualdad y estratificación social raramente se reflejan en pureza en una sociedad, al menos en las sociedades occidentales. Surgen perspectivas que se apoyan en menor o mayor medida en las teorías originales, pero con matices. En este sentido, Torres (1999) plantea una nueva tipología de la desigualdad más allá de las económicas: intergrupales o clases sociales. Se trata de desigualdades sobrevenidas por la crisis de los estados de bienestar que afectan a los individuos aisladamente y no tanto a los grupos o clases sociales; se generan a lo largo del ciclo vital de las personas y son de difícil medición y detección por los procedimientos estadísticos disponibles. Esta nueva tipología no excluye la desigualdad estructural entre grupos, sino que se suma a ella con unas características y consecuencias diferentes. Acontecimientos puntuales y, en ocasiones, por azar, pueden generar la exclusión de individuos dentro de su propio grupo o clase social, como es el caso de un divorcio mal gestionado, un accidente de tráfico, un despido del trabajo, etc. Las legislaciones en los países occidentales garantizan el derecho al trabajo, a la educación, a una vivienda..., sin embargo, esta dotación igualitaria de servicios y recursos no está asegurada, porque este mecanismo no incluye a las contingencias dentro de los grupos. Torres pone como ejemplo el fracaso escolar, que tiene multitud de causas y que no se acometen a nivel intragrupal dentro de las propias clases sociales. El autor apunta algunas características de esta nueva tipología de desigualdad; en primer lugar, señala que mientras las diferencias entre grupos pueden tender a un incremento de la solidaridad, o sentido de pertenencia entre los miembros de la misma clase, en los casos de desigualdad dentro de los grupos el sentimiento de frustración genera más fácilmente exclusión social. Torres se pregunta por el vínculo 
entre el trabajador ocupado y el parado, o cuál es la referencia de clase de la madre soltera, del jubilado forzoso o del joven sin empleo; otra característica es la difícil percepción institucional de este tipo de desigualdad. Se produce en una dimensión individual de difícil identificación, y más en un contexto con derechos reconocidos formalmente para todos los ciudadanos; por último, otra característica sería la dificultad de su constatación empírica por los procedimientos estadísticos disponibles, más orientados a las inferencias hacia grupos de población que hacia individuos.

Es necesario un enfoque multidimensional para referirse a la desigualdad y las causas de su presencia, como el que ofrece Reygadas (2004), haciendo referencia a las cualidades de los individuos, al tipo de relaciones que se establece entre ellos y a las constricciones de las estructuras sociales. En cuanto al primero de los aspectos, indica el autor que más allá de las cualidades personales, como la creatividad o la inteligencia, existen otros aspectos más difíciles de valorar, pero que también pertenecen a la esfera de lo individual, que son los de tipo social, como el capital cultural, la condición social o la raza. En el análisis de los individuos aisladamente sería posible determinar cuáles son los factores que hacen que unas personas tengan mayor facilidad de acceder a los bienes y riquezas que otras, pero no es posible explicar cómo se han construido estas diferencias; las capacidades y condiciones individuales tienen un origen social, no dependen únicamente de su genética: condiciones familiares, capital cultural, académico, además de la inexistencia de criterios unánimes a la hora de determinar qué características o condiciones son consideradas mejores o peores, no son principios o reglas que dependan o pertenezcan a los individuos, ya que es la sociedad la que determina estos criterios. Es necesario, siguiendo al mismo autor, considerar otras dimensiones de la desigualdad, como es la que hace referencia a los campos de interacción. Según esta perspectiva, no solamente las competencias personales, que tienen un marcado condicionante social, 
regulan el grado de acceso a los recursos, también las interacciones tienen un papel importante. Así, las interacciones influyen en la desigualdad, las capacidades individuales se entrelazan con las normas, el poder, los procesos culturales y demás entramados sociales. Dos jóvenes con parecidas capacidades personales pueden tener diferentes posibilidades de acceso a un empleo o diferentes retribuciones en función de sus redes de relaciones, influencias políticas o influencia del parentesco. Las capacidades individuales, junto a los campos de interacción social, influirían decisivamente en el diferente acceso a los bienes y recursos. No obstante, sería necesaria una tercera dimensión que aportara igualmente información y explicaciones en cuanto a la desigualad: sería la perspectiva relacionada con las estructuras sociales en un sentido más amplio. Este último aspecto hace referencia a la capacidad de acumulación de los grandes colectivos, como las empresas, el tercer sector o administraciones públicas en sus diferentes niveles, locales, regionales, países o agrupaciones internacionales, las relaciones entre ellos y la distribución de las riquezas a través de las redes de conocimiento, las economías de escala, etc.

Los diferentes enfoques presentados en torno a la diferenciación y desigualdad justificarían el interés por explorar las diferencias en un colectivo al que a priori se le supone cierta homogeneidad por el hecho de compartir una edad. En adelante se explorarán estas diferencias en el intervalo de edad donde se producen los eventos más representativos de la transición hacia la adultez y se evidenciarán las diferencias observadas. 


\subsection{Debates en torno al concepto de juventud}

Las primeras definiciones modernas sobre el concepto de adolescencia y juventud se las debemos a John Locke y a Jean-Jacques Rousseau, que en la obra Émile describe a la adolescencia como individuos con un carácter especial e independiente, sin prestar más atención a esta noción; tampoco teóricos sociales como Marx o Weber se ocupan en sus obras sobre cuestiones de juventud, estando más preocupados por los aspectos macrosociales, como la clase o la condición social. Teóricos marxistas posteriores, como Lenin o Gramsci, dieron gran importancia a la juventud, el primero considerándola como fuerza social básica y el segundo, por la influencia que la educación de la juventud tiene en sus postulados sobre la hegemonía y su reproducción; en cualquier caso, siempre como telón de fondo de cuestiones como la clase o el estatus (Souto, 2007). La misma autora recuerda las primeras propuestas sobre adolescencia en los ámbitos académicos en los comienzos del siglo XX y señala cómo las características de la juventud se refieren a cuestiones de tipo biológico más que social; en la misma línea, Sigmund Freud refuerza este postulado definiendo a la juventud como un periodo difícil y problemático. También en Feixa (2006) es posible observar la evolución del concepto de joven, este autor propone realizar "un paseo por las teorías de la juventud en la era contemporánea" desde la Generación A o adolescente que sitúa en los comienzos del siglo pasado donde se empieza a reconocer a un colectivo diferente que atraviesa un periodo tormentoso y de agitación que es necesario manejar de forma distinta al de la infancia y los adultos, aumentando el periodo formativo, retrasando la incorporación al trabajo o promoviendo leyes de discriminación positiva, pasando por la constatación de la especificidad del modo de vida de los jóvenes Boy Scout o Generación B que aportan un discurso emergente de una nueva cultura juvenil que desde la escuela debería influir en la renovación de la sociedad. Estos enfoque de principios de siglo darán paso en los años 20 y como 
consecuencia de los acontecimientos bélicos de la Primera Guerra mundial y también de la Revolución Soviética, al surgimiento de una nueva identificación generacional relacionada con el servicio militar obligatorio y la identificación con los ideales revolucionarios, Carles Feixa la denomina Generación K o Komsomol. El aparecimiento del fascismo en los años 30 y la utilización de la juventud para servir al totalitarismo a través de una formación política y paramilitar y en contraposición la reacción de otros grupos orientados hacia la música como los famosos rebeldes del swing en Alemania representan un nuevo colectivo que dan nombre a la generación de los años 30. En los años 40 Feixa presenta una generación escéptica después de la contienda de la Segunda Guerra Mundial por los terribles acontecimientos vividos que da paso en los años 50 a una nueva clase de edad en los países industrializados con la prolongación del periodo formativo, el auge de espectáculos como el cine, deporte, fiestas de graduación, etc. es la generación que Feixa denomina del Rock. A partir de los años 50 y 60 se generalizan los estudios de juventud desde enfoques funcionalistas o conflictualistas pero en cualquier caso ya los jóvenes como objeto de estudio.

Los estudios sobre la juventud están fundamentados sobre la base de que los jóvenes constituyen una categoría social con sus propias características, y perfectamente diferenciadas de otras categorías sociales, como los adultos, los niños, las clases sociales o las cuestiones de género, etc. No obstante, no existe un criterio común para definir el concepto de juventud, ni siquiera sobre la existencia de una categoría social joven. El fondo de la cuestión podría estar en cómo se define una categoría social para posteriormente valorar si el colectivo de personas llamadas jóvenes posee en su conjunto las características comunes suficientes para poder ser considerados como tales. En este sentido, Becerra (2011) presenta dos propuestas en torno al carácter construido a partir de las clasificaciones sociales del filósofo canadiense Ian Hacking y de la norteamericana 
Judith Butler. Para el primero, las construcciones sociales se refieren a ciertos tipos de clasificaciones y agrupamientos que se aplican sobre los sujetos, los objetos y las experiencias, produciéndose una interrelación entre los tres elementos; la clasificación opera sobre el clasificado reificándose, al igual que los sujetos clasificados interactúan con la clasificación en una relación de influencia entre ambos. De esta manera, las clasificaciones se crean, pero no permanecen estáticas, sino que sufren modificaciones en la interacción con los clasificados y con otras clasificaciones. Por otra parte, Becerra presenta el concepto de performatividad que Judith Butler propone para entender lo socialmente construido. Este concepto hace referencia, en palabras de la autora, al «poder que tiene el discurso para producir aquello que se nombra» a través de «la repetición ritualizada de las normas». En este sentido, la identificación con la clasificación adoptada requiere la repetición continua de algún tipo de ritual identificatorio. Becerra destaca algunos elementos comunes entre los dos autores sobre los que trabaja, como que la idea de construcción social se refiere a ideales normativos y clasificatorios que se generan en la interacción social llegándose a formar sujetos reales, bien individuales o colectivos, pero sin una dependencia completa del actor frente a su clasificación, pues la interrelación que se produce es constante, modificando las características de las clasificaciones o productos sociales. En cuanto a la construcción social del concepto de juventud, el autor sostiene que en los estudios de juventud existe la idea compartida de la existencia de una construcción sociohistórica, cultural y relacional, si bien en la literatura que ha trabajado existe igualmente el consenso de entender las juventudes por sus diferencias en cuanto a clases sociales, contextos socioculturales, etc. Atendiendo a estas consideraciones, una categoría social sería mucho más que un conjunto de personas que poseen alguna característica o atributo común, como el sexo, la ocupación, la actividad o incluso la edad. 
Sería necesaria la existencia de algún tipo de interrelación entre los sujetos y los propios atributos de la categoría.

El concepto de juventud desde un punto de vista sociológico es relativamente novedoso. Los primeros estudios de juventud no se producen hasta periodos muy recientes $y$, desde un enfoque básicamente empirista, las primeras oleadas de estudios de juventud se realizan en las décadas de los 50 y los 60 del siglo pasado en Estados Unidos. En el caso de España, como en el resto de los países occidentales, se generalizan los estudios de juventud a partir de las últimas décadas del siglo pasado. Diferentes instituciones, como INJUVE (Instituto Nacional de la Juventud), el CIS (Centro de Investigaciones Sociológicas), FOESSA (Fomento de Estudios Sociales y de Sociología Aplicada) o, en Europa, Eurostat, suponen un avance muy relevante en los estudios de juventud, realizándose sondeos de opinión sobre temas muy variados: valores, ocio y tiempo libre, emancipación, cultura política, vivienda, empleo, etc. (Aguinaga y Comas, 2008).

Es posible encuadrar los estudios de juventud en tres perspectivas o enfoques diferentes, por una parte la perspectiva nominalista, donde la juventud es percibida como un intervalo de edad, se define a los jóvenes únicamente por la edad biológica o por razones administrativas y se sobreentiende que quienes comparten un mismo intervalo de edad presentan características similares y una posición común en la estructura social, no prestando especial atención a una definición teórica de la juventud como categoría social. Estudios promovidos por las instituciones públicas sobre problemas juveniles, drogas, consumo, ocio, etc., y los llamados «Informes de Juventud» se apoyarían en esta perspectiva. La crítica nominalista representa otra perspectiva que surge como respuesta al enfoque anterior, cuestiona la existencia de la juventud como categoría social o se acepta hablar de diferentes juventudes; por otra parte, la perspectiva transicional, biográfica o del curso de vida muestra la juventud como un proceso, no como un estado, 
en el que influyen elementos estructurales, relacionales e individuales (Casal et al, 2006; Cardenal de la Nuez, 2006; Brunet y Pizzi, 2013; Gutiérrez, 2013).

Para la crítica nominalista, la juventud no formaría un grupo social. Bajo el nombre de juventud se agrupan sujetos y situaciones que solo tendrían en común la edad; la juventud no sería más que una proyección de los que la enuncian, nos podríamos encontrar ante un ejemplo de formación de categorías científicas a partir de premoniciones de sentido común. Se critica abiertamente la existencia de una categoría social llamada juventud en tanto se considere que detrás del nombre juventud existe la identidad de una propiedad antes de construir teóricamente el objeto de investigación; se plantea la imposibilidad de extraer una categoría social únicamente construida a expensas del lenguaje cotidiano, de sus nociones comunes, de una filosofía común, etc. La juventud no sería más que una palabra. En esta perspectiva, ya no se habla de joven como categoría social, se habla de estrategias de reproducción y condiciones sociales. El objeto de estudio deja de ser la Sociología de la Juventud para centrar los estudios en la reproducción social, el sistema escolar, el mercado de trabajo, etc. Según este desarrollo conceptual, hablar de jóvenes es un despropósito teórico, pues bajo este nombre se recubren situaciones tan variadas que solo tienen en común el nombre de joven, e implica ignorar la existencia de clases sociales y la problemática de la reproducción social de la diferencia (Bourdieu, 1984; Martín, 1998). Otros postulados más moderados se refieren a los jóvenes como una tipología al modo de los tipos ideales de M. Weber, a los que se atribuye determinadas cualidades psicológicas y de carácter, como rebeldía, conflicto o inconformismo, y que difieren dependiendo del contexto histórico, la clase social, el entorno familiar, etc. Se preguntan igualmente si los grupos de edad son una mera construcción estadística que permite operar con los datos adecuadamente o realmente corresponden con diferencias significativas. En este sentido, constata la variabilidad interna de los grupos de edad, hasta 
el punto de ver la necesidad de asociar la etiqueta de joven no a un grupo de edad, sino a un grupo específico con características concretas que debieran ser consensuadas; por tanto, lo importante no sería la edad para definir a una tipología de juventud, lo importante sería aquello que indica dicha tipología. Resultaría excesivo dar por evidentes las relaciones entre grupos de edad y las propiedades que se les atribuye, si bien se constata la necesidad de una definición medible en función de un conjunto de indicadores o variables que expresen las diferencias entre los grupos de edad. Las relaciones familiares, fundamentalmente en lo que se refiere a la emancipación residencial, la relación en el mercado laboral o la participación en la sociedad serían algunos de los elementos que considerar. Desde la crítica nominalista, el pertenecer a una misma cohorte de edad no supone la existencia de un grupo social concreto, sería necesario que además de que individuos compartan similares acontecimientos sociales en los mismos periodos de sus vidas, los afronten desde una posición social similar; la juventud es vista como una posición social, al igual que lo puede ser la vejez, pero no una categoría social, pues no presenta, objetiva y materialmente, elementos comunes lo suficientemente importantes entre sus miembros (Alaminos, 2008; Brunet y Pizzi, 2013). Con estos argumentos se pretende hablar de juventudes más que de juventud. El concepto de juventud tal y como se presenta en los estudios de juventud presentaría una clasificación política y administrativa más que una categoría social propiamente dicha; la crítica se dirige al mundo académico, que estaría interesado en legitimar la existencia del objeto de estudio, además del interés político y de los medios de comunicación por la existencia de un colectivo al que dirigir su atención.

Una de las respuestas más contundentes a estas dudas o negación de los jóvenes como categoría social la encontramos en Comas (2011), que plantea en primer lugar el cambio social que está propiciando el nuevo modelo capitalista con formas del liberalismo 
tradicional y rasgos propios del antiguo régimen, donde la condición de las personas jóvenes ha sido trasformada de una forma absoluta y que permite presentar a los jóvenes con independencia de que exista o no una equivalencia con las estructuras de clase o estratos sociales tradicionales. Reflexiona sobre tres vías de negación de la juventud como categoría social. Por una parte, la crítica nominalista o negación académica en tanto corriente teórica que no acepta una categoría social uniforme determinada por la edad y una división administrativa rígida. Comas admite en parte la crítica, si bien detecta cierta hipocresía entre quienes niegan la categoría juventud y aceptan agrupar a los jóvenes en grupos con características comunes. Por otra parte, advierte de una negación política de la juventud paradójica, se reconoce la existencia y la importancia de la condición juvenil, pero no se aplican políticas ni propuestas concretas a favor de los jóvenes. Estas dos vías de negación de lo juvenil estarían muy relacionadas con la negación social y el papel de los medios de comunicación, en tanto que los jóvenes son un grupo conflictivo, irracional, que no desea la participación política ni cívica, egoístas, que retrasan su emancipación por comodidad, etc. Este estereotipo negaría la existencia de la juventud como categoría social para convertirse en grupos marginales que no desean la participación activa en la sociedad. Domingo Comas continúa admitiendo la gran pluralidad que presenta la categoría social juventud, los propios estudios de juventud lo ponen de manifiesto, si bien no es posible negar la existencia de la categoría, como no es posible negar que exista una clase obrera, cosa que todo el mundo reconoce y, sin embargo, no todas las personas que se identifican con la clase obrera viven las mismas situaciones. A todos los obreros les identifica que son asalariados, pero existe una gran pluralidad dentro de la clase o categoría social obreros. Según Comas, la juventud es una categoría social tan plural como otras, y esta pluralidad no impide que se pueda considerar a las personas jóvenes como una categoría social. Comas considera necesario el estudio de la condición juvenil 
y las políticas de juventud, y especialmente en un momento de crisis como el actual donde las personas jóvenes se identifican como la generación de la crisis. En este sentido, propone unas nuevas políticas de juventud basadas en la consideración de los jóvenes como sujetos activos capaces de gestionar sus propias trayectorias vitales.

Los diferentes enfoques presentados en torno al concepto de juventud cuestionarían la existencia de la juventud como un estado, pero no como un proceso caracterizado por los diferentes acontecimientos que implican la transición hacia la adultez desde una perspectiva sociológica.

\subsection{La perspectiva transicional o life course como enfoque adecuado en el estudio de la transición hacia la adultez}

\subsubsection{Orígenes y desarrollo del life course}

Las investigaciones que se apoyan en el enfoque del curso de vida tienen como objetivo general el analizar cómo influyen los eventos históricos, los cambios demográficos, económicos, sociales y culturales en la vida de las personas individualmente y por cohortes o generaciones; el enfoque proviene de la demografía y surgen los primeros estudios en Francia, en la década de los 60 del siglo XX, con el demógrafo Roland Pressat, y en Estados Unidos, en los años 70, con Uhlenberg y el sociólogo Glen Elder junto a la historiadora Tamara Hareven (Blanco, 2011). Las primeras investigaciones de Glen Elder apoyadas en el enfoque del curso de vida están relacionadas con la dimensión temporal y la edad y, a su vez, vinculadas a su contexto histórico; aborda campos de estudio como la familia y el trabajo como procesos interrelacionados y en constante cambio, además de documentar las diferencias entre las trayectorias masculinas y femeninas (Elder, 1994). 
La historiadora Tamara Hareven entra en contacto con el enfoque del curso de vida junto a Elder y enfatiza en la importancia de la dimensión temporal, señalando que la historia de la familia debe ser estudiada con modelos y herramientas conceptuales de la historia, la demografía, la sociología, la antropología y la psicología. La familia no es vista como un grupo que siempre actúa cohesionado y que atraviesa etapas necesarias de recorrer, sino como una pequeña colectividad de individuos interdependientes que actúan a lo largo de su propio curso de vida (Hareven, 1995). Los estudios longitudinales han sido desde el comienzo de la implantación del enfoque del curso de vida la aproximación metodológica más apropiada para los procesos de investigación apoyados en esta perspectiva, pero las limitaciones en la información longitudinal disponible hacen necesario el uso de otras fuentes de datos y de entrevistas o historias de vida retrospectivas (Elder, 1998). Uno de los estudios más relevantes que se realizan siguiendo este enfoque y con información longitudinal es el que corresponde con los procesos de transición de los niños de la Gran Depresión en Estados Unidos (Children Of The Great Depression. Social Change In Life Experience) (Elder, 1999). En este trabajo se observan los cambios que acontecen en la vida de estos niños dependiendo del momento y las circunstancias que les va tocando vivir: familias que una vez fueron acomodadas y después pobres, cambios de trabajo, de residencia, etc., son situaciones que condicionan las diferentes trayectorias y estados de ánimo en los niños dependiendo del tipo de coyuntura socioeconómica que van atravesando en sus ciclos de vida. La influencia del contexto socioeconómico condiciona los procesos de transición. De igual manera, se considera importante para este enfoque tomar en consideración los caminos que las personas seleccionan por sí mismas, aunque obviamente estas selecciones no se producen en un vacío social, sino que están también condicionadas por elementos estructurales. En este sentido, Elder pudo comprobar la capacidad de adaptación de algunas familias a los 
periodos de depresión económica, buscando formas alternativas de ingresos, asumiendo los hijos responsabilidades, etc., con lo que se refuerza la idea de que también los individuos construyen su propio curso de vida (Elder, 1998). La familia se presenta como una institución clave en los procesos de transición, y otra autora destacada en el enfoque del curso de vida, como es Tamara Hareven, los pone de manifiesto haciendo referencia a cuestiones como la ayuda intergeneracional de hijos a padres y de padres a hijos (Hareven y Gruyere, 2014).

Los conceptos básicos que guían a los estudios enmarcados en el enfoque del curso de vida son, por un lado, el de trayectoria, que hace referencia a un camino a lo largo de toda la vida que puede variar y cambiar de dirección, y se refiere al movimiento a lo largo de la estructura de edad y abarca los ámbitos de la educación, el trabajo, la formación de nuevos núcleos familiares, etc. No presupone una secuencia, aunque sí la existencia de mayores o menores probabilidades de un tipo de secuencias respecto de otras. Por otro lado, la transición: las transiciones están contenidas en la trayectoria y hacen referencia a los cambios que se van produciendo en el curso de la vida, como las entradas y salidas del sistema educativo, el mercado de trabajo, el matrimonio, etc. En tercer lugar, el turning point está relacionado con los elementos anteriores, y se trata de eventos que provocan fuertes cambios en el curso de vida, lo que implicaría un cambio cualitativo en el curso de vida del individuo como, por ejemplo, la muerte de un familiar cercano (Blanco, 2011).

En todo caso, la estructura social como elemento cohercitivo tendría un papel determinante en los procesos de transición. Es en esta perspectiva en la que se apoyará el presente trabajo de investigación. 


\subsubsection{La estructura social en la base de las diferencias y las desigualdades}

Desde la perspectiva del curso de vida se pretende abordar la juventud como un tránsito hacia la vida adulta partiendo de un punto de vista histórico y biográfico. En este sentido, es necesario tener en cuenta los momentos claves del ciclo vital y conectarlos con los elementos que los contextualizan, como son la estructura económica, los territorios, los espacios sociales, la familia, etc., así como las desigualdades sociales que condicionan estas experiencias. Los itinerarios y trayectorias estarían definidas por los caminos que recorren los jóvenes hacia la vida adulta a través de los principales elementos de incorporación hacia la adultez, como el sistema educativo, el mercado laboral y la familia. Por tanto, la transición hacia la adultez se entiende como un proceso en el que influyen la realidad sociohistórica, las instituciones sociales y la toma de decisiones de los propios jóvenes, y no tener en cuenta todos los factores dificultaría el análisis de los procesos de transición (Furstenberg, 2005; Bird y Kruger, 2005).

La realidad sociohistórica y las instituciones sociales estarían representadas por las estructuras sociales que ejercen coerción hacia los individuos, como los modelos políticos y la coyuntura económica, las identidades culturales, el sistema educativo, el mercado de trabajo, etc., mientras que el proceso biográfico o de decisiones propias de los individuos estaría representado por el conjunto de estrategias y toma de decisiones como respuesta a la constricción que ejercen los componentes estructurales. De esta manera, la transición a la vida adulta en los diferentes ámbitos, familiar y residencial, formativo y laboral, no presenta un modelo único y lineal. Dicho proceso se dilata en el tiempo y es posible su estudio desde diversos enfoques: desde una perspectiva funcionalista, la estructura social sería el factor determinante en esta transición, aspectos como la economía, la política, la familia, etc., aportarían las explicaciones suficientes en los procesos de transición a la 
vida adulta. Sin embargo, para los teóricos del conflicto la explicación habría que buscarla en el conflicto entre los adultos y los jóvenes; aunque las estructuras sociales son igualmente determinantes, en este caso el origen del cambio es el enfrentamiento, el desencuentro, las diferencias, las desigualdades, el desigual acceso a los recursos, etc. El enfoque biográfico, donde el actor social es el punto de partida como protagonista de su propia vida, se apoya en elementos psicológicos e individualistas; los propios actores serían los responsables de sus vivencias y cambios, tomarían decisiones personales en función de las múltiples vivencias y acontecimientos a lo largo del itinerario vital, con sucesos que pueden favorecer el tránsito y otros que pueden dificultarlo, como el fracaso en el sistema educativo, un accidente o el consumo de drogas, etc. Por otra parte, no se puede olvidar que los itinerarios y trayectorias tienen un vínculo claro con la estructura y el contexto social, la familia, el entorno, los grupos de iguales, los itinerarios formativos, etc. (Urcola, 2003; Casal et al., 2006; Ulrich, 2008; Vieira y Miret, 2010; Moreno et al., 2012). En definitiva, una perspectiva de transición o itinerario hacia la vida adulta que aglutinaría estructura, acción e historia, un modelo de análisis holista, pero que, como señala Robette (2010), presenta limitaciones en tanto no tiene en cuenta la reversibilidad de los acontecimientos e incluso su no ocurrencia. En la misma línea, advierte Iacovou (2011) que este consenso que existe en Europa con relación a los factores que definen la transición puede ser rebatido en cuanto hay quienes viven toda su vida en el hogar de origen, hay quienes nunca se incorporan al mercado laboral, quienes no viven en pareja y quienes nunca son padres o madres. Estas circunstancias cuestionarían la elección de estos elementos como básicos en la incorporación a la adultez. No obstante, se considera necesario buscar el pragmatismo y la operatividad más allá de la estricta exhaustividad, que nos llevaría a perdernos en debates teóricos que no son el objeto de esta tesis. 


\subsection{Las diferentes transiciones juveniles hacia la adultez}

Las transiciones hacia la adultez han cambiado enormemente en las últimas décadas. De una secuencia predecible y pactada en la sociedad de hace 50 años, donde no existía duda de cuál era el proceso a seguir en el acceso a la edad adulta, hemos pasado en las últimas décadas a un proceso muy variado y poco normalizado en la sociedad europea. Hace medio siglo, para la gran mayoría de los hombres, ser adulto o terminar la etapa de la juventud implicaba casarse, tener un empleo que le permitiera mantener a los hijos y al cónyuge y una vivienda. En la mayoría de los casos, la institución del matrimonio era la norma. En el caso de la mujer, su juventud terminaba con el matrimonio, la maternidad y el cuidado de la familia (Encuesta Social Europea, 2006; Torres y Lapa, 2010). Esta secuencia ya no se da de forma mayoritaria en España ni en el resto de los países europeos. Torres comenta los datos de la encuesta mencionada, donde se verifica a través de diversos indicadores cómo el matrimonio no es necesariamente el momento de la emancipación del hogar de origen, como tampoco se tienen los hijos necesariamente dentro de este modelo de unión y cómo tampoco la variable empleo condiciona el momento de ser o no ser joven, con incorporaciones al mercado laboral en diferentes edades, ritmos y condiciones. Las etapas que se sucedían en el ciclo vital de los jóvenes (finalización de los estudios, introducción en el mercado laboral, salida de la casa de los padres para independizarse, formación de una relación de pareja y paternidad) se producen igualmente, pero ni el orden de aparición es siempre el mismo ni necesariamente se dan todos ellos (Gil, 2009; Torres y Lapa, 2010; Leccardi, 2010; Toulemon, 2010; Vieira y Miret, 2010). Las diferencias por sexo solo son significativas entre los jóvenes en los tramos de mayor edad y, dependiendo de los países de que se trate, mientras en los países de Europa del Este, España y Portugal las diferencias son importantes, en los países del centro y del norte no lo son tanto. No obstante, las 
desigualdades de género en la transición hacia la vida adulta proporcionan claves en las diferencias entre hombres y mujeres. La importancia de los padres en las trayectorias por diferencias de sexo es interdependiente con factores como el sistema educativo o el mercado de trabajo (La Parra, 2000; Toulemon, 2010).

\subsubsection{La transición educativa}

Las diferencias en cuanto a los estudios terminados entre los jóvenes se presentan en el capítulo tres y se tendrá ocasión de comprobar una dualidad muy acentuada entre los jóvenes españoles respecto a los estudios terminados, con jóvenes muy formados, pero también una tasa de fracaso escolar por encima de la media europea; estos datos hacen pensar en que nuestro sistema educativo no compensa las diferencias y se perpetúa la desigualdad en la educación. Para poder determinar el grado de desigualdad en educación es necesario determinar qué elementos son considerados pertinentes en la diferenciación de los individuos; si la sociedad considera importante que debe influir en el nivel educativo la riqueza, el talento o el esfuerzo, a estos elementos se les da significado dependiendo de las interacciones sociales previamente construidas y condicionadas por diversos planteamientos políticos, económicos o sociales a una escala macrosocial (Fernández, 2003). Así, Fernández Mellizo diferencia cuatro nociones en cuanto a la igualdad de oportunidades en educación. En primer lugar, se refiere al sistema de libertad natural, según el cual se considera que todas las características del individuo tienen importancia en relación con alcanzar un determinado nivel educativo: origen familiar, mérito, esfuerzo, riqueza, etc., por lo que habrá que dar mayor educación a los que más riqueza poseen o son más inteligentes. La segunda de las nociones hace referencia a la igualdad de oportunidades meritocrática. Según esta noción, la riqueza ya no sería significativa, pero sí el talento, el mérito o el esfuerzo personal: quienes posean estos 
atributos tendrán mejores condiciones educativas. Esta tipología no considera que los atributos personales tienen un componente social a tener en cuenta. La tercera de las nociones es la igualdad de oportunidades igualitaria o universal, donde ninguna variable tendría relevancia frente al igual acceso a la educación: ni el talento o el mérito personal ni cuestiones económicas ligadas al origen familiar. Este modelo o perspectiva tampoco tendría en cuenta el peso social de las desigualdades, por lo que seguiría reproduciendo las desigualdades en tanto y cuanto no todos los individuos se encontrarían en las mismas condiciones de aprovechar las oportunidades. Esta última perspectiva orientaría hacia una noción de igualdad de oportunidades compensatoria, de tal manera que el sistema educativo debería compensar esas carencias con el ofrecimiento de más recursos a quienes más lo necesiten. Más allá de la influencia de los modelos políticos en los sistemas educativos y en las diferencias y desigualdades en la transición escolar en Merino et al. (2006) se ofrece una perspectiva más amplia donde se analizan diferentes tipologías de itinerarios escolares con un componente biográfico que se construye a través de experiencias y decisiones personales condicionadas por la propia socialización del individuo, la orientación familiar, los propios condicionantes que impone el sistema escolar o análisis racionales de coste benéfico. Merino apunta que a partir de tan diversas trayectorias biográficas habría tantos itinerarios diferentes como individuos, si bien sería posible establecer diferentes tipologías como la vía del fracaso escolar o alumnos que no adquieren la formación mínima exigida por el sistema, la vía que conecta la enseñanza secundaria con la profesional o la vía que conecta la enseñanza secundaria con la académica, además de diferentes sub tipologías intermedias.

Resulta interesante la apreciación de García (2009) con relación al coste de oportunidad de continuar o no en el sistema educativo dependiendo de la mayor o menor posibilidad de incorporarse al mercado laboral; a más tasa de paro, menor coste de oportunidad de 
continuar con los estudios, mientras que, a la inversa, cuando las condiciones laborales son favorables, el coste de oportunidad de seguir estudiando se eleva. Las consecuencias prácticas resultan evidentes: cuando las condiciones de empleabilidad son favorables, antes se abandonan los estudios. En un contexto de crisis global profunda como el actual, se produce un incremento en las matrículas en las diversas ofertas educativas. Por otra parte, existe una relación directa entre la inversión en capital humano y los ingresos, siendo la formación reglada uno de los factores más determinantes en el capital humano. La educación contribuye a favorecer la igualdad de oportunidades en un contexto de crisis económica global como el actual, si bien en España, a pesar de los avances significativos en educación en las últimas décadas, no ha sido posible desvincular el nivel formativo alcanzado con el origen familiar: la ayuda familiar, la existencia de redes familiares que favorezcan el encontrar empleo y razones internas en la familia de tipo psicológico, como el efecto de contagio o simpatía; las expectativas son más favorables cuando existen empleados en el entorno familiar, mientras son más negativas cuando no existen miembros de la unidad familiar adecuadamente integrados en el mercado laboral (Toharia, 2002; Becker, 2005; Moreno, 2011).

\subsubsection{La transición laboral}

El trabajo, tal y como lo conceptualizamos en la sociedad moderna y contemporánea, es una construcción social creada al amparo de la sociedad industrial e inherente a ella, no se trata de una categoría invariable en el tiempo. La sociedad del empleo, y más del pleno empleo, es un invento relativamente reciente y desconocido en el Antiguo Régimen, donde no existía paro sencillamente porque no existía la norma del trabajo tal y como lo entendemos desde la modernidad; una buena parte de la población estaba representada por jornaleros y mendigos. No se puede obviar el nivel de bienestar general que se 
experimenta con el nuevo modelo de organización social en el periodo industrial, donde se acentúa la división del trabajo y el trabajo es remunerado; ya se ha comentado anteriormente que ha implicado una mejora sustancial en grandes estratos de la población, mejoras en la alimentación, en la higiene, progresos médicos, el paso de una demografía antigua donde la natalidad es alta, pero la mortalidad también, a una demografía donde estas mejoras contribuyen decisivamente a unas mejores condiciones de vida, cuya consecuencia más evidente es un descenso significativo de la mortalidad y un aumento de la población (Livi Bacci, 2001). No obstante, el modelo de trabajo no tiene por qué ser un modelo estanco ni universalmente válido en el espacio y en el tiempo. Cabe la posibilidad de que, en la sociedad contemporánea, con unos modelos económicos y políticos convulsos y cuestionados donde el trabajo convencional va a escasear y será más precario e inestable, surjan nuevos modelos de organización laboral. En este sentido se expresa Beck (2003) cuando se refiere al trabajo cívico. Uno de los iconos que definen a una sociedad competitiva, siguiendo parámetros exclusivamente económicos, es la productividad; esto significa básicamente el producir lo mismo o más con menos trabajo, lo que obviamente está muy directamente relacionado con un mayor desempleo.

Déficit público, deudas de los Estados, rebaja de salarios, cierre de empresas, burbuja inmobiliaria, paro, impagos, desahucios, etc., son las consecuencias de la crisis y, en el caso de España, un nivel de desempleo desconocido desde hacía décadas: en torno al $20 \%$ de la población activa y, dependiendo del intervalo de edad al que hagamos referencia, en torno al $45 \%$ de la población joven. Se trata de una situación insólita y específica de nuestro país. El resto de nuestros vecinos no sufren estos niveles de desempleo, a pesar de la crisis económica. No obstante, la crisis empeora, pero no modifica las pautas de emancipación residencial y laboral que ya existían en tiempos de bonanza económica entre los jóvenes; la elevada tasa de temporalidad, menores sueldos y una mayor tasa de 
desempleo no son una novedad entre la población joven española (García, 2009; Calderón et al., 2010; Moreno et al., 2012). La importancia que tiene el tener un trabajo estable para decidir la emancipación difiere por países. Mientras en los países con más desempleo, como España, es el motivo fundamental de incorporación a la adultez, para Alemania y otros países donde el desempleo es menor, es la salida del hogar de origen lo que más condiciona la transición a la vida adulta (Toulemon, 2010; Vitali, 2010).

Tejerina et al. (2012) advierte de que la actual crisis económica no es un hecho puntual o coyuntural, se trata más bien de un cambio de modelo económico y social que estaría caracterizado por un modelo que ya no puede estar garantizado por los trabajos estables y remunerados en función de su productividad, además de un estado de bienestar capaz de hacer frente a las crisis. Este modelo se caracterizaría también por la disminución de los derechos laborales adquiridos y a la incapacidad de los estados para hacer frente a las desigualdades, los conflictos sociales y las limitaciones para intervenir en los mecanismos del mercado. En el nuevo modelo se produce un debilitamiento de los vínculos sociales en favor de la búsqueda de las soluciones individuales que provoca una transformación cultural que ya no está centrada en el esfuerzo y la ética en el trabajo. El proceso de globalización y la dualidad en los tipos de empleos, sobrecualificado y subcualificados, son igualmente características de un nuevo mercado de trabajo que dificulta la transición laboral de los jóvenes y que explicaría en parte los bajos niveles de emancipación europeos. La relación entre juventud y empleo en los países del Sur de Europa presentaría semejanzas si bien también diferencias relacionadas con la oferta y demanda laboral y las normativas específicas de cada país en materia laboral.

Tezanos (2009) alerta sobre una generación perdida refiriéndose a los jóvenes y las dificultades de integración en las diferentes estructuras de la sociedad actual. Se trata de un colectivo que puede, o está ya, cayendo en la exclusión social básicamente por su 
marginación en el mercado laboral. Paradójicamente, nos encontramos con la generación más formada de la historia, conocedora de idiomas, al día en las nuevas tecnologías y sus aplicaciones, pero que tienen unas perspectivas de futuro peores que las que han tenido sus padres. Tezanos alerta sobre los riesgos y consecuencias de la sociedad del conocimiento y la automatización de los sistemas productivos que dejan fuera del mundo laboral a un colectivo cada vez con más posibilidades de caer en la exclusión social. Tezanos se refiere también a las agarraderas que estos jóvenes tienen para poder seguir manteniendo el estado social alcanzado por sus padres y que de forma aparente y artificial quieren heredar; son hijos de una generación que ascendió en la clase social, con buenos trabajos y estables, con una situación económica desahogada, y que pueden mantener la posición de sus hijos de forma temporal, pero el tiempo es inexorable y esta situación acabará irremediablemente con la jubilación de los padres y la pérdida de poder económico que a ella suele acompañar. Tezanos asemeja este nuevo tiempo de cambios sociales de profundo calado con situaciones de tránsito en el pasado de unos modelos económicos y sociales a otros; es el caso del paso de las sociedades agrarias a las industriales, pero con la diferencia de que los cambios se produjeron de forma gradual, mientras que en la actualidad se producen de una forma muy rápida.

La precariedad en el trabajo y algunos problemas que se acentúan en los jóvenes, como son los accidentes y riesgos laborales, resulta una nueva forma de exclusión social por ser joven. El modelo ocupacional español se caracteriza por una dualidad muy acusada en lo que se refiere a la estabilidad y la calidad de los trabajos. Por una parte, los trabajadores mayores, con trabajos muy estables y de cierta calidad, frente a la precariedad laboral de los jóvenes, con contratos temporales y condiciones de trabajo poco adecuadas, exposiciones a riesgos, nocturnidad, etc. Parece que el interés fundamental de los agentes que integran el entramado económico y social es la duración de los contratos y los 
salarios, prestando menos atención a las condiciones de trabajo y sus consecuencias (López y Segado, 2009). Estos autores alertan sobre esta situación: accidentes puntuales, otros con consecuencias de futuro o, en el peor de los casos, el fallecimiento. Los datos lo muestran claramente: la tasa de accidentes laborales casi se triplica en el intervalo de edades de entre 16 y 19 años, frente al de 40-65 años. En general, estos autores apuntan a unos mayores índices de siniestralidad entre los trabajadores jóvenes, tanto en el trabajo como en el transporte.

\section{Jóvenes que ni estudian ni trabajan}

El periodo de tiempo en el que los jóvenes terminan sus estudios y comienzan a trabajar ha dado lugar a diferentes interpretaciones con relación al grado de voluntad de los propios jóvenes y a la imposición del mercado laboral. En los últimos años, y muy relacionado con el contexto de crisis económica, se utiliza con frecuencia el concepto de ninis para referirse al colectivo de jóvenes que ni estudia ni trabaja. No es un concepto nuevo, Bermúdez-Lobera (2014) recuerda el uso del término neet, que es la abreviatura de Not in Employment, Education or Training en el Reino Unido para referirse a jóvenes de entre 16 y 18 años que ni estudiaban ni trabajaban y que supuso la aplicación de políticas públicas dirigidas a la integración de estos jóvenes; el termino se ha generalizado y la Organización Internacional del Trabajo así como la OCDE lo reconocen, si bien los intervalos de edad utilizados por los países son muy diferentes, 12-24 años, 15-29 años o incluso 15-34 años. En el ámbito de la Unión Europea también se está considerando el porcentaje jóvenes que ni estudian ni trabajan como un indicador válido para realizar un seguimiento de la situación laboral y social de los jóvenes, y todo ello a pesar de la disparidad a la hora de cuantificar a los ninis. Según los datos de Eurostat 2011, el porcentaje de jóvenes que ni estudia ni trabaja de entre 15 y 24 años en la Europa de los 27 era del 12,8 \%, en torno a 7,5 millones de jóvenes (CAUCES, 2013). 
Siguiendo a Saraví (2004), es posible realizar el estudio de los jóvenes que ni estudian ni trabajan desde dos perspectivas distintas, por una parte atendiendo únicamente a la falta de trabajo como problema central. Los jóvenes, una vez que abandonan el sistema educativo, permanecen un periodo determinado sin estudiar y sin trabajar hasta que se produce su entrada en el mercado laboral; en el caso de España, en torno a la mitad de los jóvenes que termina sus estudios tarda un año en incorporarse al mercado laboral, situación que depende de su nivel formativo: a mayor nivel formativo, menos tiempo permanecen inactivos o parados (Alemany et al., 2011). Este enfoque tiene el inconveniente de que se incluyen en la misma categoría a jóvenes en desempleo, pero que desean un empleo y en un tiempo determinado lo consiguen, y a jóvenes inactivos no estudiantes que han abandonado el mercado laboral por diversos motivos, como el desencanto, la desmotivación, etc. La segunda perspectiva que propone Saraví se refiere al análisis por separado de los jóvenes que ni estudian ni trabajan, pero únicamente por falta de trabajo y, por otra parte, a los jóvenes inactivos que no son estudiantes, jóvenes que tampoco estarían dispuestos a incorporarse al mercado laboral. Según este enfoque, se considera al colectivo de los ninis en un sentido mucho más estricto, es decir, jóvenes que han renunciado al trabajo y a los estudios como elementos para la inclusión y la normalización social. Se trataría de un grupo de jóvenes que no estudian ni trabajan ni lo intentan, que no padecen incapacidad por enfermedad y que no asumen cargas familiares (CAUCES, 2013). Barbería (2009) se estaría refiriendo a esta segunda perspectiva cuando reflexiona sobre la encuesta de Metroscopia, que ofrece datos según los cuales el $54 \%$ de los jóvenes españoles de entre 18 y 34 años no tiene proyectos ni ilusión, se pregunta si habrá surgido... una generación apática, desvitalizada, indolente, mecida en el confort familiar... La crisis económica ha incentivado el desánimo y la percepción de que un modelo de vida basado en el consumismo y unas condiciones de vida en alza de forma 
aparentemente ilimitada puede haber llegado a su fin, y la calidad de vida de los hijos de las clases medias puede ser peor que la de sus padres. Barbería continúa refiriéndose a que los cambios culturales estarían motivando este desencanto y falta de proyectos e ilusión más que la propia crisis. La inseguridad en un proceso más o menos pautado desde el paso por la formación a la ocupación laboral ha dado lugar a una gran incertidumbre, donde no está claro que la formación percibida preceda necesariamente a un trabajo adecuado. Por otra parte, los ninis, vistos desde esta perspectiva, estarían favorecidos por un modelo familiar donde los jóvenes tienen cubiertas sus necesidades de manutención, alojamiento y ocio, convirtiéndose en jóvenes conservadores, retrasando su emancipación tanto residencial como laboral hasta pasados los 30 años; la pregunta en el actual contexto de crisis económica es cuánto aguantará el colchón familiar español.

\subsubsection{La transición residencial o emancipación}

\subsubsection{El cambio familiar en España}

El estudio sociológico de la familia ha sido desde el nacimiento de la sociología como disciplina científica un campo de estudio de relevancia. Los primeros sociólogos situaban a la familia como una institución intermedia entre la sociedad y el individuo, de los papeles desempeñados y comportamientos en la familia se podrían deducir en buena medida los comportamientos sociales.

Los cambios experimentados en la sociedad española a partir de los años 70 del siglo pasado han favorecido la convergencia con los países de nuestro entorno en aspectos como la política, la economía, las relaciones internacionales, etc., que tienden a normalizarse después de un periodo de aislamiento respecto de la comunidad internacional. La nueva situación económica, cambios en los estilos de vida, en buena 
medida causados por los viajes a países de nuestro entorno, una nueva realidad demográfica caracterizada por un índice de fecundidad muy bajo, claramente por debajo del nivel de reemplazo, y una tasa de mortalidad también muy baja, condicionan la estructura de las familias, que irá determinando los nuevos modelos familiares y sus estrategias evolutivas. Jurado (2006) hace referencia a todos estos cambios con especial atención al papel jugado por la mujer en todo este proceso, en especial las mujeres jóvenes que se incorporan al sistema educativo en niveles superiores de manera masiva, al igual que al mercado de trabajo fuera del hogar. Si a esto unimos el control de la fecundidad, las nuevas formas de unión y las rupturas matrimoniales, favorecidas por los cambios legislativos, nos encontramos unos modelos familiares muy diferentes a los de décadas pasadas y muy cambiantes y variados. En la misma línea, Iglesias de Ussel y Ayuso (2005) presentan la evolución de la familia española haciendo especial referencia a la rapidez, extensión y profundidad con la que se producen estos cambios, que se dan igualmente en los países de nuestro entorno, pero más tardíamente. En pocas décadas hemos pasado de una estructura familiar casi única a una gran variedad de modelos familiares (cohabitación o matrimonio, hijos dentro o fuera del matrimonio, uniones homosexuales o heterosexuales, etc.). La convergencia con los países de nuestro entorno en lo que se refiere al cambio en la estructura familiar es un hecho, pero no hay que descuidar los matices con relación al sentido familista de la población española y las peculiaridades en cuanto a las relaciones intergeneracionales. En este sentido, es posible diferenciar claramente entre los modelos familiares en los países del centro y norte de Europa y los del sur, como España, Portugal e Italia, relacionando directamente esta circunstancia al diferente modelo de estado de bienestar. Tradicionalmente, en los países del sur los estados de bienestar son más débiles en lo que se refiere a políticas de apoyo a las familias, continuando estas asumiendo en gran medida las funciones tradicionales 
de atención a los menores, ancianos y demás personas dependientes, hecho que ha favorecido la prolongación del modelo del varón sustentador en el seno familiar ante la imposibilidad de poder conciliar por parte de la mujer la vida laboral fuera del hogar con la vida familiar: pocas ayudas a la infancia, como es el caso de guarderías, a la familia, un mercado laboral donde el trabajo a tiempo parcial está muy limitado y un elevado grado de familismo, tal vez heredado de antiguas concepciones muy tradiciones de la familia por la influencia de la Iglesia católica o por regímenes políticos que favorecieron este tipo de modelos familiares, han contribuido a que los países en el sur de Europa tengan ciertas peculiaridades (Moreno, 2005; Flaquer, 2007). Por otra parte, Ramos (2006) afirma que no existe una diferencia tan clara en cuanto al sentimiento familista en el entorno europeo, existiendo una solidaridad intergeneracional que parece que es compartida por toda Europa. Más bien existen, dependiendo de los países, otras alternativas a la familia a la hora de proveer de servicios, como las prestadas a través de las políticas de bienestar por los Estados y que difieren en unos y otros países. El análisis de esta autora se centra en las políticas sociales y apoyo familiar a los ancianos, pero es posible extrapolar la reflexión hacia los niños y jóvenes.

Para intentar comprender los comportamientos y relaciones entre padres e hijos y la solidaridad intergeneracional que se produce, en especial en determinados momentos del ciclo vital, y más aún en contextos económicos de dificultad como el actual, es interesante comentar el concepto que desarrolla Meil (2010) para definir el actual clima de convivencia en las familias españolas, la familia negociadora, pasando de un modelo de familia autoritaria, donde la potestad paternal no se cuestionaba y era el padre el encargado de valorar los comportamientos y las actitudes de los hijos, imponiendo los premios o castigos que en su caso considerase oportunos, a un modelo dialogante y negociador en el que los hijos tienen gran influencia en las decisiones propias y del resto 
de la familia. Los hijos, en el modelo autoritario, se tenían como un seguro para la vejez o para perpetuar el patrimonio familiar, y se les consideraba como seres a los que socializar y educar al margen de ellos mismos. Hemos pasado a un modelo de familia en los principios del siglo XXI en el cual prima una sentimentalización de las relaciones basadas en el amor y el bienestar afectivo más que en elementos económicos o de superioridad. En este modelo, las familias tienen pocos hijos y sus motivos están básicamente relacionados con ese bienestar afectivo.

A pesar de los profundos cambios en la estructura familiar, existen comportamientos que no cambian o lo hacen en menor medida, como es el caso de las estrategias económicas. Puede haber variado el modo en que se afrontan las necesidades económicas, cómo y a qué se destina el presupuesto de la familia, quién aporta ingresos y en qué medida, pero la familia sigue siendo una institución basada en cierta manera en estrategias económicas. Así se expresa Segalen (2006), quien apunta, además, hacia la familia como una unidad productiva, de ingreso y de consumo. En las familias entran ingresos que proceden del trabajo remunerado de los cónyuges, cada vez con más frecuencia del trabajo de ambos o, en otros casos, como en las familias monoparentales, de un solo progenitor, y otras prestaciones económicas como pensiones, etc. También como unidad de consumo la familia es una institución básica. Alquiler o compra de la vivienda, alimentos, vestidos, educación, ocio, etc., constituyen gastos que se asumen por las familias. La clase social es un elemento diferenciador, como también lo es el patrimonio doméstico y su transmisión, y el componente económico de la familia es decisivo a la hora de producirse la solidaridad intergeneracional, pues más allá del núcleo familiar Segalen incluye al parentesco y a los grupos de parentelas como elementos influyentes en las oportunidades futuras de los hijos. Aunque las teorías de la individualización hacen referencia al repliegue de la familia sobre sí misma, Segalen demuestra cómo la solidaridad de la 
familia de origen hacia los jóvenes emancipados y los nuevos matrimonios son un hecho empíricamente demostrado en la sociedad contemporánea, al igual que sucediera en los modelos de familia extensa campesina en toda Europa. Estas ayudas se producen de otras maneras: es el caso de la ayuda de las madres a las hijas en el momento de ser madres, ayudas económicas a los hijos en el momento del matrimonio, cualquier otro modelo de unión o de emancipación, ayuda en la adquisición de viviendas y, muy significativa también, la influencia de la red de parentesco en la obtención de trabajo.

\subsubsection{La emancipación residencial. El apoyo intergeneracional y reproducción}

\section{social}

El abandono del hogar de origen es una de las variables fundamentales en el proceso de transición, si bien con grandes diferencias entre los países europeos, pues el abandono del hogar de origen es muy temprano en el centro y norte de Europa y más tardío en el sur y este. Resulta llamativa la tardanza en la emancipación cuanto más renta tienen los hogares de origen en el sur, mientras esta circunstancia es la contraria en el centro y norte de Europa, con un adelanto en la emancipación residencial cuanto más renta se dispone en el hogar de origen (Iacovou, 2011; Sironi y Barban, 2015). La prolongación del tiempo en el que los jóvenes dependen de las familias de origen en parte está motivada por la creciente demanda de formación, que hace que esta etapa se alargue en muchos casos hasta la treintena o incluso más tarde. Por otra parte, también influiría la incertidumbre y la imprevisibilidad del futuro más inmediato en un momento de cambios económicos y crisis global: precios de la vivienda o el alquiler, etc. En el caso de la población joven española, el problema se acentúa por un mercado de trabajo excesivamente rígido que prima la estabilidad en el empleo a los trabajadores adultos, dificultando la incorporación de los más jóvenes; también la estructura el mercado inmobiliario, con viviendas caras y poca oferta de viviendas en alquiler, sería otra causa de la emancipación tardía. Por 
último, el modelo de estado de bienestar en España, con pocas o ninguna ayuda a la emancipación juvenil, favorece la dependencia de las generaciones jóvenes respecto de los padres (Vitali, 2010; Albertini, 2010; Becker et al., 2010; Moreno, 2011; Albertini y Radl, 2012). A estas circunstancias habría que añadir explicaciones más conductuales o psicologistas, como que en las últimas décadas las relaciones familiares son más abiertas, flexibles y negociadoras; los jóvenes encuentran un espacio ideal en el seno familiar donde disfrutar de amplios privilegios, servicios y comodidades que influyen en el retraso del momento de la emancipación, máxime ante horizontes claramente inciertos fuera del apoyo familiar (Leccarni, 2010; Meil, 2010).

El apoyo intergeneracional se produce fundamentalmente en el sentido de padres a hijos; con unos empleos precarios, las jóvenes generaciones tienen capacidad de consumo porque disponen de ingresos extra procedentes de sus progenitores dependiendo del país de que se trate. En países del centro y norte de Europa las ayudas son en general monetarias, mientras que en los países del sur, como es el caso de España, esas ayudas están más centradas en la permanencia en el hogar y, en su caso, en el retorno a la familia de origen cuando las circunstancias son desfavorables. Este soporte se da incluso cuando los padres están por encima de los 70 años, aunque en menor intensidad, constatando un mayor apoyo de las familias a sus hijos en los países del sur de Europa frente a los del centro y norte. Este comportamiento estaría relacionado con los diferentes modelos de estados de bienestar, como ya se ha comentado (Albertini et al., 2007; Alonso y Fernández, 2009). En este sentido se expresa también Furstenberg (2010) refiriéndose al débil sistema de bienestar de Estados Unidos, que presentaría similitudes con los países del sur de Europa, y analiza el retraso en el tránsito hacia la adultez desde mediados del siglo pasado, especialmente acentuado en Estados Unidos frente a Europa por su débil estado de bienestar. La pérdida de empleos bien remunerados ha retrasado el paso a la 
adultez, que después de la Segunda Guerra Mundial estaba perfectamente pautado. Los jóvenes permanecen más tiempo en las escuelas y se retrasan el matrimonio y la paternidad y, como consecuencia, se produce un incremento de la carga financiera y emocional de las familias de origen, que se traduce igualmente en una carga para la sociedad, en el sentido de que un retraso en la emancipación propicia un descenso en la natalidad, al considerar menos gratificante la decisión de tener hijos. En un estado de bienestar muy débil como el de Estados Unidos, el apoyo intergeneracional es más necesario que en el resto de Estados occidentales, con fuertes sistemas de bienestar.

Unas políticas compensatorias tenderían a fomentar una sociedad más igualitaria y a minimizar los riesgos de reproducción social entre las generaciones jóvenes respecto de sus familias de origen. A este respecto, Beck (2003) analiza la movilidad social que se produjo en Alemania desde los años 50 del pasado siglo, en pleno proceso desarrollista, una vez superadas las consecuencias desastrosas de la Segunda Guerra Mundial. Según este autor, las desigualdades entre clases sociales se mantienen constantes, si bien se produce una mejora significativa en las clases intermedias que les supone una mejora en las condiciones de vida. Beck habla del efecto ascensor producido por unas mejoras sustanciales en el mercado laboral, en especial en lo que se refiere a subidas salariales; aparecen nuevos estilos de vida en las clases trabajadoras, lo que les permite participar de espacios y hábitos de consumo desconocidos hasta el momento, propios de las clases altas de la sociedad. Otro aspecto significativo al que Ulrich Beck hace referencia en este periodo es el de la educación. En este sentido, se produce una desvinculación de las nuevas generaciones con la clase de procedencia, en buena medida motivada por unos niveles formativos muy superiores a los de los progenitores. Con estos cambios laborales y los avances en educación, parece que lo que se produce es una mejora generalizada en las condiciones de vida, pero no una modificación en la estructura de clases en la 
población. Las desigualdades siguen existiendo, aunque los niveles de vida se hayan elevado. Este análisis podría ser aplicado a la actualidad, pues el nivel socioeconómico y socioeducativo es superior en las generaciones actuales respecto a sus precedentes inmediatas, pero se sigue manteniendo la misma estructura social.

Es complejo determinar si un joven ha sufrido o está sufriendo un descenso en la clase social. La proyección de la trayectoria vital es muy dilatada en el tiempo en condiciones normales, y la movilidad social en cuanto a condiciones socioeconómicas, bien por logro, adscripción o herencia, puede variar sustancialmente. No obstante, teniendo en cuenta el amplio intervalo de edad sobre el que una persona es considerada joven, sí existen datos que reflejan el grado de reproducción social entre los jóvenes con 25 y más años procedentes de la Encuesta de Condiciones de Vida que el INE publica anualmente y que en los capítulos correspondientes al análisis de resultados se analiza. Las teorías de la reproducción social son perfectamente aplicables a la transferencia intergeneracional de las condiciones socioculturales. Muchos estudios han demostrado la influencia que tienen las condiciones socioeconómicas y socioculturales de origen en el nivel económico o cultural que se posee. A este respecto, Moreno (2011) analiza el nivel formativo alcanzado en función del grado formativo, condición social y ocupación de los padres; constata los avances experimentados en educación en las últimas décadas en todos los países europeos, pero con diferencias dependiendo del origen socioeconómico y sociocultural. También apunta a importantes desigualdades entre países, de tal manera que España e Irlanda serían los que muestran una mayor equidad, frente a Francia, Alemania y Portugal, donde tendrían la mitad de posibilidades de acceder a la enseñanza universitaria cuando sus padres son trabajadores poco cualificados. En el caso de España, a pesar de la diferenciación positiva apuntada, Almudena Moreno constata la existencia de una clara desigualdad en las condiciones socioeconómicas y socioculturales 
alcanzadas en función de las condiciones de la familia de origen. Es posible aplicar el análisis de Beck respecto a ese efecto ascensor que se produjo en los años de posguerra, en el sentido de un mayor nivel educativo y de bienestar general en las últimas décadas, pero manteniéndose las desigualdades.

Una vez descritas algunas de las perspectivas teóricas en las que se sustentan los estudios de juventud y sus transiciones hacia la adultez desde un punto de vista sociológico, se ha comprobado cómo la estructura social actúa como elemento coercitivo en los procesos de transición en todas las perspectivas, tanto de corte funcionalista como conflictivista y biográfico. Por este motivo y por las limitaciones que ofrece la base de datos utilizada, se ha considerado que una perspectiva estructural es la adecuada para dar respuesta a los objetivos que se han presentado en la introducción y que en el capítulo siguiente se describen en profundidad. Será posible identificar el momento y la duración de los itinerarios y trayectorias que, aunque estén construidos en parte por las decisiones de los individuos, son decisiones que se encuentran bajo las determinaciones del entorno más próximo, como la familia, y por elementos estructurales de un contexto más amplio, como el sistema educativo, el económico o el político. La juventud comenzaría en la pubertad biológica y el término tiene componentes básicamente sociales y se producen a ritmos muy diversos según el origen familiar, la posición social, la formación, etc. Por otra parte, los elementos estructurales permitirán la puesta en evidencia de la diversidad en los itinerarios; la juventud como proceso social tiene realidades muy diversas que entroncan directamente con la estructura y segmentación de la propia sociedad, los diferentes modelos y situaciones familiares darían origen a transiciones diferentes; los éxitos y fracasos en el sistema educativo igualmente condicionarían las trayectorias o itinerarios de transición hacia la adultez. De igual manera, la transición al trabajo es diversa y estaría muy relacionada con el nivel formativo alcanzado. En los procesos de transición habría 
una segmentación social fuerte, que enlazaría directamente con el origen familiar y la desigualdad en cuanto a educación y condiciones económicas. Los periodos donde se producen diferentes coyunturas económicas, ciclos políticos, etc., también tendrían influencia en el momento y duración en que se producen los itinerarios, además de las edades a las que se producen los eventos.

En este capítulo se han repasado un número importante de aportaciones de diferentes autores con las que ha sido posible sentar las bases que dan el apoyo teórico a esta tesis. En primer lugar, sobre cuestiones como la demografía y situación económica, que han sido los elementos elegidos para contextualizar el tiempo y el espacio en el que se desarrolla este trabajo; la definición de algunos términos importantes como desigualdad, diferenciación o heterogeneidad representan los objetivos básicos, pues poner en evidencia las diferencias en el colectivo que es objeto de estudio y en los procesos de transición es el fin último de esta tesis. Por otra parte, los debates en torno al concepto de juventud, la controversia sobre si se está ante una categoría social, las limitaciones que supone la definición de un colectivo únicamente por compartir la misma edad y la perspectiva adoptada para esta tesis, según la cual la juventud sería vista como un proceso más que como un estado. Por último, las aportaciones referidas a las transiciones, la evolución de la familia y la transmisión intergeneracional como elementos influyentes en los procesos de transición. Estas aportaciones, junto a las posibilidades que ofrece la base de datos utilizada, han contribuido a la elección de los diferentes modelos de análisis que en el capítulo siguiente se describirán y que aportarán los indicadores necesarios que posibilitarán los análisis y aportaciones que en adelante se presentan en cada uno de los capítulos que corresponden con los análisis de resultados, y de manera resumida en las conclusiones finales. 


\subsection{Estado de la cuestión sobre la heterogeneidad en la transición hacia la vida adulta}

He de recordar una vez más que para un estudio exhaustivo de las transiciones hacia la adultez sería necesario el uso de una metodología longitudinal o de entrevistas retrospectivas que nos aportaran información sobre cómo fueron aconteciendo cada una de las transiciones que completarían este proceso desde un punto de vista sociológico, como se han definido en esta tesis: termino de los estudios formales, inserción en el mercado laboral, emancipación residencial, vida en pareja y asumir la paternidad/maternidad. El objetivo de esta tesis no es estrictamente un estudio de transición, es evidenciar las diferencias de los jóvenes en cuanto a los elementos que influyen en la transición hacia la adultez y la estructura de estos eventos; ¿cuándo se producen? ¿Cuál es la duración? las diferencias por sexo, origen, condiciones económicas, coyuntura económica, etc. en definitiva la heterogeneidad de los jóvenes vista a partir de las diferencias en los procesos de transición.

Ya se ha comentado en anteriores apartados que el concepto de juventud en tanto proceso que atraviesa diferentes transiciones es una cuestión consensuada desde el punto de vista sociológico, pero que ofrece limitaciones en tanto hay quienes no pasan por todas las transiciones consideradas, o lo hacen únicamente por algunas de ellas y en diferente orden y ritmos (Iacovou, 2011) esta autora plantea por otra parte la reversibilidad de los eventos de transición y la probabilidad de que los jóvenes regresen a sus hogares una vez que se han emancipado. En este mismo sentido Furstenberg (2005) sostiene cómo desde la perspectiva del curso de la vida los sucesos inoportunos e imprevistos, las secuencias de estatus desordenadas y transiciones no normalizadas tienen consecuencias para el éxito en los itinerarios de transición, en este sentido las transiciones estandarizadas que siguen una secuencia lógica (término de los estudios, inserción laboral, emancipación residencial 
y creación de nuevos núcleos familiares) regulan el paso a la adultez, crean apoyos sociales, expectativas y recompensas para quienes siguen las pautas culturalmente establecidas. Fustemberg aporta argumentos teóricos que apoyan la idea de que la planificación, el tiempo y la secuencia ordenada de las transiciones aumentan la probabilidad de una transición exitosa. También estudia las vías no normalizadas de transición, las acciones correctivas de los individuos cuando se producen distorsiones en las secuencia normalizada como trabajar antes de terminar los estudios, maternidad o divorcio en adolescentes, etc. desde la perspectiva del curso de la vida sería posible identificar los mecanismos que moderan las transiciones no normalizadas. Más allá de lo deseable o no de una transición normalizada, lo cierto es que la desestandarización o no normalización de las transiciones hacia la adultez parece que es lo que caracterizaría a estos procesos en la juventud europea actual, Du Bois-Reymond y López (2004) hablan de las transiciones tipo yo yo para referirse al orden y grado de reversibilidad de los eventos de transición. Muchos jóvenes experimentan la reversibilidad de sus procesos de transición, es posible estar estudiando y al mismo tiempo trabajando, como también es posible haber experimentado la transición escolar y laboral y retornar de nuevo a los estudios o experimentar la transición residencial y retornar al hogar de origen, etc. La falta de igualdad de oportunidades entre los jóvenes trabajadores británicos, el desajuste entre escuela y mercado laboral entre los italianos o el fracaso de un sistema escolar altamente selectivo entre los jóvenes alemanes que desmotiva a aquellos jóvenes que fracasan en el sistema educativo serian motivos para trayectorias fallidas que implican reversibilidad en los procesos de transición europeos.

\section{El caso de España}

Diversos autores analizan las transiciones hacia la vida adulta con datos transversales comparando periodos de distinta coyuntura económica y por sexo, es el caso para España 
en Moreno et al., (2012) en el informe sobre las transiciones juveniles de la Caixa donde a partir de datos de la Encuesta de Población Activa, Eurostat y otras fuentes, es posible valorar la estructura de las transiciones juveniles constatando la precariedad de los jóvenes en el acceso al trabajo o el retraso continuado de la emancipación residencial, de tal manera que la crisis empeora las ya de por sí condiciones de precariedad de los jóvenes en el acceso al empleo pero que no modifica la pautas de emancipación que se vienen retrasando progresivamente por las dificultades de acceso a empleos bien remunerados, dificultades de acceso a la vivienda y altas tasas de desempleo. En el mismo sentido se expresa Gentile (2016) describiendo los problemas estructurales de España más allá de la propia crisis económica. Abandono escolar, sobre-cualificación, paro juvenil, flexibilidad laboral, etc. son problemas endémicos de España que la crisis económica ha agravado y que dificultan el acceso a la vivienda y la transición juvenil en su conjunto. Se retrasa la emancipación residencial ante la incertidumbre y poca seguridad en el futuro, asumiendo posturas conservadoras como la prolongación de la vida en la familia de origen donde los jóvenes gozan de un bienestar que temen perder. Estas circunstancias condicionan las trayectorias vitales y las pautas de inserción social.

Esta precarización es analizada también en la tesis de Carballo (2014) con especial interés en las estrategias para la emancipación residencial de la juventud en el País Vasco, constatando cómo la precarización en los procesos de transición de la juventud a la adultez tienen clara concordancia con la precarización de la población adulta. Según este autor el proceso de individualización propio de la Modernidad culmina con el acceso a la vivienda en propiedad, cuestión claramente condiciona por la precariedad en los itinerarios de acceso al mercado laboral. La transición a la vida en pareja estaría en parte supeditada a la adquisición de una vivienda en propiedad y muy relacionada con las políticas de vivienda que la administración vasca, en este caso, lleve a cabo (Carballo, 
2014). La emancipación residencial en una vivienda en alquiler sería una consecuencia de la precariedad en el empleo y paso intermedio para la búsqueda de una residencia en propiedad. Este trabajo centra los itinerarios de transición en torno a la emancipación residencial como elemento básico de acceso a la vida adulta en tanto condiciona la creación de una pareja estable y nuevos núcleos familiares.

La precariedad en las trayectorias laborales junto a los desajustes entre formación y empleo son también el objeto de estudio de López (2012) constatando cómo las situaciones laborales de los jóvenes y las biografías que se van tejiendo tienen un orden complejo repleto de conexiones difícilmente precisas. La complejidad del contexto, incertidumbres y crisis a la que se enfrentan los jóvenes provoca que el acceso al trabajo ya no sea algo normal sobrevenido, más bien se convierte en un trabajo en sí mismo. La inserción laboral juvenil es tratada como un problema de empleabilidad sin considerar la inestabilidad e inseguridad económicas que genera los empleos precarios.

\section{El caso europeo}

La emancipación residencial es una de las transiciones hacia la adultez más representativas pues suele ir asociada a estar incorporado al mercado laboral y a la proyección de nuevos núcleos familiares, al menos en el sur de Europa. Sin embargo las diferencias en el contexto europeo son notables y están asociadas a los diferentes modelos de estados de bienestar. En este sentido Santos et al., (2016) presentan el resumen de dos artículos sobre emancipación juvenil y su relación con los Estados de bienestar en Europa: uno donde se comparan las transición residencial en europea y el Estado de bienestar de Jordi Bosch Meda y otro sobre la emancipación y las políticas de vivienda en el Reino Unido de Julie Rugg y Deborah Quilgars. Por una parte el modelo de emancipación socialdemócrata que estaría caracterizado por una fuerte intervención del estado en los sistemas de bienestar, educación, sanidad, servicios sociales, etc. con exitosa transiciones 
al mercado laboral, bajo porcentaje de viviendas en propiedad y emancipación residencial muy temprana, es propio de los países nórdicos. El modelo de emancipación corporativista característico de los Países Bajos y Luxemburgo centrado en las políticas de empleo con ausencia de universalidad del Estado de bienestar, implica la centralidad de las familias en la ayuda a los jóvenes favoreciendo altos niveles de desigualdad, las políticas de vivienda favorecen un mayor número de viviendas en propiedad que en los países nórdicos. En el modelo de emancipación mediterráneo se encuadra España, Italia, Portugal y Malta, el sistema se caracteriza por su debilidad a pesar de la universalidad de la atención sanitaria, educación, etc. La familia es el elemento fundamental de protección ante las limitaciones del estado, la emancipación residencial depende del éxito en la inserción laboral y de la capacidad de apoyo familiar, lo que provoca la permanencia en el hogar de origen hasta edades muy avanzadas. El modelo de emancipación de los países en transición como es el caso de la Unión Soviética y países del este de Europa, es similar a los países mediterráneos con un débil gasto público, escasa recaudación, sin ayudas a la vivienda o muy escasas y elevados niveles de pobreza, en consecuencia la familia se convierte en el factor determinante para la emancipación juvenil. Por último el modelo de emancipación liberal presente en Gran Bretaña e Irlanda prima al mercado frente al estado, lo que implica que las ayudas solo las reciben la población con muy pocos recursos y es el mercado quien se encarga de aportar los servicios propios del Estado de bienestar. La emancipación suele ser temprana con itinerarios formativos cortos y con rápida inserción en el mercado laboral, si bien en los últimos años por la crisis económica las tasas de emancipación residencial entre los jóvenes británicos se han reducido. Jordi Bosch Meda citado en Santos et al., (2016) constata evidencias de la relación entre emancipación juvenil y características del Estado de bienestar. En este sentido el gasto social tendría una notable relación estadística con la emancipación juvenil más temprana, 
lo que implica la necesidad de acometer estudios de emancipación juvenil desde la perspectiva de los Estados de bienestar.

Estudios más concretos donde se comparan países a nivel europeo corroboran las aportaciones realizadas en el párrafo anterior, es el caso de las contribuciones realizadas por Alessandro Gentile en el VIII Congreso Español de Ciencia Política y de la Administración Política comparando las transiciones a la vida adulta y políticas de juventud en los casos de España y Suecia, dos Estados de bienestar muy diferentes y donde sus políticas de juventud influyen decididamente en los ritmos de transición hacia la vida adulta con resultados conocidos como el retraso en las transiciones en España con respecto a Suecia, pero incorporando nuevos elementos de tipo conceptual sobre el cómo se definen las transiciones, los jóvenes y la juventud desde el punto de vista cultural y político. En Suecia el discurso sobre la juventud es positivo, es un momento de oportunidades, un colectivo con potencialidades innovadoras para la sociedad, mientras en España las instituciones políticas están ancladas en un discurso paternalista y discriminante (Gentile, 2007)

Afrontar las transiciones es siempre un reto cargado de incertidumbres y que pueden acentuar el riesgo de pobreza, los datos apuntan a que los jóvenes en la mayoría de los países europeos se enfrentan a un riesgo de pobreza superior a la media del resto de la población, en Aassve et al. (2005) valoran el riesgo de pobreza al afrontar la transición hacia la vida adulta en los jóvenes europeos comparando 13 países y han constatado cómo el factor de mayor riesgo de pobreza entre los jóvenes es la emancipación residencial, no trabajar y tener hijos, mientras el vivir con los padres o compañeros minimiza este riesgo. Han constado cómo el nivel de estudios también es un factor predictivo con relación al nivel de pobreza pero sin lugar a dudas es el origen familiar el factor más determinante. El matrimonio y la cohabitación protegen contra la pobreza mientras la presencia de niños 
tendría poco efecto hasta el primer año del nacimiento. Las diferencias por países o grupos de países son importantes como la mayor pobreza cuando se es estudiante en el Norte que en el Sur. Por otra parte la salida del hogar tiene efectos más dramáticos sobre el riesgo de pobreza en los países escandinavos, menor efecto en la Europa continental y ningún efecto en los países mediterráneos e Irlanda. Tener hijos incrementaría la pobreza en el Sur y no tiene efecto en los países del Norte. Con relación a la transición laboral cuando esta transición implica tener un trabajo obviamente tiene un efecto positivo reduciendo la pobreza. Los autores de la investigación comentada son conscientes de que ofrecen muchas más preguntas que respuesta y confían en que futuros trabajo determinen las relaciones causales para las diferencias apuntadas. En cualquier caso interesa evidenciar las diferencias que tienen los procesos de transición, en este caso con relación al riesgo de pobreza, entre los países europeos, esta cuestión también ha sido tratada por Fahmy (2007) con diferente metodología pero con similares conclusiones. En Becker et al. (2005) de ofrecen algunas respuestas a las aportaciones anteriores con relación a la emancipación tardía en el Sur de Europa y algunas consecuencias de futuro. Estos autores han valorado la influencia que tiene en la emancipación residencial la inseguridad laboral por parte de los padres y por parte de los jóvenes, constatando que cuando en el hogar de origen los padres sufren inseguridad laboral la emancipación de hijos es más temprana que cuando son los hijos los que perciben inseguridad laboral, en este caso retrasan las salida del hogar. Los efectos de una emancipación residencial tardía serían por una parte una baja movilidad geográfica reduciendo la capacidad de la economía para reaccionar ante incertidumbres económicas y baja fertilidad que pondría en peligro los sistemas de pensiones de los países del Sur de Europa. 
Fundamentación de los objetivos de la tesis.

Las transiciones hacia la vida adulta son diferentes como lo es la propia estructura social, aun en una supuesta transición ideal perfectamente normalizada las diferencias por razón de sexo, clase social, condiciones económicas, nivel formativo alcanzado, etc. serían evidentes, las transiciones se producen a difentes ritmos y con distintos niveles de éxito y si aceptamos la idead de unos procesos de transición menos normalizados que en décadas pasadas, las diferencias que se producen serían más acusadas y deben ser estudiadas y puestas en evidencia. En el panorama internacional más allá de las fronteras europeas (Fussell et al., 2007; Sironi et al., 2015; Tian, 2016) en el contexto europeo (Berrington, 2010; Toulemon, 2010; Robette, 2010) y en el panorama español (La Parra, 2000; Vieira y Miret, 2010) son estudios que prestan su atención explícitamente a la heterogeneidad en los procesos de transición a través de diferentes metodologías.

Los estudios mencionados que prestan atención a evidenciar las diferencias en los procesos de transición estiman las cuatro o cinco dimensiones o eventos de transición que habitualmente son considerados en el conjunto del proceso de transición hacia la adultez, estos son el termino o abandono de los estudios, la incorporación al mercado laboral, la emancipación residencial, la vida en pareja y convertirse en padre/madre. Fuera del contexto europeo Fussell et al. (2007) ha constatado cómo en Estados Unidos la transición hacia la adultez es más uniforme y más corta que en Australia o Canadá, aunque con tendencia a alargarse en los tres países. Las diferencias se producirían básicamente porque en Estados Unidos el paso al trabajo se produce muy pronto tras un periodo formativo relativamente corto, de igual manera el asumir la responsabilidad de un hogar y el emparejamiento se producen de manera más temprana que en Australia o Canadá. Los tres países comparten una estructura económica similar por lo que los autores concluyen que las diferencias estarían reflejando los valores más tradicionales de Estados Unidos, 
concediendo un peso relevante a los elementos culturales en los procesos de transición. En China Tian (2016) ha observado pocos cambios en las transiciones hacia la adultez entre el año 1982 y el año 2005 observa un leve retraso en la transición escolar y laboral pero incluso un adelanto en la formación de nuevos nucleas familiares, presenta un proceso muy estandarizado y normalizado condicionado por las políticas de familia y con pocas semejanzas con los países occidentales salvo por ese ligero retaso en el término de los estudios y la incorporación al trabajo; en este caso las políticas institucionales serían un condicionante importante en los cambios experimentados en los procesos de transición. En Sironi et al. (2015) se presta especial atención a la clase social de origen para determinar el grado de desestandarización, es decir el grado de distorsión en la secuencia ordinaria de las transiciones, comparando a los Estados Unidos con Italia. En un análisis de regresión la significación estadística entre la clase social de los padres y el grado de desestandarización (trabajo antes de terminar los estudios, emancipación muy temprana, emparejamientos antes de experimentar la transición laboral, etc.) es alto en ambos países pero en sentido contrario, mientras en los Estados Unidos entre los jóvenes de las clases altas se produce una mayor desestandarización, en Italia es entre los jóvenes de clases bajas donde se da esta circunstancia. En anteriores apartados del conjunto del marco teórico se ha hecho referencia a la emancipación residencial y la clase social comparando grupos de países europeos, constatándose una situación similar, en los países del sur de Europa la emancipación es más temprana entre los jóvenes que proceden de hogares en malas condiciones económicas mientras en el centro y norte de Europa es entre los hogares con mejores condiciones económicas donde los jóvenes se emancipan a edades más tempranas.

Las diferencias del estatus de las familias de origen medidos en nivel formativo o económico, las diferencias por sexo o por intervalos de edad, son elementos comunes en 
el análisis de la heterogeneidad en los eventos de transición. En el Reino Unido Berrington y Falkingham (2010) revelan las diferencias por sexo como consecuencia de la feminización de la educación superior, las diferencias entre los grupos de edad más jóvenes por sus dificulades en la incorporación al mercado laboral entre 1998 y 2008 y la relativa estabilidad en los eventos de transición entre los jóvenes de mayor edad pero a menudo ocupando múltiples roles combinando por ejemplo estudio y trabajo. En esta década el porcentaje de jóvenes emancipados ha aumentado y la elección de la cohabitación como forma de convivencia en pareja (Berrington y Falkingham, 2010). En Toulemon (2010) se comparan las transiciones de los jóvenes hacia la vida adulta en Europa desde los años 60, este autor considera que el análisis de las secuencias de los eventos de transición sigue siendo válido a pesar de la creciente desestandarización de la transición, pues permite una descripción global de todo el proceso. Centra su atención en las diferencias por sexo y ha constatado la evolución hacia una disminución de las diferencias entre hombres y mujeres, el retraso en el primer empleo, en la primera unión y en el primer hijo en toda Europa. El matrimonio ya no es la única opción de vida en pareja, consecuentemente aumentan los nacimientos fuera del matrimonio. En la Europa occidental se observa un retraso en la vida en pareja mientras en la Europa del Este no. La transición escolar y laboral se retrasa en todos los países y la emancipación residencial especialmente en los países del Sur de Europa. Las diferencias por sexo aumentan en la Europa del Este y disminuyen en España y Portugal en especial entre las mujeres nacidas en la décadas de los 70. Toulemon apunta a que puesto que las transiciones son diferentes en los distintos países deben de existir políticas específicas en cada país encaminadas a solucionar y facilitar los procesos de transición. Con estos elementos junto a los ya comentados resulta obvia la necesidad de acometer estudios que permitan observar las diferencias en estos procesos y determinar si existen modelos diferentes de transición sin 
que ello implique necesariamente problemas y dificultades o más bien una distorsión en la secuencia ordinaria de transición que fomenta la precariedad en los jóvenes respecto al trabajo, vivienda, etc.

Ya se ha comentado con anterioridad diversos estudios de transición realizados en el ámbito español en su conjunto o en alguna de sus comunidades autónomas y pocos son los que hacen referencia explícita a la heterogeneidad en estos procesos. Son frecuentes los estudios que hacen referencia la al transición laboral, las dificultades de acceso a empleos adecuados, la precariedad en el trabajo, la falta de linealidad entre formación y empleo, etc. además de las dificultades en la emancipación residencial y el acceso a una vivienda en propiedad o alquiler, pero por separado o incluyendo solamente algunos de los eventos de transición. Los itinerarios de transición en su conjunto no han sido muy tratados y menos aún aquellos que prestan su atención a evidenciar la diferencias en cuanto al momento en el que se producen su duración o su grado de complejidad, en La Parra (2000) y Vieira y Miret (2010) sí se realizan estas comparaciones sirviéndose de metodologías muy dispares, en el primer caso de entrevistas retrospectivas en profundidad a jóvenes de entre 30 y 34 años que ya han experimentado los eventos de transición o estarían a punto de ello, además de a sus respectivas familias y en el segundo caso comparando datos sirviéndose del índice de entropía, para las posibles combinaciones de estatus o transiciones experimentadas en diferentes grupos de edad con datos de censos. En ambos trabajos a pesar de su disparidad en lo que se refiere a la cuestión metodológica, las diferencias se presentan por sexo y en el caso de Vieira y Miret por periodos. Más allá de las conclusiones ya aportadas en otros estudios como el retraso progresivo en todos los procesos de transición y la influencia del contexto familiar aportada por La Parra, es necesario evidenciar las carencias observadas en el panorama español en cuanto al estudio de las diferencias entre los jóvenes frente a los procesos de 
transición en su conjunto y cruzando otras variables además del sexo como es el riesgo de pobreza, la coyuntura económica, nivel formativo alcanzado o grado de urbanización del hábitat donde se reside. Si tenemos en cuenta que el proceso de transición estaría compuesto por el término de los estudios, la incorporación al mercado laboral, emancipación residencial, formación de pareja y transición parental, son frecuentes los estudios que tratan uno, dos o tal vez tres de estos aspectos, pero raramente todos ellos en su conjunto. En esta tesis se tratará de presentar un enfoque más completo al referirnos al proceso de transición en su conjunto aportando información relativa a los cinco apartado mencionados y observando el grado de heterogeneidad que hay en el colectivo objeto de estudio teniendo en cuenta variables independientes como el sexo, periodo de coyuntura económica, riesgo de pobreza y grado de urbanización del hábitat donde se reside, si bien como ya se ha comentado reiteradamente con el único propósito de observar los cambios y diferencias en la estructura de las transiciones. Ciertamente el estudio de las diferencias por sexo y por periodos diferentes son habituales en los estudios de transición, como se ha comentado, pero no lo son tanto las condiciones económicas y el grado de urbanización del hábitat donde se reside. Con esta tesis se pretende cubrir este vacío y evidenciar las diferencias tan notables que existen en los jóvenes y sus procesos de transición considerando todas las transiciones en su conjunto y dependiendo de las variables independientes que se han comentado. 


\section{CAPÍTULO 2. METODOLOGÍA Y BASES DE DATOS UTILIZADOS EN LA INVESTIGACIÓN}

\subsection{Objetivos perseguidos e hipótesis}

El objetivo general de esta tesis será evidenciar y valorar las diferencias de los jóvenes en la estructura de los procesos de transición en cuanto al momento en el que se producen los eventos, su duración y su heterogeneidad o diversidad, así como las diferencias con relación a las variables que más influencia tienen para alcanzar las respectivas transiciones. No se persigue, por tanto, el estudio exhaustivo de las transiciones en el sentido estricto y longitudinal sobre cómo se están produciendo, posible retroactividad o creación de tipologías de transición (trayectorias de éxito precoz, trayectorias obreras, trayectorias de adscripción familiar, trayectorias de precariedad, trayectorias erráticas o de bloqueo, etc. (Casal et al., 2006) se describirán las transiciones a través de la ocurrencia de los eventos, duración y heterogeneidad en las variables que describen cada proceso. Para ello se plantean los siguientes objetivos secundarios:

1. Describir y valorar el grado de diferenciación en los jóvenes teniendo en cuenta las variables que más influyen en las diferentes transiciones (escolar, laboral, residencial, vida en pareja y parental). Se explorarán las diferencias en los estudios terminados, el tipo de ocupación con especial atención al porcentaje de parados o las diferencias en cuanto al momento en el que se produce la emancipación residencial. Estas diferencias se valorarán teniendo en cuenta las variables independientes edad, sexo, estudios terminados, relación con la actividad, etc., además de comparar secuencias de varios años en aquellos casos que se considere de interés y sea posible, con objeto de observar las diferencias en el periodo previo a la crisis económica y en la crisis económica. 
2. Igualmente, describir y valorar las diferencias en los momentos en los que se producen las diferentes transiciones en función del grupo de edad, el sexo, el riesgo de pobreza, el tipo de hábitat donde se reside (más o menos urbanizado) y comparando dos periodos que representan los años previos a la crisis económica y la salida de la crisis económica. También se ofrecerá el intervalo de años en el que se produce cada una de las transiciones, así como la edad media. De la misma manera que en los casos anteriores, cruzando las variables independientes que serán habituales a lo largo de todo este trabajo: edad, sexo, riesgo de pobreza y coyuntura económica.

3. Valorar el grado de heterogeneidad de cada grupo de edad según el grado de complejidad de todas las posibles combinaciones de los cinco estatus o estados que representarían cada transición (estudiante, activo, emancipado, vida en pareja y padre) medido con el índice de entropía. Además de la valoración de la heterogeneidad de cada grupo de edad y cruzando las variables independientes habituales, será posible construir secuencias de transición donde poder identificar el término de la transición hacia la adultez.

4. Buscar relaciones de probabilidad en la ocurrencia de los eventos de transición y en las diferencias observadas mediante un análisis de regresión logística; también se observarán las diferencias entre los índices de entropía observados y predichos en cada una de las distribuciones de posibles combinaciones de estatus en las que se ha eliminado uno de ellos. Con este procedimiento, que en adelante se detallará, será posible observar el peso de cada estatus en las diferencias.

Estos objetivos conducirán a refutar la hipótesis que es posible plantear una vez expuesto el apoyo teórico y las aportaciones citadas: los jóvenes estarían ubicados en la estructura de clase y económica heredada de sus padres, que condicionaría las posibilidades de construir sus propios itinerarios de transición. El nivel de estudios alcanzado discrimina 
a los jóvenes, la escuela no compensaría las diferencias asociadas al origen social; de igual manera, los itinerarios que conducen a la transición laboral son variados e influenciados por la estructura económica y tendiendo igualmente hacia la segmentación social de los jóvenes. La juventud concluiría con la incorporación al mercado laboral y la emancipación residencial, y entre los jóvenes se producen elecciones y estrategias para hacer frente a los determinismos estructurales y contextuales que provocan diferencias, en especial por sexo, como el adelanto de las relaciones de pareja, la emancipación y la maternidad en las mujeres. Todas estas circunstancias condicionarían las diferencias en el comienzo, la duración y el final de la transición hacia la adultez.

De entre las aproximaciones metodológicas que nos aportan las ciencias sociales en los procesos de investigación, se ha utilizado una metodología cuantitativa y un modelo de análisis descriptivo y de regresión logística. El análisis de resultados está dividido en dos apartados claramente diferenciados, por una parte un análisis puramente descriptivo, donde se describen la transición escolar, laboral, residencial, de vida en pareja y parental, ¿cuándo se produce?, ¿cuánto dura?, y la edad media a la que se producen los sucesos; y un análisis de regresión logística donde se valorará la influencia de algunas de las variables independientes que más influirían en los procesos de transición. En tercer lugar, se presenta el análisis de entropía, que a su vez aporta dos posibles lecturas de los datos, por una parte, el grado de heterogeneidad por grupos de edad y, por otra, la secuencia de transición donde identificar el comienzo y el final de la transición. Todos estos análisis permitirán una valoración sobre la heterogeneidad de los jóvenes en su transición hacia la adultez. 


\subsection{Bases de datos}

Los diferentes índices e indicadores que se presentan en este trabajo proceden del análisis de la información obtenida en bases de datos, son datos, por tanto, secundarios. En ocasiones, estos indicadores se presentan tal y como los ofrece la base de datos consultada, únicamente comentándolos y ordenándolos en gráficos o tablas; para la mayor parte de los casos son fruto del análisis minucioso de los microdatos que la base de datos ofrece tratados con el programa estadístico SPSS. Para el primer caso se han consultado las bases de datos del Banco de España, del CIS (Centro de Investigaciones Sociológicas), del INJUVE (Instituto Nacional de la Juventud) y de EUROSTAT; estas bases de datos constituyen un apoyo en la contextualización para algunos de los análisis que se realizan. Para el segundo caso, se ha utilizado del INE (Instituto Nacional de Estadística) y la ECV (Encuesta de Condiciones de Vida). De todas las bases de datos y sondeos consultados, es esta encuesta (ECV) la que ha servido de apoyo principal para la realización de la presente tesis.

Hay que recordar en este punto que el objetivo de la tesis no es el análisis en profundidad de cada una de las variables seleccionadas. Se trata de realizar comparaciones en un periodo determinado o periodos, en su caso, y para las variables elegidas, con la finalidad de detectar las diferencias entre la población considerada joven en cuanto a los elementos que influyen en los procesos de transición. Por tanto, no se debe esperar una información minuciosa y especialmente actualizada del desempleo, la formación, la emancipación, etc., cuestiones estas que sí podrán ser tratadas en posteriores trabajos de manera monográfica y sirviendo de base la presente tesis.

La ECV aporta una gran información, especialmente sobre el nivel renta, pobreza y exclusión social, si bien, por su magnitud cuantitativa, su alto grado de calidad en lo que 
a su actualidad y grado de comparabilidad se refiere, la inclusión de multitud de otro tipo de variables, como son las demográficas, etc., permite el análisis de otros muchos aspectos de la realidad social. El uso de la encuesta es prioritariamente transversal; no obstante, es posible la obtención de información longitudinal, al estar diseñada de tal manera que se entrevista a las mismas personas en diferentes momentos a lo largo del tiempo. El análisis estrictamente longitudinal es muy limitado, en tanto los ciclos que corresponden a los mismos individuos se desarrollan únicamente en periodos de cuatro años. Para poder ofrecer un enfoque longitudinal en un periodo amplio de tiempo, donde se incluyen desde los años previos a la crisis económica hasta los años en los que es posible considerar que se produce la salida de la crisis, se ha decidido fusionar los ficheros transversales construyendo secuencias que, aun no siendo estrictamente longitudinales, aportan información en este sentido. El INE ofrece los microdatos en formato CSV (formato de texto separado por comas), figurando el nombre de la variable en la primera fila en diferentes ficheros. Se han seleccionado los ficheros $\mathrm{P}$, que corresponden con las características personales de los entrevistados, y los ficheros $\mathrm{H}$ y $\mathrm{D}$, que aportan información sobre el tipo de hogar al que se pertenece. Se han utilizado los ficheros que corresponden a los años 2006, 2007, 2008, 2009, 2010, 2011, 2012, 2013, 2014 y 2015. Los dos primeros corresponden a años previos a la crisis económica y los dos últimos a los años que corresponden con la salida de la crisis económica. Se ha comprobado cómo los datos descriptivos de los años 2006 y 2007 son prácticamente idénticos, al igual que los que corresponden a los años 2014 y 2015, por este motivo en los análisis descriptivos únicamente se comparan los años 2007, como previo a la crisis, y el año 2014 como año que representa el comienzo de la salida de la crisis. En el análisis de entropía, que se describirá más adelante, se han fusionado los archivos de los años 2006 y 2007, que representan el momento previo a la crisis económica, y los años 2014 y 2015 como 
momento en el que se comienzan a observar indicadores que reflejan la salida de la crisis; el motivo ha sido el trabajar con ficheros con un número de casos mayor, con el objetivo de minimizar la distorsión en los resultados que se puede producir por la escasez de casos para algunas de las categorías de las distribuciones con las que se ha trabajado.

El objeto de estudio son los jóvenes y el intervalo de edad dependerá del tipo de análisis que se esté realizando; lo habitual será de entre 17 y 34 años, agrupados en cohortes de tres años, por considerar que en este intervalo es donde se producen en mayor medida los eventos de transición, si bien para otros análisis el intervalo seleccionado será de 25-34 años, como es el caso de la transferencia intergeneracional de las condiciones socioeconómicas y socioculturales. Por otra parte, para la construcción de una secuencia de transición con los índices de entropía para las posibles combinaciones de estatus en cada cohorte de edad, se ha decidido el aumentar la edad hasta los 46 años, con el único propósito de visualizar más claramente el término de la transición. Los indicadores únicamente se presentan para la edad unitaria cuando se ofrece la edad media a la que se producen las transiciones respectivas, lo habitual será el que se ofrezcan por grupos de tres años (17-19 años, 20-22, 23-25, 26-28, 29-31 y 32-34 años).

Los ficheros utilizados de la ECV son los siguientes: Fichero D, que corresponde a los datos básicos del hogar con un número que identifica el hogar, año de la encuesta, grado de urbanización, etc.; el Fichero R, corresponde a los datos básicos de la persona, información demográfica, situación respecto a la actividad, etc.; el Fichero H, que incluye información detallada sobre diferentes secciones como vivienda, exclusión social, renta, etc., y, por último, el Fichero $\mathrm{P}$, que contiene datos detallados sobre los adultos con $16 \mathrm{o}$ más años, información sobre educación, salud, datos laborales, renta y otras informaciones. 
Las variables que se han utilizado para los objetivos perseguidos en este trabajo están directamente relacionadas con las aportaciones teóricas con relación a las variables que más influencia tienen en los procesos de transición y desigualdad entre los jóvenes: el nivel formativo, el empleo, la emancipación residencial, la relación conyugal o cualquier modelo de vida en pareja, riesto de pobreza..., son cuestiones ampliamente tenidas en cuenta en los estudios de juventud, que son pertinentes para el estudio de la desigualdad y diferenciación entre los jóvenes. Cada una de las variables que contiene un fichero está nombrada con un código; para conocer a qué variable se refiere, cuáles son sus categorías y cómo está codificada, es necesario acudir al documento que acompaña a cada encuesta llamado Ficheros Transversales de Usuario de la Encuesta del año al que corresponda. Es importante tener en cuenta que, aunque sistemáticamente las variables son las mismas y con los mismos nombres, códigos, categorías y valores, para alguna de las variables puede haber algún cambio; por ejemplo, para la variable relación con la actividad cambian algunas categorías y también los valores a partir del año 2009. Igualmente se observa cómo existen variables que únicamente se han utilizado en un año, como es el caso de las variables que se refieren a la transferencia intergeneracional de la pobreza, que se pasaron únicamente en el año 2011 y son objeto de análisis en el capítulo correspondiente.

Ya se ha comentado anteriormente que el tratamiento estadístico de los datos se ha realizado con el paquete estadístico SPSS, el primer paso es importar los archivos de microdatos que ofrece el INE, para posteriormente nombrar, etiquetar y valorar las variables que a continuación se analizarán. Los diferentes ficheros mencionados se presentan de manera independiente, pudiendo realizar análisis en cada fichero con independencia de los demás, si bien las posibilidades de análisis quedan limitadas a análisis de los hogares o a análisis de los datos personales, ambos por separado. Para 
poder cruzar estos datos es necesario fusionar los archivos a través de las diversas opciones que ofrece el programa SPSS. El fichero que corresponde a los datos de personas es mucho más numeroso que el de los hogares, pues a cada hogar le suelen corresponder varias personas. Utilizando la variable identificador personal PB030, cuyo valor está compuesto por el número del hogar más el número de orden que tiene en el hogar, se ha creado una nueva variable eliminando las cifras que corresponden con el orden dentro del hogar, de tal manera que en la nueva variable el dato que se refleja para cada caso es el hogar al que pertenece; se trata de una variable clave, para que al fusionar el fichero de hogar con el de personas a cada caso de personas se le adjuntan todas las variables que correspondan al hogar al que pertenecen. Con esta acción ha sido posible obtener una matriz de datos con las variables seleccionadas, etiquetadas y valoradas, de los casos de personas y con las variables que corresponden al hogar al que pertenece.

\subsection{Variables seleccionadas}

De entre las numerosas variables que ofrece la ECV se han seleccionado aquellas que más directamente influyen en los procesos de transición, algunas de ellas tal y como las ofrece la encuesta y otras modificadas e incluso creadas a partir de las que la encuesta incluye. Las variables dependientes son las siguientes:

Estar o no estar estudiando, esta variable la ofrece tal cual la ECV.

Ser o no ser activo, esta variable no la ofrece la encuesta, si bien se ha conseguido mediante una agrupación de las diferentes categorías de activos y de no activos que contiene la variable relación con la actividad. 
Estar o no estar emancipado, esta variable no está incluida en la ECV, sumando a los que tienen cónyuge o pareja de hecho (se ha supuesto que los que tienen cónyuge o viven en pareja, con independencia del tipo de unión, estarían todos emancipados) más aquellos que no tienen cónyuge o pareja de hecho, pero son responsables de hogar.

Tener o no tener cónyuge o pareja de hecho, esta variable la aporta la encuesta, pero con tres categorías, sí con base jurídica, sí sin base jurídica y no, agrupando las dos primeras categorías se dispone de la variable dicotómica buscada. La categoría en positivo incluiría a todas las personas con relación de pareja y que viven en el mismo hogar, con independencia del modelo de pareja; estarían incluidos matrimonios, parejas de hecho o cualquier otro tipo de relación de pareja con independencia de que exista o no base jurídica. Para evitar confusiones, se ha decidido nombrar la nueva variable con el nombre de vida en pareja y las categorías sí y no, y la transición a la que se accedería transición a vida en pareja. De tal manera que siempre que se esté haciendo referencia a pareja se estará refiriendo a parejas que cohabitan, en ningún caso relaciones de noviazgo u otro tipo de relación que no implique compartir el mismo hogar.

Ser o no ser padre, esta variable no se incluye en la encuesta y se ha obtenido sumando a los que viven en pareja y en hogares con hijos, a los responsables de hogar que viven en hogares con hijos y sin pareja. No es un dato exacto, pero sí muy aproximado, pues parece lógico pensar que todos aquellos que viven en hogares con hijos y son pareja son padres, como también lo son aquellos responsables de hogar sin pareja, pero que viven en hogares con hijos.

Como variables independientes se han utilizado: coyuntura económica, representada por los años 2006-2007, antes de la crisis, y en la salida de la crisis 2014-2015; la variable edad, la variable sexo, la variable riesgo de pobreza del hogar, que la ECV ofrece con las 
categorías sí o no, el grado de urbanización del hábitat donde se reside, además de las dependientes que en ocasiones actúan como independientes.

En los siguientes párrafos se explicará el procedimiento de creación de las nuevas variables con más detalle.

La creación de nuevas variables sirviéndose de los datos de otras ya existentes ha sido posible mediante los siguientes procedimientos: la primera de ellas ha sido la edad. La ECV no ofrece este dato tal cual, pero sí el año de la encuesta PB010 y el año de nacimiento PB140; en las opciones transformar y calcular variable del programa utilizado se restan PB010-PB140 y se obtiene la nueva variable edad. Lo habitual en los estudios de estas características es presentar los datos por grupos de edad; la creación de una nueva variable de edad por grupos es posible desde el menú transformar y agrupación visual. Con esta operación se dispone en la matriz de la nueva variable que permite las comparaciones por grupos o cohortes de edad en función de las necesidades del análisis que se esté realizando.

La variable activos se refiere a estar incorporado al mercado de trabajo, estarían reflejados todos los casos que trabajan o quieren trabajar, por tanto, también los parados. Ha sido necesario calcular una variable de activos y no activos a través de la variable que la encuesta ofrece relacionada con la actividad, sumando las categorías de trabajadores por cuenta propia y ajena más desempleados, para los activos y, por otra parte, para los no activos, las categorías de estudiando, jubilados, incapacitados, trabajo en el hogar y otros no económicamente activos. Es necesario advertir que las categorías que contiene la variable relación con la actividad son excluyentes entre sí, por tanto, no es posible comparar los datos de parados que ofrece la ECV con los ofrecidos por otras encuestas, como la EPA (Encuesta de Población Activa), en tanto que la condición de parado puede simultanearse con la de estar estudiando. 
Las variables responsable de hogar y emancipación residencial no se ofrecen tal cual en la ECV, pero, como en los casos anteriores, es posible crearlas a partir de otras existentes. En el Fichero P (fichero de personas), la variable PB030 corresponde con la identificación personal, que como ya se ha dicho indica un valor donde los dos primeros dígitos empezando por la derecha corresponde al orden dentro del hogar mientras el resto al identificador del hogar; en el Fichero H (fichero de hogares), la variable HB080 corresponde con la identificación del primer responsable del hogar; con esta información, nuevamente acudiendo al menú transformar del programa SPSS y después a calcular variable realizando la selección $\mathrm{PB} 030=\mathrm{HB} 080$ obtenemos la nueva variable responsable de hogar. Ha sido posible obtener a los emancipados residencialmente con los siguientes criterios: por una parte, sumamos a todos los que tienen cónyuge; tener cónyuge en España y en este momento implica estar emancipados residencialmente. En las familias extensas donde convivían varias generaciones habría jóvenes cónyuges nunca emancipados residencialmente, pero el cambio familiar acontecido en España en las últimas décadas hace pensar en que, de existir, serían pocos estos casos (Del Campo y Del Mar, 2002). A los que tienen cónyuge se les suma los que no tienen cónyuge responsable de hogar y tenemos una cifra con mucha aproximación de la variable emancipados residencialmente.

La variable padre/madre tampoco se ofrece en la ECV; lo más aproximado es la variable tipo de hogar, donde es posible obtener los hogares con niños. Obviamente no es una solución, pues en los casos de edades menores los propios casos son los hijos del hogar, no sus propios hijos. Ha sido posible conseguir este dato, o muy aproximado, sumando a los hogares con hijos de entre los que tienen pareja y cohabitan con los hogares con hijos de entre los que no tienen pareja, pero son responsables de hogar; parece lógico que quienes tienen pareja y pertenecen a un hogar con hijos la pareja son padres, y que al ser 
responsable de hogar y pertenecer a un hogar con hijos también se es padre; con este procedimiento ha sido posible la obtención de la variable padres.

En el capítulo donde se analizan las cuestiones relativas a la formación se incluye el concepto de ninis, ya se ha comentado en el apartado teórico y que representa al colectivo de jóvenes que ni estudia ni trabaja, y para cuyo análisis y su cuantificación existen diferentes perspectivas, dependiendo de qué jóvenes se incluyen: intervalo de edad, si el no trabajar o estudiar es consecuencia de las condiciones socioeconómicas o es voluntad del joven, etc. Este indicador es definido por la OIT (Organización Internacional del Trabajo) como el porcentaje de jóvenes que no están empleados y no siguen ningún tipo de educación o formación y se calcula sumando el número de jóvenes desempleados con el número de jóvenes no económicamente activos y restando el número de jóvenes no económicamente activos y de jóvenes desempleados que sí siguen algún programa de educación o formación (CAUCES, 2013). La definición no incluye intervalos de edad, ni excluye a los incapacitados, ni tiene en cuenta la voluntad de trabajar o estudiar, pero es un indicador considerado válido en la Unión Europea para valorar la situación de los jóvenes en el mercado laboral. La ECV ofrece datos sobre ocupación y sobre formación, pero no con el detalle que ofrece la EPA. No obstante, es posible identificar a los jóvenes que ni trabajan ni estudian creando una nueva variable a partir de la de estar realizando algún tipo de estudios (PE010) y de la variable relación con la actividad (PL030 o PL031). Esta codificación depende del año de la encuesta y también cambian los códigos de las diferentes categorías. Siguiendo los mismos pasos que para la creación de las variables anteriores, menú transformar, opción calcular variable, se introduce la selección PE010=2 (el 2 corresponde con la categoría no estar en un plan formativo) \& PL030 o 031=3 o 5 (que corresponde con la categoría estar en paro). Con estos pasos se dispone de la nueva variable ninis. 


\subsection{Análisis y estadísticas}

\subsubsection{Análisis descriptivos}

Este nivel de análisis permitirá una primera aproximación a las diferencias entre los jóvenes y en los procesos de transición, diferencias en cuanto al nivel de estudios terminados, tipo de relación con la actividad, porcentaje de emancipados residencialmente, etc., y cruzando variables como sexo, coyuntura económica, riesgo de pobreza o tipo de hábitat, ofrecen los primeros indicadores que pondrán de manifiesto las diferencias y desigualdad entre los jóvenes. Por otra parte, con relación a las diferencias exploradas en las diferentes transiciones, se ofrecerá la edad media a la que se produce la transición escolar, laboral, residencial, de vida en pareja y parental, el porcentaje de jóvenes que ostentan un estatus o estado determinado y la extensión o duración de la transición. Todo ello comparativamente, según las variables independientes que se han considerado, coyuntura económica, sexo y riesgo de pobreza del hogar donde se reside, etc.

La extensión o duración de la transición se refiere al tiempo necesario para que se realice un evento. Este indicador corresponde con la diferencia entre la edad al noveno y al primer decil de la distribución de los individuos considerados. De esta manera, no se consideran los que realizan la transición antes del primer decil ni los que lo realizan después del noveno decil, por considerarlos fuera del grupo central. El cálculo se ha realizado entre los individuos que están siendo objeto de estudio, de los 17 a los 34 años. Tanto la edad media a la que se produce un suceso determinado como la extensión de este son datos que pueden variar dependiendo del grupo de edad al que nos estemos refiriendo. No obstante, lo que más interesa para el presente trabajo no es tanto la edad media o la 
duración de una transición en sí misma, son las diferencias que se puedan detectar atendiendo a las variables independientes seleccionadas.

\subsubsection{Análisis multivariante. Regresión logística binaria}

La regresión logística es un procedimiento estadístico que se utiliza cuando se dispone de una variable dicotómica dependiente y sobre la que se pretende predecir o establecer la relación o grado de asociación que existe con una o varias variables independientes o predictoras. Las variables independientes pueden ser tanto continuas como categóricas.

Se ha realizado un análisis de regresión logística para cada una de las variables dependientes y dicotómicas que definen las respectivas transiciones. Para la transición escolar, la variable estudia; hay que recordar que esta variable la ofrece tal cual la ECV con las únicas categorías de sí está realizando algún tipo de estudios o no está realizando algún tipo de estudios. Para la transición laboral, la variable dicotómica activos, ya descrita anteriormente. Para la transición residencial, la variable emancipados; la variable dicotómica pareja para la transición a la vida en pareja y padre para la transición parental, todas ellas descritas igualmente en el epígrafe correspondiente. Como variables independientes o predictoras se han utilizado las mismas que han sido habituales para el resto de los análisis que se ofrecen a lo largo de toda la tesis: edad, sexo, riesgo de pobreza, periodos precrisis, en crisis y postcrisis y grado de urbanización del hábitat en el que se reside.

La regresión logística ofrece la posibilidad de evaluar la influencia de cada una de las variables independientes sobre la variable dependiente, si bien hay que tener en cuenta que la regresión logística valora el peso predictivo de cada una de las variables independientes en la dependiente teniendo en cuenta todas las variables seleccionadas, la 
elección de estas variables está justificada en tanto que existe base teórica que aporta información suficiente en este sentido, además de la información que aportan los análisis descriptivos en los capítulos correspondientes. Por otra parte, la lectura de los indicadores que nos ofrece el análisis de regresión logística no permite valorar cuál de las variables independientes tiene un mayor peso en la probabilidad del suceso, únicamente ha sido posible observar qué variables de las estudiadas tienes significación estadística y el sentido dependiendo de qué categoría se toma como referencia. Con la excepción de la variable independiente hábitat, que para alguno de los análisis no tendría significación, para el resto de los análisis todas las variables presentan un p-valor inferior a 0,05 , lo que nos está diciendo que la variable independiente es significativa y que, por tanto, influye en la variable dependiente. El signo del coeficiente estimado del modelo $B$ aporta la dirección en la que se produce la probabilidad, positivo aumenta la probabilidad de ser activo, emancipado, tener pareja, etc., y negativo a la inversa. La única variable cuantitativa utilizada será la edad, para este caso la probabilidad de que se produzca uno de los sucesos de los que se analizan se referirá a la probabilidad, en positivo o negativo, de que se produzca el hecho por cada año que aumenta la edad. En el capítulo correspondiente se presentan las tablas con los indicadores obtenidos.

\subsubsection{Análisis de entropía}

Las posibilidades de aplicación del análisis de entropía en ciencias sociales han sido exploradas por diversos autores, fundamentalmente para los análisis de la desigualdad de la renta (Dagum, 1993; Fernández y Costa, 1998; Lechuga, 1998). Una aplicación menos estudiada es para la que se utiliza este indicador en el presente trabajo, valorar la heterogeneidad de los jóvenes en los procesos de transición. En Vieira (2013) se ponen de manifiesto estas posibilidades recordando que el concepto de entropía se desarrolla 
originalmente en la física, en estudios para medir la transformación de la materia en un sistema determinado; la entropía mediría el grado de segmentación o fragmentación dentro del sistema. En este sentido, la entropía es una medida de descomposición y también de heterogeneidad, pues cuanto mayor es la entropía, mayor será la complejidad de un fenómeno. Vieira explica el procedimiento matemático a seguir en el uso de este indicador en ciencias sociales y basa sus explicaciones en los análisis estadísticos de descomposición propuestos por Theil (1972); por tanto, el índice de entropía es un indicador que puede ser utilizado para valorar la heterogeneidad de los jóvenes en la transición a la vida adulta según la mayor o menor complejidad en una distribución de posibles combinaciones de estatus ${ }^{1}$ (Fussell et al., 2007; Vieira y Miret, 2010; Vieira, 2013; Felicia F. Tian, 2016). En esta tesis, la entropía se utilizará para medir la heterogeneidad de un colectivo midiendo la complejidad en las distribuciones compuestas por las posibles combinaciones de los estatus o estados que definen la transición hacia la adultez. Estos estatus se producen en diferentes momentos y en ocasiones se solapan, de tal manera que la combinación de los diferentes estatus es distinta según el momento vital en el que el joven se encuentre. Así, es posible estar formándose, incorporarse al mercado laboral, tener pareja y emanciparse, como también es posible únicamente estar formándose y no asumir ninguno del resto de estados. Los cambios y ajustes en la transición hacia la vida adulta hacen pensar en un sistema donde intervienen diferentes elementos, el sistema sería el proceso de transición en su conjunto y los elementos que entran y salen del sistema las diferentes combinaciones de estatus que se asumen en cada momento del ciclo vital; el índice de entropía mide la complejidad en la combinación de

\footnotetext{
${ }^{1}$ La bibliografía consultada que sirve de apoyo en el análisis de entropía utiliza la terminología de estatus para referirse a la situación en la que se encuentra el joven con relación a los estudios, el mercado laboral, la emancipación, etc., si bien la palabra estatus utilizada estrictamente haría referencia a la posición en la estructura social. Con la intención de no crear confusión, se ha decidido utilizar indistintamente la palabra estatus y estado para referirse a la situación en la que se encuentra un joven con relación a los estudios, el mercado laboral, la emancipación residencial, la vida en pareja o a ser padres.
} 
estos estatus para cada edad, periodo, sexo y demás variables consideradas. La mayor complejidad en la distribución de estatus representada por el punto ápice de entropía correspondería con el final del periodo de transición, mientras que la disminución y la estabilidad indicarían la culminación de la transición hacia la vida adulta (Vieira, 2013). En una combinación donde intervengan los estatus de estudiante, activo, emancipado, con pareja y ser padre, todos los individuos de 12 años, por ejemplo, se concentrarían en una posible combinación estudiantes, no activos, no emancipados, sin pareja y sin hijos; en este ejemplo la entropía sería 0; las combinaciones de estatus o estados se van complicando progresivamente al compartir diferentes estatus y cambiar con frecuencia esta combinación, estaríamos hablando de los años centrales de la juventud; la máxima entropía posible depende del número de estatus que se combinen y se produciría en aquella distribución donde para cada una de sus categorías existe el mismo número de casos. La etapa del ciclo vital en la que las personas asumen posiciones muy similares: la mayor parte no estudian, son activos, están emancipados residencialmente, tienen pareja y tienen hijos, se corresponde con una etapa del ciclo vital donde la entropía o heterogeneidad tiende a estabilizarse.

Desde el enfoque del curso de vida, descrito en el apartado metodológico, el análisis de entropía se muestra como una posibilidad con fuerza para describir el continuo que supone la transición hacia la adultez en función de la asunción de los diferentes estados que se han indicado. A través del índice de entropía será posible describir la trayectoria hacia la adultez en función del grado de complejidad en la distribución de la combinación de estatus que proporciona el índice de entropía. Para poder valorar las diferencias en el proceso de transición se realizarán diferentes comparaciones: en dos momentos de diferente coyuntura económica, diferencias por sexo, diferencias cuando se pertenece a un hogar con o sin riesgo de pobreza y diferencias por tipo de hábitat donde se reside. El 
interés para estas comparaciones está fundamentado en los resultados que se observarán en los análisis descriptivos de los epígrafes precedentes a este análisis. En este sentido, los análisis descriptivos nos aportan la información necesaria que permite plantear hipótesis relacionadas con la diferente forma de afrontar las transiciones en los dos periodos de distinta coyuntura económica, como también las diferencias observadas por sexo ofrecen las primeras pistas para formular hipótesis relacionadas con una diferente transición entre varones y mujeres. El estatus socioeconómico, medido por el riesgo de pobreza de los hogares al que se pertenece, también merece la atención a tenor de las diferencias observadas en los análisis descriptivos.

\section{Descripción del indicador}

Todo el razonamiento metodológico está basado en el uso del índice de entropía general de Theil y en las indicaciones propuestas por Vieira, Miret y Fussell. La fórmula matemática es la siguiente:

$$
E_{x}=\sum_{s} p_{s, x} \cdot \ln \left(1 / p_{s, x}\right)
$$

Donde $E$ es el índice de entropía, $s$ indica una determinada combinación de estatus, $x$ a una cierta edad y $P_{s x}$ la proporción de la población $x$ que se encuentra en el estatus $s$. El índice de entropía es el sumatorio de la proporción de una edad determinada que se encuentra en la combinación de estatus multiplicado por el logaritmo natural de la proporción inversa de esa combinación.

El índice de entropía va desde el 0, cuando la homogeneidad es perfecta, es decir, cuando todos los individuos están concentrados en el mismo estatus o combinación de estatus, 
hasta la entropía máxima, que varía dependiendo del número de posibles combinaciones de estatus y se refiere a la máxima heterogeneidad, cuando existe el mismo número de casos para cada combinación de estatus. En Fussell (2006) se recomienda convertir los índices en porcentajes para hacer más entendible la información que se presenta; para conseguir este fin ha sido necesario calcular la entropía máxima, siendo la entropía máxima el $100 \%$ resulta simple calcular el porcentaje que corresponde a la entropía obtenida. La representación gráfica permite visualizar claramente la evolución de la entropía facilitando los análisis y la comprensión de los resultados (Vieira y Miret, 2010). La entropía máxima está definida por la siguiente fórmula:

$$
E_{\max }=\Sigma\left(1 / C_{s}\right) \cdot \ln \left[1 /\left(1 / C_{s}\right)\right]
$$

Donde $E_{\max }$ es la entropía máxima y $C_{s}$ es el número total de combinaciones de estatus posibles. La entropía máxima para la combinación de cinco estatus es de 3,466 teniendo en cuenta que el número total de combinaciones posibles es de 32 .

Hasta este momento se ha valorado la heterogeneidad de cada cohorte de edad y para las diferentes variables independientes seleccionadas, así como construir esa secuencia de transición sobre la que visualizar la duración de la transición en su conjunto; con el fin de estimar la influencia que tiene cada uno de los estatus en la heterogeneidad observada, se han creado distribuciones a partir de cuatro posibles estatus, una suprimiendo el estatus de estudiante, otra el de activo, otra el de emancipado, otra el de cónyuge o pareja de hecho y otra el de padre; para estas distribuciones con cuatro estatus, el número de combinaciones posibles es 16 , en este caso la entropía máxima es de 2,773. Para poder 
analizar y valorar la entropía observada una vez suprimido un estatus, es necesario calcular la entropía predicha; en tanto que la entropía observada sea mayor que la entropía predicha, es posible interpretar que el estatus suprimido tiene influencia en la heterogeneidad o entropía total obtenida con la combinación de los cinco estatus. Las fórmulas son las siguientes:

Entropía predicha $=\quad P=(($ Max E - Max Er $) /$ Max E $) .100$

Donde $P$ es la entropía predicha, MaxE la máxima entropía con los cinco estatus y $\mathrm{MaxEr}$ la máxima entropía reducida, es decir, con cuatro estatus.

Entropía observada $=\quad O=((E-E r) / E) .100$

Donde $O$ es la entropía observada, $E$ la entropía observada en las distribuciones construidas con los cinco estatus y Er la entropía observada reducida obtenida con de las distribuciones construidas con cuatro estatus.

El resultado de restar de la entropía observada la entropía predicha, si es positivo, ofrece el peso del estatus eliminado en la entropía total. Una vez obtenida la influencia de cada estatus en el índice total de entropía para una cohorte de edad, se ha calculado el porcentaje que corresponde a cada estatus eliminado, observándose con claridad el peso de cada estatus en el índice de entropía total para cada grupo de edad.

\section{Limitaciones en el alcance de la tesis}

Es necesario enfatizar las posibilidades y limitaciones de los datos. El tamaño muestral en la ECV es grande, pues para el colectivo que está siendo objeto de estudio (17-34 años) estaríamos ante un tamaño muestral de en torno a 8000 casos, dependiendo del año al que pertenezcan los datos. La primera de las limitaciones se deriva de la base de datos 
utilizada, se trata de una encuesta. La ECV ${ }^{2}$ tiene una calidad reconocida por su rigor en la obtención y tratamiento de los datos que supone una garantía en sí misma y dispone de una variable factor de ponderación que minimiza en parte la posible distorsión de los datos cuando estos son escasos al cruzar varias variables. Por otra parte, se recuerda a lo largo de la tesis que este trabajo no es un análisis sobre la formación de los jóvenes, sobre el empleo o sobre la emancipación residencial, sino que se trata de, sirviéndose de estas variables y de otras, evidenciar las diferencias entre los jóvenes, por lo que no se pueden esperar datos estrictamente coincidentes con otras bases de datos. De igual manera, los datos no permiten un análisis estricto sobre cómo se están produciendo las respectivas transiciones, para lo que sería necesario un estudio longitudinal amplio que la ECV no ofrece, lo que se describen son las diferencias en cuanto a la estructura de las transiciones, cuándo se producen, en qué intervalo de tiempo, su heterogeneidad y cuándo terminan. Y, por último, en los itinerarios de transición la reversibilidad es un concepto importante en tanto que determinados sucesos queden anulados, otros se repitan u otros ni siquiera se produzcan, lo que pone de manifiesto la limitación que supone un enfoque de transición que contemple necesariamente una secuencia de eventos lineal y rígida de transición hacia la adultez (término de los estudios, incorporación al mercado laboral, emancipación residencial, vida en pareja y ser padres). No obstante, los autores que se han consultado a este respecto enfatizan la baja reversibilidad y el impacto de la desigualdad de oportunidades (Casal et al., 2008).

\footnotetext{
${ }^{2}$ Nos remitimos al INE para consultar la ficha técnica, cuestionario y metodología utilizada en la elaboración de la encuesta.
} 
Finalmente, se exponen las referencias bibliográficas, páginas web y demás fuentes consultadas. En las notas a pie de página no se incluyen referencias bibliográficas, salvo cuando se refiere a páginas web; son en general aclaraciones, explicaciones o definiciones de conceptos que se excluyen del texto ordinario con el fin de no sobrecargar el contenido y hacer más fluida la lectura. La tesis finaliza con las conclusiones, donde se recoge la respuesta a los objetivos apuntados en la introducción y se refuta o falsea la hipótesis planteada. Tanto el formato del texto como la bibliografía que da apoyo teórico a la tesis se redacta siguiendo las normas APA. 
BLOQUE DE ANÁLISIS DE RESULTADOS

CAPÍTULO 3. Desigualdad y diferencias entre los jóvenes desde la estructura y el contexto familiar.

CAPÍTULO 4. Diferencias en las transiciones hacia la adultez.

CAPÍTULO 5. Las diferencias entre los jóvenes en la probabilidad de la ocurrencia de un evento de transición desde un modelo multivariante.

CAPÍTULO 6. La heterogeneidad en los procesos de transición vistos desde el índice de entropía. 


\section{CAPÍTULO 3. DESIGUALDAD Y DIFERENCIAS ENTRE LOS JÓVENES DESDE LA ESTRUCTURA Y EL CONTEXTO FAMILIAR}

\subsection{El sistema educativo. Los estudios terminados entre los jóvenes}

Los indicadores que en adelante se presentan muestran cómo en España el porcentaje de alumnos universitarios está entre los mayores de toda Europa, pero, aunque resulte paradójico, el porcentaje de alumnos que no termina la Educación Secundaria Obligatoria también es el mayor o de los mayores de entre los países de la OCDE. Estas cuestiones, unidas a una deficiente empleabilidad entre los jóvenes, en ocasiones muy bien formados, pero con un mercado de trabajo que no demanda el tipo de formación que se posee y, en otro extremo, con jóvenes muy poco formados con también muchas dificultades de incorporación al mercado de trabajo, hacen de la cuestión formativa un elemento diferenciador a considerar.

El gráfico 3.1 muestra la evolución del porcentaje de población de entre 18 y 24 años que ha abandonado de forma temprana el sistema educativo, en una serie de años que va del 2001 al 2011; se puede observar que el porcentaje es elevado en toda la serie, en torno al $30 \%$, sin variaciones significativas, con la excepción del último tramo de la serie, del 2009 al 2011, donde se produce un descenso de unos 5 puntos porcentuales. Se aprecian claramente dos cuestiones que merecen ser destacadas, por una parte, cómo en los años de crisis económica el abandono del sistema educativo disminuye, parece que las dificultades en la incorporación al mercado laboral en tiempos de crisis incentiva a prolongar el tiempo formativo y, por otra, la diferencia entre varones y mujeres tan notable; resulta llamativo los más de doce puntos de diferencia en el porcentaje de los varones que abandonaron tempranamente el sistema educativo frente a las mujeres. Estos 
datos enlazarían directamente con la menor tasa de ocupados entre las mujeres respecto de los varones, como se comprobará en el apartado correspondiente. Es conocida la mayor dificultad de las mujeres en acceder al mercado laboral con tasas de actividad muy por debajo de los varones, especialmente en las edades más jóvenes, 17-24 años.

Gráfico 3.1. Porcentaje de la población de entre 18 y 24 años que ha abandonado de manera temprana el sistema educativo en España.

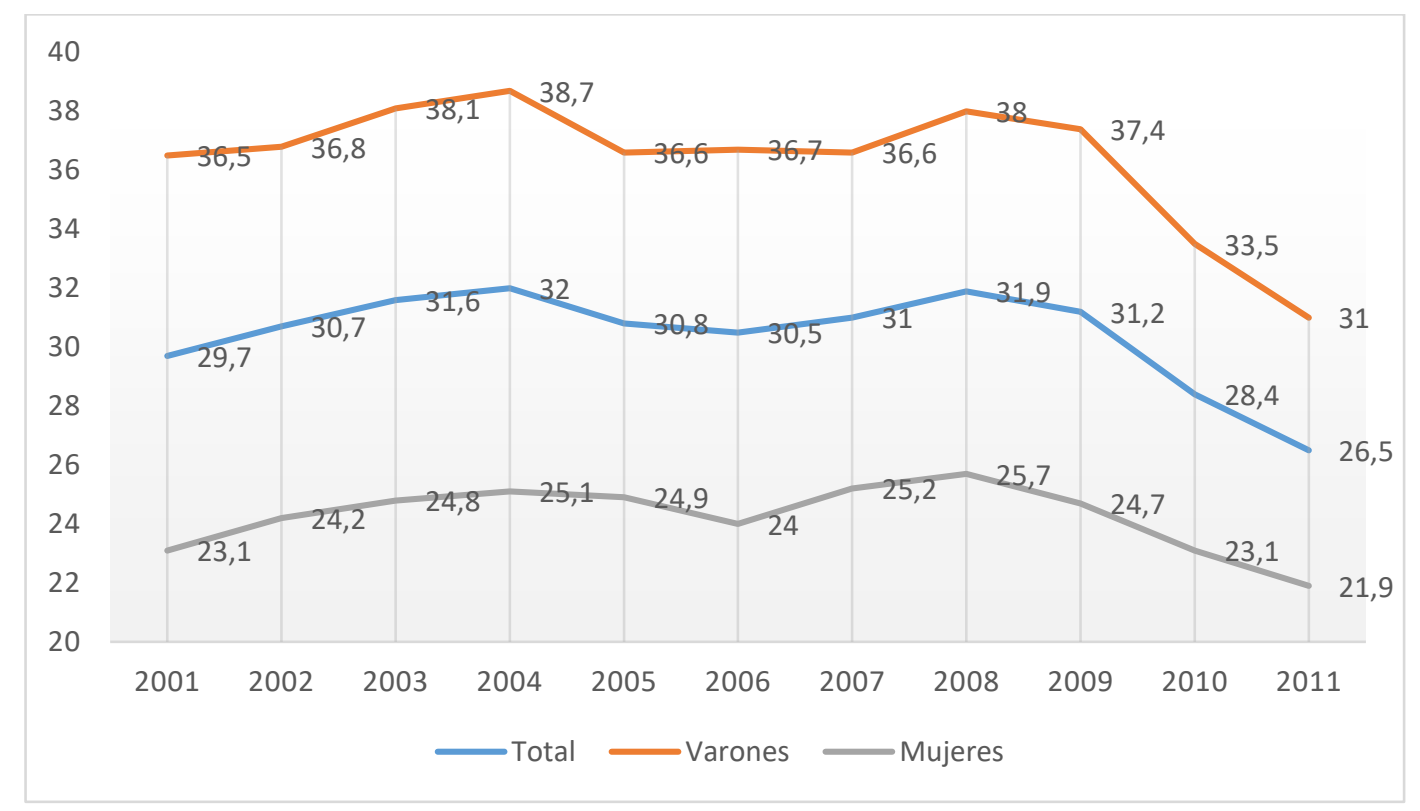

Fuente: Ministerio de Educación, Cultura y Deportes de España. Indicadores de la educación 2012.

En comparación con los países de nuestro entorno, España es el país donde un mayor número de jóvenes de entre 18 y 24 años ha abandonado el sistema educativo precozmente, solo superado por Malta. El gráfico 3.2 muestra cómo el porcentaje medio de abandono temprano en este intervalo de edad en el conjunto de los 27 países de la Unión Europea es del 13,5\%, muy por debajo de ese 26,5 \% de España y mucho más 
distante de países como Polonia, Alemania, Francia o Reino Unido, con el 5,6 \%, 11,5 \%, $12 \%$ y $15 \%$ respectivamente.

Gráfico 3.2. Porcentaje de jóvenes de entre 18 y 24 años que abandona de forma temprana el sistema educativo en algunos de los principales países de la UE.

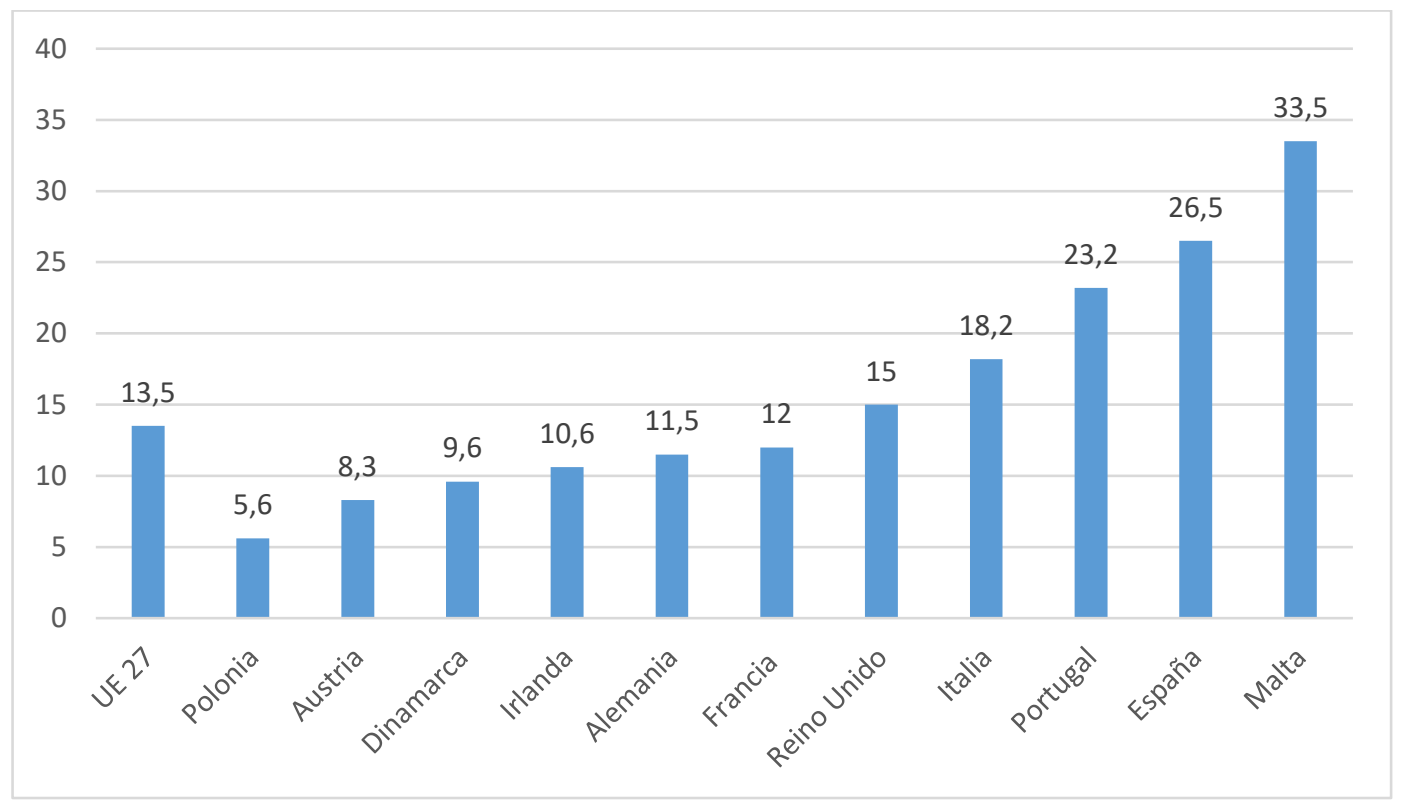

Fuente: Ministerio de Educación, Cultura y Deportes de España. Indicadores de la educación 2012.

\section{Estudios terminados según edad, sexo, ocupación, hábitat y renta}

En el gráfico 3.3 se muestra el cruce de las variables edad y sexo con el nivel de estudios terminados; a cada uno de los intervalos le corresponde dos columnas, la primera para los varones y la segunda para las mujeres. Es necesario matizar que, en las cohortes de menor edad, en especial 17-19 años, los jóvenes aún se encuentran mayoritariamente en formación, lo que posibilitaría un mayor nivel de estudios en un futuro; no obstante, tiene interés el reflejar los datos de este intervalo por la información referida a la categoría de 
Educación Primaria, pues no tener completados estudios primarios a los 17 años indicaría fracaso escolar y abandono temprano de los estudios. El dato que más llama la atención es el relacionado con la variable sexo, en el sentido de un mayor nivel de estudios terminados para las mujeres, en todas las cohortes, que para los varones. La segunda transición demográfica, caracterizada por los cambios de roles en las mujeres, con una menor fecundidad, la incorporación plena al mercado laboral y a todos los niveles de ciclos formativos, junto a cambios culturales tendentes hacia una mayor igualdad de oportunidades entre varones y mujeres, pero aún incompleta en el plano laboral, explicaría las diferencias en el nivel de estudios terminados entre varones y mujeres.

Gráfico 3.3. Estudios terminados por cohorte de edad y sexo.

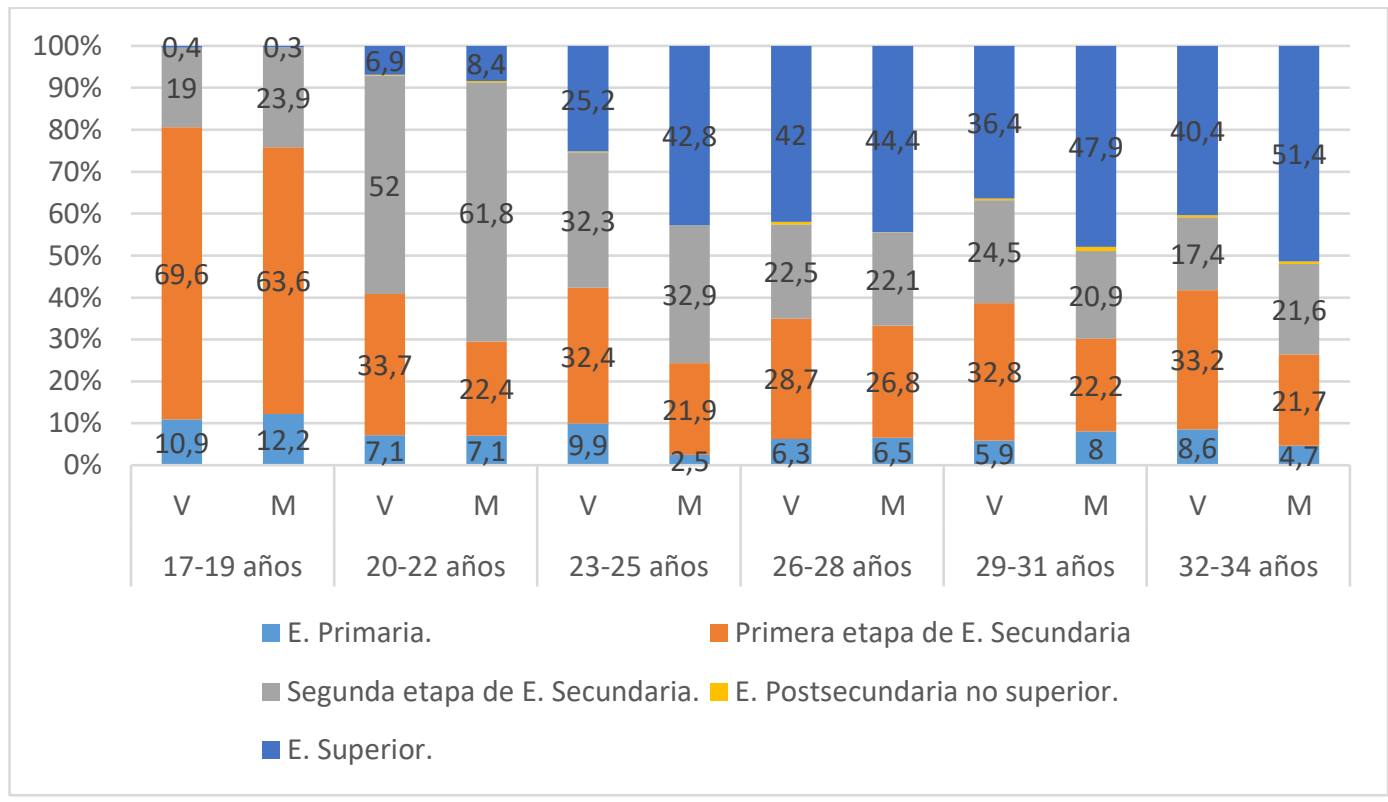

Fuente: elaboración propia con los microdatos de la ECV 2014 del INE.

En el gráfico 3.4 se muestra igualmente una columna por cada sexo para cruzar la variable estudios terminados con hábitat y sexo. En este caso, el intervalo es de 25 a 34 años, sería 
el momento en el que se puede entender que se han completado mayoritariamente los estudios formales. Una vez más, es necesario resaltar el mayor nivel formativo de las mujeres que de los varones para todas las categorías. Entre los varones que viven en zonas medias o poco pobladas se incrementa ligeramente el porcentaje de los que únicamente tienen estudios primarios terminados frente a las zonas muy urbanizadas, pero la diferencia más notable se encuentra en los estudios superiores; así lo muestra ese $14 \%$ más de varones que tienen estudios superiores en las zonas muy urbanizadas frente a las poco urbanizadas o rurales, o el $12 \%$ entre las mujeres. Parece clara la existencia de mayores oportunidades formativas en las zonas más urbanizadas frente a las zonas menos pobladas, en especial en lo que se refiere a estudios de mayor nivel que secundaria. Las menores infraestructuras en el medio rural, la dificultad en los desplazamiento a las universidades, situadas habitualmente en los núcleos más urbanizados, influirían en estas diferencias.

Gráfico 3.4. Estudios terminados entre los 25 y 34 años por hábitat y sexo.

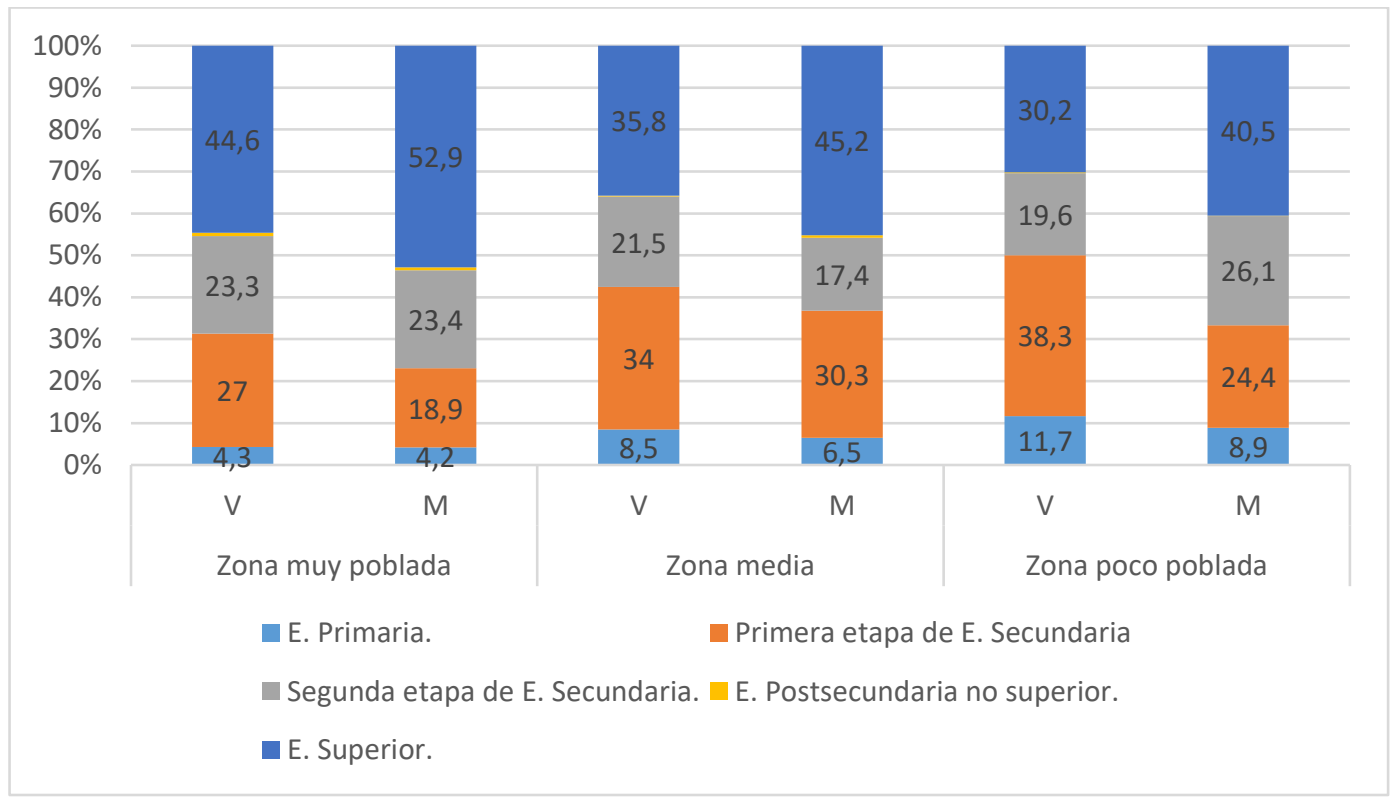

Fuente: elaboración propia con los microdatos de la ECV 2014 del INE. 
En el gráfico 3.5 se muestran los estudios terminados por el riesgo de pobreza del hogar donde se reside. Se constata claramente la influencia de las condiciones económicas de la familia en los rendimientos académicos. Observando las categorías que corresponden con los niveles formativos extremos, Ed. primaria y Ed. superior, los datos de la segunda se duplican en los hogares sin riesgo de pobreza con relación a aquellos donde sí existe este riesgo; mientras son la mitad cuando se refiere a Estudios primarios los que poseen los jóvenes que viven en hogares donde hay riesgo de pobreza. Estos datos evidenciarían cómo el sistema educativo no estaría compensando las diferencias por origen socioeconómico, constatando que aquellos que proceden de entornos con dificultades económicas obtienen menores niveles formativos que aquellos que proceden de entornos sin dificultades económicas. Más adelante se profundizará en las diferencias entre los jóvenes causadas por la reproducción intergeneracional de las condiciones socioeconómicas y socioculturales de la familia de origen.

Gráfico 3.5. Estudios terminados según el riesgo de pobreza del hogar al que se pertenece, para los jóvenes de entre 25-34 años y por sexo.

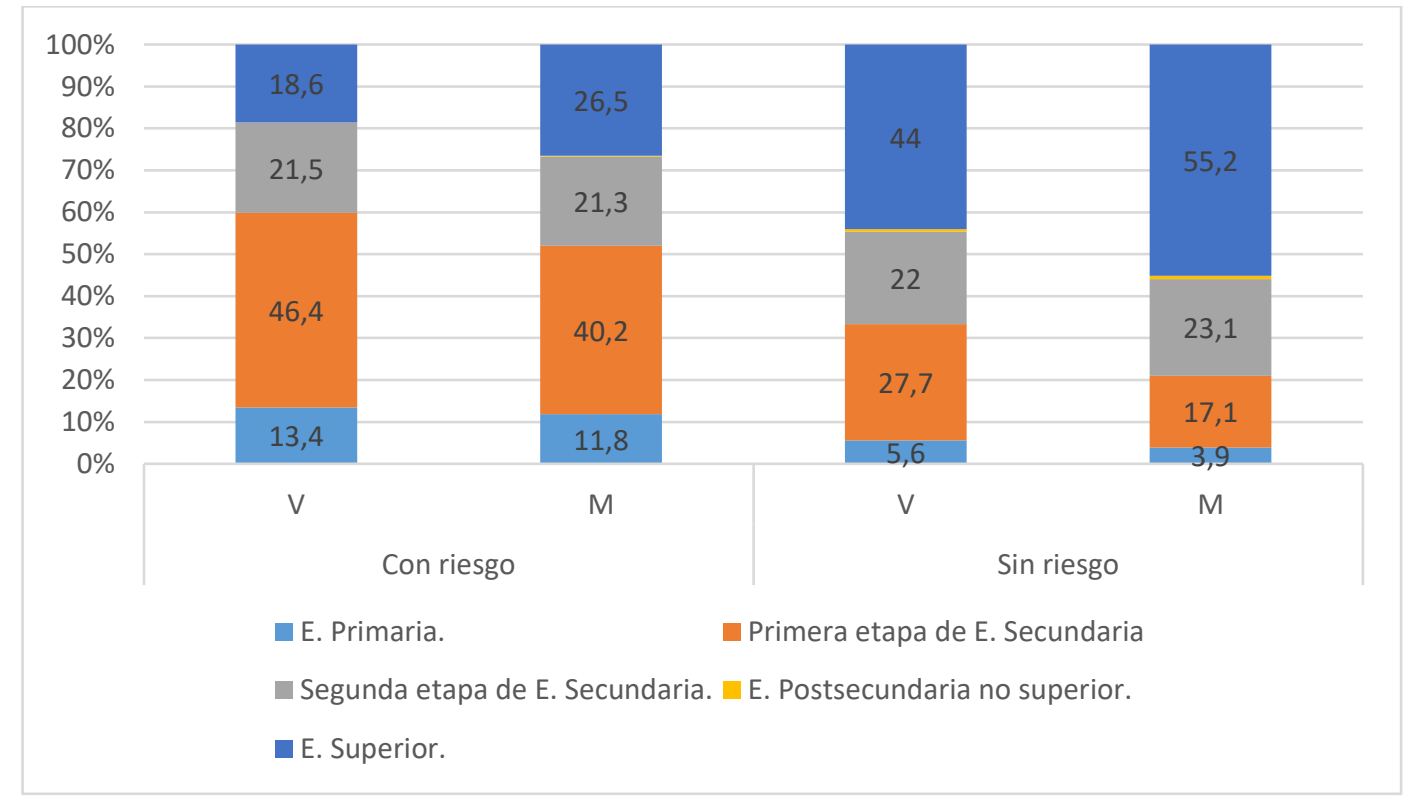

Fuente: elaboración propia con los microdatos de la ECV 2014 del INE. 
En estos primeros gráficos se evidencian las diferencias que se producen entre los jóvenes relacionadas con el nivel de estudios terminados; lo más significativo es una dualidad muy acusada, en el sentido de un porcentaje de jóvenes con estudios superiores terminados al nivel de los países de nuestro entorno y un nivel de fracaso escolar también muy elevado, claramente por encima de los países de la la Unión Europea. Por otra parte, las diferencias por sexo son significativas, con porcentajes mayores de mujeres en formación y con mayor nivel académico que de varones en todos los intervalos de edad. Los jóvenes que pertenecen a un hogar en riesgo de pobreza o que viven en un hábitat rural tienen menores niveles de estudios que aquellos que viven en un hogar sin riesgo de pobreza y en un hábitat urbano. Las desiguadades en educación son una realidad comentada en el apartado teórico, y parece que nuestro sistema educativo no estaría compensando estas carencias.

\subsection{Los condicionantes económicos. Tipo de ocupación con relación a la actividad y tipo de hábitat entre los jóvenes}

\subsubsection{La actual crisis económica como elemento diferenciador}

Entre el año 2007 y 2008 la mayor parte de las principales economías mundiales entraron en recesión con grandes desequilibrios en las cuentas públicas y de las grandes corporaciones financieras que pusieron al borde de la bancarrota a instituciones públicas y privadas. En el caso de Europa, se agravan especialmente las condiciones de la crisis con un retroceso en los indicadores macroeconómicos desconocido hasta el momento, después de un periodo de varios años con un fuerte crecimiento en todos los Estados de la UE. La economía española ha crecido de forma ininterrumpida en todo el periodo desde 
que se incorporó a la UE en 1986, adquiriendo unos niveles de bienestar convergentes con cualquiera de los países socios, si bien el endeudamiento ha sido un arma de doble filo. Por una parte, ha permitido cotas de progreso y bienestar desconocidas y, por otra, una dependencia financiera que ha significado una mayor dificultad a la hora de afrontar los problemas de la crisis. Entre 1999 y 2007, la deuda de las empresas y las familias ha pasado del $270 \%$ y $60 \%$ al $600 \%$ y $130 \%$ respectivamente (Ordóñez, 2009). Estas circunstancias han propiciado que España sea uno de los países de la UE donde la crisis económica ha azotado con mayor dureza, especialmente en lo referente a los altos niveles de desempleo. 
En la reciente historia de España, el desempleo siempre ha sido una constante entre nuestra población activa. Así, en el año 2008, en el comienzo de la crisis, pero con cierta inercia por los años de bonanza precedentes, el paro en la Europa de los 27 estaba en un 7,1 \% mientras que en España era del 11,4\%. Si bien la pérdida de empleo es una de las características generales de esta crisis en todos los países afectados, se puede observar en la tabla 3.1 cómo la tasa de desempleo en España se sitúa en unas cifras mucho más elevadas que en el resto de los países. En países vecinos, como Francia y Reino Unido, o en Italia, con una situación económica similar a España, el desempleo aumenta, pero de una manera moderada y, en cualquier caso, con tasas mucho menores que la española. En Alemania y en el conjunto de los países de la OCDE incluso se crea empleo en condiciones de crisis, pasando el paro, en el caso de Alemania, de un 7,8\% en el año 2009 al 5,3\% en el año 2013.

Tabla 3.1. Evolución de la tasa de paro. Comparativa internacional.

\begin{tabular}{|l|l|l|l|l|l|l|l|l|l|}
\hline & OCDE & Eur. 27 & Zona & Alemania & España & EE. & Francia & Italia & UK \\
\hline 2006 & 6,1 & 8,3 & 8,5 & 10,2 & 8,5 & 4,6 & 9,2 & 6,8 & 5,4 \\
\hline 2007 & 5,6 & 7,3 & 7,6 & 8,7 & 8,3 & 4,6 & 8,4 & 6,1 & 5,3 \\
\hline 2008 & 6 & 7,1 & 7,6 & 7,5 & 11,4 & 5,8 & 7,8 & 6,8 & 5,6 \\
\hline 2009 & 8,1 & 9 & 9,6 & 7,8 & 18 & 9,3 & 9,5 & 7,8 & 7,6 \\
\hline 2010 & 8,3 & 9,7 & 10,1 & 7,1 & 20,1 & 9,6 & 9,7 & 8,4 & 7,8 \\
\hline 2011 & 8 & 9,7 & 10,2 & 6 & 21,7 & 8,9 & 9,6 & 8,4 & 8 \\
\hline 2012 & 8 & 10,5 & 11,4 & 5,5 & 25,1 & 8,1 & 10,3 & 10,7 & 7,9 \\
\hline 2013 & 8 & 10,9 & 12 & 5,3 & 26,3 & 7,6 & 10,9 & 12 & 7,7 \\
\hline
\end{tabular}

Fuente: elaboración propia con datos del Banco de España. 
El gráfico 3.6 muestra la evolución de la tasa de desempleo entre el año 2006 y el año 2013 comparando series que corresponden a diferentes países o grupos de países. Salvo en el caso de Alemania, que experimenta una subida del empleo continuada en toda la secuencia, en el conjunto de los países de la OCDE, la UE y EE. UU. se produce una caída del empleo moderada entre el año 2008 y el año 2013, entre 2 y 3 puntos porcentuales en el peor de los casos, mientras en España desciende el nivel de empleo en 15 puntos, con niveles de desempleo en los años centrales de la crisis económica de hasta el $25 \%$ entre la población activa en general y del $50 \%$ entre los jóvenes de hasta 24 años de edad. La excesiva dependencia de sectores productivos como la construcción y el endeudamiento serían elementos a considerar como responsables de estos datos.

Gráfico 3.6. Evolución de la tasa de paro del 2006 a agosto de 2013. Comparativa internacional.

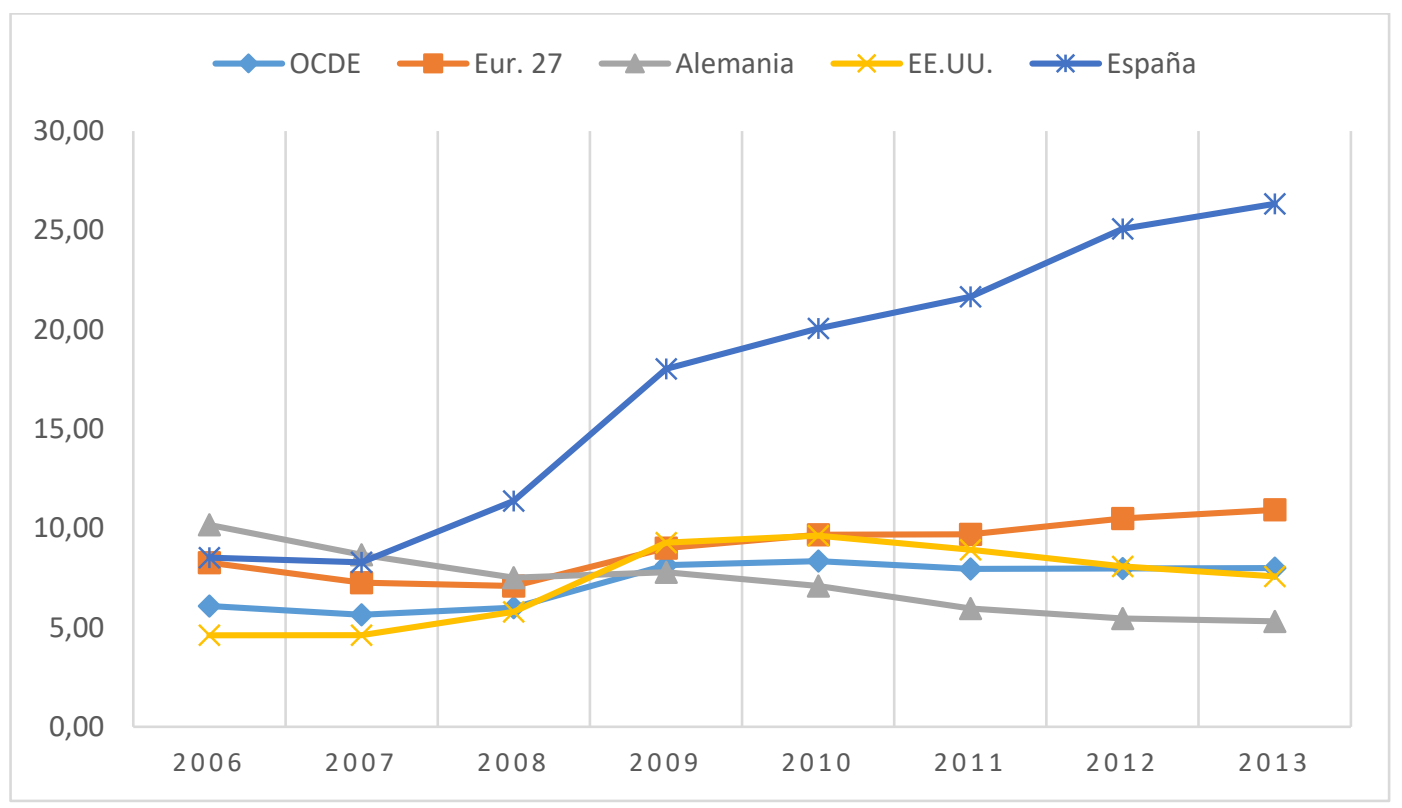

Fuente: elaboración propia con datos del Banco de España. 


\subsubsection{Diferencias entre los jóvenes ocupados}

En este epígrafe se presentan algunas de las diferencias que se observan entre los jóvenes en el ámbito de su relación con la actividad, en especial en lo que se refiere a la incorporación al trabajo. En el gráfico 3.7 se presenta el porcentaje de ocupados ${ }^{3}$ por sexo, grupo de edad y año. La primera lectura que es posible realizar es la diferencia por sexo, entre los varones el porcentaje de ocupados es mayor que entre las mujeres en todas las cohortes de edad, se puede observar cómo en las cohortes de mayor edad en el año 2006, en los varones casi el $90 \%$ estaban ocupados, frente al $70 \%$ en el caso de las mujeres. Estas diferencias se observan en todas la cohortes, si bien en la de los más jóvenes, 1719 años, no son tan acusadas, tendiendo a igualarse en los años centrales de la crisis. Una vez más, es necesario hacer referencia a la crisis económica, esta vez como el motivo del descenso en los ocupados; en las series que se presentan para cada grupo de edad y por sexo es posible observarlo con claridad. La crisis habría afectado más a los varones que a las mujeres, observándose una tendencia a igualarse los porcentajes en todos los grupos de edad en los años finales de la crisis económica, en especial en el año 2014. La crisis económica habría contribuido a igualar a varones y mujeres en cuanto a porcentaje de ocupados, una igualdad poco deseable, en tanto que iguala a todos hacia menores tasas de ocupación.

\footnotetext{
${ }^{3}$ Los ocupados se han obtenido de la variable relación con la actividad que la ECV ofrece, agrupando las categorías de trabajando por cuenta propia y trabajando por cuenta ajena.
} 
Gráfico 3.7. Porcentaje de ocupados entre los jóvenes por grupos de edad, sexo y año.

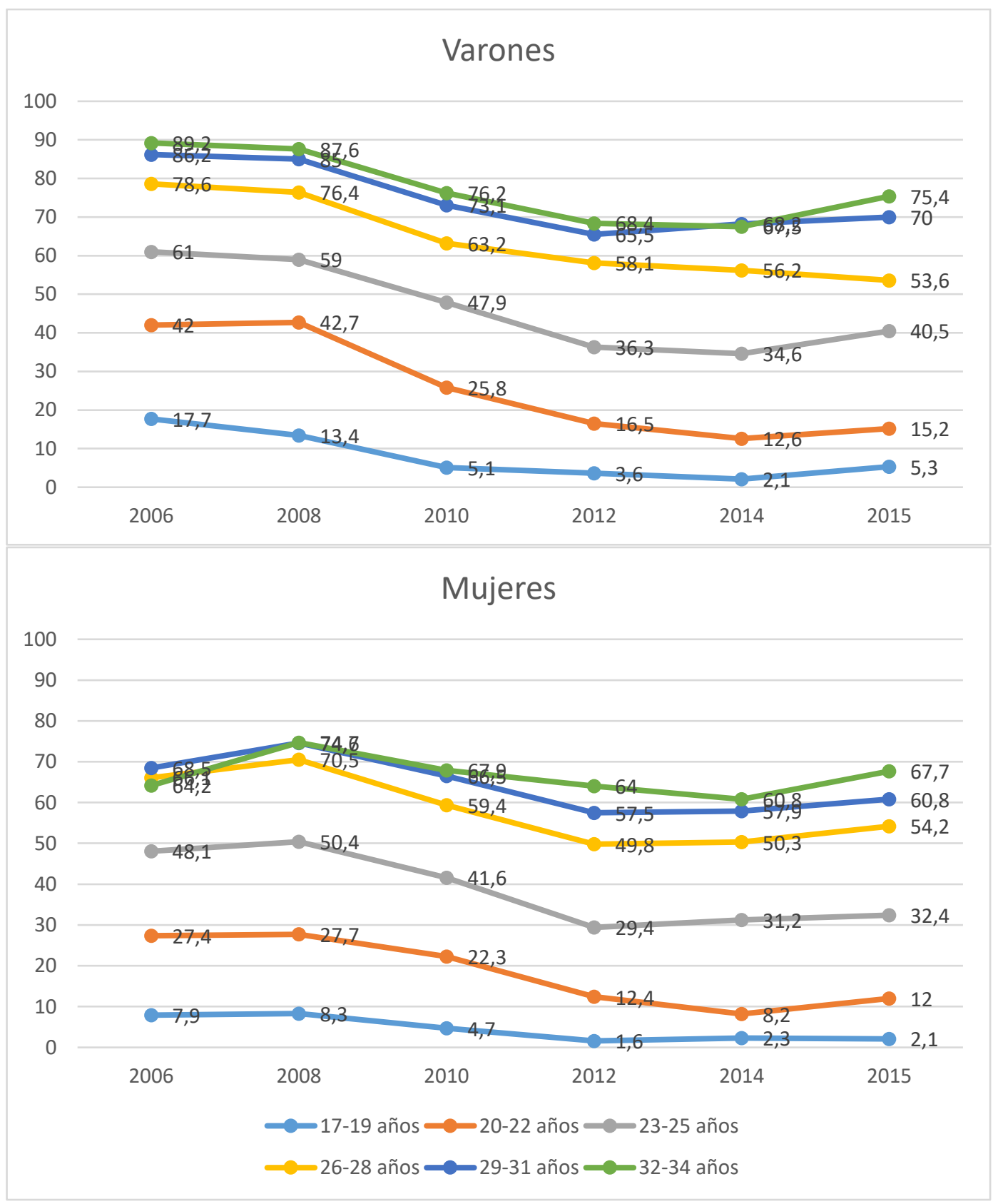

Fuente: elaboración propia con los microdatos de la ECV 
En el gráfico 3.8 se muestra la ocupación según se viva en una zona urbana o rural por grupos de edad y por año. Con relación a la edad, a partir de los 23 años no se observan diferencias entre los ocupados por tipo de hábitat, las diferencias observadas en estas series tienen únicamente que ver con el periodo económico; con un descenso de jóvenes ocupados de entre 15 y 20 puntos porcentuales entre los años previos a la crisis económica y el año 2014, en el año 2015 se observa en todas las series un ligero incremento de ocupados. La mejora en los indicadores macroeconómicos y la disminución progresiva del desempleo pueden hacer pensar que el año 2015 es el año que representa la salida de la crisis económica. En los grupos de edad más jóvenes, 17-19 y 20-22 años, sí es posible observar diferencias entre los dos tipos de hábitat. La tendencia de las series es la misma que para los grupos de mayor edad, los ocupados descienden significativamente entre el momento previo a la crisis económica y los años donde es posible identificar mejoras económicas que pudieran corresponder con la salida de la crisis. Por otra parte, los ocupados tienen una relación directa con la edad, a más edad más ocupados, y con relación al tipo de habitat son más los ocupados en el medio rural en los grupos de menor edad que en las zonas urbanas. Se han apuntado anteriormente datos según los cuales en el medio rural se terminaría antes el periodo formativo, alcanzando menores niveles de estudios. Esto posibilitaría una mayor tasa de ocupados en los grupos de menor edad, pues abandonan más pronto los ciclos formativos. 
Gráfico 3.8. Ocupados por tipo de hábitat, edad y año.
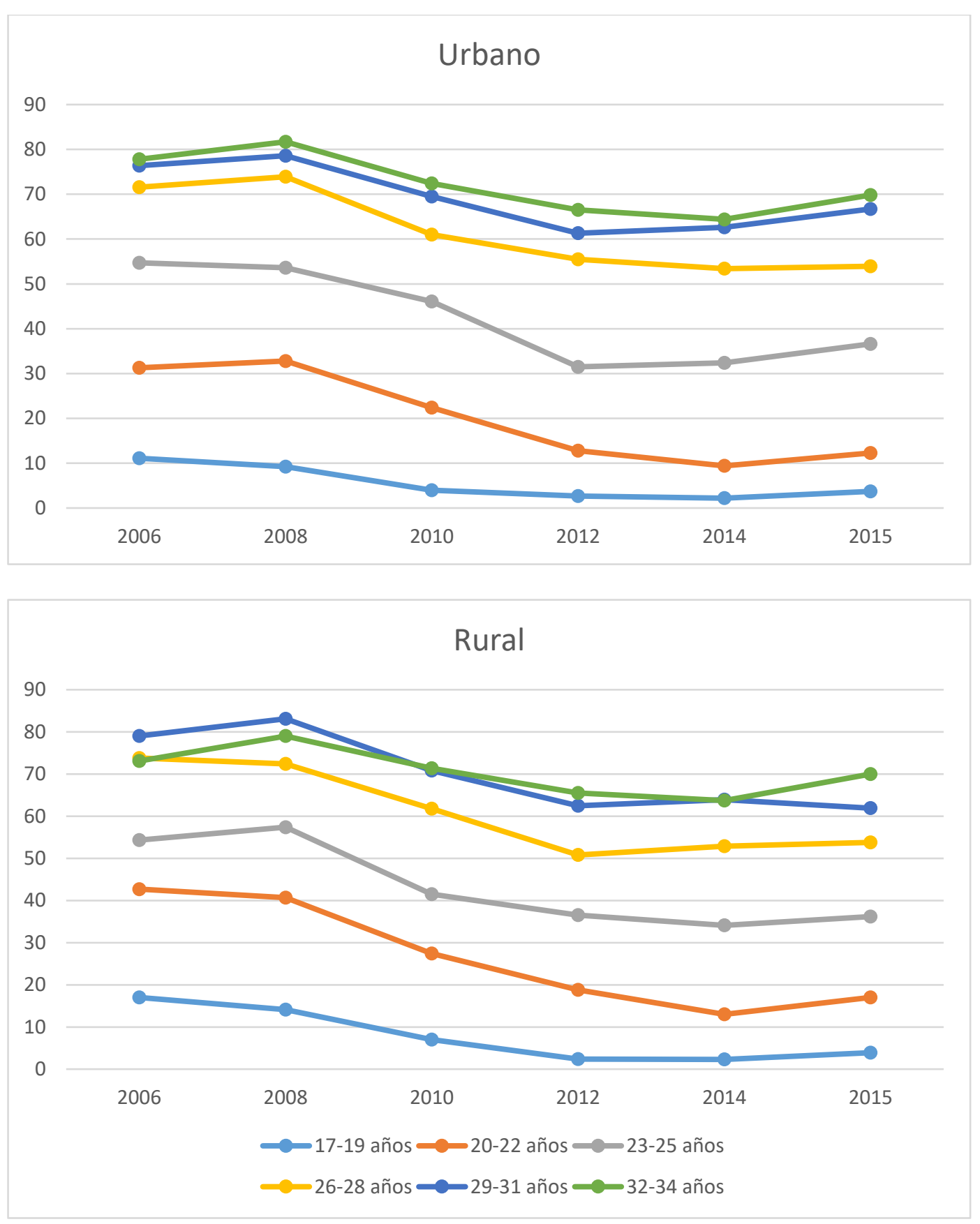

Fuente: elaboración propia con los microdatos de la ECV

Por último, en este epígrafe se ofrece otro indicador en el que es posible observar diferencias en el colectivo que está siendo objeto de estudio a través de otro elemento 
estructural, como es el territorio al que se pertenece. En el gráfico 3.9 se presentan los ocupados por año y por algunas de las comunidades autónomas, comparando las más ricas y con bajos niveles de desempleo con otras más pobres y con mayores niveles de desempleo globales. Al igual que en las series presentadas anteriormente, los ocupados descienden de manera notable a lo largo del periodo que representa la crisis económica en todos la comunidades autónomas que se presentan; las diferencias entre la comunidad que más jóvenes ocupados tiene (Cataluña) y la que menos (Andalucía) es de unos 15 puntos porcentuales en todo el periodo considerado. El pertenecer a una comunidad autónoma con mejores o peores condiciones económicas influye claramente en el porcentaje de jóvenes ocupados, poniendo en evidencia las diferencias entre los jóvenes ocupados según se resida en una comunidad autónoma u otra.

Gráfico 3.9. Ocupados por comunidades autónomas de jóvenes entre 17 y 34 años.

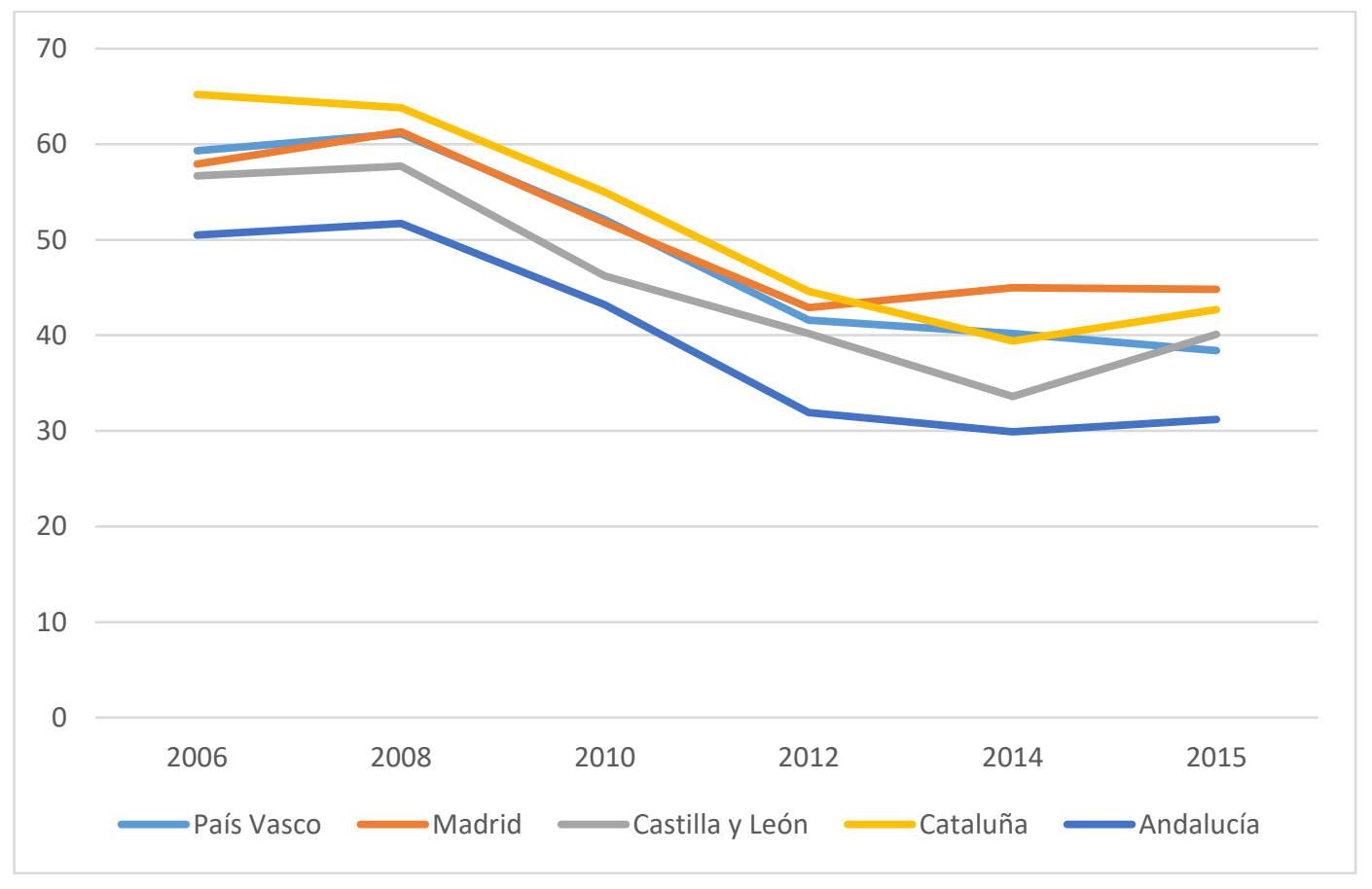

Fuente: elaboración propia con los microdatos de la ECV 


\subsection{El aporte de la educación a la empleabilidad}

Se ha constatado en las informaciones anteriores que la coyuntura económica influye decisivamente en los niveles de desempleo. En este epígrafe se valorará la influencia del nivel formativo alcanzado en la tasa de desempleo y en la calidad del empleo. Los indicadores manejados sobre formación hasta el momento muestran esa dualidad, ya comentada, en lo que se refiere a la formación de los jóvenes españoles: por una parte, un buen número de alumnos en enseñanza superior y un fuerte fracaso escolar o abandono temprano del sistema educativo. Los datos, en cuanto a estudios terminados en sí mismos, no nos aportan nada si no tienen consecuencias y, como se puede apreciar en el gráfico 3. 10, el nivel formativo sí influye decididamente en la tasa de desempleo de una manera inversa: a más formación, menos desempleo. El gráfico muestra una secuencia de tres años donde se sucedieron diferentes ciclos económicos, especialmente el periodo de recesión que se experimenta en el año 2010; en este año, en los jóvenes de 25 y 34 años que únicamente poseían una enseñanza primaria o inferior, la tasa de desempleo se situaba en el $40 \%$, mientras que entre la población de esta edad que poseía una enseñanza superior la tasa de desempleo fue del $14 \%$, nada menos que 26 puntos por debajo. El gráfico muestra claramente la trayectoria ascendente del nivel de desempleo conforme disminuye el nivel formativo: 14, 22, 29 y $40 \%$ en el año 2010. En los otros años de referencia, 2004 y 2006, esta progresión no es tan acusada; también es mayor el desempleo entre quienes han alcanzado un menor nivel educativo, pero con una diferencia no tan notable como ocurre en el año 2010; esos 26 puntos de diferencia entre los menos formados y los más formados que se dan en el año 2010 quedan muy lejos de los 7 puntos en 2007 y los 5 puntos de diferencia en el año 2004. 
Gráfico 3.10. Tasa de desempleo por nivel educativo entre los jóvenes de entre 25 y 34 años de edad.

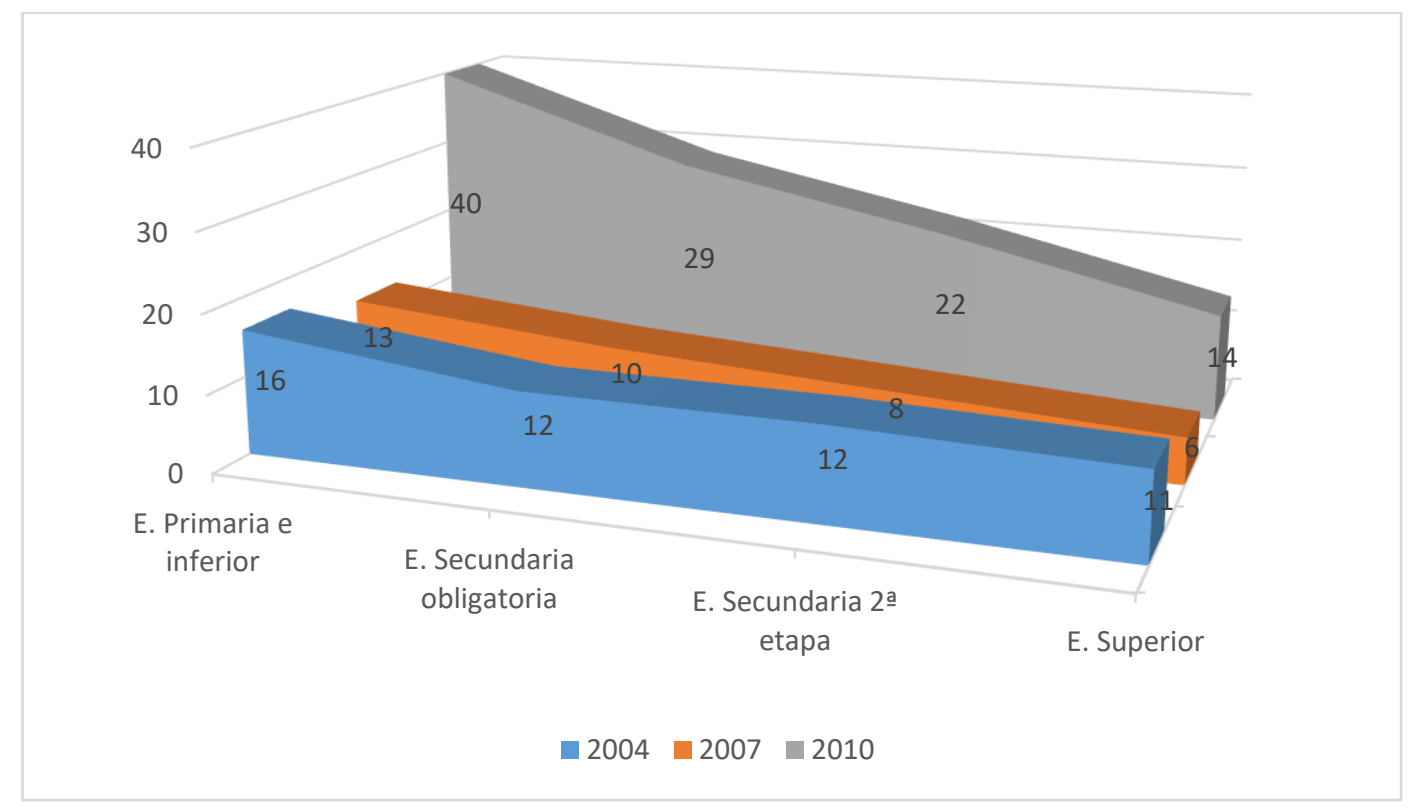

Fuente: Ministerio de Educación, Cultura y Deportes de España. Sistema estatal de indicadores de la educación 2012.

Con la información que nos aporta la ECV es posible valorar la relación que existe entre el tipo ocupación y el nivel de estudios terminados. La tabla 3.2 muestra los datos y las diferencias observadas. La influencia del nivel de estudios alcanzado afecta a la posibilidad de obtener un puesto de trabajo y también a la calidad de este. Es posible observar cómo a una mayor formación el porcentaje de ocupados es mayor que cuando la formación es más precaria; es significativo el dato de los ocupados en tareas del hogar, con un $17,3 \%$ para las mujeres que solamente han alcanzado estudios primarios frente al 1,4\% si han alcanzado estudios superiores. Entre los varones, esta ocupación es prácticamente inexistente. Otro dato de interés es el porcentaje de parados. La secuencia es clara: a mayor formación, menos parados. Los datos son semejantes para varones y mujeres y merece la atención en aquellos varones que poseen un nivel formativo para el que es necesario poseer secundaria, pero que no son estudios superiores, lo que indicaría 
una mejor empleabilidad para quienes poseen este tipo de formación. Otro dato que destaca es el menor porcentaje de parados entre quienes tienen educación secundaria respecto a los jóvenes varones que poseen educación superior. Sería necesario contar con más información para contrastar este dato que, a priori, resulta discordante; no obstante, es necesario recordar que la variable relación con la actividad que la ECV ofrece y que se ha utilizado para la elaboración de esta tabla cruzada está compuesta por categorías excluyentes; si tenemos en cuenta que un porcentaje importante de los jóvenes que poseen educación secundaria dice estar en formación, el 45,1\%, sería lógico pensar que el porcentaje que corresponde con el resto de categorías tiene que disminuir. Para las mujeres esto no sucede: quienes dicen estar en paro disminuyen conforme aumenta el nivel formativo alcanzado.

Tabla 3.2. Actividad principal según estudios terminados. Jóvenes de 17 a 34 años.

\begin{tabular}{|c|c|c|c|c|c|c|}
\hline & & $\begin{array}{c}\text { Educación } \\
\text { primaria }\end{array}$ & $\begin{array}{c}\text { Primera } \\
\text { etapa de } \\
\text { ed. } \\
\text { secundaria }\end{array}$ & $\begin{array}{l}\text { Segunda } \\
\text { etapa de } \\
\text { ed. } \\
\text { secundaria }\end{array}$ & $\begin{array}{c}\text { Ed. } \\
\text { postsecundaria } \\
\text { no superior }\end{array}$ & $\begin{array}{l}\text { Educación } \\
\text { superior }\end{array}$ \\
\hline \multirow[b]{6}{*}{ Varones } & Asalariados & 34,2 & 31,8 & 35,3 & 79,8 & 60,5 \\
\hline & Cuenta propia & 3,9 & 5,5 & 3,7 & & 5,7 \\
\hline & Parados & 30,7 & 29 & 13,9 & 11,3 & 17,7 \\
\hline & En formación & 20 & 31,3 & 45,1 & 8,8 & 15,1 \\
\hline & Labores del hogar & & & 0,6 & & 0,3 \\
\hline & Otros no activos & 11,3 & 2,3 & 1,3 & & 0,7 \\
\hline \multirow[b]{6}{*}{ Mujeres } & Asalariadas & 14 & 26,4 & 24,5 & 52,3 & 59,9 \\
\hline & Cuenta propia & 0,6 & 2,3 & 2,1 & 13,3 & 4 \\
\hline & Paradas & 30,7 & 28,7 & 19,4 & 18 & 18,2 \\
\hline & En formación & 28,9 & 33,9 & 48,8 & 16,4 & 15,3 \\
\hline & Labores del hogar & 17,3 & 6,4 & 3,1 & & 1,4 \\
\hline & Otros no activas & 8,5 & 2,2 & 2 & & 1,1 \\
\hline
\end{tabular}

Fuente: elaboración propia con los microdatos de la ECV. INE 2014. 


\section{Jóvenes que ni trabajan ni estudian}

El concepto de ninis, jóvenes que ni trabajan ni estudian, está ampliamente aceptado como indicador de la evolución del empleo y formación entre los jóvenes, pero no todos los países y organismos internacionales utilizan el mismo rango de edad ni la misma definición: jóvenes que simplemente están en desempleo transitoriamente a la espera de su incorporación al mercado laboral, jóvenes que quedan en desempleo pero que desean trabajar o jóvenes inactivos económicamente que no desean trabajar son algunas de las consideraciones que se interpretan de diferentes maneras; por otra parte, entre los jóvenes que ni estudian ni trabajan puede haber jóvenes inactivos por padecer algún tipo de discapacidad, bien transitoria o permanente, jóvenes que, obviamente, tienen una consideración diferente. Por todos estos motivos, los datos que se ofrecen a continuación han de tomarse con cautela en lo referente a si el ser nini es una opción o es una situación transitoria sobre la que la voluntad de los jóvenes influye poco. En el aparatado metodológico ya se ha indicado que, a efectos de esta tesis, los jóvenes ninis son aquellos seleccionados de la ECV donde para la variable estás en estos momentos en algún plan formativo corresponden con la categoría no y en la variable relación con la ocupación corresponden con la categoría parado, no es posible discernir entre quiénes son ninis forzosos y quiénes siguiendo algún tipo de estrategia, si bien en el análisis se pueden realizar algunas interpretaciones.

El gráfico 3.11 muestra las diferencias por sexo de los ninis en una secuencia de 10 años, entre los años 2006 y 2015, donde la evolución de los ninis es descendente hasta el 2007 en los varones y 2008 en las mujeres. A partir del años 2008 el aumento es continuado hasta los años 2012-2013, donde se estabiliza o comienzan a descender estos porcentajes, en torno a estos años el porcentaje de jóvenes que ni estudian ni trabajan es el mayor de toda la serie, con entre el $21 \%$ y el $22 \%$ de varones en esta situación y en torno al $18 \%$ 
de las mujeres. Prácticamente en toda la serie son más los varones que ni estudian ni trabajan que las mujeres, con una diferencia de tres puntos porcentuales, con la excepción del año 2008 y del año 2015, donde no se observan diferencias por sexo entre los jóvenes ninis. El periodo de crisis económica tiene una relación evidente con la evolución en el porcentaje de jóvenes que ni estudian ni trabajan, afectando en menor medida a las mujeres, que, como se viene viendo en todas los datos que se presentan, estarían en mayor medida en formación respecto de los varones; no obstante, la crisis económica habría propiciado un cierto igualamiento entre varones y mujeres, como es posible observar en el año 2015, que se podría considerar como año en el que se comienza a salir de la crisis económica, con prácticamente el mismo porcentaje de varones que de mujeres jóvenes que ni estudian ni trabajan. En los primeros años de la serie, el porcentaje de ninis se mantiene en torno al $10 \%$; a partir del año 2008 el ascenso es continuado y en el 2013 los jóvenes que no están en un plan formativo ni trabajan son el 20,4 \%. Resulta obvia la relación de este indicador con el periodo que comprende la actual crisis económica y cómo en periodos de bonanza este indicador desciende hasta el 8,9\%, como ocurre en el año 2007. En el gráfico 3.12 se representan gráficamente estas diferencias por rangos de edad. Lógicamente, entre los más jóvenes, el porcentaje es pequeño tanto en el 2007 como en el año 2015, son jóvenes mayoritariamente en formación; a partir de los 20 años se aprecian ya diferencias muy notables en los tres periodos y son los de los intervalos centrales, 23-25 y 26-28 años, donde esta diferencia es mayor, especialmente entre los años 2007 y 2015, con unos 15 puntos porcentuales de diferencia. Hay que recordar que en este trabajo el concepto de ninis no se refiere a aquellos jóvenes que voluntariamente han decidido la no incorporación al mercado laboral y no están en programas formativos, estos jóvenes habrían renunciado al trabajo como elemento de inclusión social en favor de otras alternativas y modos de vida, en los gráficos que se presentan los ninis estarían 
definidos por quienes no estudian y dicen estar en paro, pero desean trabajar. El análisis que es posible realizar con los datos presentados tiene nuevamente relación con elementos estructurales, como es la coyuntura económica desfavorable, que dificulta el acceso al trabajo en las cohortes donde a priori ya habrían concluido sus ciclos formativos y, por otra parte, es posible realzar otra lectura según la cual la ausencia de planes formativos para aquellos que se encuentran en desempleo es notable; jóvenes que han quedado fuera del mercado laboral y no tienen posibilidades formativas que les permitan acceder a nuevos empleos formarían el colectivo de esa generación perdida a la que diversos autores hacer referencia en el apartado teórico de esta tesis.

Gráfico 3.11. Jóvenes ninis de entre 17 y 34 años por sexo.

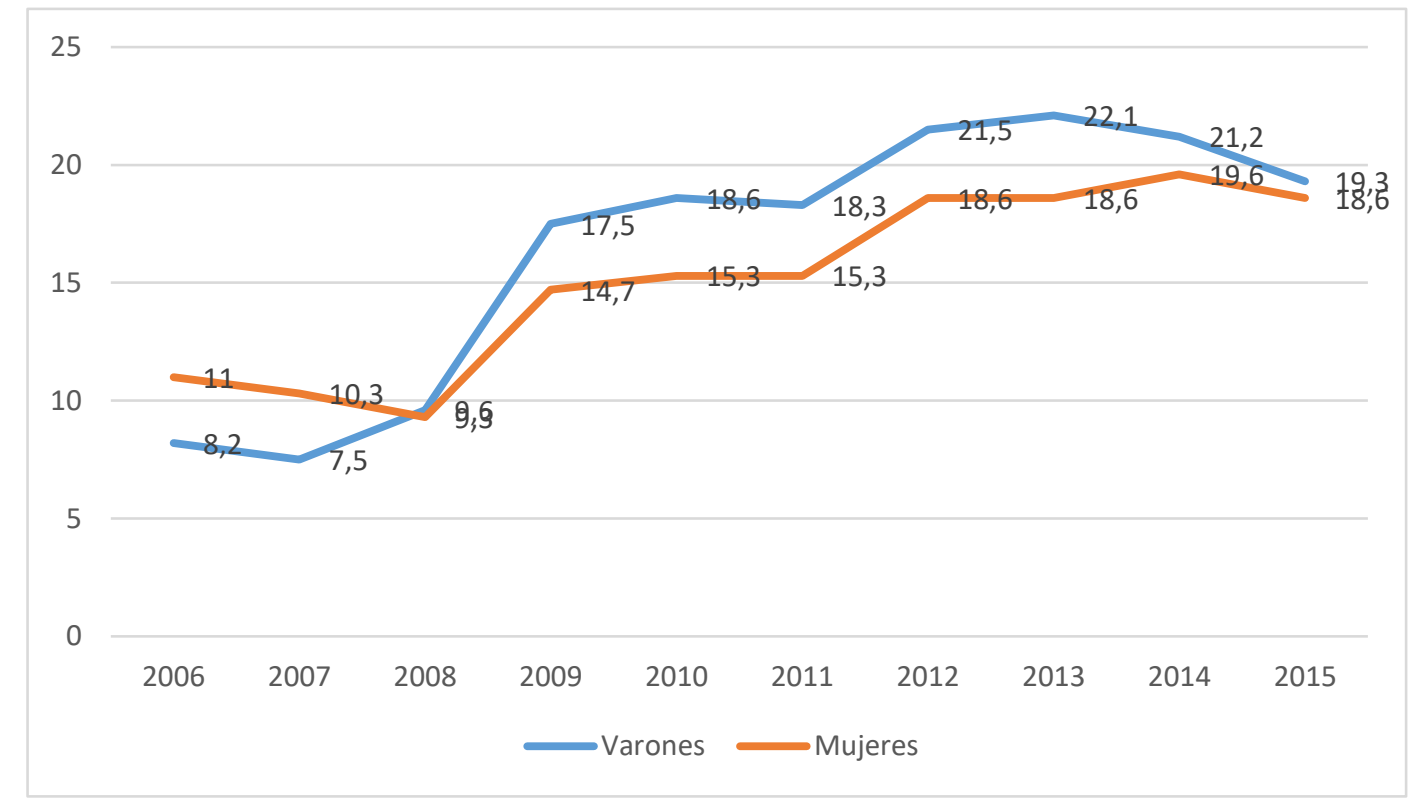

Fuente: elaboración propia con los microdatos de la ECV. 
Gráfico 2.12. Jóvenes que ni estudian ni trabajan por grupos de edad.

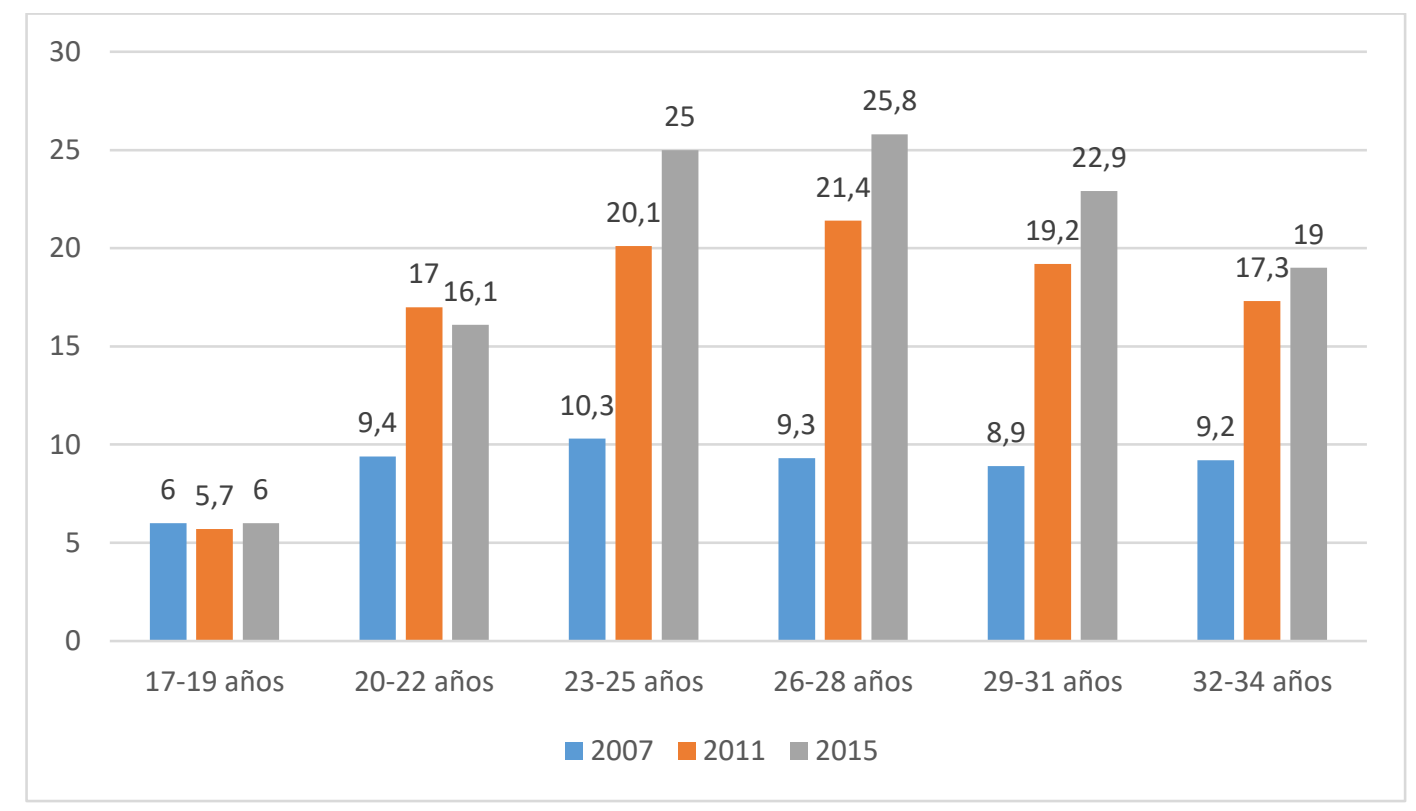

Fuente: elaboración propia con los microdatos de la ECV.

\subsection{Estructura de la población española por ocupación y clase social. La influencia de la institución familiar. Reproducción sociocultural y socioeconómica}

\subsubsection{Evolución de la estructura de la población española por ocupación y clase social}

A continuación se presenta la evolución de la estructura de la población española en cuanto a tipo de ocupación, con este epígrafe se pretende contextualizar la reproducción sociocultural y socioeconómica de los jóvenes españoles. Se tendrá ocasión de comprobar cómo la evolución en algunas categorías ha sido positiva, como el descenso del trabajo en el hogar no remunerado o mayor porcentaje de empleos de mayor cualificación. Estos cambios en la estructura del conjunto de la población no impiden que la reproducción de padres a hijos de las condiciones socioculturales y socioeconómicas se siga produciendo, 
en adelante se analizará esta circunstancia para valorar las diferencias y desigualdades entre los jóvenes y sus procesos de transición.

En la tabla 3.3 se presenta la estructura de la población en cuanto a la condición socioeconómica y ocupación de los individuos. En la secuencia de años se muestra desde 1995 a 2005 en intervalos de cinco años, y seguidamente hasta 2015 año a año. Los datos se refieren a los publicados por el CIS en el mes de enero de cada uno de los años. Si tenemos en cuenta el primero, 1995, y el último de la serie, 2015, se aprecian diferencias muy notables: uno de los aspectos más significativos es ese $22,2 \%$ de personas con trabajo doméstico no remunerado en el año 1995, frente al 6,6\% en el año 2015. Se produce claramente un brusco descenso de las personas que trabajan en un hogar sin remuneración; es un dato muy útil para valorar la incorporación de la mujer al trabajo fuera del hogar en los últimos 15 años. Por otra parte, merece la atención el aumento de jubilados y pensionistas, así como la disminución de estudiantes. Estos datos enlazan directamente con los condicionantes de tipo demográfico, como son la mayor esperanza de vida y el bajo índice de natalidad. En la secuencia se aprecia también una evolución positiva en cuanto a las ocupaciones de mayor calidad, con aumentos significativos en categorías como directores, técnicos, pequeños empresarios y empleados de oficinas; mientras, el porcentaje de los obreros, tanto cualificados como no cualificados, disminuye. Con relación a la evolución de técnicos y cuadros medios, se produce un incremento de este colectivo en estos últimos 15 años muy relevante, pasando de un 5,4\% en el año 1995 a un $12 \%$ en el año 2015; es claramente el reflejo de un mercado de trabajo directamente influenciado por la robotización de los sistemas productivos, nuevas tecnologías de la información, etc. Para los trabajadores por cuenta ajena, de más y menos cualificación, y para los desempleados, hasta los años del comienzo de la crisis económica la evolución es ligeramente favorable para todas las categorías. A partir del año 2008 el 
desempleo aumenta y disminuyen ligeramente todas las categorías de trabajadores. Con este análisis es posible deducir que entre los dos extremos de la secuencia, si no fuese por la elevada tasa de desempleados en los últimos años, la evolución ha sido positiva en cuanto a ocupaciones de mayor calidad. Otra lectura que es posible hacer es la comparación entre el año 2006, donde se registra el dato de parados menor de toda la serie y con una coyuntura económica favorable, y el año 2015, con una tasa de desempleados muy elevada y unas condiciones económicas aún desfavorables. En lo referente a las categorías superiores, no existe una diferencia apreciable, con la excepción de los pequeños empresarios, que disminuye un $1 \%$; este dato puede deberse a los autónomos y pequeñas empresas que han desparecido en los últimos años. Disminuyen las categorías de agricultores, oficinas y servicios y obreros, engrosando el indicador correspondiente a parados. 
Tabla 3.3. Condiciones socioeconómicas de la sociedad española. Porcentajes.

\begin{tabular}{|c|c|c|c|c|c|c|c|c|c|c|c|c|c|}
\hline & 1995 & 2000 & 2005 & 2006 & 2007 & 2008 & 2009 & 2010 & 2011 & 2012 & 2013 & 2014 & 2015 \\
\hline $\begin{array}{l}\text { Directores y } \\
\text { profesionales }\end{array}$ & 2,4 & 4,1 & 4,2 & 4,2 & 4,5 & 4,4 & 5,1 & 4,9 & 4,4 & 4,8 & 4,3 & 3,3 & 4,6 \\
\hline $\begin{array}{c}\text { Técnicos y cuadros } \\
\text { medios }\end{array}$ & 5,4 & 7 & 8,7 & 8,5 & 9,3 & 9,6 & 8,5 & 9,8 & 10 & 9,5 & 9,3 & 11 & 12 \\
\hline Pequeños empresarios & 4,9 & 4,2 & 4,5 & 4,5 & 4,3 & 5,1 & 3,8 & 3,4 & 3,8 & 3,6 & 3,5 & 3,7 & 3,9 \\
\hline Agricultores & 1,8 & 1,5 & 1 & 1,2 & 0,7 & 0,8 & 1,2 & 0,8 & 0,8 & 0,8 & 0,7 & 0,8 & 0,6 \\
\hline $\begin{array}{c}\text { Empleados de } \\
\text { oficinas y servicios }\end{array}$ & 5,7 & 8,2 & 10 & 10 & 9,1 & 9,2 & 8,1 & 8,4 & 7,5 & 6,8 & 7 & 4,6 & 4,8 \\
\hline Obreros cualificados & 8,4 & 8,3 & 11 & 11 & 10 & 12 & 8,9 & 8 & 8,2 & 6,4 & 4,6 & 4,8 & 5,6 \\
\hline $\begin{array}{l}\text { Obreros no } \\
\text { cualificados }\end{array}$ & 6,5 & 8 & 9,2 & 8,7 & 11 & 10 & 10 & 9,2 & 8,8 & 8,6 & 7,9 & 8,2 & 8,7 \\
\hline $\begin{array}{l}\text { Jubilados y } \\
\text { pensionistas }\end{array}$ & 17 & 20 & 22 & 23 & 23 & 24 & 24 & 22 & 23 & 23 & 22 & 23 & 24 \\
\hline Parados & 13 & 9,6 & 9,3 & 8,9 & 9,2 & 9,4 & 16 & 19 & 19 & 24 & 26 & 27 & 23 \\
\hline Estudiantes & 7,4 & 8,4 & 4,8 & 5,2 & 5 & 4,6 & 4 & 3,7 & 3,6 & 4,1 & 4,3 & 4,2 & 5 \\
\hline $\begin{array}{c}\text { Trabajo doméstico no } \\
\text { remunerado }\end{array}$ & 22 & 18 & 13 & 12 & 12 & 10 & 10 & 10 & 9,3 & 8,1 & 8,7 & 7,6 & 6,6 \\
\hline No clasificaciones & 4,4 & 2 & 2,3 & 3,3 & 2,1 & 1,5 & 1,3 & 1,1 & 1,4 & 0,9 & 0,9 & 1,9 & 1,3 \\
\hline
\end{tabular}

Fuente: elaboración propia con datos de los Barómetros de Opinión de enero de cada año de la serie del CIS.

\subsubsection{Reproducción de las condiciones socioculturales}

En el apartado teórico se ha comentado cómo diferentes autores están haciendo referencia a la posibilidad de que los jóvenes pierdan calidad de vida con relación a sus generaciones inmediatamente anteriores, que tengan trabajos más inestables y de peor calidad y como consecuencia de ello que puedan sufrir una movilidad descendente en la clase social (Beck, 2003; Tezanos, 2009). En este epígrafe se presentan las diferencias entre los jóvenes en cuanto a formación y renta según las condiciones que vivieron en su hogar de origen cuando estos fueron adolescentes. Para valorar esta cuestión se han utilizado los 
microdatos de la Encuesta de Condiciones de Vida que el INE proporciona del año 2011. Las preguntas relacionadas con las variables que hacen referencia a la transferencia intergeneracional de las características socioculturales y socioeconómicas, únicamente se pasaron a entrevistados que tienen entre 25 y 59 años en el momento de realizar la entrevista, por lo que se ha seleccionado el intervalo de entre 25 y 34 años. Y en cuanto a la referencia temporal, las variables se refieren al periodo de cuando la persona entrevistada era adolescente, con una edad en torno a los 14 años.

Una de las variables que suscita gran interés, por su repercusión en cuestiones de tipo laboral y económico, es el nivel de estudios terminados con relación al alcanzado por los padres. A continuación, se presentan dos tablas donde se relaciona el nivel de estudios alcanzado y el que poseían sus padres cuando los encuestados eran adolescentes. En la tabla 3.4 se relacionan con los estudios terminados del padre y en la tabla 3.5, con los de la madre; en este sentido, cabe señalar que no existe una diferencia significativa de los estudios terminados relacionándolos con los niveles de estudios de la madre o del padre; no obstante, sí se aprecia algún matiz en la línea de un mayor porcentaje de jóvenes que poseen estudios superiores cuando las madres también los tienen frente a cuando son los padres los que los poseen. Cuando son las madres las que tienen estudios superiores, el $74,3 \%$ de los hijos alcanzan estudios superiores, frente al 71,5\% cuando es el padre quien posee este nivel de estudios.

Por otra parte, lo que sí reflejan claramente los datos es la reproducción sociocultural intergeneracional. Es cierto que en todos los niveles formativos los hijos alcanzan en su gran mayoría un nivel formativo mayor que el de los padres, pero siempre en la relación de a más formación de los padres, mayor nivel de estudios terminados de los hijos, y a la inversa. 
Si se observa la tabla 3.4, la que se refiere a los estudios terminados según estudios del padre, en el caso de estudios superiores es muy notoria la diferencia de los jóvenes cuyos padres tienen estudios superiores frente a los que han alcanzado ciclos inferiores o no saben leer ni escribir. En este último caso, aunque no es un dato muy fiable, pues las frecuencias son muy pocas, obviamente existen muy pocas personas padres de hijos de entre 25 y 34 años que no sepan leer ni escribir. En la tabla se muestra que el 12,1\% de estos jóvenes ha alcanzado un nivel de estudios superior, frente al 33,3 \% cuando el padre posee la primera etapa de educación secundaria; el $55 \%$, cuando se posee la segunda etapa de secundaria, y el 71,5\%, cuando el padre posee estudios superiores. En el sentido opuesto, igualmente se produce esa reproducción social en cuanto a formación alcanzada; cuando el padre no ha alcanzado un nivel formativo de educación secundaria, por encima del $30 \%$ de los hijos tampoco alcanza este nivel. En la tabla 3.5 se muestra el nivel de estudios terminado según la formación de la madre; igualmente se observa un alto grado de reproducción sociocultural, pero con algunos matices, como ya se ha indicado. Según estos datos se constata que la influencia de los estudios de la madre favorece en mayor medida el nivel de estudios de los hijos que cuando son considerados los del padre. El $71,5 \%$ de los hijos cuyos padres tienen estudios superiores tienen estos mismos estudios, mientras que cuando es la madre la que tiene estudios superiores, son el 74,3\%. También son ligeramente más los que tienen estudios superiores cuando la madre tiene primaria o secundaria. En el lado opuesto, son menos los que únicamente tienen estudios primarios cuando la madre solo tiene primarios, que cuando es el padre el que únicamente tiene este nivel de estudios. 
Tabla 3.4. Nivel de estudios terminados de los jóvenes de entre 25 y 34 años por estudios del padre.

\begin{tabular}{|c|c|c|}
\hline $\begin{array}{c}\text { Nivel de } \\
\text { estudios del } \\
\text { padre }\end{array}$ & & Porcentaje \\
\hline \multirow{5}{*}{$\begin{array}{l}\text { No sabe } \\
\text { leer ni } \\
\text { escribir }\end{array}$} & Ed. primaria & 36,2 \\
\hline & Ed. secundaria primera etapa & 37,9 \\
\hline & Ed. secundaria segunda etapa & 12,1 \\
\hline & $\begin{array}{l}\text { Formación que precisa de secundaria } \\
\text { segunda etapa }\end{array}$ & 1,7 \\
\hline & Ed. superior & 12,1 \\
\hline \multirow{5}{*}{$\begin{array}{c}\text { Secundaria } \\
\text { primera } \\
\text { etapa o } \\
\text { inferior }\end{array}$} & Ed. primaria & 9,6 \\
\hline & Ed. secundaria primera etapa & 30,9 \\
\hline & Ed. secundaria segunda etapa & 24,7 \\
\hline & $\begin{array}{l}\text { Formación que precisa de secundaria } \\
\text { segunda etapa }\end{array}$ & 1,6 \\
\hline & Ed. superior & 33,3 \\
\hline \multirow{5}{*}{$\begin{array}{l}\text { Secundaria } \\
\text { segunda } \\
\text { etapa }\end{array}$} & Ed. primaria & 1,9 \\
\hline & Ed. secundaria primera etapa & 16,4 \\
\hline & Ed. secundaria segunda etapa & 26,2 \\
\hline & $\begin{array}{l}\text { Formación que precisa de secundaria } \\
\text { segunda etapa }\end{array}$ & 0,5 \\
\hline & Ed. superior & 55 \\
\hline \multirow{5}{*}{ Superiores } & Ed. primaria & 0,6 \\
\hline & Ed. secundaria primera etapa & 5,4 \\
\hline & Ed. secundaria segunda etapa & 21,8 \\
\hline & $\begin{array}{l}\text { Formación que precisa de secundaria } \\
\text { segunda etapa }\end{array}$ & 0,6 \\
\hline & Ed. superior & 71,5 \\
\hline
\end{tabular}

Fuente: elaboración propia sirviendo de base los microdatos de la ECV 2011 INE. 
Tabla 3.5. Nivel de estudios terminados de los jóvenes de entre 25 y 34 años según los estudios de la madre.

\begin{tabular}{|c|c|c|}
\hline $\begin{array}{l}\text { Nivel de } \\
\text { estudios de } \\
\text { la madre }\end{array}$ & & Porcentaje \\
\hline \multirow{5}{*}{$\begin{array}{l}\text { No sabe } \\
\text { leer ni } \\
\text { escribir }\end{array}$} & Ed. primaria & 35,4 \\
\hline & Ed. secundaria primera etapa & 44,3 \\
\hline & Ed. secundaria segunda etapa & 12,7 \\
\hline & $\begin{array}{l}\text { Formación que precisa de secundaria segunda } \\
\text { etapa }\end{array}$ & 2,5 \\
\hline & Ed. superior & 5,1 \\
\hline \multirow{5}{*}{$\begin{array}{l}\text { Secundaria } \\
\text { primera } \\
\text { etapa o } \\
\text { inferior }\end{array}$} & Ed. primaria & 8,9 \\
\hline & Ed. secundaria primera etapa & 30 \\
\hline & Ed. secundaria segunda etapa & 24,2 \\
\hline & $\begin{array}{l}\text { Formación que precisa de secundaria segunda } \\
\text { etapa }\end{array}$ & 1,4 \\
\hline & Ed. superior & 35,5 \\
\hline \multirow{5}{*}{$\begin{array}{l}\text { Secundaria } \\
\text { segunda } \\
\text { etapa }\end{array}$} & Ed. primaria & 0,7 \\
\hline & Ed. secundaria primera etapa & 11,8 \\
\hline & Ed. secundaria segunda etapa & 30 \\
\hline & $\begin{array}{l}\text { Formación que precisa de secundaria segunda } \\
\text { etapa }\end{array}$ & 0,7 \\
\hline & Ed. superior & 56,8 \\
\hline \multirow{5}{*}{ Superiores } & Ed. primaria & 0,6 \\
\hline & Ed. secundaria primera etapa & 5,7 \\
\hline & Ed. secundaria segunda etapa & 19 \\
\hline & $\begin{array}{l}\text { Formación que precisa de secundaria segunda } \\
\text { etapa }\end{array}$ & 0,3 \\
\hline & Ed. superior & 74,3 \\
\hline
\end{tabular}

Fuente: elaboración propia sirviendo de base los microdatos de la Encuesta de Condiciones de Vida 2011 INE. 
En la tabla 3.6 se muestra la influencia del tipo de hogar al que se perteneció con el nivel de estudios terminados. Con la cautela debida por estar manejando datos de una encuesta, lo que supone que para algunas categorías el número de caso será muy pequeño, se puede asegurar que el modelo del hogar de origen también constituye un factor de desigualdad en cuanto al nivel de estudios terminados. Cuando vivieron con ambos progenitores, el $36,5 \%$ y $46,5 \%$ para varones y mujeres, respectivamente, han alcanzado estudios superiores, frente al 28,5\% y 45,9\% cuando se vivía con la madre. Cuando vivieron únicamente con el padre, el porcentaje de jóvenes que alcanzaron estudios superiores es significativamente menor, del $23,8 \%$ para los varones y el $30 \%$ para las mujeres. Si tenemos en cuenta los casos con estudios primarios o secundarios en primera etapa, es decir, aquellos que sufrieron fracaso escolar ${ }^{4}$, pues no completaron la Educación Secundaria Obligatoria, se observa cómo en el caso de vivir con ambos progenitores en el $37,8 \%$ en varones y $29,1 \%$ para las mujeres sufren fracaso escolar, en torno al $57 \%$ tanto en varones como mujeres cuando viven solamente con su padre, 43,9\% varones y 23,7 \% mujeres cuando vivieron con la madre únicamente. En cuanto a poseer únicamente la enseñanza secundaria, los datos son más igualitarios tanto en varones como en mujeres, con la excepción del grupo perteneciente a aquellos individuos que vivieron únicamente con su padre, que siguen teniendo los peores resultados con un $19 \%$ y un $13 \%$, respectivamente.

\footnotetext{
${ }^{4}$ Fracaso escolar es un concepto controvertido y con claras connotaciones negativas y efectos estigmatizadores al relacionarlo con exclusión social, hasta el punto de que puede llevar a que esta relación se convierta en una profecía autocumplida (Martínez, 2013). Este autor operacionaliza este concepto a través de cuatro indicadores: tasa bruta de fracaso escolar, tasa neta de fracaso escolar, fracaso escolar según PISA y abandono escolar temprano. En esta tesis los datos de fracaso escolar se refieren al fracaso escolar administrativo, que se define por el porcentaje de aquellos que no optienen el título educativo que la legislación plantea como obligatorio.
} 
Tabla 3.6. Nivel de estudios terminados en los jóvenes de entre 25 y 34 años según la composición de su hogar de origen cuando eran adolescentes, por sexo.

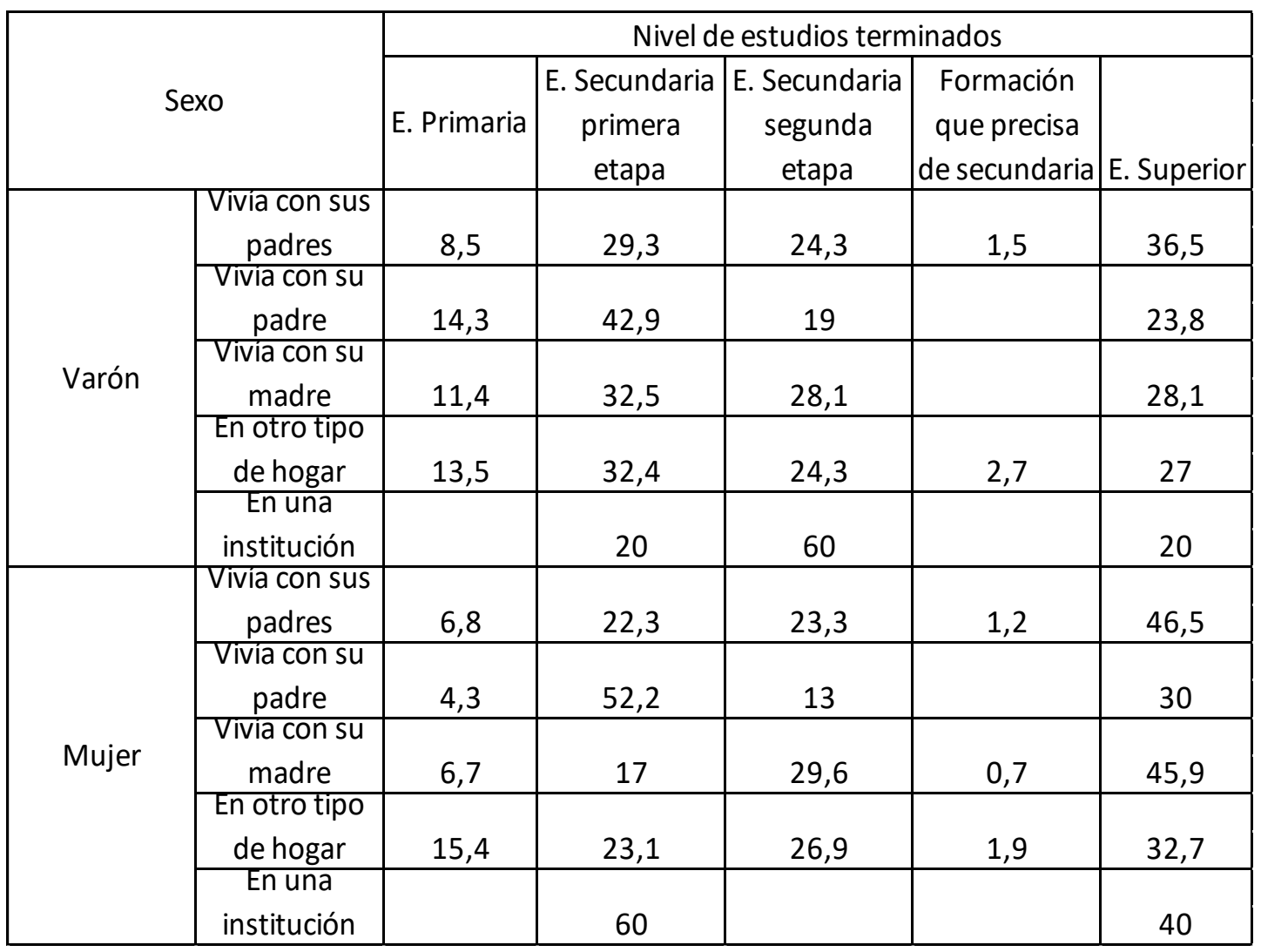

Fuente: elaboración propia, sirviendo de base los microdatos de la ECV 2011 INE.

Los datos que se refieren a la influencia que pudo tener el convivir con más o menos menores de 18 años se incluyen en la tabla 3.7, se presentan los resultados académicos alcanzados, prácticamente idénticos cuando se convivió con uno o dos menores; los resultados académicos empeoran cuando se convive con tres o cuatro menores, incrementándose los porcentajes de fracaso escolar y disminuyendo ostensiblemente el porcentaje de jóvenes que han alcanzado un nivel de estudios superior cuando convivieron con tres o cuatro menores en su adolescencia. No es posible determinar una relación causal únicamente con esta variable, pues es muy probable que los condicionantes económicos tengan una importancia decisiva, pues a más miembros en el 
hogar más necesidades de renta, y la renta resulta ser otro factor importante en el nivel de estudios terminados, como se comprobará a continuación.

Tabla 3.7. Nivel de estudios terminados según número de menores conviviendo.

\begin{tabular}{|c|c|c|}
\hline Menores de 18 años & Nivel de estudios & Porcentaje \\
\hline \multirow{5}{*}{1} & Ed. primaria & 6,9 \\
\hline & Ed. secundaria primera etapa & 24 \\
\hline & Ed. secundaria segunda etapa & 23,3 \\
\hline & $\begin{array}{l}\text { Formación que precisa de } \\
\text { secundaria segunda etapa }\end{array}$ & 1,5 \\
\hline & Ed. superior & 44,4 \\
\hline \multirow{5}{*}{2} & Ed. primaria & 6,4 \\
\hline & Ed. secundaria primera etapa & 23,3 \\
\hline & Ed. secundaria segunda etapa & 24,8 \\
\hline & $\begin{array}{l}\text { Formación que precisa de } \\
\text { secundaria segunda etapa }\end{array}$ & 1,2 \\
\hline & Ed. superior & 44,3 \\
\hline \multirow{5}{*}{3} & Ed. primaria & 9,2 \\
\hline & Ed. secundaria primera etapa & 29,8 \\
\hline & Ed. secundaria segunda etapa & 25 \\
\hline & $\begin{array}{l}\text { Formación que precisa de } \\
\text { secundaria segunda etapa }\end{array}$ & 1,5 \\
\hline & Ed. superior & 34,6 \\
\hline \multirow{5}{*}{4} & Ed. primaria & 10,8 \\
\hline & Ed. secundaria primera etapa & 39,9 \\
\hline & Ed. secundaria segunda etapa & 24,7 \\
\hline & $\begin{array}{l}\text { Formación que precisa de } \\
\text { secundaria segunda etapa }\end{array}$ & 0,6 \\
\hline & Ed. superior & 24,1 \\
\hline
\end{tabular}

Fuente: elaboración propia sirviendo de base los microdatos de la Encuesta de Condiciones de Vida 2011 INE. 


\subsubsection{Reproducción en los jóvenes de las condiciones económicas del hogar de origen}

El nivel de estudios alcanzado está muy relacionado con la situación económica de la familia del joven cuando este se encontraba en periodo formativo. Así lo muestra la tabla 3.8 que se presenta a continuación, donde conforme empeora la situación económica, aumenta el número de jóvenes que no superaron la enseñanza obligatoria y disminuye el porcentaje de los que alcanzaron estudios superiores. En una situación económica mala o muy mala, el fracaso escolar se sitúa en torno al $60 \% \%^{5}$, disminuyendo hasta el $22 \%$ cuando la situación económica fue buena. En cuanto a estudios superiores, de una manera inversa, la desigualdad sigue siendo muy notable dependiendo de la situación económica que se disfrutó en la adolescencia; en torno al $20 \%$ posee estudios superiores cuando la situación fue mala o muy mala, y al 50 \% cuando se disfrutó de unas buenas condiciones económicas.

Resultan llamativos los datos referentes a una situación económica muy buena, pues se produce un descenso en los niveles educativos alcanzados con relación a la categoría anterior. No obstante, en cualquier caso son muy superiores a categorías donde las dificultades económicas son importantes.

\footnotetext{
${ }^{5}$ Hay que tener en cuenta que haber alcanzado únicamente estudios primarios o primera etapa de secundaria representa fracasar en el sistema educativo al no conseguir superar la enseñanza obligatoria, que corresponde con la educación secundaria completa.
} 
Tabla 3.8. Nivel de estudios terminados según situación económica del hogar de origen.

\begin{tabular}{|c|c|c|}
\hline $\begin{array}{l}\text { Situación económica } \\
\text { del hogar de origen }\end{array}$ & Estudios & Porcentaje \\
\hline \multirow{5}{*}{ Muy mala } & Ed. primaria & 43,1 \\
\hline & Ed. secundaria $1 .^{\text {a }}$ etapa & 25,3 \\
\hline & Ed. secundaria $2 .^{\text {a }}$ etapa & 16,2 \\
\hline & $\begin{array}{l}\text { Ed. para la que se precisa secundaria } 2 .^{\text {a }} \\
\text { etapa }\end{array}$ & $\underline{0}$ \\
\hline & Ed. superior & 15,5 \\
\hline \multirow{5}{*}{ Mala } & Ed. primaria & 24,4 \\
\hline & Ed. secundaria $1 .^{\mathrm{a}}$ etapa & 29,7 \\
\hline & Ed. secundaria $2 .^{\text {a }}$ etapa & 21,2 \\
\hline & $\begin{array}{l}\text { Ed. para la que se precisa secundaria } 2 .^{a} \\
\text { etapa }\end{array}$ & 0,9 \\
\hline & Ed. superior & 23,8 \\
\hline \multirow{5}{*}{$\begin{array}{l}\text { Moderadamente } \\
\text { mala }\end{array}$} & Ed. primaria & 9,8 \\
\hline & Ed. secundaria $1 .^{a}$ etapa & 32,3 \\
\hline & Ed. secundaria $2 .^{a}$ etapa & 28,7 \\
\hline & $\begin{array}{l}\text { Ed. para la que se precisa secundaria } 2 .^{\text {a }} \\
\text { etapa }\end{array}$ & 1,5 \\
\hline & Ed. superior & 27,7 \\
\hline \multirow{5}{*}{$\begin{array}{l}\text { Moderadamente } \\
\text { buena }\end{array}$} & Ed. primaria & 7,7 \\
\hline & Ed. secundaria $1 .^{\text {a }}$ etapa & 26,9 \\
\hline & Ed. secundaria $2 .^{a}$ etapa & 24 \\
\hline & $\begin{array}{l}\text { Ed. para la que se precisa secundaria } 2 .^{a} \\
\text { etapa }\end{array}$ & 1,6 \\
\hline & Ed. superior & 39,9 \\
\hline \multirow{5}{*}{ Buena } & Ed. primaria & 3,1 \\
\hline & Ed. secundaria $1 .^{a}$ etapa & 18,8 \\
\hline & Ed. secundaria $2 .^{\text {a }}$ etapa & 25 \\
\hline & $\begin{array}{l}\text { Ed. para la que se precisa secundaria } 2 .^{a} \\
\text { etapa }\end{array}$ & 1 \\
\hline & Ed. superior & 52,2 \\
\hline \multirow{5}{*}{ Muy buena } & Ed. primaria & 2,4 \\
\hline & Ed. secundaria $1 .^{a}$ etapa & 23,3 \\
\hline & Ed. secundaria $2 .^{a}$ etapa & 29,5 \\
\hline & $\begin{array}{l}\text { Ed. para la que se precisa secundaria } 2 .^{a} \\
\text { etapa }\end{array}$ & 1,7 \\
\hline & Ed. superior & 43,2 \\
\hline
\end{tabular}

Fuente: elaboración propia sirviendo de base los microdatos de la ECV 2011 INE. 
Con los datos expuestos hasta este momento relativos al nivel de estudios alcanzado con relación a la situación económica del hogar de origen, es posible afirmar que el sistema educativo no compensó adecuadamente las carencias que los jóvenes de entre 25 y 34 años tuvieron cuando fueron adolescentes, resultando una desigualdad muy notable entre el grado formativo alcanzado dependiendo de las condiciones económicas de la familia de origen.

La ECV contiene la variable numérica renta monetaria, y sirviendo como base los datos que contiene, se ha creado una variable categórica con el fin de valorar y comparar la situación económica actual con la que existía en sus hogares de origen cuando los jóvenes de entre 25 y 34 años eran adolescentes. En el gráfico 3.10 se representa la situación económica de los hogares dependiendo de si el responsable es un varón o una mujer, para el total de la población y para los jóvenes responsables de hogar; en los hogares donde son responsables varones no hay diferencias importantes cuando nos referimos al total de la población y cuando es a los jóvenes, el porcentaje de aquellos que tienen malas condiciones económicas es prácticamente igual, con un $15 \%$ y $16 \%$ respectivamente; donde se observa una mayor diferencia es entre los hogares con buenas condiciones económicas, con un $42 \%$ y un $37 \%$, respectivamente, entre el total de la población y los hogares regentados por jóvenes. También se observan mayores diferencias en los hogares donde las mujeres son las responsables, tanto cuando la comparación se realiza con relación a los varones como entre los hogares regentados por mujeres en la población total y en la población joven. En los datos que corresponden con el total de hogares donde son mujeres las responsables se observan 10 puntos porcentuales más en la categoría que corresponde con malas condiciones económicas, sin embargo, si nos referimos a los hogares donde son las mujeres responsables y son jóvenes, la diferencia es de 5 puntos. Entre jóvenes varones y jóvenes mujeres las diferencias, con la excepción de este matiz, 
no son tan importantes, es en los datos que representan a toda la población donde los hogares en los que son responsables mujeres presentan peores condiciones económicas, esos 5 puntos porcentuales más para hogares con malas condiciones y 5 puntos menos para los hogares con condiciones moderadas o buenas.

Gráfico 3.10. Situación económica del hogar según sean los responsables varones o mujeres y el total de la población y jóvenes de 25-34 años.

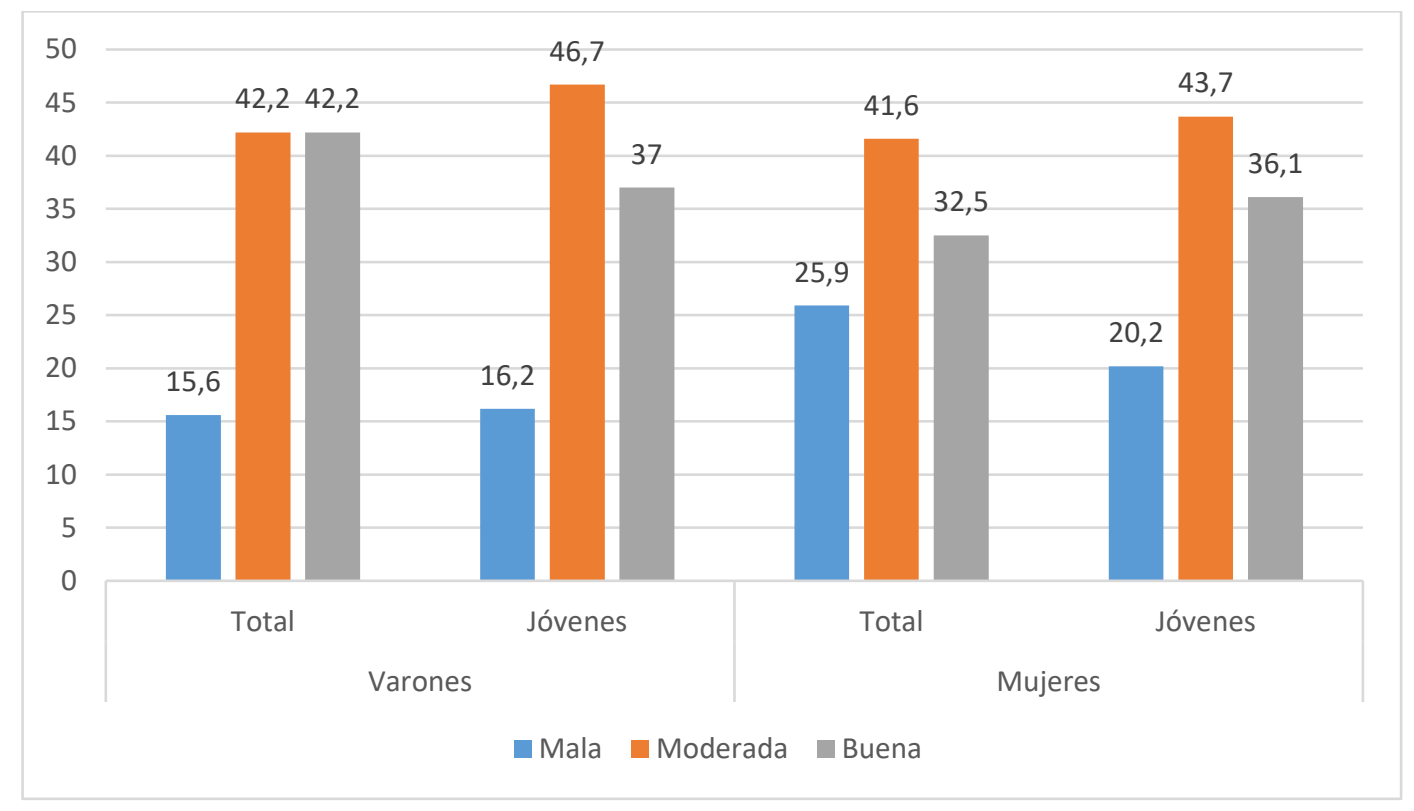

Fuente: elaboración propia sirviendo de base los microdatos de la ECV 2011 INE.

La situación económica de los hogares en los que son responsables jóvenes según fueron las condiciones económicas de su hogar de origen queda definida en el gráfico 3.11, donde es posible realizar las siguientes lecturas: de entre los jóvenes que pertenecieron a un hogar con una situación económica mala o muy mala, el $48 \%$ de los jóvenes responsables de hogar siguen sufriendo esa misma situación, lo que indicaría una reproducción intergeneracional de la pobreza importante. No obstante, más de la mitad 
de estos jóvenes tienen mejores condiciones en sus hogares que las que tuvieron cuando fueron adolescentes, lo que estaría indicando una evolución favorable en este colectivo; no sucede lo mismo entre aquellos jóvenes responsables de hogar que pertenecieron a hogares con moderadas, buenas o muy buenas condiciones económicas, pues por encima del $30 \%$ en ambos casos sufren una situación económica mala o muy mala, si bien los datos indican unos porcentajes para aquellos que tienen unas condiciones moderadas, buenas o muy buenas muy superior a los que las tuvieron malas o muy malas, con una diferencia de más de 15 puntos porcentuales. Es posible detectar un cierto grado de reproducción de las condiciones económicas, pues conforme se avanza hacia categorías más favorables económicamente en los hogares de origen, se da un mayor porcentaje de jóvenes que dicen disfrutar de unas condiciones económicas moderadamente buenas o muy buenas.

Gráfico 3.11. Situación económica en los hogares donde son los responsables jóvenes según las condiciones de su hogar de origen.

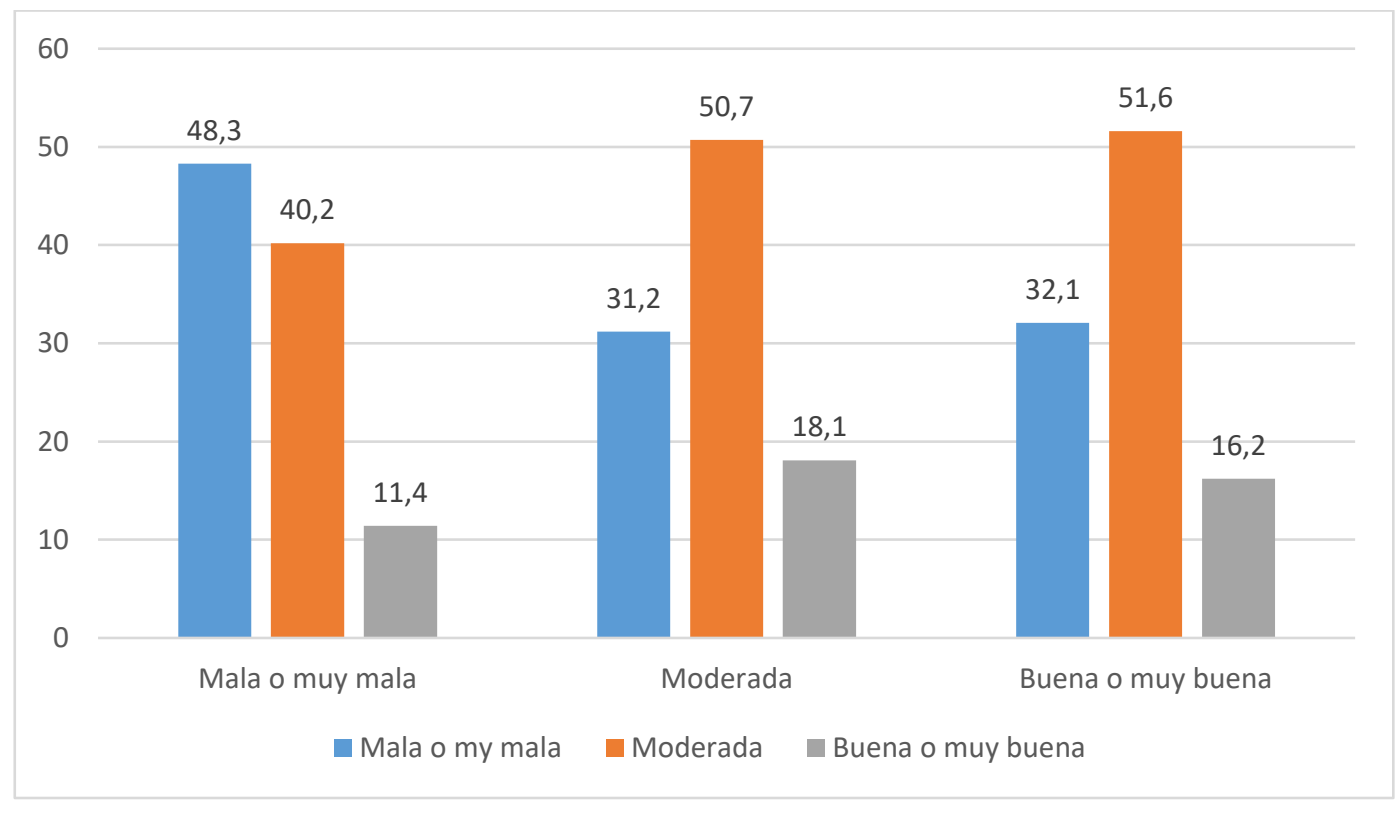

Fuente: elaboración propia sirviendo de base los microdatos de la ECV 2011 INE. 
Otra variable que permite valorar el grado de reproducción social de la pobreza y que la ECV ofrece directamente es riesgo de pobreza o exclusión social, esta información se presenta el gráfico 3.12 y es posible apreciar con una mayor claridad la reproducción intergeneracional de la pobreza; en este caso se han utilizado las seis categorías que ofrece la encuesta de la variable situación económica en el hogar de origen y es posible visualizar con toda claridad la disminución del riesgo de pobreza y exclusión social en los hogares de jóvenes cuando estos son los responsables conforme se tuvieron mejores condiciones económicas en el hogar de origen, con un $44 \%$ entre aquellos que pertenecieron a un hogar en muy malas condiciones económicas y un $16 \%$ entre aquellos que pertenecieron a un hogar en buenas o muy buenas condiciones económicas. Resulta llamativo que un $16 \%$ de jóvenes que pertenecieron a hogares con muy buenas condiciones económicas estén en riesgo de pobreza o exclusión social; es necesario recordar que el objeto de estudio en este análisis son los jóvenes de entre 25 y 34 años de edad y responsables de hogar. Aunque los datos son preocupantes, es posible pensar que las condiciones económicas de estos hogares pueden mejorar en su todavía larga trayectoria laboral y vital. 
Gráfico 3.12. Hogares de los jóvenes de 25-34 años cuando estos son los responsables, en riesgo de pobreza o exclusión social.

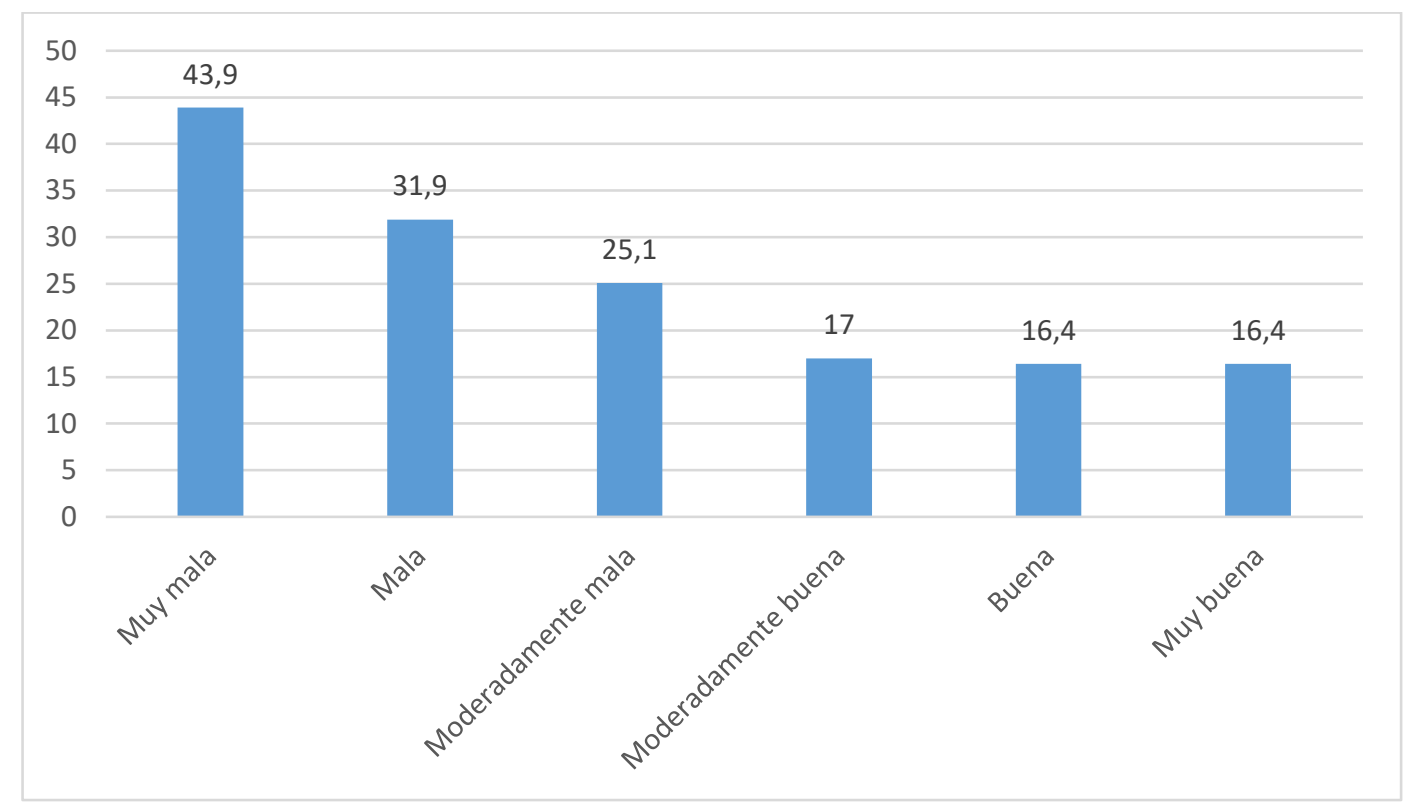

Fuente: elaboración propia sirviendo de base los microdatos de la ECV 2011 INE.

En el gráfico 3.14 se presenta la misma información que anteriormente, pero comparando algunas comunidades autónomas y agrupadas las categorías de las condiciones económicas del hogar de origen en tres, para minimizar los riesgos que supone la pérdida de casos al segmentar el archivo de datos utilizado. De esta manera, se ha pretendido minimizar el riesgo de distorsión de los resultados obtenidos. Para la lectura del gráfico 3.14 es necesario tener presentes los datos que se ofrecen en el gráfico 3.13, en este caso corresponden al porcentaje de hogares totales en riesgo de pobreza o exclusión social en las comunidades autónomas que se pretende comparar. Llama la atención que en el País Vasco exista un $30 \%$ de hogares en los que los jóvenes son los responsables en riesgo de exclusión social cuando sus condiciones económicas en el hogar de origen fueron malas, frente, por ejemplo, al $10 \%$ en Castilla-La Mancha, si bien la lectura es muy distinta si 
se tiene en cuenta que en el País Vasco tan solo existe un $10 \%$ de hogares totales en riesgo de pobreza frente al $31 \%$ en Castilla-La Mancha. Entre las comunidades autónomas que presentan un menor riesgo de pobreza y exclusión social, la Comunidad de Madrid ofrece unas pautas distintas al resto, lo habitual es que cuanto mejores fueron las condiciones en el hogar de origen, menor es el riesgo de pobreza en el hogar actual. En esta comunidad no se repite esta tendencia, con un porcentaje de riesgo de pobreza entre los hogares regentados por jóvenes que es mayor entre quienes tuvieron buenas condiciones económicas que entre los que las tuvieron malas, $19 \%$ y $21 \%$, respectivamente. Más allá de los matices, lo que parece claro es que en aquellas comunidades donde existe un mayor riesgo de pobreza o exclusión social en el total de la población, también se observa un mayor porcentaje de hogares jóvenes en riesgo de pobreza.

Gráfico 3.13. Porcentaje de hogares en riesgo de pobreza o exclusión social en algunas comunidades autónomas.

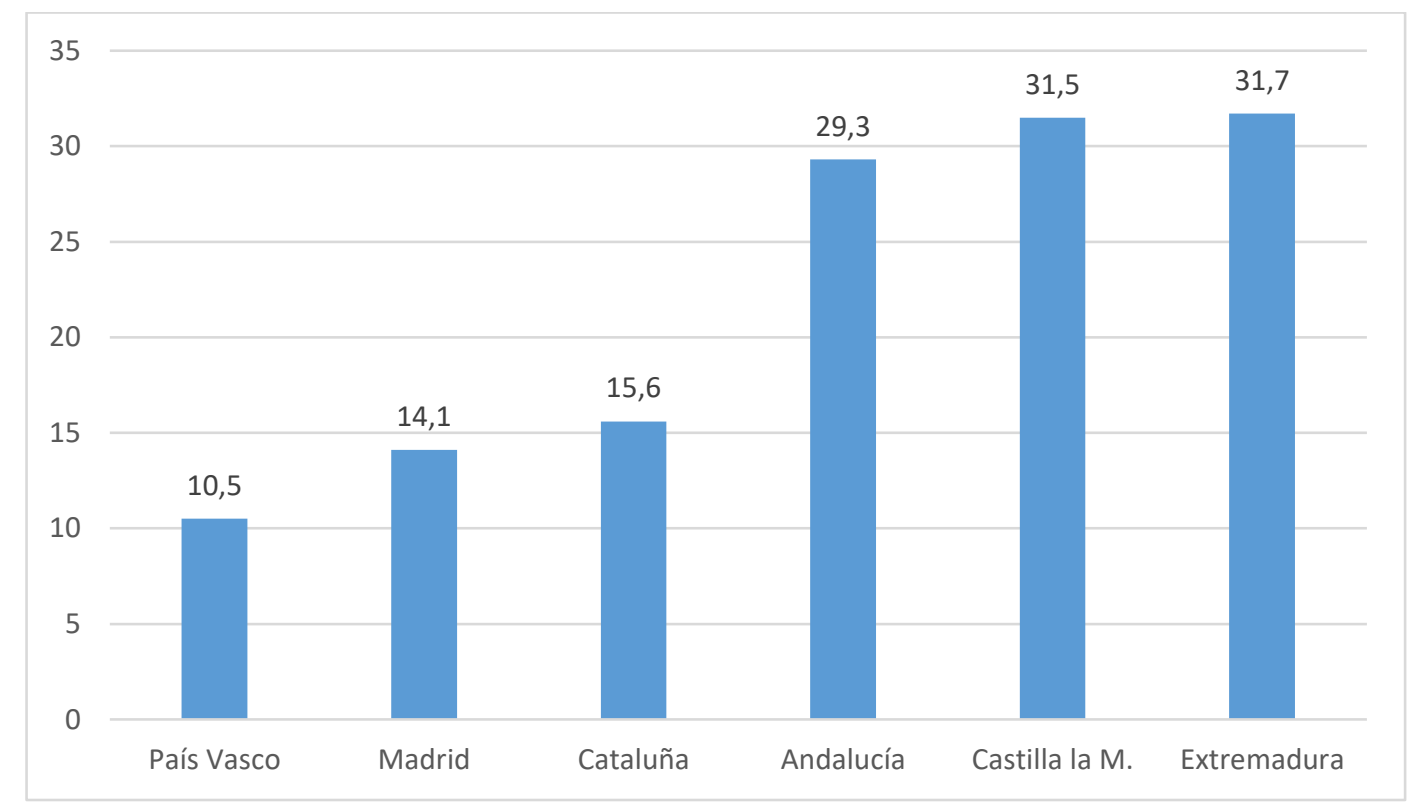

Fuente: elaboración propia sirviendo de base los microdatos de la ECV 2011 INE. 
Gráfico 3.14. Riesgo de pobreza en los hogares regentados por jóvenes de 25-34 años según situación económica del hogar de origen y por comunidades autónomas.

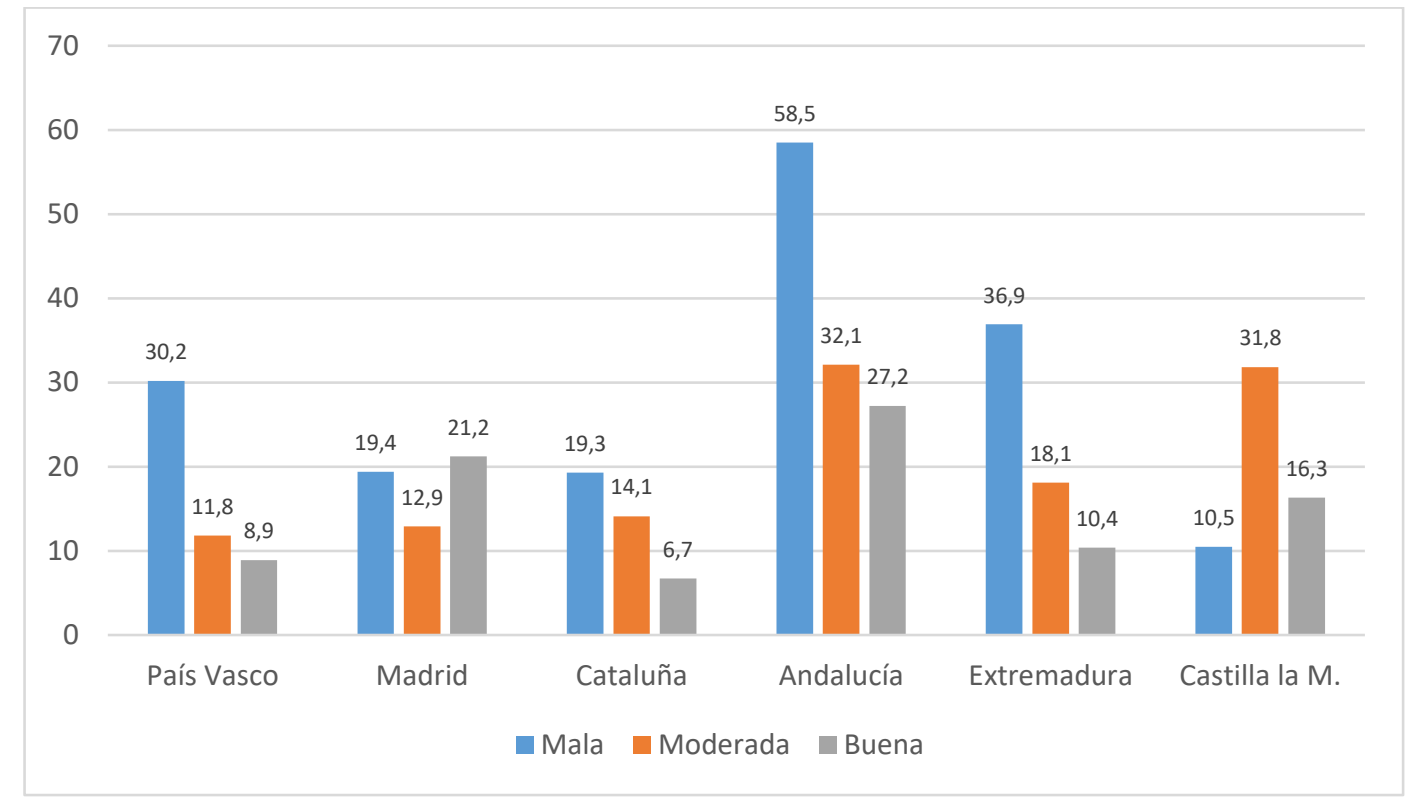

Fuente: elaboración propia sirviendo de base los microdatos de la ECV 2011 INE.

En este capítulo del bloque del análisis de resultados se ha puesto de manifiesto cómo los elementos estructurales (sistema económico, sistema educativo, el tipo de hábitat o el territorio) tienen influencia en algunos de los elementos que más influencia tienen en los procesos de transición, como son los estudios terminados o la ocupación, además de las diferencias por sexo y periodo económico. También se ha analizado la influencia en las diferencias y la desigualdad del contexto más inmediato (la familia) valorando la reproducción intergeneracional de las condiciones socioculturales y socioeconómicas. La crisis económica ha dificultado la incorporación al mercado laboral, retornando los jóvenes a los planes formativos, en especial los varones, que eran quienes en buenas condiciones económicas abandonaban los estudios prematuramente ante las buenas expectativas laborales. Las mujeres, por su parte, antes, durante y en la salida de la crisis 
se forman más tiempo y presentan mejores niveles formativos que los varones. El tipo de hábitat, y en especial el territorio, actúan como elementos coercitivos que marcan diferencias entre los jóvenes con relación a la formación y el empleo. El origen familiar es otro elemento de primer orden a considerar en las diferencias entre los jóvenes, con jóvenes menos formados cuando proceden de entornos socioculturales y socioeconómicos bajos y mayores niveles de pobreza y exclusión social entre aquellos jóvenes responsables de hogares que pertenecieron a un hogar con malas condiciones económicas. 


\section{CAPÍTULO 4. DIFERENCIAS EN LAS TRANSICIONES HACIA LA ADULTEZ}

En este capítulo se describen las diferentes transiciones que los jóvenes experimentan en su tránsito hacia la vida adulta. Estas estarían representadas por las variables dicotómicas estar estudiando, ser activo, estar emancipado, tener pareja y ser padre. Habrían completado la transición escolar aquellos que ya no estudian, la transición laboral aquellos que son activos, la transición residencial aquellos que se han emancipado, la transición hacia la vida en pareja aquellos que tienen cónyuge o pareja de hecho con o sin base jurídica y la transición parental aquellos que son padres. En el apartado metodológico de esta tesis se ha detallado cómo se han construido estas variables a partir de las que la ECV ofrece, con la excepción de estar cursando algún tipo de estudios, que se ofrece tal cual. Es necesario tener en cuenta esta información, pues los indicadores que se ofrecen pueden no ser comparables con los aportados por otras bases de datos. Igualmente, es necesario recordar que con los datos que están sirviendo de base para este trabajo de investigación, no es posible un estudio estricto sobre cómo se están produciendo las respectivas transiciones, para lo que sería necesario una información longitudinal amplia. Con los datos que ofrece la ECV es posible obtener una información longitudinal muy limitada, insuficiente para un anális que valore en profundidad cómo se está produciendo la transición hacia la adultez; lo que se ofrece es la estructrura de las transiciones, que pivotaría en el momento en el que se producen los sucesos de cada uno de los eventos que conformarían este proceso desde un punto de vista sociológico (el momento de terminar los estudios, de incoporarse al mercado laboral, de emanciparse residencialmente, de vivir en pareja y de tener hijos), cruzando variables independientes como: año en el que se produce el evento, sexo, grupo de edad, riesgo de pobreza o grado de urbanización del hábitat donde se reside. 


\subsection{Diversidad en los jóvenes que han experimentado los eventos de transición}

\subsubsection{Jóvenes cursando algún tipo de estudios}

Como se ha mencionado en la introducción de este capítulo, la transición escolar se produciría cuando ya no se está estudiando; en este sentido, se describirá esta transición en los análisis posteriores, si bien para el presente epígrafe se ha decidido representar y comparar gráficamente a quienes sí están estudiando para ofrecer una lectura diferente a la que se hará de la transición laboral, pues ambas transiciones se producirían básicamente al mismo tiempo. En el gráfico 4.1 se representa gráficamente y también se incluyen los datos del porcentaje de jóvenes que está realizando algún tipo de estudios por edad, por sexo y en dos años con diferente coyuntura económica, el año 2007, previo a la crisis económica, y el año 2014, en el comienzo de la salida de la crisis. Lo más llamativo es el mayor número de jóvenes en formación de menor edad, si bien el interés está en la comparación entre las mismas cohortes. En primer lugar, según la diferencia por coyuntura económica, se puede observar cómo hasta los 23-25 años habría una diferencia de entre 10 y 15 puntos porcentuales en el sentido de más jóvenes formándose en crisis que en el año que corresponde con una coyuntura económica aún favorable. Las diferencias por sexo se concentran entre las cohortes intermedias, ni entre los más jóvenes, 17-19 años, ni entre los de más edad, 32-34 años, existen diferencias sustanciales; en el resto de cohortes se observa una diferencia de entre 8 y 10 puntos porcentuales a favor de las mujeres, especialmente entre los 20 y los 25 años de edad.

Con estos datos es posible concluir que la crisis económica ha incentivado a los jóvenes a prolongar su periodo formativo, en especial entre las mujeres, que son, como lo eran en un momento de bonanza económica, quienes más prolongan este periodo. 
Gráfico 4.1. Porcentaje de jóvenes cursando estudios por edad y por sexo

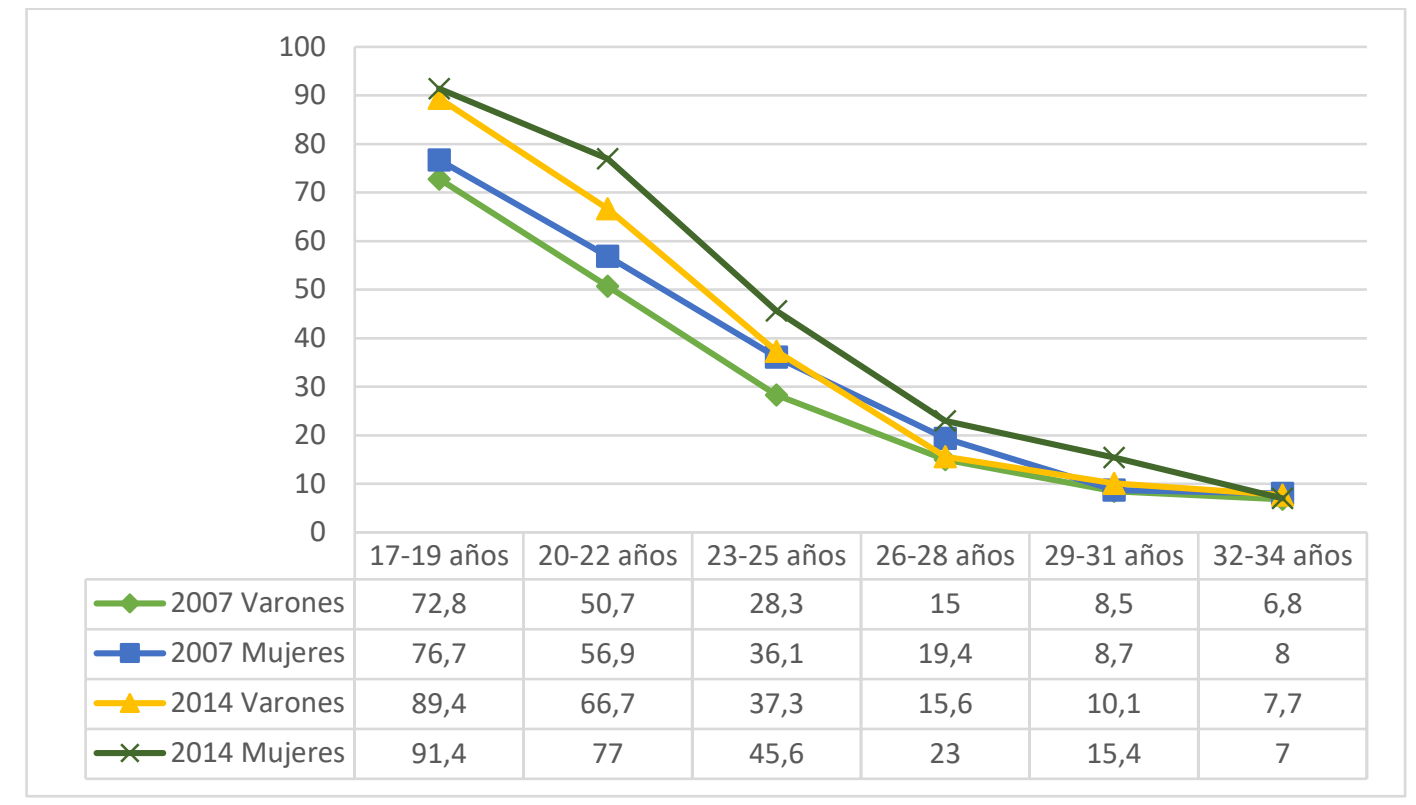

Fuente: elaboración propia con datos de la ECV.

La influencia de pertenecer a un hogar en riesgo de pobreza queda reflejada en el gráfico 4.2, donde se presenta el porcentaje de jóvenes que está cursando estudios por cohorte de edad y en los años que están sirviendo de referencia, que representan el comienzo y el término o salida de la crisis económica: 2007 y 2014. Obviamente, los jóvenes que más están en formación son los que pertenecen a los grupos de menor edad, si bien lo que interesa nuevamente es poner en evidencia las diferencias entre las mismas cohortes, pero en las diversas circunstancias; las diferencias en cuanto a estar o no en formación son prácticamente inexistentes para la cohorte de mayor edad, entre los 32 y 34 años de edad no hay diferencias con relación a estar en un plan formativo, ni por año de diferente coyuntura económica ni por pertenecer a un hogar en riesgo, o no, de pobreza. Las diferencias se encuentran en las cohortes más jóvenes, y especialmente entre los 17 y los 25 años de edad. En este caso se puede observar con claridad cómo entre aquellos jóvenes que pertenecen a hogares sin riesgo de pobreza ha aumentado el porcentaje de quienes están estudiando, entre 20 y 30 puntos porcentuales entre el año 2007 y el año 2014; sin 
embargo, esta diferencia no existe entre quienes pertenecen a un hogar en riesgo de pobreza, tan solo en este caso los jóvenes de entre 17 y 19 años habrían aumentado porcentualmente entre el año 2007 y 2014 unos 10 puntos, de un 72,5\% a un $85 \%$. A partir de los 20-22 años no se observan diferencias entre los jóvenes pertenecientes a hogares en riesgo de pobreza en los periodos de referencia. Cabría resumir el análisis en el sentido de que la crisis económica no habría influido en los jóvenes pertenecientes a hogares pobres en cuanto a su intención de incrementar el periodo formativo, con la única excepción de la cohorte de 17-19 años, en la que sí habrían aumentado ligeramente aquellos que deciden estar en formación; por el contrario, entre los jóvenes que pertenecen a hogares sin riesgo de pobreza habrían aumentado considerablemente aquellos que deciden seguir formándose entre un periodo previo a la crisis y en la salida de esta.

Gráfico 4.2. Porcentaje de jóvenes cursando estudios por edad y riesgo de pobreza del hogar.

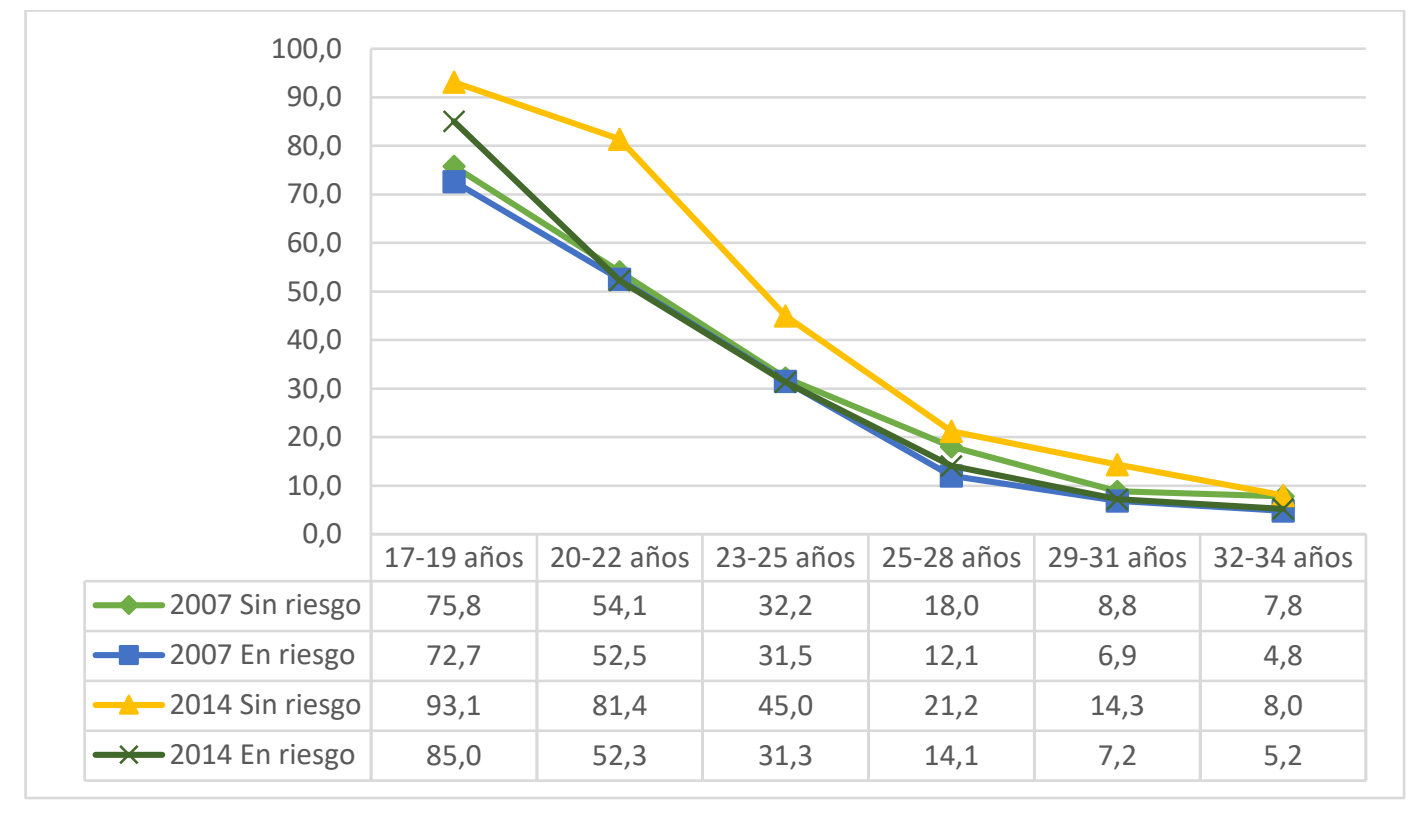

Fuente: elaboración propia con datos de la ECV. 
El grado de urbanización del hábitat donde se reside, representado por las categorías urbano y rural, constituye otro elemento para valorar las diferencias entre los jóvenes en los procesos de transición, en este caso relacionados con la transición escolar. En el gráfico 4.3 es posible observar las diferencias en los porcentajes de jóvenes que están cursando estudios por cohortes de edad y tipo de hábitat. Si se observan las cohortes de los extremos, los más jóvenes y los de mayor edad, es posible ver cómo entre los de mayor edad no se observan diferencias en ningún caso, ni por año, ni por hábitat; para los de menor edad, 17-19 años, no se observan diferencias por tipo de hábitat, el porcentaje de jóvenes que dice estar en formación es igual, pertenezcan a un hábitat más o menos urbanizado, pero sí hay diferencias por coyuntura económica, con 15 puntos porcentuales más de jóvenes que dicen estar estudiando en el año 2014 frente al año 2007. Entre quienes tienen 20-22 años se observan diferencias entre los dos periodos incluso mayores, de unos 20 puntos, y además también por tipo de hábitat, con una diferencia de unos 10 puntos más para quienes viven en un medio urbano frente a quienes viven en el medio rural. En las cohortes intermedias, 23-25 y 26-28 años, se repiten estas diferencias, pero de manera menos acusada cuanta más edad. La ausencia de diferencias entre quienes viven en el medio rural frente a quienes viven en entornos más urbanizados entre los más jóvenes indicaría unas idénticas posibilidades de formación para los ciclos formativos obligatorios, pero las diferencias observadas en las cohortes intermedias podrían reflejar unas menores oportunidades formativas para los jóvenes del medio rural frente a los que residen en los hábitats más urbanizados. 
Gráfico 4.3. Porcentaje de jóvenes cursando estudios por edad y grado de urbanización del hábitat donde residen.

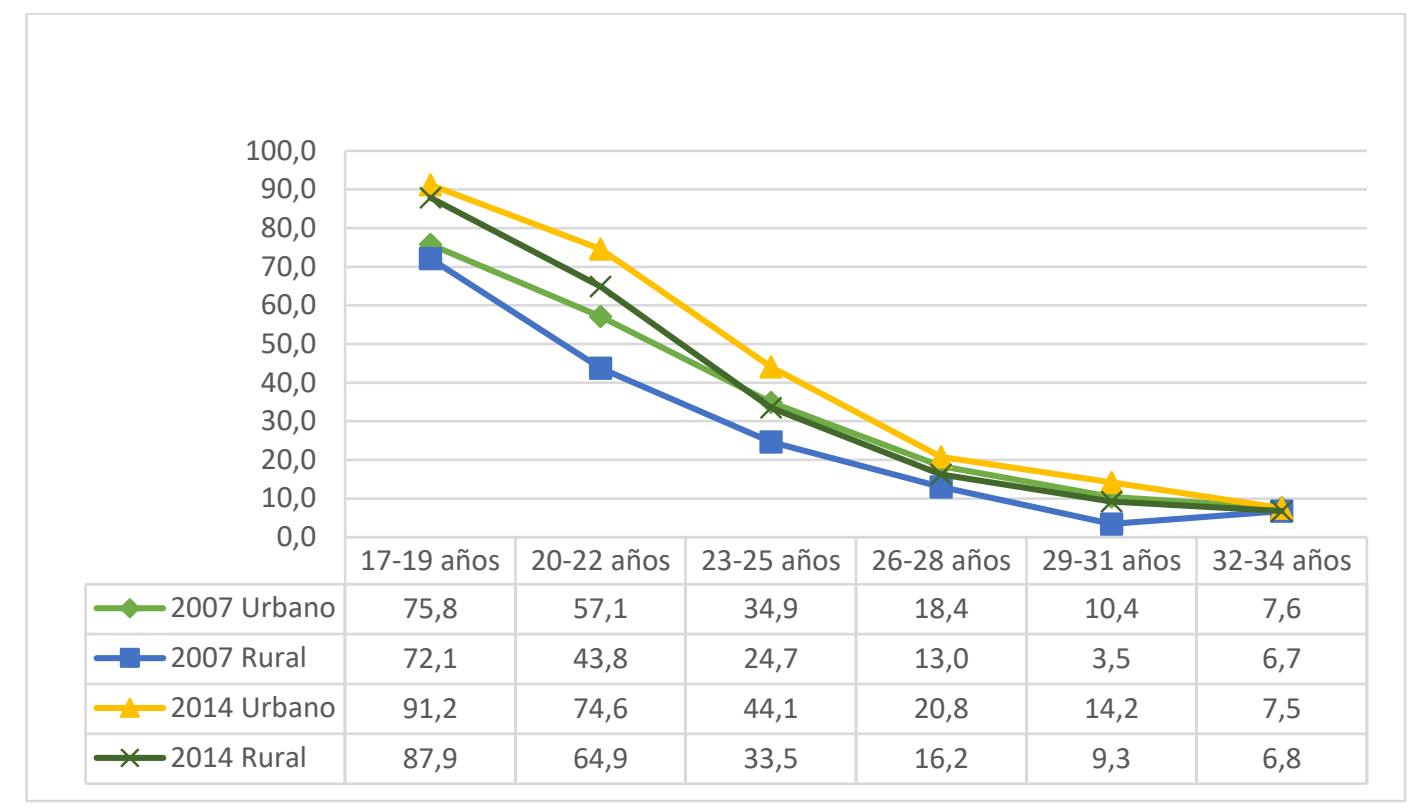

Fuente: elaboración propia con datos de la ECV.

\subsubsection{La incorporación al mercado laboral}

En el gráfico 4.4 se presentan los datos que corresponden con los jóvenes activos y están muy relacionados con los presentados anteriormente sobre quiénes están estudiando, lo cual tiene sentido, pues lo habitual es que la transición laboral se produzca en el mismo momento que la transición escolar, es decir, los jóvenes son activos en el momento que dejan de estudiar. Las diferencias se observan en los jóvenes de 17 a 25 años, en las cohortes de mayor edad no existen diferencias ni por sexo ni por coyuntura económica. Entre años con diferente coyuntura económica se observa una diferencia de 20 puntos entre los varones del año 2007 y del año 2014 en las cohortes más jóvenes, 17-19 años y 20-22 años; en torno a 13 puntos de diferencia entre las mujeres en el mismo sentido. Las altas tasas de desempleo en el periodo de crisis provocan un retraso en la incorporación 
al mercado laboral de los jóvenes, incrementándose el porcentaje de los que deciden seguir formándose. En cuanto a las diferencias por sexo antes de la crisis, ya se observan desde la cohorte más joven, 17-19 años, unas diferencias de unos 6 puntos, mientras en crisis no existe diferencia entre los varones y las mujeres más jóvenes; a partir de esta cohorte las diferencias se mantienen en torno a esos 6 puntos porcentuales en ambos periodos hasta los 26-28 años, donde las diferencias son escasas, y en las siguientes cohortes son inexistentes.

Con estos datos, es posible concluir que la crisis económica ha retrasado la incorporación a la población activa entre las cohortes más jóvenes, de los 17 a los 25 años, y que las diferencias por sexo se producen igualmente en este colectivo y en la misma intensidad en crisis que en bonanza económica.

Gráfico 4.4. Porcentaje de jóvenes que son activos por edad y sexo.

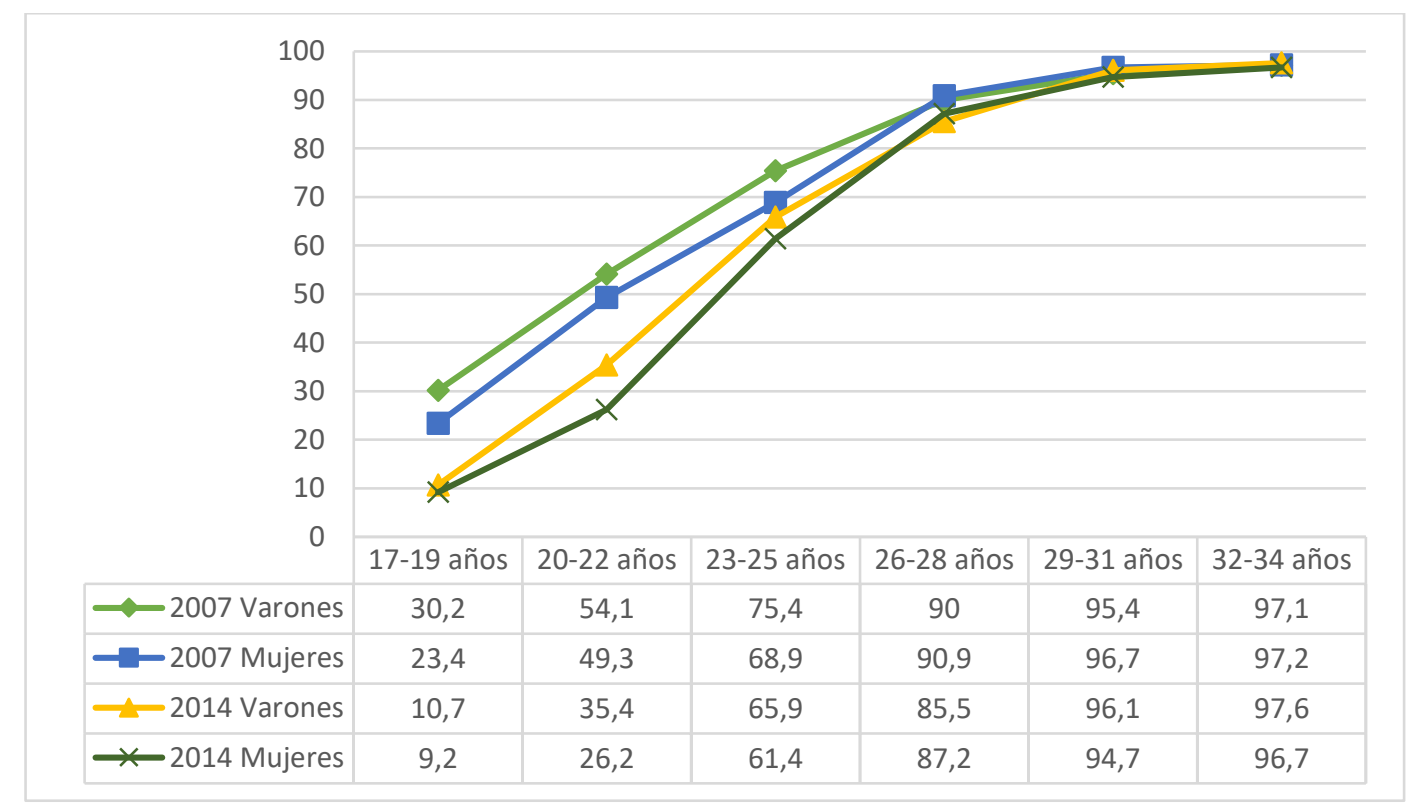

Fuente: elaboración propia con datos de la ECV. 
Como se viene observando, el pertenecer o no a un hogar en riesgo de pobreza es un elemento diferenciador para cualquier variable dependiente que se quiera cruzar. En el gráfico 4.5 se presenta el porcentaje de jóvenes que son activos por edad y riesgo de pobreza del hogar. El porcentaje de activos aumenta, lógicamente, con la edad, siendo a partir de los 25-28 años cuando alcanza los mayores porcentajes de jóvenes activos. En el año 2007 y entre los de menos edad, 17-19 años, no se observan diferencias por pertenecer a un hogar con o sin riesgo de pobreza, en ambos grupos fueron activos el $20 \%$, porcentaje que baja hasta el $10 \%$ en el año 2014 para quienes viven en riesgo de pobreza, y hasta el $4 \%$ para los que no tienen riesgo de pobreza que son activos y pertenecen a la cohorte de menor edad. En el año 2007, y a partir de la cohorte de 23-25 años, las diferencias entre sufrir y no sufrir riesgo de pobreza son en torno a 20 puntos porcentuales entre quienes son activos, a favor de aquellos que no tienen riesgo de pobreza, sin embargo, en el año 2014 las diferencias se producen a la inversa, hay más activos entre quienes están en riesgo de pobreza, pero únicamente en las cohortes de 2022 y 23-25 años, en las de mayor edad no se observan diferencias a considerar. 
Gráfico 4.5. Porcentaje de jóvenes que son activos por edad y riesgo de pobreza en el hogar donde residen.

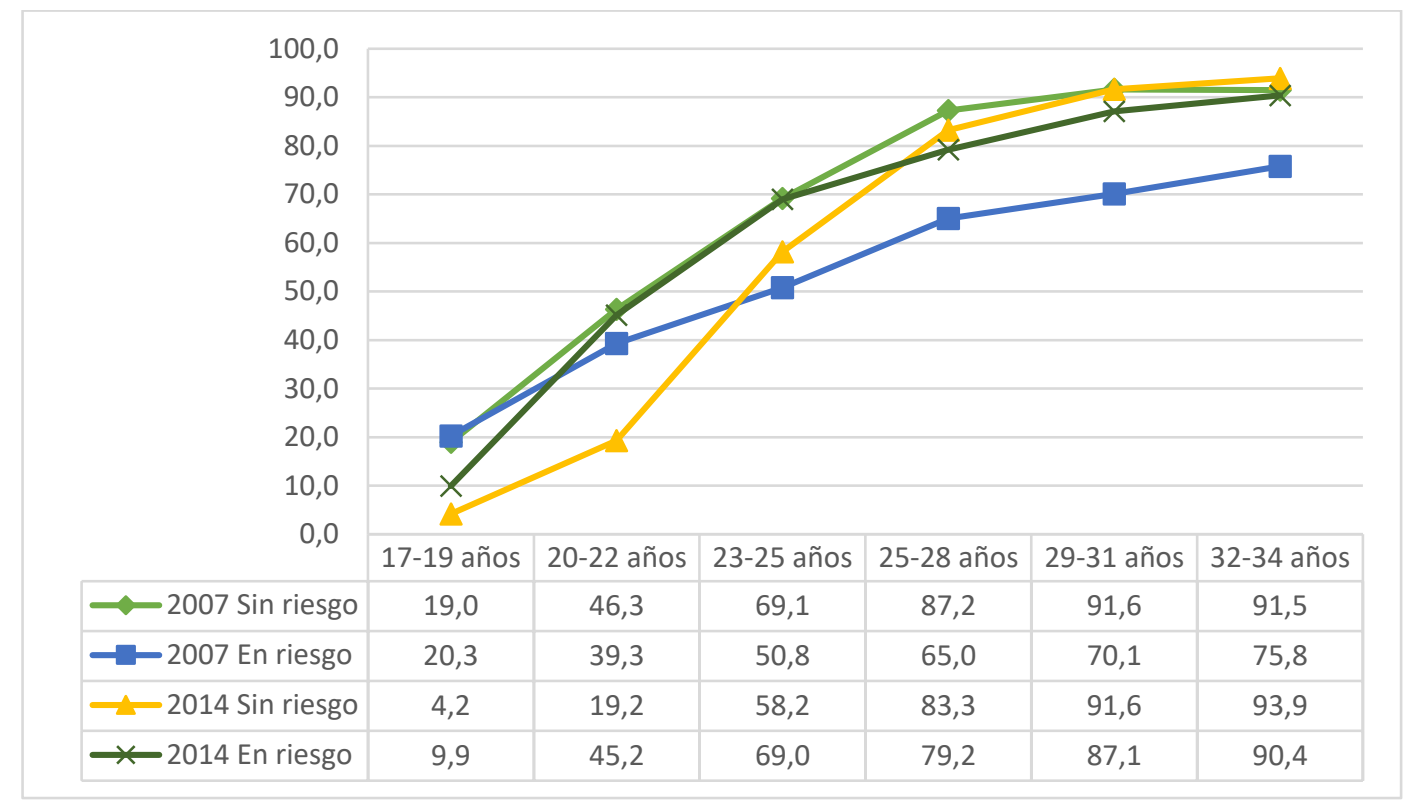

Fuente: elaboración propia con datos de la ECV.

El tipo de hábitat con relación a ser o no ser activos tiene influencia en las cohortes centrales, entre los 20-22 años y 23-25 años, con una diferencia de unos 10 puntos porcentuales más activos en el medio rural que en las zonas urbanas. Entre los más jóvenes y las cohortes de mayor edad no se observan diferencias evidentes en ambos tipos de hábitat en relación con ser o no ser activos. Por otra parte, las diferencias en completar la transición laboral presentarían cambios sustanciales si se comparan los porcentajes de activos antes y después de la crisis económica; en el año 2007, año que está sirviendo de referencia como periodo precrisis, los jóvenes activos de 17-19 años tan solo fueron de un $5 \%$, mientras que para los mismos jóvenes en el año 2014, año que es posible considerar como el de la salida de la crisis, estos jóvenes activos sumaban el $18 \%$ para quienes pertenecían al hábitat urbano, mientras fue del $7 \%$ y $22 \%$, respectivamente, para 
aquellos pertenecientes al hábitat rural. Las diferencias se mantienen en esta línea cuando nos referimos a la siguiente cohorte, con diferencias de entre 15 y 20 puntos porcentuales a favor del año 2007 frente al año 2014. Para las cohortes incluidas entre los 26 y 34 años, lógicamente aumenta el porcentaje de activos y no se observan diferencias llamativas ni en cuanto a hábitat ni en diferentes coyunturas económicas.

Gráfico 4.6. Porcentaje de jóvenes que son activos por edad y tipo de hábitat donde residen.

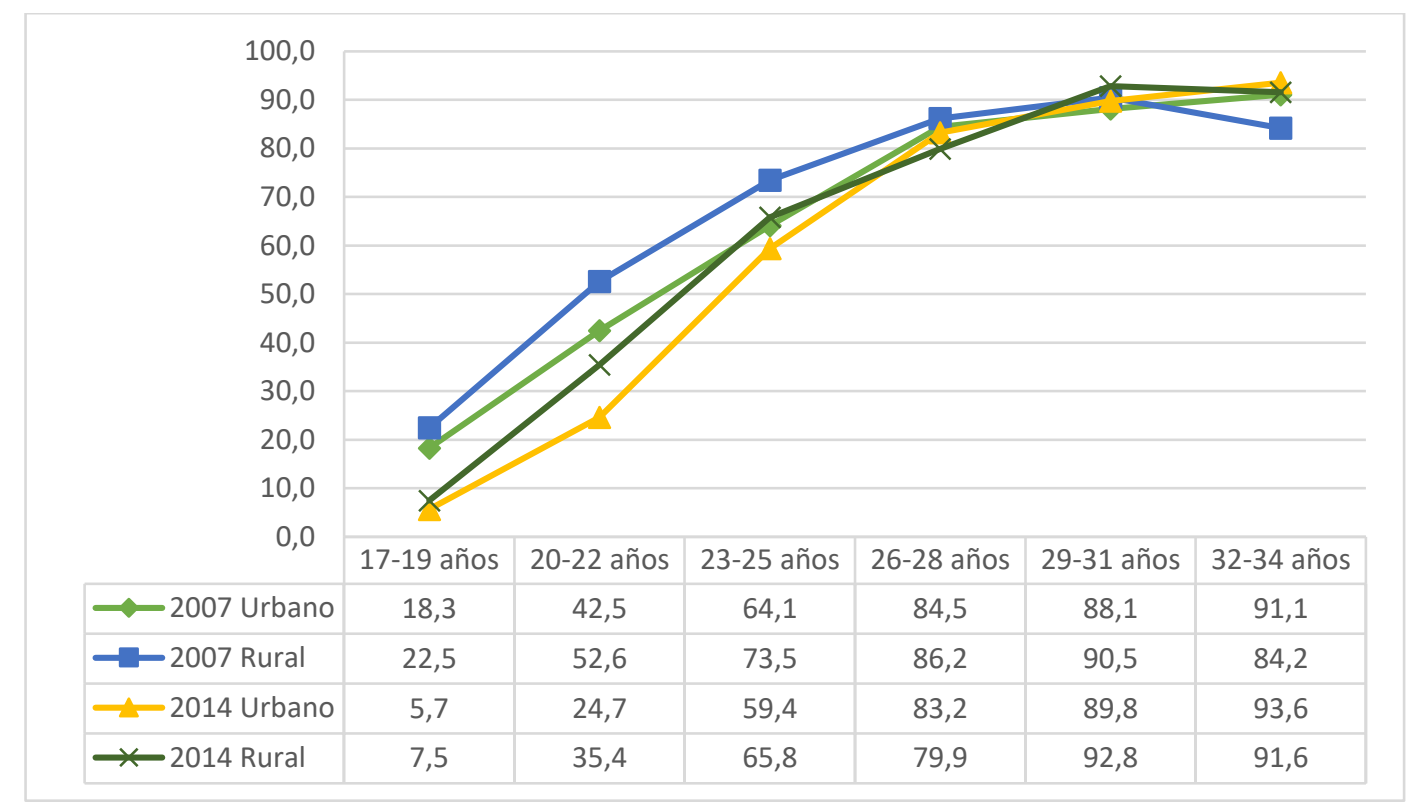

Fuente: elaboración propia con datos de la ECV.

\subsubsection{El abandono del hogar de origen o transición residencial}

Las pautas de emancipación no habrían variado significativamente durante la crisis económica. Los datos se ofrecen en el gráfico 4.7, donde es posible apreciar con toda claridad cómo las diferencias que se observan para cada cohorte son por sexo y no por coyuntura económica. A partir de los 23-25 años comienza a tener relevancia la 
emancipación residencial, con un $12 \%$ de emancipados varones frente al $20 \%$ entre las mujeres. El porcentaje de emancipados residencialmente crece, lógicamente, con la edad y se incrementan las diferencias entre varones y mujeres con unos 15 puntos.

Gráfico 4.7. Porcentaje de jóvenes emancipados por edad y por sexo.

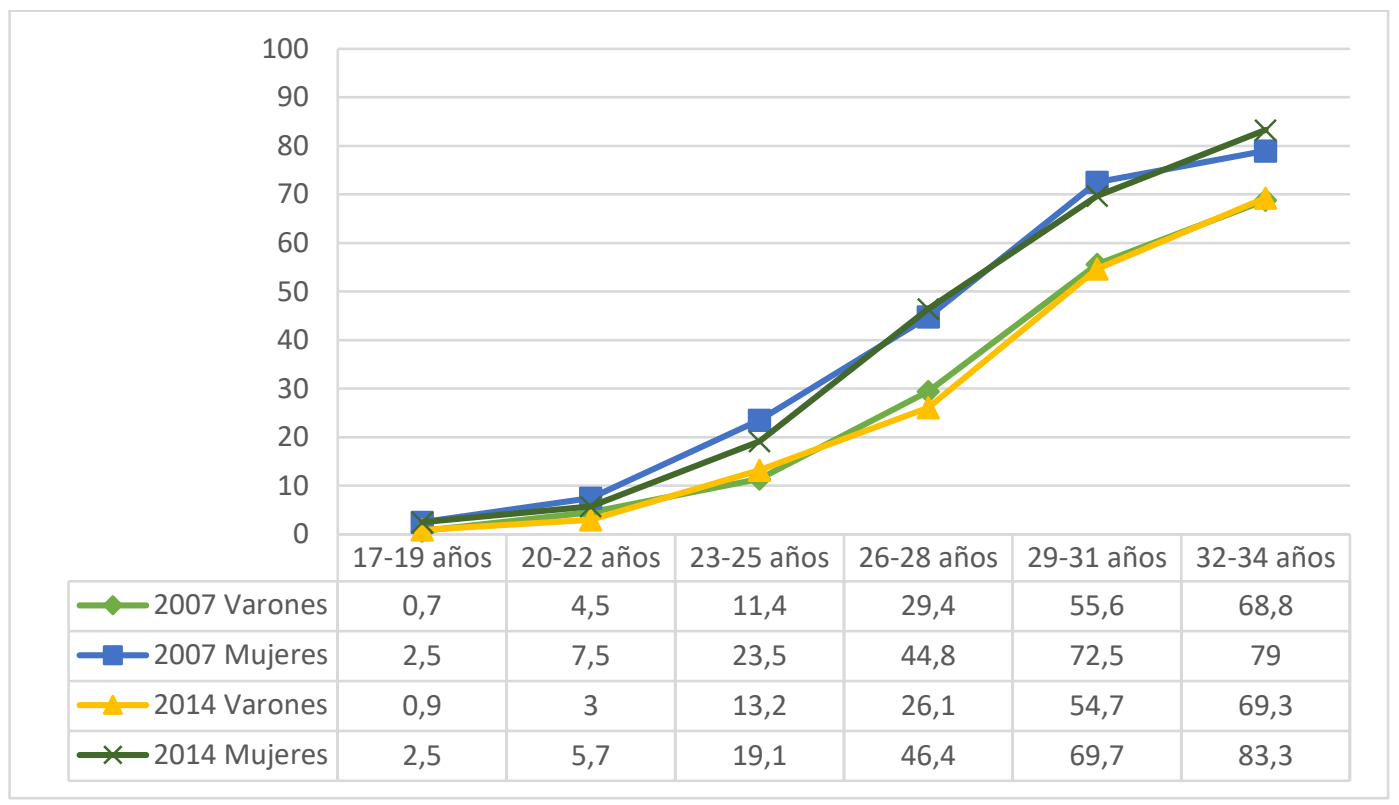

Fuente: elaboración propia con datos de la ECV.

En el gráfico 4.8, que se ofrece a continuación, se presenta el porcentaje de jóvenes emancipados por edad y riesgo de pobreza del hogar donde se vive. Con los datos que se presentan no es posible afirmar que exista una diferencia llamativa en cuanto a las pautas de emancipación antes y durante la salida de la crisis si se tiene en cuenta el factor riesgo de pobreza. Las diferencias que sí es posible observar serían el mayor porcentaje de jóvenes emancipados entre quienes viven en un hogar en riesgo de pobreza frente a aquellos que no; esta diferencia sería de hasta 20 puntos porcentuales entre aquellos que tienen 25-28 años y de unos 10 puntos si nos referimos a aquellos que tienen entre los 29 
y los 34 años. Para las cohortes de menor edad no se observan tantas diferencias, llegando a ser nulas entre los más jóvenes, con porcentajes de emancipados lógicamente muy bajos, entre el 1 y el $3 \%$ únicamente.

Gráfico 4.8. Porcentaje de jóvenes emancipados por edad y riesgo de pobreza del hogar donde se reside.

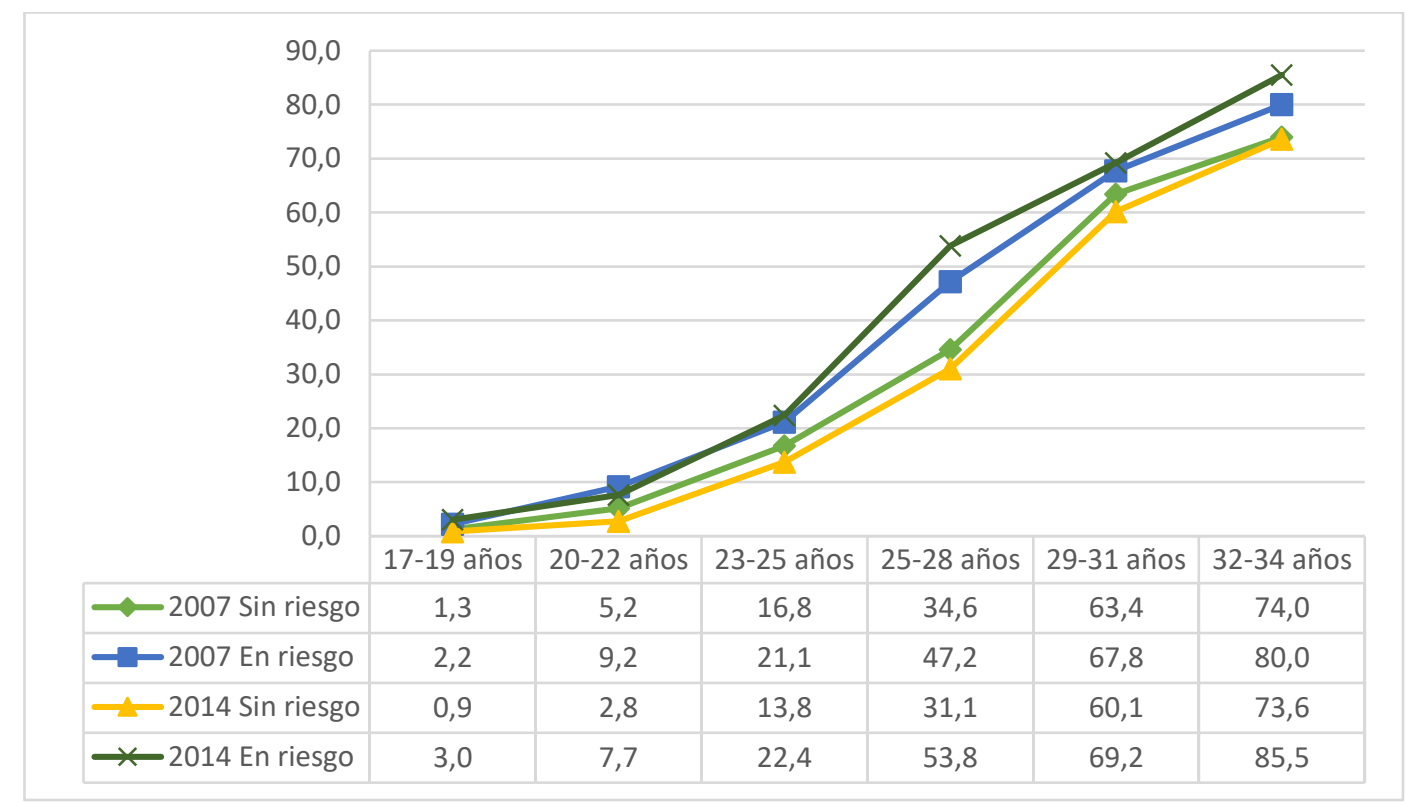

Fuente: elaboración propia con datos de la ECV.

El residir en un hábitat urbano o en uno rural no implica diferencias en cuanto al momento de la emancipación residencial, tampoco si se comparan los años 2007 y 2014 se puede afirmar que existan diferencias sustanciales en cuanto al porcentaje de jóvenes emancipados para cualquiera de las cohortes que se elija, en especial entre los de menor edad, 17-19 años, con un porcentaje de emancipados para este intervalo de edad muy bajo, entre el $1 \%$ y el $2 \%$ en ambos tipos de hábitat y en ambos años. 
Gráfico 4.9. Porcentaje de jóvenes emancipados por edad y tipo de hábitat donde residen.

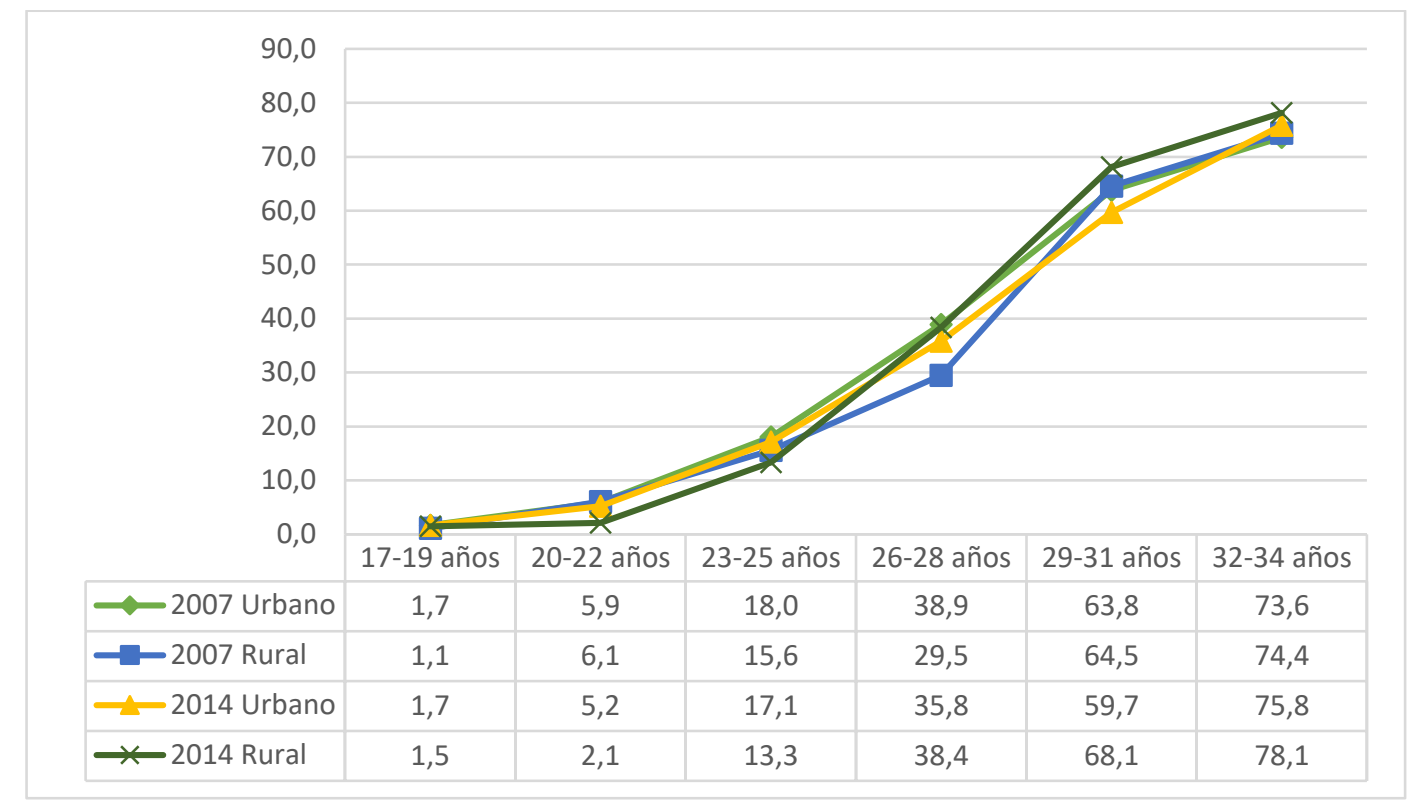

Fuente: elaboración propia con datos de la ECV.

\subsubsection{La vida en pareja y diferencias entre los jóvenes que han experimentado este evento de transición}

La lectura que es posible hacer del grafico 4.10 es básicamente la misma que se ha hecho para el gráfico anterior. No es posible decir que la crisis económica haya modificado la decisión de tener pareja, los datos para el 2007 y para el 2014 son muy similares y así lo muestran los gráficos. En las cohortes más jóvenes la relevancia de este estatus es muy escasa, si bien dentro de esta poca relevancia, son las mujeres las que aparecen con datos, en torno al $5 \%$ de mujeres con pareja y al $3 \%$ de mujeres madres en la cohorte de 20-22 años. A partir de los 23-25 años, los datos son más contundentes cuantitativamente, manteniendo una diferencia notable entre varones y mujeres, que oscilan entre 10 y 15 puntos en todas las cohortes de los de mayor edad. Es posible concluir que las diferencias que se observan en los mismos grupos de edad son por sexo y no por periodo económico, 
como ocurría para el análisis de la transición residencial, con la excepción de los grupos de menor edad que, como es lógico, presentan unos porcentajes de vida en pareja muy pequeños, aunque en cualquier caso siempre hay más mujeres que varones viviendo en pareja.

Gráfico 4.10. Porcentaje de jóvenes que viven en pareja por edad y sexo.

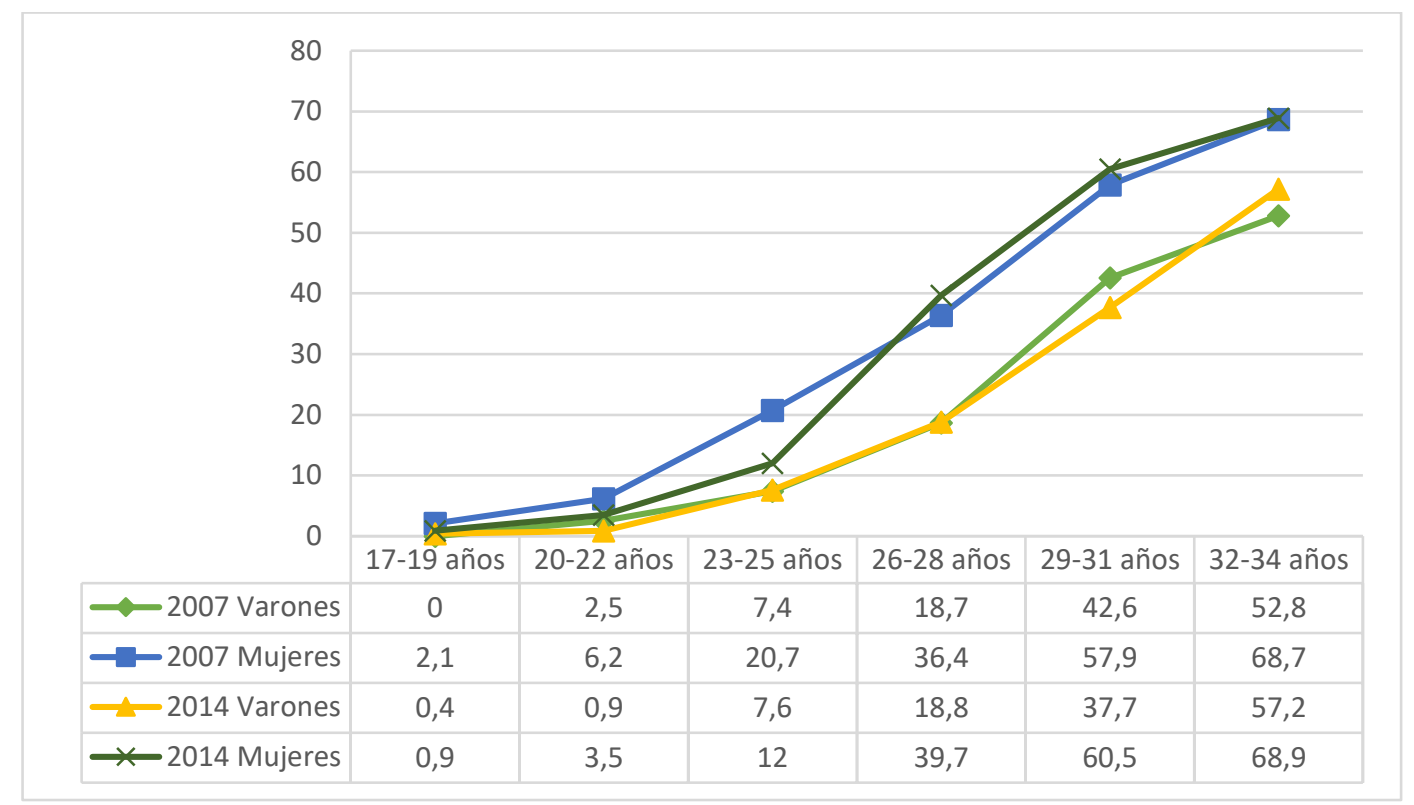

Fuente: elaboración propia con datos de la ECV.

Las diferencias observadas en la transición de vida en pareja con relación a si se pertenece a un hogar en riesgo de pobreza o no se centran básicamente entre los 23 y 28 años, con entre 5 y 10 puntos porcentuales más para aquellos que pertenecen a hogares en riesgo de pobreza, no observándose diferencias por coyuntura económica. Esta información se presenta en el gráfico 4.11. 
Gráfico 4.11. Porcentaje de jóvenes que tienen pareja por edad y riesgo de pobreza del hogar donde residen.

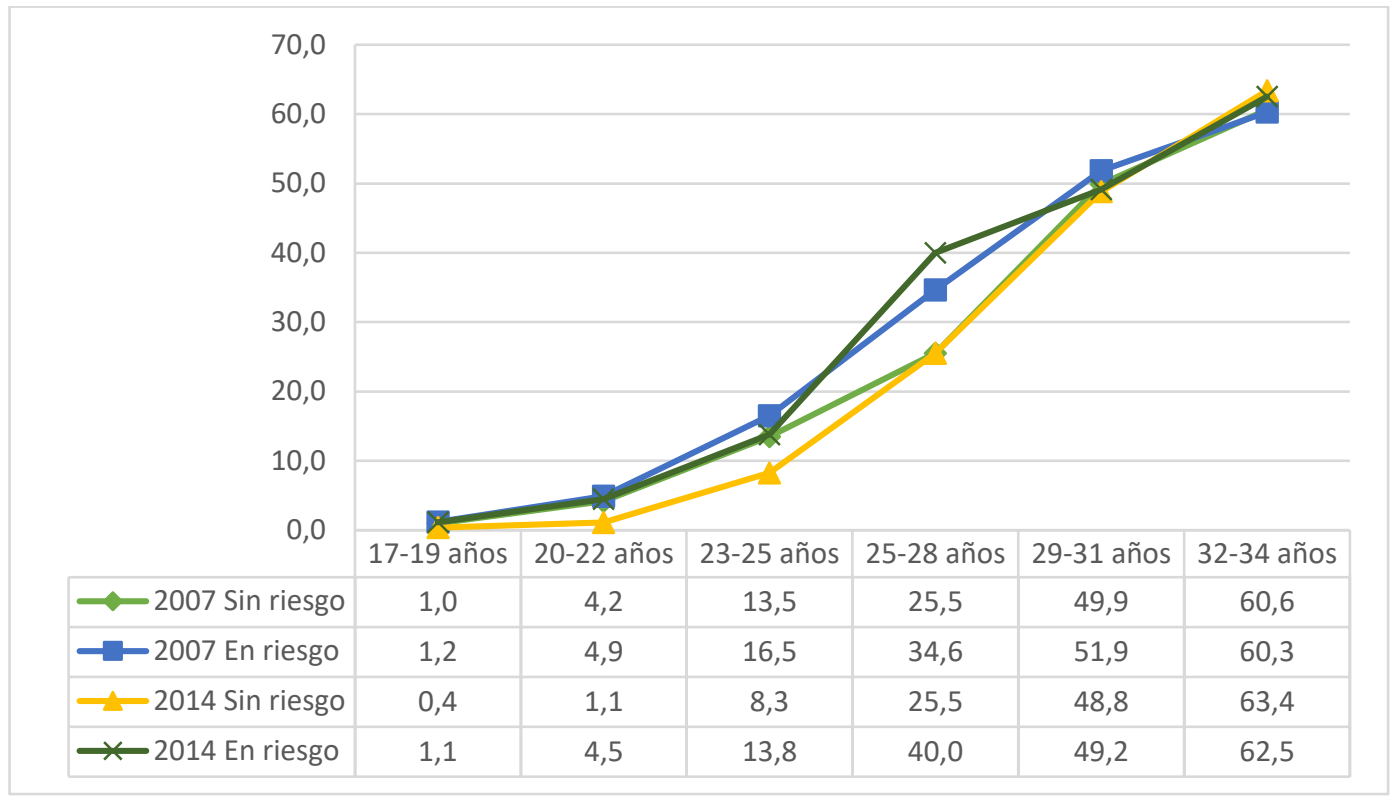

Fuente: elaboración propia con datos de la ECV.

En el gráfico 4.12 se presenta el porcentaje de jóvenes que tienen pareja por edad y tipo de hábitat, y en él únicamente se observan diferencias sustanciales entre los que tienen 29-31 años, con unos 10 puntos porcentuales más con cónyuge o pareja de hecho entre aquellos que viven en el medio rural y con unos 5 puntos porcentuales más jóvenes con pareja de esta misma edad y unos 5 puntos entre los años 2007 y 2014. 
Gráfico 4.12. Porcentaje de jóvenes que tienen pareja por edad y tipo de hábitat donde residen.

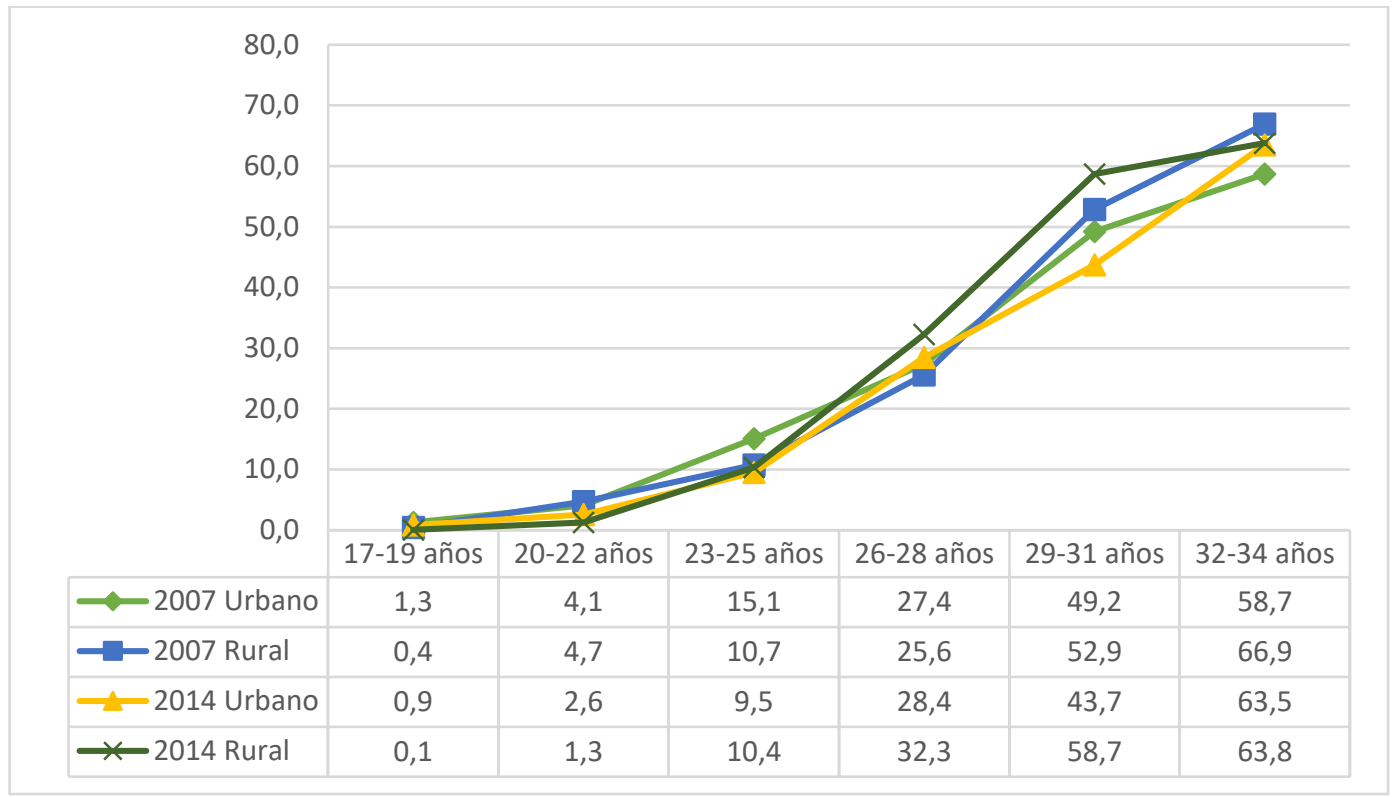

Fuente: elaboración propia con datos de la ECV.

\subsubsection{La maternidad/paternidad en los jóvenes como evento de transición}

En las siguientes figuras se presenta gráficamente el porcentaje de jóvenes por edad, sexo, riesgo de pobreza del hogar, hábitat rural o urbano y para el año 2007 y 2014. En la primera de las representaciones, que corresponde con el gráfico 4.13, se observan las diferencias por sexo, en este caso es posible observar con claridad cómo estas diferencias se centran en las cohortes de mayor edad, entre los 26 y 34 años, con unas diferencias a favor de las mujeres de entre 10 y 15 puntos porcentuales. No se observan diferencias apreciables entre el año que corresponde con el momento precrisis, 2007, y el de la salida de la crisis, 2014. El riesgo de pobreza una vez más marca las diferencias, en este caso frente a la paternidad; estas diferencias se presentan en el gráfico 4.14 y se observan a partir de los 23-25 años y hasta los 31-34 años; son sustancialmente más los jóvenes 
padres que viven en hogares en riesgo de pobreza frente a los que no, con diferencias en el intervalo de edad descrito de hasta 20 puntos porcentuales entre los de mayor edad. Por otra parte, entre quienes no tienen riesgo de pobreza no presentan diferencias por años, pero sí entre los que viven en hogares en riesgo de pobreza, con una diferencia entre el año 2007 y 2014 de unos 10 puntos porcentuales de más padres en el año 2007 frente al año 2014. En el gráfico 4.15 se ofrece el porcentaje de jóvenes que son padres según el tipo de hábitat donde se residen, urbano o rural, y aquí las diferencias se producen en el mismo sentido que en el caso anterior, pero únicamente en el intervalo de mayor edad, 31-34 años.

Gráfico 4.13. Porcentaje de jóvenes que son padres por edad y sexo.

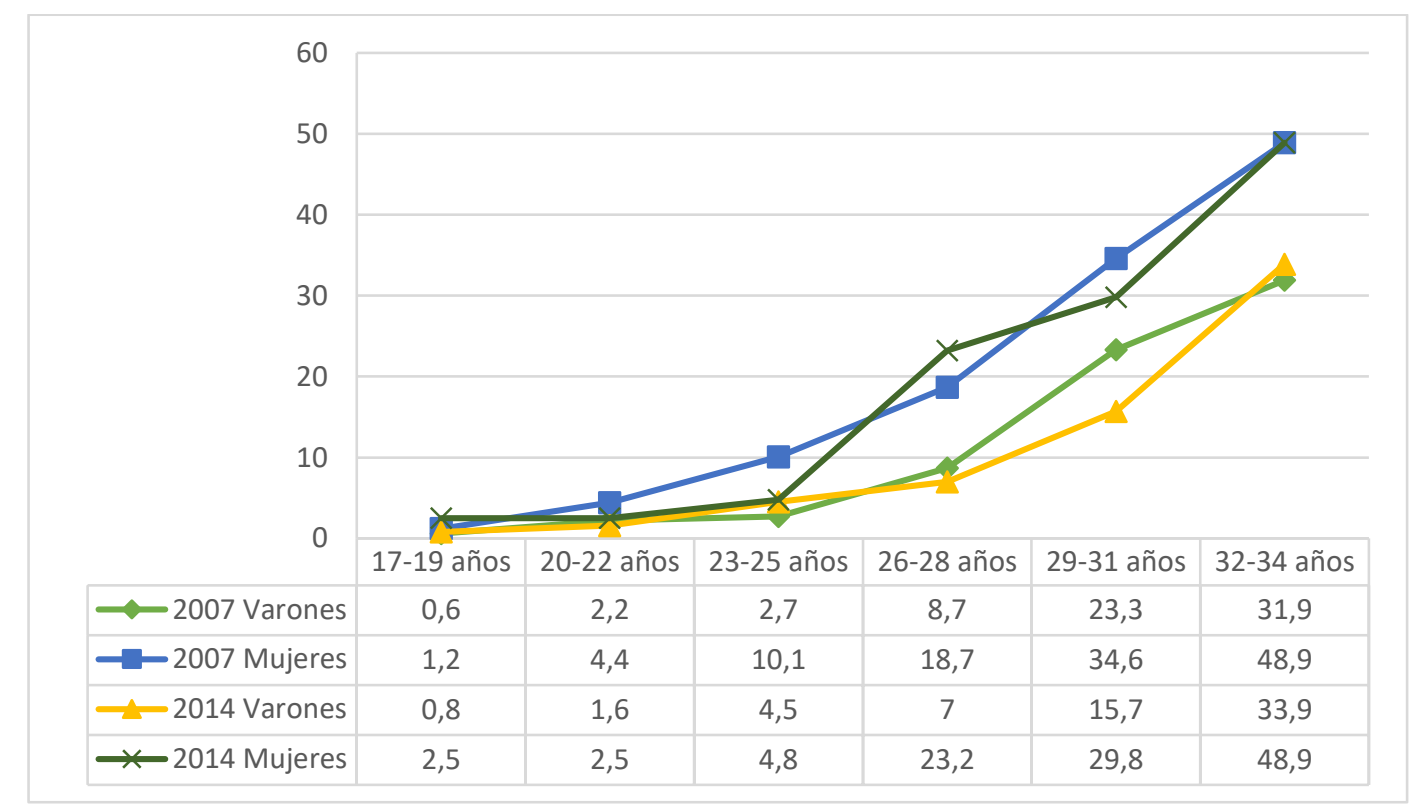

Fuente: elaboración propia con datos de la ECV. 
Gráfico 4.14. Porcentaje de jóvenes que son padres por edad y riesgo de pobreza del hogar donde se reside.

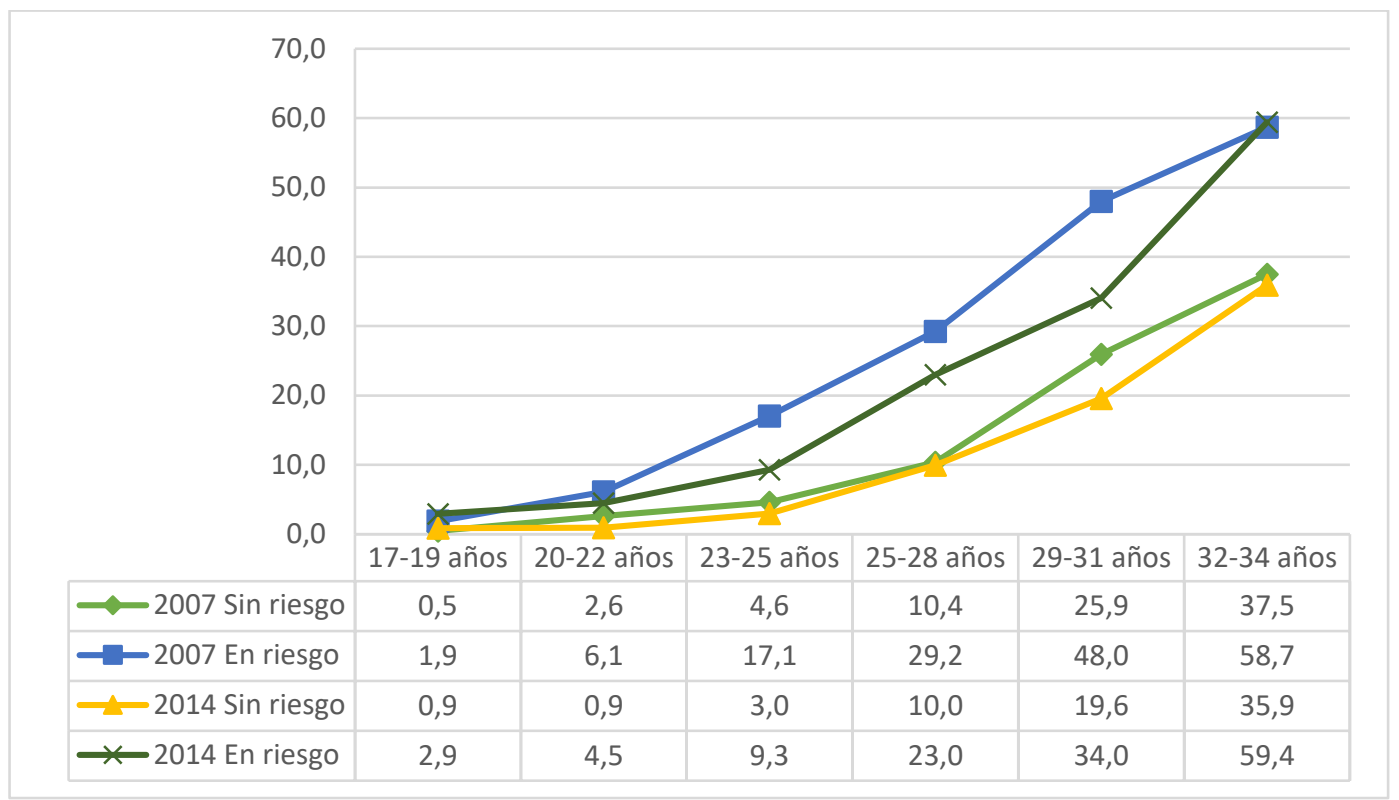

Fuente: elaboración propia con datos de la ECV.

Gráfico 4.15. Porcentaje de jóvenes que son padres por edad y por tipo de hábitat donde residen.

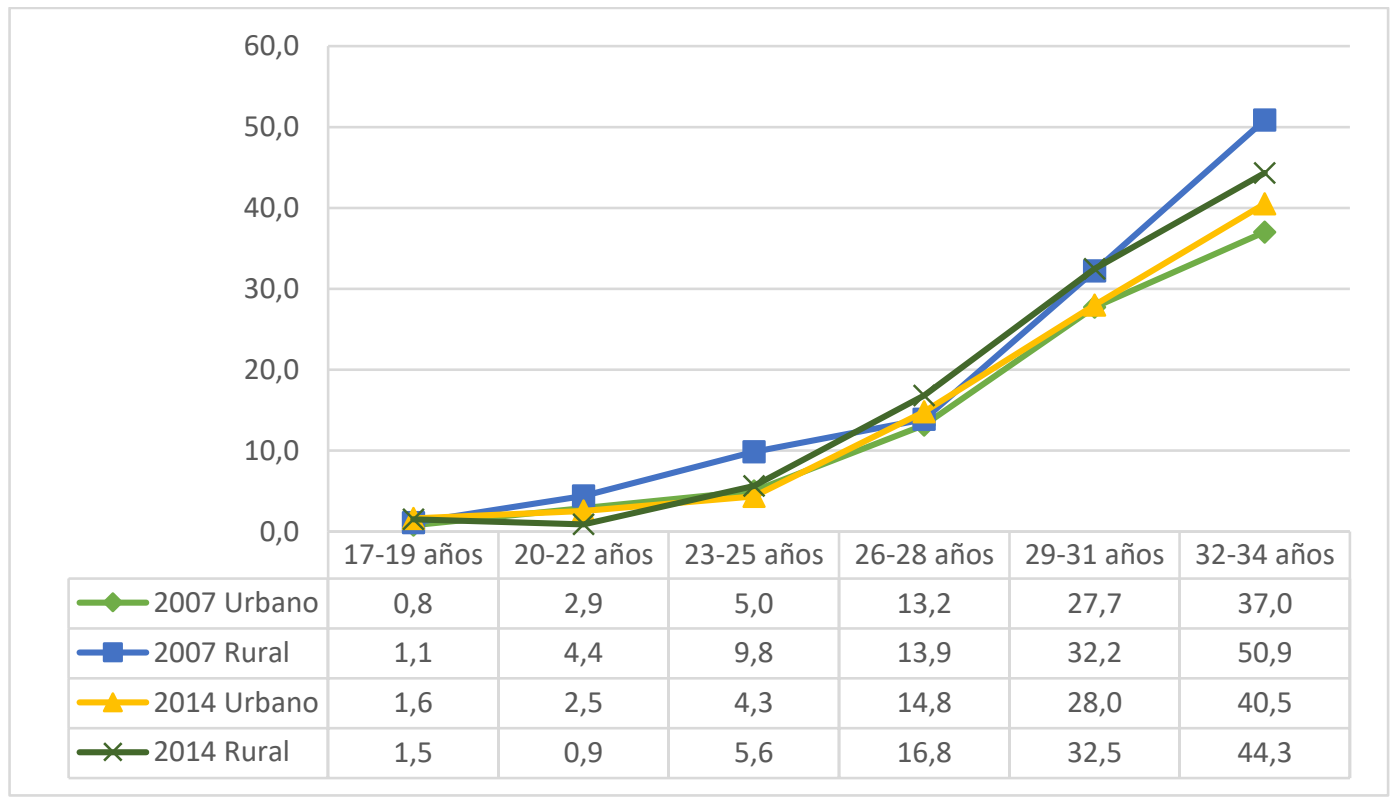

Fuente: elaboración propia con datos de la ECV. 


\subsection{La duración de los eventos de transición en diferentes periodos}

En este epígrafe se va a presentar la duración de las cinco transiciones que caracterizan la transición hacia la adultez, teniendo en cuenta las variables independientes que vienen siendo habituales hasta este momento y que nuevamente pondrán en evidencia las diferencias, en este caso en el momento de ocurrencia y tiempo de duración, de estos eventos. En la tabla 4.1 se presenta el número de años en los que se produce cada una de las transiciones por sexo y coyuntura económica, en este caso la coyuntura económica viene reflejada por el año previo a la crisis económica en España, el 2007, un año de plena crisis económica, el 2011 y el de la salida de la crisis, 2015, con el fin de tener una secuencia más clarificadora de la evolución del proceso. Para la transición escolar ${ }^{6}$ lo primero que llama la atención, tanto en varones como en mujeres, es lo prolongado de esta, vemos cómo se producen a lo largo de 12 o 13 años, lo que está indicando una diferencia ya sustancial en el colectivo que está siendo objeto de estudio, jóvenes que a los 21 años han culminado su trayectoria escolar junto a jóvenes que la prolongan hasta los 34 años de edad. Las diferencias entre varones y mujeres se producen en el sentido de un adelanto de la transición en los varones respecto de las mujeres de un año, y en las diferencias por año se observa cómo tanto en varones como en mujeres la crisis económica ha retrasado dos años la transición escolar en los varones y un año en las mujeres. El intervalo de años en los que se produce la transición laboral en el colectivo que se está estudiando es prácticamente idéntico a la transición escolar, es fácil pensar que cuando se terminan los estudios inmediatamente se incorporan al mercado laboral ${ }^{7}$, por lo que los comentarios que se pueden hacer son los mismos que para la transición

\footnotetext{
${ }^{6}$ Hay que recordar que en esta tesis la transición escolar viene definida por la variable de la ECV, de estar en un plan formativo, con independencia de si se está refiriendo a una enseñanza formal o no formal.

${ }^{7}$ Se recuerda que esta transición viene definida por la variable activos, y son considerados activos quienes trabajan o quieren hacerlo, por tanto, también quienes están en paro.
} 
escolar. El periodo en el que se produce la transición residencial es sustancialmente más corto que las transiciones anteriores e igualmente presenta diferencias por sexo y coyuntura económica. En las mujeres comienza a producirse la transición residencial un año antes que entre los varones y se retrasa un año, tanto en varones como en mujeres, entre el año 2007 y el año 2015. La crisis habría retrasado ligeramente el comienzo de la transición residencial. La transición ha la vida en pareja se comienza a producir dos años antes en las mujeres que en los varones y la crisis económica habría retrasado el comienzo de esta transición dos años para los varones y uno para las mujeres. La transición parental se comienza a producir entre uno y dos años antes en las mujeres que en los varones; para estos últimos no se observa cambio alguno por periodos, pero sí para las mujeres, que retrasarían en uno o dos años el comienzo de esta transición en el año 2015 respecto al 2007 y al 2011.

Tabla 4.1. Duración de las diferentes transiciones por sexo y coyuntura económica.

\begin{tabular}{|c|c|c|c|c|c|c|c|c|c|c|c|c|c|c|c|c|c|c|c|c|}
\hline & & & 17 & 18 & 19 & 20 & 21 & 22 & 23 & 24 & 25 & 26 & 27 & 28 & 29 & 30 & 31 & 32 & 33 & 34 \\
\hline \multirow{6}{*}{$\begin{array}{c}\text { Duración de } \\
\text { la transición } \\
\text { escolar }\end{array}$} & \multirow{3}{*}{ Varones } & 2007 & & & & & & & & & & & & & & & & & & \\
\hline & & 2011 & & & & & & & & & & & & & & & & & & \\
\hline & & 2015 & & & & & & & & & & & & & & & & & & \\
\hline & \multirow{3}{*}{ Mujeres } & 2007 & & & & & & & & & & & & & & & & & & \\
\hline & & 2011 & & & & & & & & & & & & & & & & & & \\
\hline & & 2015 & & & & & & & & & & & & & & & & & & \\
\hline & & & 17 & 18 & 19 & 20 & 21 & 22 & 23 & 24 & 25 & 26 & 27 & 28 & 29 & 30 & 31 & 32 & 33 & 34 \\
\hline \multirow{6}{*}{$\begin{array}{c}\text { Duración de } \\
\text { la transición } \\
\text { laboral }\end{array}$} & \multirow{3}{*}{ Varones } & 2007 & & & & & & & & & & & & & & & & & & \\
\hline & & 2011 & & & & & & & & & & & & & & & & & & \\
\hline & & 2015 & & & & & & & & & & & & & & & & & & \\
\hline & \multirow{3}{*}{ Mujeres } & 2007 & & & & & & & & & & & & & & & & & & \\
\hline & & 2011 & & & & & & & & & & & & & & & & & & \\
\hline & & 2015 & & & & & & & & & & & & & & & & & & \\
\hline & & & 17. & 18 & 19 & 20 & 21 & 22 & 23 & 24 & 25 & 26 & 27 & 28 & 29 & 30 & 31 & 32 & 33 & 34 \\
\hline \multirow{7}{*}{$\begin{array}{l}\text { Duración de } \\
\text { la transición } \\
\text { residencial }\end{array}$} & \multirow{3}{*}{ Varones } & 2007 & & & & & & & & & & & & & & 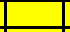 & & & & \\
\hline & & 2011 & & & & & & & & & & & & & & & & & & \\
\hline & & 2015 & & & & & & & & & & & & & & & & & & \\
\hline & \multirow{3}{*}{ Mujeres } & 2007 & & & & & & & & & & & & & & & & & & \\
\hline & & 2011 & & & & & & & & & & & & & & & & & & \\
\hline & & 2015 & & & & & & & & & & & & & & & & & & \\
\hline & & & 17 & 18 & 19 & 20 & 21 & 22 & 23 & 24 & 25 & 26 & 27 & 28 & 29 & 30| & 31 & 32 & 33. & 34 \\
\hline \multirow{6}{*}{$\begin{array}{c}\text { Duración de } \\
\text { la transición } \\
\text { conyugal }\end{array}$} & \multirow{3}{*}{ Varones } & 2007 & & & & & & & & & & & & & & & & & & \\
\hline & & 2011 & & & & & & & & & & & & & & & & & & \\
\hline & & 2015 & & & & & & & & & & & & & & & & & & \\
\hline & \multirow{3}{*}{ Mujeres } & 2007 & & & & & & & & & & & & & & & & & & \\
\hline & & 2011 & & & & & & & & & & & & & & & & & & \\
\hline & & 2015 & & & & & & & & & & & & & & & & & & \\
\hline \multirow{6}{*}{$\begin{array}{c}\text { Duración de } \\
\text { la transición } \\
\text { parental }\end{array}$} & \multirow{3}{*}{ Varones } & & 17 . & 18 & 19 & 20 & 21] & 22 & 23 & 24 & 25! & 26] & 27| & 28 & 29) & 30| & 31 & 32 & 33) & 34 \\
\hline & & 2007 & & & & & & & & & & & & & & 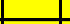 & & & & \\
\hline & & 20011 & & & & & & & & & & & & & & & & & & \\
\hline & \multirow{3}{*}{ Mujeres } & 2007 & & & & & & & & & & & & & & & & & & \\
\hline & & 2011 & & & & & & & & & & & & & & & & & & \\
\hline & & 2015 & & & & & & & & & & & & & & & & & & \\
\hline
\end{tabular}

Fuente: elaboración propia con datos de la ECV. 
En la tabla 4.2 se presenta el comienzo y final de cada una de las transiciones según el riesgo de pobreza del hogar y se observan diferencias más acentuadas que cuando se ha comparado por sexo. Con relación a la transición escolar, habría una diferencia en el comienzo de esta transición de hasta tres años entre quienes viven en riesgo de pobreza y quienes no. Por otra parte, la crisis económica habría modificado sustancialmente el momento de comienzo de la transición en los hogares sin riesgo de pobreza, retrasando el comienzo y el término de este proceso, pero no habría sufrido cambios significativos el colectivo que vive en hogares en riesgo de pobreza. La transición laboral, también en este caso, se produciría en el mismo momento que la escolar, por lo que las pautas de comienzo y término son básicamente las mismas, como es posible apreciar en el sombreado de la tabla. La transición residencial se comienza a producir dos o tres años antes entre aquellos con malas condiciones económicas respecto de los que disfrutan de buenas condiciones; por otra parte, mientras la crisis económica habría retrasado en un año el comienzo de esta transición para los que tienen buenas condiciones económicas, para aquellos que viven en riesgo de pobreza se produce lo contrario, es decir, se adelanta en uno o dos años el comienzo de la transición. El análisis que es posible realizar para las transiciones de vida en pareja y parental se produce en la misma línea, las transiciones comienzan a producirse dos o tres años antes entre quienes tienen peores condiciones económicas, no modificándose esta tendencia en crisis o salida de la crisis e incluso adelantando en un año la transición, como es el caso de la parental en el año 2015 respecto del 2007 y el 2011; entre los que tienen buenas condiciones económicas se observa un retraso en el comienzo de las transiciones entre el año 2007 y el año 2015. 
Tabla 4.2. Duración de las diferentes transiciones según exista o riesgo de pobreza en el hogar.

\begin{tabular}{|c|c|c|c|c|c|c|c|c|c|c|c|c|c|c|c|c|c|c|c|c|}
\hline & & & 17] & & 8 & $\begin{array}{ll}19 & 20 \\
\end{array}$ & 21 & $1 \quad 22$ & 23 & 24 & 25 & 26 & \begin{tabular}{|r|}
27 \\
\end{tabular} & \begin{tabular}{|r|}
28 \\
\end{tabular} & \begin{tabular}{|r|}
29 \\
\end{tabular} & \begin{tabular}{|l|} 
\\
\end{tabular} & 31 & $1 \quad 32$ & \begin{tabular}{|r|}
33 \\
\end{tabular} & \begin{tabular}{|r|}
34 \\
\end{tabular} \\
\hline \multirow{6}{*}{$\begin{array}{c}\text { Duración de } \\
\text { la transición } \\
\text { escolar } \\
\end{array}$} & \multirow{3}{*}{$\begin{array}{l}\text { Sin riesgo } \\
\text { de pobreza }\end{array}$} & 2007 & & & & & & & & & & & & & & & & & & \\
\hline & & 2011 & & & & & & & & & & & & & & & & & & \\
\hline & & 2015 & & & & & & & & & & & & & & & & & & \\
\hline & \multirow{3}{*}{$\begin{array}{l}\text { Con riesgo } \\
\text { de pobreza }\end{array}$} & 2007 & & & & & & & & & & & & & & & & & & \\
\hline & & 2011 & & & & & & & & & & & & & & & & & & \\
\hline & & 2015 & & & & & & & & & & & & & & & & & & \\
\hline & & & 17 & 18 & 8 & 19 & 21 & 22 & 23 & 24 & 25 & 26 & 27 & 28 & 29 & 30 & 31 & 32 & 33 & 34 \\
\hline \multirow{5}{*}{$\begin{array}{c}\text { Duración de } \\
\text { la transición } \\
\text { laboral } \\
\end{array}$} & \multirow{5}{*}{$\begin{array}{l}\text { Sin riesgo } \\
\text { de pobreza } \\
\text { Con riesgo } \\
\text { de pobreza }\end{array}$} & 2007 & & & & & & & & & & & & & & & & & & \\
\hline & & 2011 & & & & & & & & & & & & & & & & & & \\
\hline & & 2015 & & & & & & & & & & & & & & & & & & \\
\hline & & 2011 & & & & & & & & & & & & & & & & & & \\
\hline & & 2015 & & & & & & & & & & & & & & & & & & \\
\hline & & & 17 & 18 & 8 & 19 & 20 & 22 & 23 & 24 & 25 & 26 & 27 & 28 & 29 & 30 & & & & 3 \\
\hline \multirow{6}{*}{$\begin{array}{l}\text { Duración de } \\
\text { la transición } \\
\text { residencial } \\
\end{array}$} & \multirow{5}{*}{$\begin{array}{l}\text { Sin riesgo } \\
\text { de pobreza } \\
\text { Con riesgo } \\
\text { de pobreza }\end{array}$} & 2007 & & & & & & & & & & & & & & & & & & \\
\hline & & 2011 & & & & & & & & & & & & & & & & & & \\
\hline & & 2015 & & & & & & & & & & & & & & & & & & \\
\hline & & 2007 & & & & & & & & & & & & & & & & & & \\
\hline & & 2015 & & & & & & & & & & & & & & & & & & \\
\hline & & & 17 & & & & 20 & 22 & 23 & 24 & & 26 & 27 & 28 & 29 & & 311 & & 33 & 34 \\
\hline \multirow{5}{*}{$\begin{array}{c}\text { Duración de } \\
\text { la transición } \\
\text { conyugal } \\
\end{array}$} & \multirow{5}{*}{$\begin{array}{l}\text { Sin riesgo } \\
\text { de pobreza } \\
\text { Con riesgo } \\
\text { de pobreza }\end{array}$} & 2007 & & & & & & & & & & & & & & & & & & \\
\hline & & 2011 & & & & & & & & & & & & & & & & & & \\
\hline & & 2015 & & & & & & & & & & & & & & & & & & \\
\hline & & $\begin{array}{l}2000 \\
20\end{array}$ & & & & & & & & & & & & & & & & & & \\
\hline & & 2015 & & & & & & & & & & & & & & & & & & \\
\hline \multirow{7}{*}{$\begin{array}{c}\text { Duración de } \\
\text { la transición } \\
\text { parental }\end{array}$} & & & & & & 20 & 20 & 22 & 23 & 24 & 25 & 26 & 27 & 28 & & & & & 33 & 34 \\
\hline & \multirow{6}{*}{$\begin{array}{l}\text { Sin riesgo } \\
\text { de pobreza } \\
\text { Con riesgo } \\
\text { de pobreza }\end{array}$} & 2007 & & & & & & & & & & & & & & & & & & \\
\hline & & 2011 & & & & & & & & & & & & & & & & & & \\
\hline & & 2015 & & & & & & & & & & & & & & & & & & \\
\hline & & 2007 & & & & & & & & & & & & & & & & & & \\
\hline & & 2011 & & & & & & & & & & & & & & & & & & \\
\hline & & 2015 & & & & & & & & & & & & & & & & & & \\
\hline
\end{tabular}

Fuente: elaboración propia con datos de la ECV.

En la tabla 4.3 se presentan las diferencias en el comienzo y el término de las transiciones por tipo de hábitat donde se reside, es decir, que este sea urbano o rural, y para los años 2007, 2011 y 2015, como en los análisis anteriores. Para esta comparación el único dato que se ha observado relevante es el adelanto de la transición escolar de un año en el medio rural respecto del urbano. Para el resto de las transiciones no se observan diferencias en la duración de estos procesos por tipo de hábitat, sí teniendo en cuenta los periodos de referencia, constatándose el retraso de un año en el comienzo de las transiciones en crisis respecto del periodo que representa aún una buena coyuntura económica. 
Tabla 4.3. Duración de las diferentes transiciones según el grado de urbanización del lugar donde viven.

\begin{tabular}{|c|c|c|c|c|c|c|c|c|c|c|c|c|c|c|c|c|c|c|c|c|}
\hline & & & 17| & 18 & 19 & 20 & 21 & 22 & 23 & 24 & 25 & 26 & 27| & 28 & 29 & 30 & 31 & 32 & & 34 \\
\hline \multirow{5}{*}{$\begin{array}{c}\text { Duración de } \\
\text { la transición } \\
\text { escolar }\end{array}$} & \multirow{3}{*}{$\begin{array}{l}\text { Hábitat } \\
\text { urbano }\end{array}$} & 2007 & & & & & & & & & & & & & & & & & & \\
\hline & & 2011 & & & & & & & & & & & & & & & & & & \\
\hline & & 2015 & & & & & & & & & & & & & & & & & & \\
\hline & \multirow{3}{*}{ Hábitat rural } & 2007 & & & & & & & & & & & & & & & & & & \\
\hline & & 2011 & & & & & & & & & & & & & & & & & & \\
\hline & & 2015 & 17 & & & & & & & & & & & & 291 & & & & & \\
\hline \multirow{6}{*}{$\begin{array}{c}\text { Duración de } \\
\text { la transición } \\
\text { laboral }\end{array}$} & \multirow{3}{*}{$\begin{array}{l}\text { Hábitat } \\
\text { urbano }\end{array}$} & 2007 & & & & & & & & & & & & & & & & & & \\
\hline & & 2011 & & & & & & & & & & & & & & & & & & \\
\hline & & 2015 & & & & & & & & & & & & & & & & & & \\
\hline & \multirow{3}{*}{ Hábitat rural } & 2007 & & & & & & & & & & & & & & & & & & \\
\hline & & 2011 & & & & & & & & & & & & & & & & & & \\
\hline & & 2015 & & & & & & & & & & & & & & & & & & \\
\hline & & & 17) & 18 & 19 & 20 & 21 & 22 & 23 & 24 & 25 & 26 & 27) & 28 & 29 & 30 & 31 & 32 & 33 & 34 \\
\hline \multirow{5}{*}{$\begin{array}{l}\text { Duración de } \\
\text { la transición } \\
\text { residencial }\end{array}$} & \multirow{3}{*}{$\begin{array}{l}\text { Hábitat } \\
\text { urbano }\end{array}$} & 2007 & & & & & & & & & & & & & & & & & & \\
\hline & & 2011 & & & & & & & & & & & & & & & & & & \\
\hline & & 2015 & & & & & & & & & & & & & & & & & & \\
\hline & \multirow{2}{*}{ Hábitat rural } & 2007 & & & & & & & & & & & & & & & & & & \\
\hline & & $\frac{2011}{2015}$ & & & & & & & & & & & & & & & & & & \\
\hline & & & 17 & 18 & 19 & 20 & 21 & 22 & 23 & 24 & 25 & 26 & 27 & 28 & 29 & 30 & 31 & 32 & 33 & 34 \\
\hline \multirow{5}{*}{$\begin{array}{c}\text { Duración de } \\
\text { la transición } \\
\text { conyugal } \\
\end{array}$} & \multirow{3}{*}{$\begin{array}{l}\text { Hábitat } \\
\text { urbano }\end{array}$} & 2007 & & & & & & & & & & & & & & & & & & \\
\hline & & 2011 & & & & & & & & & & & & & & & & & & \\
\hline & & 2015 & & & & & & & & & & & & & & & & & & \\
\hline & \multirow{2}{*}{ Hábitat rural } & 2007 & & & & & & & & & & & & & & & & & & \\
\hline & & $\frac{2011}{2015}$ & & & & & & & & & & & & & & & & & & \\
\hline & & & 17 & 18 & 19 & 20 & 211 & 22 & 23 & 24 & 25 & 26 & 27 & 28 & 29 & 30 & 31 & 32 & 33 & 34 \\
\hline \multirow{5}{*}{$\begin{array}{l}\text { Duración de } \\
\text { la transición } \\
\text { parental }\end{array}$} & \multirow{3}{*}{$\begin{array}{l}\text { Hábitat } \\
\text { urbano }\end{array}$} & 2007 & & & & & & & & & & & & & & & & & & \\
\hline & & 2011 & & & & & & & & & & & & & & & & & & \\
\hline & & 2015 & & & & & & & & & & & & & & & & & & \\
\hline & \multirow{2}{*}{ Hábitat rural } & $\frac{2007}{2011}$ & & & & & & & & & & & & & & & & & & \\
\hline & & 2015 & & & & & & & & & & & & & & & & & & \\
\hline
\end{tabular}

Fuente: elaboración propia con datos de la ECV.

\subsection{Los cambios en la edad media a la que se experimenta cada transición}

Por último, en este apartado se presenta la edad media a la que se producen las respectivas transiciones para el colectivo que se está estudiando, los jóvenes de entre 17 y 34 años de edad. En el gráfico 4.16 se representan las secuencias desde el año 2007 hasta el año 2015, y el cambio más evidente es el aumento de casi un año en la edad a la que se producen la transición escolar y la transición laboral. Esta información estaría claramente relacionada con el incremento del tiempo de formación y las dificultades de incorporación al mercado laboral durante los años de crisis económica. Por otra parte, las transiciones residencial, 
de vida en pareja $^{8}$ y parental no experimentan un cambio apreciable, aunque sí una tendencia al retraso en producirse estos sucesos. De las tres transiciones, la que corresponde con la vida en pareja es la que experimentaría un retraso mayor, de medio año. En los apartados anteriores se ha comprobado cómo la crisis económica no ha influido decisivamente en las pautas de emancipación residencial y creación de nuevos núcleos familiares tanto como cabría esperar, que las diferencias entre los jóvenes estarían más centradas en las diferencias por sexo e incluso, como en adelante se comprobará, por pertenecer o no a un hogar en riesgo de pobreza.

Gráfico 4.16. Edad media a la que se producen las respectivas transiciones para los jóvenes de entre 17 y 34 años de edad.

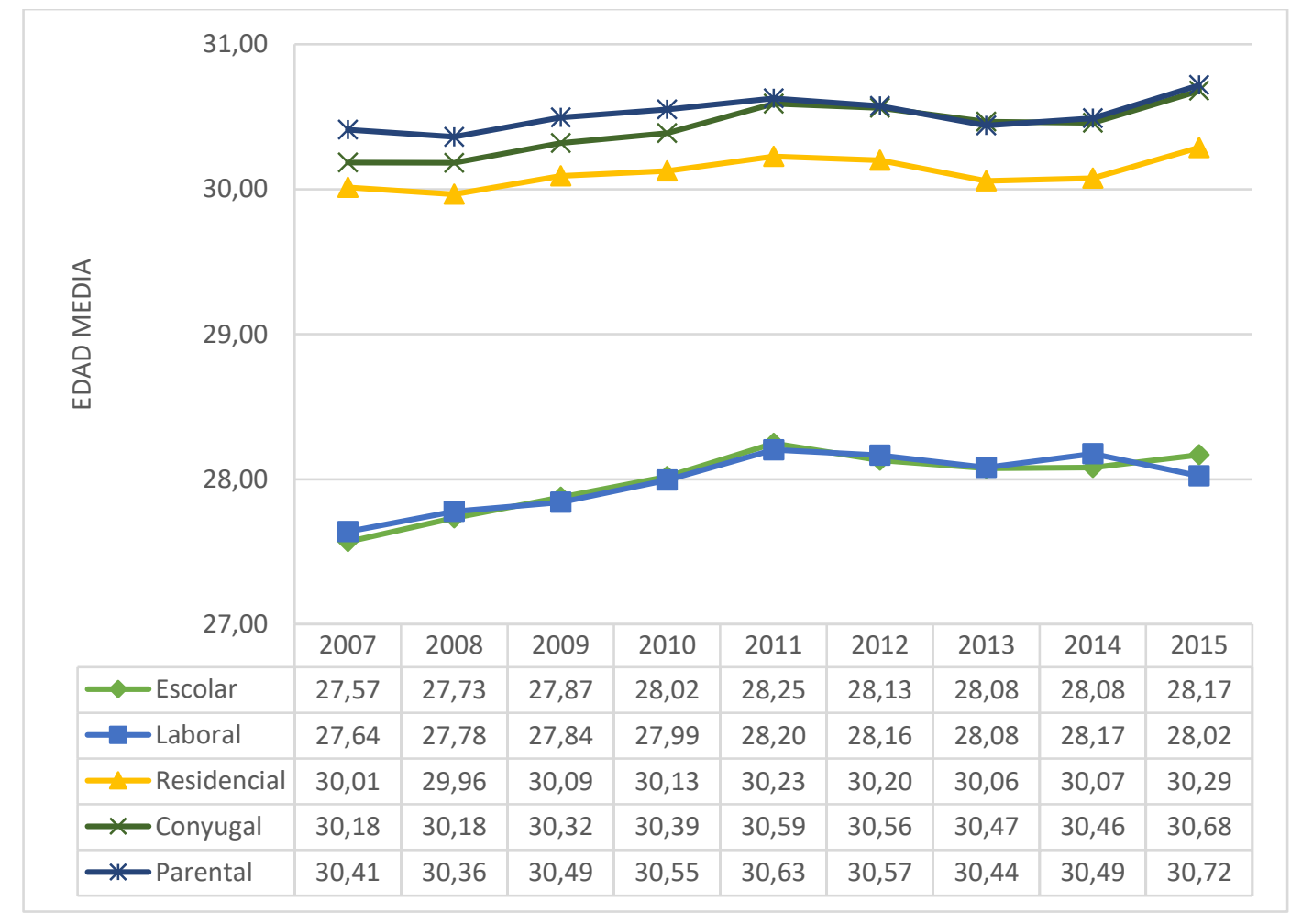

Fuente: elaboración propia con datos de la ECV.

\footnotetext{
${ }^{8}$ En los gráficos aparece definida la transición de vida en pareja como transición conyugal por simplificar el texto, si bien en todo momento hace referencia no solo a la vida en pareja como cónyuges, también a cualquier tipo de pareja de hecho, con o sin base jurídica.
} 
En el gráfico 4.17 se presenta la edad media a la que se producen las respectivas transiciones en un periodo desde 2007 al 2015, pero en años alternos y comparándolas por sexo. La lectura más evidente que es posible hacer es la misma que para el gráfico anterior, es decir, el ligero aumento progresivo de la edad media a la que se producen las transiciones desde el comienzo de la crisis hasta la salida de esta, y especialmente en las transiciones escolar y laboral. En este gráfico se comparan ambos sexos y se observa con claridad cómo, por una parte, las transiciones escolar y laboral coinciden y cómo las mujeres tienen una edad media mayor en 0,3 años que los varones. La edad media, tanto de las mujeres como de los varones, habría subido un año hasta el 2013, con tendencia a bajar en el año 2015 para ambas transiciones. Con relación a la transición residencial, se observa una diferencia entre ambos sexos en la edad media de 0,5 años más para las mujeres que para los varones en todo el periodo, y habría aumentado la edad media medio año para ambos sexos, con una edad media de 30,9 años en varones y de 30,5 años en mujeres. Para la edad media en las transiciones de vida en pareja y parental se observa una diferencia entre los varones y mujeres de un año más para los varones y con un aumento en todo el periodo de medio año aproximadamente para ambos sexos. 
Gráfico 4.17. Edad media a la que se producen las respectivas transiciones por sexo.

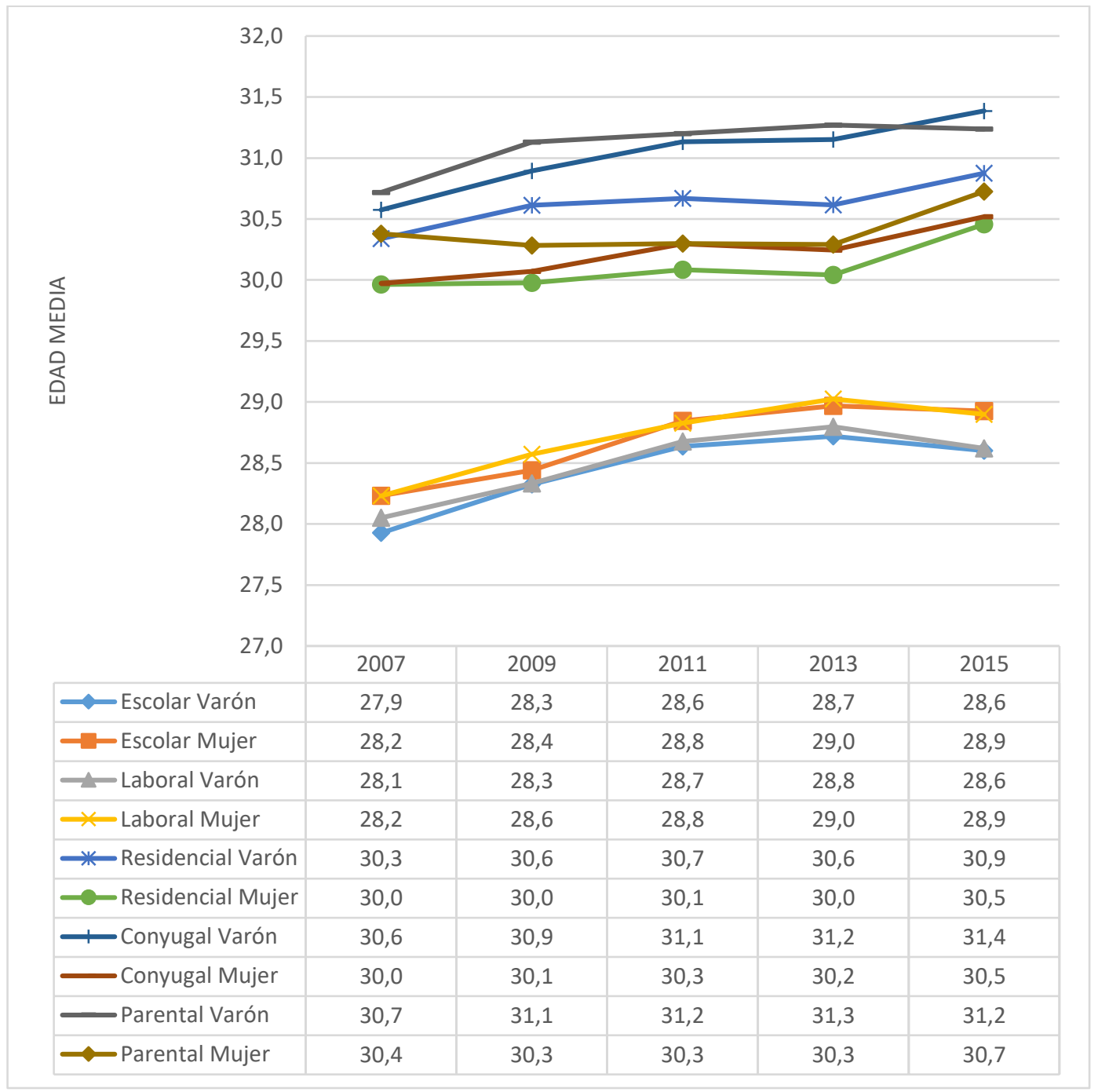

Fuente: elaboración propia con datos de la ECV.

El riesgo de pobreza, una vez más, es el elemento que más influencia tiene en las diferencias según los análisis que se vienen efectuando hasta ahora. En el gráfico 4.18 se muestra la edad media a la que se produciría la transición según el riesgo de pobreza, y la información que más llama la atención es la diferencia en las transiciones escolar y laboral, ya que en el 2007, año aún con buenas condiciones económicas en España, la diferencia entre la edad media para ambas transiciones fue de un año más entre quienes 
proceden de un entorno con normales o buenas condiciones económicas y los que sufren malas condiciones económicas, 28,2 años y 27,2 años, respectivamente. La crisis económica ahondaría en esta diferencia, con una edad media en las transiciones escolar y laboral para los que no están en riesgo de pobreza y sí lo están de dos años en 2015: 29,3 años y 27,3 años, respectivamente. Para las transiciones residencial, de vida en pareja y parental, entre aquellos que no presentan riesgo de pobreza se observa en todo el periodo de referencia una diferencia de un año más con respecto a los que sí tienen riesgo de pobreza. Las diferencias con las transiciones escolar y laboral están en que en el periodo de crisis no se incrementa esta diferencia, se mantiene estable, con una tendencia ascendente en la edad media en todas las transiciones y en las dos categorías de unos 0,5 años en la edad media a la que se producen estos sucesos entre el año 2007 y 2015. 
Gráfico 4.18. Edad media a la que se producen las respectivas transiciones según el riesgo de pobreza del hogar.

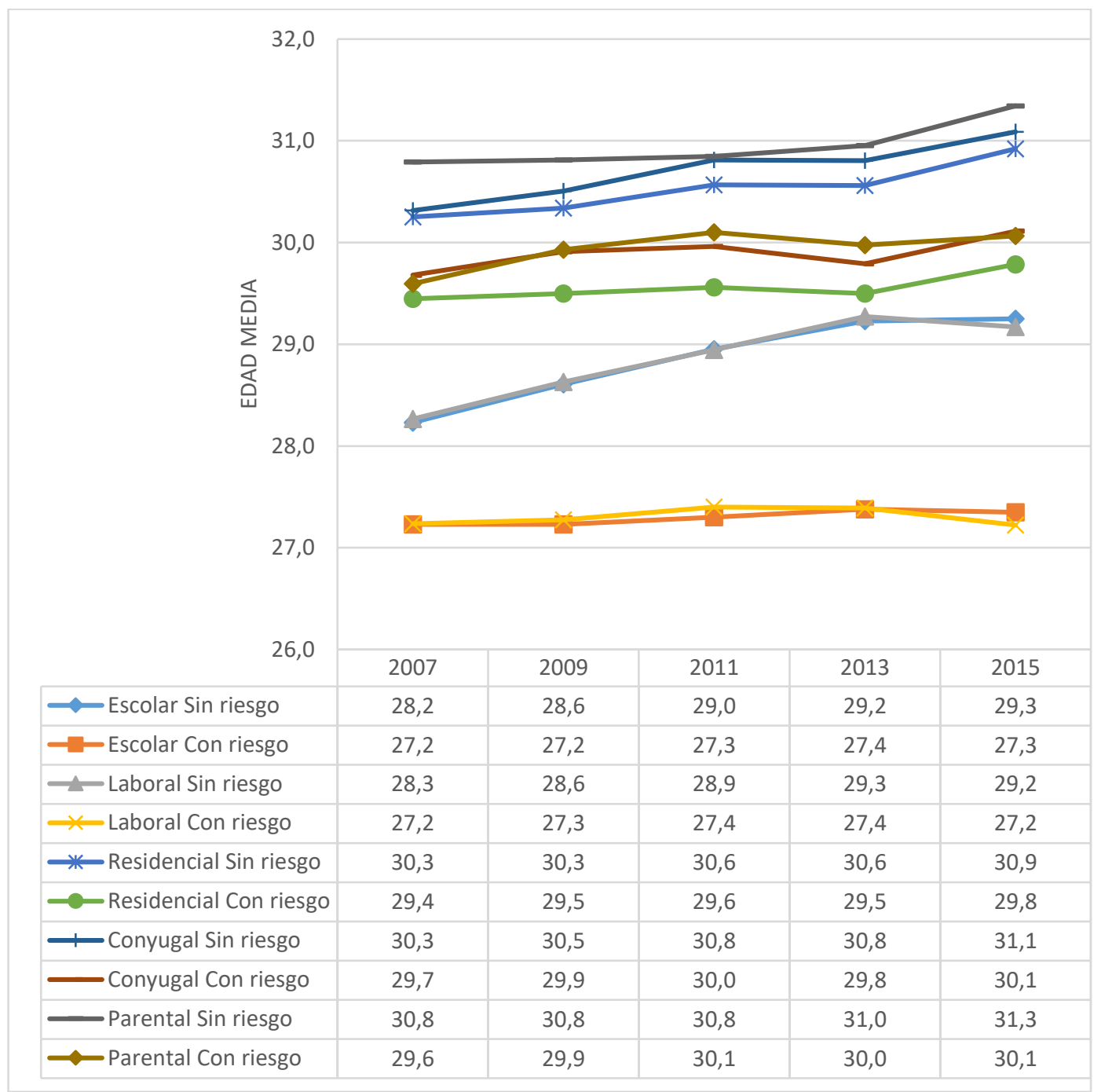

Fuente: elaboración propia con datos de la ECV.

La edad media en la que se produce la transición escolar y laboral es de medio año más para quienes viven en un hábitat urbano frente a quienes viven en el medio rural, no presentando diferencias apreciables entre los años que están sirviendo de referencia, si bien desde el comienzo de la crisis y hasta el momento de la salida de la crisis, representados por los años 2007 y 2015, se produce un aumento de la edad media en 
ambos tipos de hábitat, de entre 0,7 y 0,8 años para las transiciones escolar y laboral. Con relación al resto de las transiciones, no se observa una diferencia que merezca atención, pero sí es posible advertir la tendencia a aumentar la edad media en todas estas transiciones desde el año 2007 al año 2015 entre 0,5 a 0,8 años, dependiendo de la transición y la categoría.

Gráfico 4.19. Edad media a la que se producen las respectivas transiciones según el grado de urbanización del hábitat donde se reside.

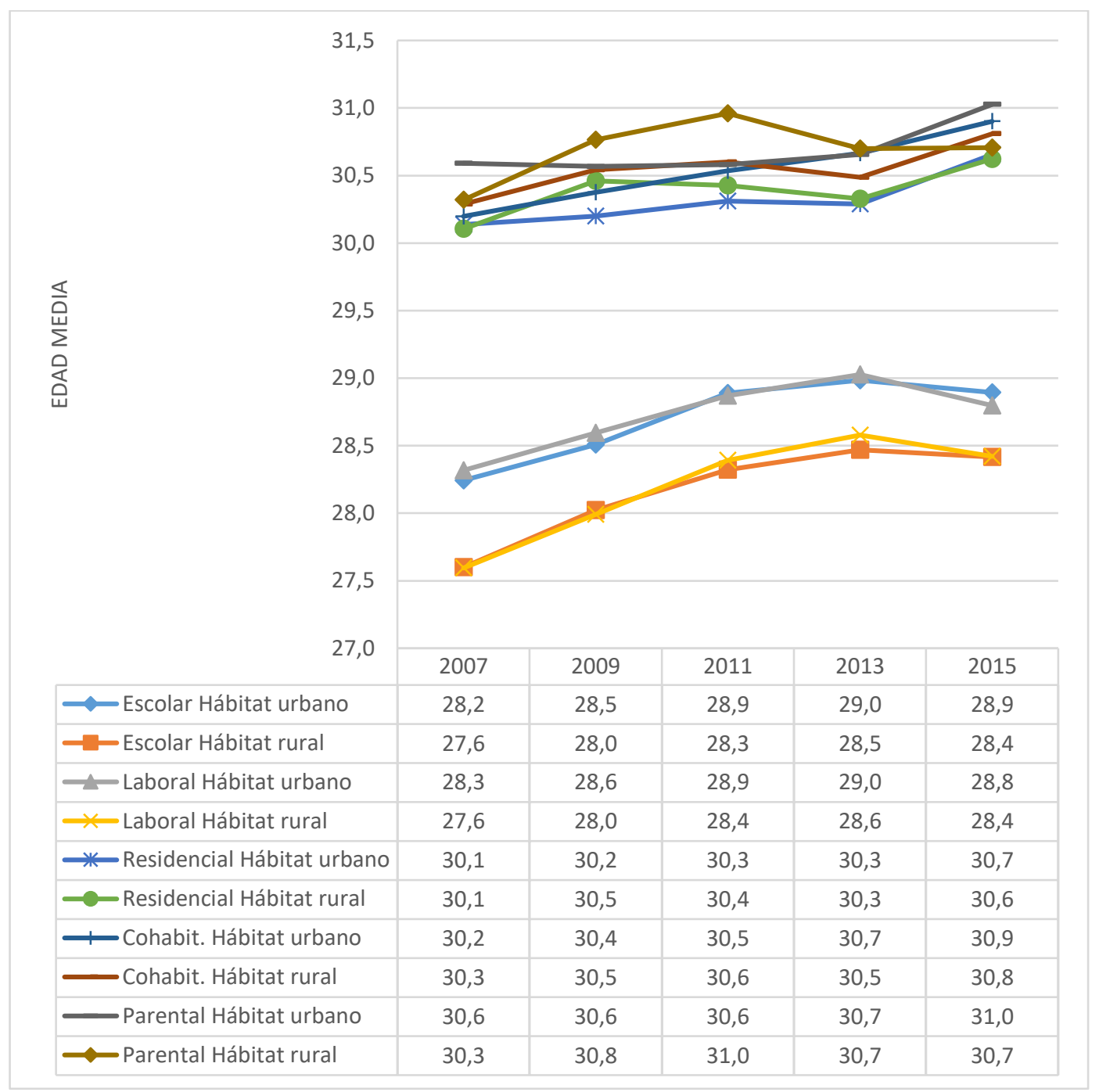

Fuente: elaboración propia con datos de la ECV. 
Los análisis realizados en este epígrafe apuntan claramente hacia un aumento en la edad media en todas las transiciones desde el año 2007 al año 2015. Este aumento dependería de las variables independientes que se consideren y sería especialmente llamativo en las transiciones escolar y laboral, con aumentos de un año en la edad media de estas transiciones e incremento de las diferencias cuando se cruza la variable riesgo de pobreza de dos años más de edad media entre quienes no tienen y sí tienen riesgo de pobreza. Por sexo, la edad media de las mujeres es ligeramente mayor que la de los varones en las transiciones escolar y laboral y mucho más acusada si nos referimos al resto de las transiciones, con diferencias en torno a medio año para la transición residencial y de casi uno para la conyugal. Resulta llamativo el comportamiento de quienes viven en riesgo de pobreza respecto de las transiciones escolar y laboral, pues estos no presentan ninguna variación en toda la secuencia, con la misma edad media antes, durante y en la salida de la crisis.

\section{Edad media a la que se producen las transiciones por comunidades autónomas}

En las tablas que se presentan a continuación se ofrecen las edades medias para cada una de las transiciones que se vienen describiendo para el año 2007, que representaría el momento previo a la crisis económica, para el año 2011, que representaría el periodo central de la crisis económica, y para el año 2015, año que representaría el momento de la salida de la crisis económica, y cruzando los datos por comunidades autónomas. Se ha decidido incluir este epígrafe una vez realizados algunos análisis previos y después de observar las diferencias tan notables que existen en cuanto a la evolución de la edad media a las transiciones en las distintas comunidades autónomas.

En la tabla 4.4 se presenta la edad media a la que se produce la transición escolar, y aunque en su conjunto se puede observar cómo se produciría un aumento de en torno a 
un año entre el momento previo a la crisis y en la postcrisis económica, dato que ya ha sido ofrecido en anteriores análisis, las diferencias son muy llamativas por comunidades autónomas. Si se excluyen las ciudades autónomas por su poca relevancia cuantitativa, sería posible establecer a priori dos categorías: comunidades ricas y comunidades pobres. Entre las primeras, Madrid, País Vasco, Cataluña, Navarra o Valencia experimentan un aumento en la edad media en la transición escolar de $0,7,0,9,0,7,1,3$ y 1, respectivamente, mientras en el segundo grupo, en comunidades como Galicia, Asturias, Aragón, Castilla-La Mancha o Andalucía se incrementa la edad media en la transición escolar 0,3, 0,2, 0,3, 0,3, 0,3 y 0,6, respectivamente. La crisis económica afectaría menos a esta transición en las comunidades más pobres, produciéndose cierta analogía con los datos presentados en otros epígrafes y capítulos de esta tesis, según los cuales la crisis habría afectado en menor media a aquellos que viven en riesgo de pobreza. Los análisis ofrecerían esta información, si bien las edades medias a las que se produce la transición escolar siempre son mayores para las comunidades más ricas, lo que indicaría un periodo mayor de la etapa formativa. Esta generalidad no se produce con exactitud, pues comunidades autónomas con similares características sociodemográficas y socioeconómicas, como Castilla y León y Castilla-La Mancha, presentan diferencias entre el periodo previo y posterior a la crisis de 1,5 y 0,3 años, respectivamente. Para la transición laboral, que se presenta en la tabla 4.5, resulta mucho más complicado el crear categorías, lo que caracteriza a esta tabla son las diferencias entre comunidades autónomas en la edad de la transición laboral, pero sin sentido aparente, sería necesario un estudio específico de esta apreciación, que no es el objeto de esta tesis; sí que lo es el poner de manifiesto las diferencias y datos como que en Aragón se mantiene la misma edad media en esta transición antes, durante y en la salida de la crisis, o que en Extremadura se incrementa en 1,8 años, o que en las islas Baleares disminuye en tres 
décimas; estos indicadores ponen nuevamente de manifiesto las diferencias, en este caso por territorios.

Tabla 4.4. Edad media en la transición escolar por CC. AA.

\begin{tabular}{|c|c|c|c|c|}
\hline & 2007 & 2011 & 2015 & $\begin{array}{l}\text { Diferencia } \\
\text { precrisis y } \\
\text { postcrisis }\end{array}$ \\
\hline Galicia & 28,3 & 28,9 & 28,6 & 0,3 \\
\hline Principado de Asturias & 28,7 & 29,2 & 28,8 & 0,2 \\
\hline Cantabria & 28,4 & 29,2 & 29,6 & 1,2 \\
\hline País Vasco & 29,0 & 29,6 & 29,9 & 0,9 \\
\hline Comunidad Foral de Navarra & 28,2 & 29,4 & 29,5 & 1,3 \\
\hline La Rioja & 27,6 & 28,9 & 27,8 & 0,2 \\
\hline Aragón & 29,0 & 29,0 & 29,3 & 0,3 \\
\hline Comunidad de Madrid & 28,5 & 28,9 & 29,2 & 0,7 \\
\hline Castilla y León & 27,7 & 29,0 & 29,2 & 1,5 \\
\hline Castilla-La Mancha & 27,7 & 28,5 & 28,0 & 0,3 \\
\hline Extremadura & 27,2 & 28,6 & 28,8 & 1,7 \\
\hline Cataluña & 28,2 & 28,8 & 28,9 & 0,7 \\
\hline Comunidad Valenciana & 28,1 & 28,7 & 29,1 & 1,0 \\
\hline Illes Balears & 27,9 & 28,3 & 27,7 & $-0,2$ \\
\hline Andalucía & 27,6 & 28,3 & 28,2 & 0,6 \\
\hline Región de Murcia & 27,7 & 28,3 & 28,0 & 0,3 \\
\hline Ciudad Autónoma de Ceuta & 27,1 & 27,6 & 28,2 & 1,1 \\
\hline Ciudad Autónoma de Melilla & 26,4 & 29,4 & 28,8 & 2,4 \\
\hline Canarias & 27,8 & 28,7 & 28,8 & 1,1 \\
\hline
\end{tabular}

Fuente: elaboración propia con datos de la ECV. 
Tabla 4.5. Edad media en la transición laboral por CC. AA.

\begin{tabular}{|c|c|c|c|c|}
\hline & 2007 & 2011 & 2015 & $\begin{array}{l}\text { Diferencia } \\
\text { precrisis y } \\
\text { postcrisis }\end{array}$ \\
\hline Galicia & 28,4 & 28,8 & 28,8 & 0,4 \\
\hline Principado de Asturias & 28,9 & 29,1 & 28,9 & 0,0 \\
\hline Cantabria & 28,3 & 28,9 & 29,3 & 1,0 \\
\hline País Vasco & 29,0 & 29,6 & 29,9 & 0,9 \\
\hline Comunidad Foral de Navarra & 28,5 & 29,3 & 29,4 & 0,8 \\
\hline La Rioja & 28,0 & 28,6 & 27,8 & $-0,1$ \\
\hline Aragón & 29,1 & 29,1 & 29,1 & 0,0 \\
\hline Comunidad de Madrid & 28,5 & 28,8 & 28,9 & 0,4 \\
\hline Castilla y León & 27,8 & 29,1 & 29,2 & 1,4 \\
\hline Castilla-La Mancha & 27,6 & 28,6 & 28,0 & 0,5 \\
\hline Extremadura & 27,0 & 28,6 & 28,9 & 1,8 \\
\hline Cataluña & 28,3 & 28,8 & 28,7 & 0,5 \\
\hline Comunidad Valenciana & 28,1 & 28,7 & 28,9 & 0,8 \\
\hline Illes Balears & 28,6 & 28,5 & 28,3 & $-0,3$ \\
\hline Andalucía & 27,6 & 28,4 & 28,2 & 0,7 \\
\hline Región de Murcia & 27,8 & 28,2 & 28,1 & 0,3 \\
\hline Ciudad Autónoma de Ceuta & 27,7 & 27,3 & 28,1 & 0,4 \\
\hline Ciudad Autónoma de Melilla & 27,5 & 29,7 & 28,7 & 1,1 \\
\hline Canarias & 27,9 & 29,1 & 28,6 & 0,7 \\
\hline
\end{tabular}

Fuente: elaboración propia con datos de la ECV.

Para el resto de las transiciones no ha sido posible ofrecer los datos de las edades medias por CC. AA. por el bajo número de casos que han concluido estos eventos en el intervalo de edad que está siendo objeto de estudio, 17-34 años, lo que provoca, aun utilizando el factor de ponderación que la ECV ofrece, una distorsión evidente de los resultados. 


\section{CAPÍTULO 5. LOS FACTORES DETERMINANTES EN LA PROBALBILIDAD \\ DE LA OCURRENCIA DE UN EVENTO DE TRANSICIÓN DESDE UN MODELO MULTIVARIANTE}

En los capítulos anteriores se han descrito algunas de las variables que más influencia tienen en las diferencias entre los jóvenes, como el nivel de estudios terminados, el tipo de ocupación, el momento de la emancipación residencial, etc., y las diferencias en cada una de las transiciones que desde una perspectiva sociológica definirían el tránsito hacia la adultez, la transición escolar, la transición laboral, la transición residencial, la transición conyugal o vida en pareja y la transición parental; se han considerado en los análisis habitualmente las variables independientes coyuntura económica, edad, sexo, estudios, riesgo de pobreza y tipo de hábitat (más o menos urbanizado). En estos análisis se ha puesto en evidencia las grandes diferencias que existen en un colectivo que a priori estaría definido por características comunes, pero en el que, como se ha puesto de manifiesto, las diferencias son sustanciales, en especial teniendo en cuenta el sexo y el riesgo de pobreza del hogar en el que se reside. En este capítulo se ofrecen cinco análisis de regresión logística multivariante, uno para cada una de las variables que definen las respectivas transiciones, con el fin de valorar si existe influencia estadísticamente significativa de las variables independientes que se han considerado en cada una de las transiciones. De la misma manera que en el resto de los capítulos anteriores, y también en el posterior, se evidenciarán nuevamente las diferencias entre los jóvenes, en este caso desde un modelo de análisis de regresión logística.

En el apartado metodológico se explica con más detalle el procedimiento seguido en el análisis y lo que aportaría cada uno de los indicadores obtenidos. Al respecto, únicamente recordar que la regresión logística ofrece la posibilidad de evaluar la influencia de cada 
una de las variables independientes sobre la variable dependiente. Por otra parte, hay que tener en cuenta que en la regresión logística se valora el peso predictivo de cada una de las variables independientes en la dependiente teniendo en cuenta todas las variables seleccionadas, la elección de estas variables está justificada en tanto que existe base teórica que aporta información suficiente en este sentido y, por otra parte, la información que han aportado los análisis descriptivos en los capítulos anteriores, donde ya se percibe la influencia de estas variables en los procesos de transición.

\subsection{Los factores que más influencia tienen en estar o no estar estudiando}

Como es lógico, la transición escolar tiene como principal condicionante la edad, algo ya valorado en los capítulos anteriores. De igual manera, se ha valorado la influencia que tiene el sexo, el riesgo de pobreza, la coyuntura económica, etc. A partir de un modelo de análisis de regresión logística, los resultados son diferentes, en tanto lo que se pretende es valorar objetivamente la probabilidad que tiene cada variable en la transición escolar, si bien las conclusiones son similares. Obviamente, a mayor edad la probabilidad de estar estudiando disminuye, mientras que ser mujer aumenta esta probabilidad con respecto a los hombres. Esta información ha sido contrastada reiteradamente: las mujeres, en especial en los rangos intermedios del colectivo que está siendo objeto de estudio, prolongan más su periodo formativo. Tener estudios secundarios o superiores aumenta la probabilidad de cursar algún tipo de estudios, parece lógico pensar que aquellos que tienen completados estudios secundarios continúen con algún plan formativo, pero es llamativo que aquellos que tienen estudios superiores continúen formándose, nuevamente hay que decir que es una información contrastada en los análisis descriptivos. Pertenecer a un hogar en riesgo de pobreza disminuye la posibilidad de estar estudiando, un dato 
también observado especialmente para las cohortes intermedias y de mayor edad, no así para los más jóvenes. En los años de crisis y postcrisis, la probabilidad de cursar algún tipo de estudios aumentó con respecto a los años anteriores a la crisis, las menores posibilidades de empleabilidad habrían favorecido la prolongación del periodo formativo. Con respecto al hábitat, vivir en un entorno urbano aumenta la probabilidad de estar estudiando con respecto a vivir en un entorno rural.

Tabla 5.1. Efecto de las variables sociodemográficas y socioeconómicas en estar estudiando.

\begin{tabular}{|c|c|c|c|c|c|}
\hline Variable & B (ET) & Wald & OR & IC95 \% OR & p-valor \\
\hline Edad & $-0,34(0,01)$ & 4600,04 & 0,71 & $0,70-0,72$ & $<0,001$ \\
\hline $\begin{array}{l}\text { K } \\
\text { Sexo (mujer vs. hombre) }\end{array}$ & $0,24(0,04)$ & 40,75 & 1,26 & $1,18-1,36$ & $<0,001$ \\
\hline \multicolumn{6}{|l|}{ Estudios } \\
\hline Ed. primaria & Ref. & & & & \\
\hline Ed. secundaria & $1,25(0,08)$ & 280,85 & 3,50 & $3,02-4,05$ & $<0,001$ \\
\hline Ed. superior & $1,70(0,09)$ & 402,68 & 5,48 & $4,64-6,47$ & $<0,001$ \\
\hline Hogar en riesgo de pobreza (sí vs. no) & $-0,20(0,05)$ & 18,46 & 0,82 & $0,75-0,90$ & $<0,001$ \\
\hline \multicolumn{6}{|l|}{ Año } \\
\hline Precrisis & Ref. & & & & \\
\hline Crisis & $0,47(0,04)$ & 113,63 & 1,59 & $1,46-1,74$ & $<0,001$ \\
\hline Postcrisis & $0,51(0,05)$ & 123,66 & 1,66 & $1,52-1,81$ & $<0,001$ \\
\hline Hábitat (urbano vs. rural) & $0,36(0,04)$ & 78,14 & 1,43 & $1,32-1,55$ & $<0,001$ \\
\hline Constante & $5,93(0,13)$ & 2076,58 & 374,84 & & $<0,001$ \\
\hline
\end{tabular}

\subsection{Los factores que influyen en la incorporación al mercado laboral}

La transición escolar se produciría al mismo tiempo que la transición laboral, una vez que se terminan los estudios es lógico pensar que la mayor parte de los casos se incorporen al mercado laboral con independencia del tipo de actividad, pues estar en paro implica ser 
activo. En la tabla 5.2 se muestra la regresión logística para la variable dependiente activo, como es lógico la edad muestra un efecto directo y significativo, de forma que a mayor edad la probabilidad de ser activo aumenta. El hecho de ser mujer disminuye la probabilidad de ser activo con respecto a los hombres, es conocida la menor actividad de las mujeres respecto de los varones, si bien existen diferencias, que se ofrecen en los análisis de los capítulos precedentes, en el sentido de que estas diferencias se presentan especialmente en las cohortes medias o de mayor edad, no entre los de menor edad del colectivo que está siendo objeto de estudio. Con relación a los estudios terminados los resultados, no por obvios y conocidos, resultan de menos interés, el tener estudios secundarios o superiores aumenta la probabilidad de ser activo, mientras que estar cursando algún tipo de estudios la disminuye. Pertenecer a un hogar en riesgo de pobreza también disminuye la probabilidad de ser activo, mientras que en los años de postcrisis esta probabilidad aumentaría con respecto a los años anteriores a la crisis. El tipo de hábitat no mostró efecto significativo en cuanto a ser activo. 
Tabla 5.2. Efecto de las variables sociodemográficas y socioeconómica en ser activo.

\begin{tabular}{lrrrrr}
\hline Variable & B (ET) & Wald & OR & IC95 \% OR & p-valor \\
\hline Edad & $0,14(0,01)$ & 657,88 & 1,15 & $1,14-1,17$ & $<0,001$ \\
Sexo (mujer $v s$. hombre) & $-0,73(0,05)$ & 226,63 & 0,48 & $0,44-0,53$ & $<0,001$ \\
Estudios & & & & & \\
$\quad$ Ed. primaria & Ref. & & & & \\
$\quad$ Ed. secundaria & $0,49(0,08)$ & 37,97 & 1,64 & $1,40-1,91$ & $<0,001$ \\
$\quad$ Ed. superior & $1,49(0,10)$ & 241,73 & 4,42 & $3,66-5,33$ & $<0,001$ \\
Cursando estudios (sí vs. no) & $-3,73(0,06)$ & 4668,72 & 0,02 & $0,02-0,03$ & $<0,001$ \\
Hogar en riesgo de pobreza (sí $v s$. no) & $-0,57(0,06)$ & 97,89 & 0,57 & $0,51-0,64$ & $<0,001$ \\
Año & & & & & \\
$\quad$ Precrisis & Ref. & & & & \\
$\quad$ Crisis & $-0,02(0,06)$ & 0,18 & 0,98 & $0,87-1,09$ & 0,668 \\
$\quad$ Postcrisis & $0,12(0,06)$ & 4,26 & 1,13 & $1,01-1,27$ & 0,039 \\
Hábitat (urbano vs. rural) & $-0,04(0,05)$ & 0,47 & 0,97 & $0,87-1,07$ & 0,492 \\
Constante & $-1,62(0,16)$ & 98,65 & 0,20 & $0,00-0,00$ & $<0,001$ \\
\hline ET: error típico. OR: Odds ratio. IC: intervalo confianza. Modelo: $\chi^{2}(9)=14791,9, \mathrm{p}<0,001 . \mathrm{R}^{2}$ Nagelkerke $=0,7$.
\end{tabular}

\subsection{Las causas que influyen en el abandono del hogar de origen o emancipación residencial}

Los resultados del modelo de regresión logística para estudiar el efecto de las variables sociodemográficas y socioeconómicas sobre la emancipación se muestran en la tabla 5.3. Nuevamente, la edad mostró un efecto directo y significativo, de forma que a mayor edad la probabilidad de emancipación aumenta. El hecho de ser mujer aumenta la probabilidad de emanciparse con respecto a los varones; esta información coincidiría plenamente con los análisis realizados en los capítulos anteriores, donde se constató cómo las mujeres comenzarían su transición residencial uno o dos años antes que los varones, dependiendo del periodo que se considere. Tener estudios superiores disminuye la probabilidad de 
emanciparse y el hecho de estar cursando algún tipo de estudios la disminuye igualmente. La segunda de las afirmaciones tiene todo el sentido, la emancipación en España está muy relacionada con la incorporación al trabajo, por lo que estar en formación tendría poca probabilidad de influir sobre la emancipación residencial. Ser una persona activa y pertenecer a un hogar en riesgo de pobreza también aumenta la probabilidad de emancipación; la primera afirmación es una situación que también ha sido constatada en los análisis descriptivos, como se ha dicho anteriormente en España el ser activo sería un paso previo a la emancipación, pero no ocurre lo mismo en los países del centro y norte de Europa, donde la emancipación en periodo estudiantil es mucho más frecuente. El riesgo de pobreza acorta el periodo de transición, como se comprobará en el capítulo siguiente, donde se describe el periodo de transición a través de los índices de entropía para las distribuciones de posibles combinaciones de estatus. El análisis de regresión también muestra cómo en los años de crisis y de postcrisis la probabilidad de emanciparse disminuye con respecto a los años anteriores a la crisis, considerando precrisis $2006 \mathrm{y}$ 2007, crisis 2011 y postcrisis 2014 y 2015. El tipo de hábitat no mostró efecto significativo en la emancipación. 
Tabla 5.3. Efecto de las variables sociodemográficas y socioeconómicas en la emancipación.

\begin{tabular}{lrrrrr}
\hline Variable & B (ET) & Wald & OR & IC95 \% OR & p-valor \\
\hline Edad & $0,31(0,01)$ & 3181,18 & 1,36 & $1,34-1,37$ & $<0,001$ \\
Sexo (mujer vs. hombre) & $0,68(0,04)$ & 299,15 & 1,98 & $1,83-2,14$ & $<0,001$ \\
Estudios & & & & & \\
$\quad$ Ed. primaria & Ref. & & & & \\
$\quad$ Ed. secundaria & $-0,07(0,07)$ & 0,85 & 0,94 & $0,81-1,08$ & 0,356 \\
$\quad$ Ed. superior & $-0,43(0,08)$ & 31,29 & 0,65 & $0,56-0,76$ & $<0,001$ \\
Cursando estudios (sí vs. no) & $-0,79(0,06)$ & 149,61 & 0,46 & $0,40-0,52$ & $<0,001$ \\
Situación (activos vs. no activos) & $0,33(0,06)$ & 26,70 & 1,39 & $1,23-1,57$ & $<0,001$ \\
Hogar en riesgo de pobreza (sí $v s$. no) & $0,38(0,05)$ & 55,22 & 1,46 & $1,32-1,61$ & $<0,001$ \\
Año & & & & & \\
$\quad$ Precrisis & Ref. & & & & \\
$\quad$ Crisis & $-0,10(0,05)$ & 5,06 & 0,90 & $0,83-0,99$ & 0,024 \\
$\quad$ Postcrisis & $-0,18(0,05)$ & 13,31 & 0,84 & $0,76-0,92$ & $<0,001$ \\
Hábitat (urbano $v$ s. rural) & $0,01(0,04)$ & 0,03 & 1,01 & $0,93-1,09$ & 0,862 \\
Constante & $-9,45(0,18)$ & 2818,65 & & & $<0,001$ \\
\hline
\end{tabular}

\subsection{Los factores que influyen en la probabilidad de vivir en pareja entre los jóvenes}

Nuevamente la edad mostró un efecto directo y significativo, de forma que a mayor edad la probabilidad de tener pareja aumenta, si bien el interés está en la influencia de otras variables como, por ejemplo, el sexo; el hecho de ser mujer aumenta la probabilidad de vivir en pareja con respecto a los hombres. Por otra parte, con relación a los estudios terminados, tener estudios superiores disminuye la posibilidad de tener pareja entre los jóvenes, de igual manera, si se tiene en cuenta la variable dicotómica estar estudiando para la respuesta positiva, es decir, cuando se está realizando algún tipo de estudios, disminuye la posibilidad de tener pareja. En los periodos de crisis y postcrisis la probabilidad de tener pareja disminuyó con respecto a los años anteriores a la crisis; este 
dato tiene clara relación con los análisis descriptivos, según los cuales la crisis económica habría retrasado la edad a la que se tiene cónyuge. Pertenecer a un hogar en riesgo de pobreza y el tipo de hábitat no han mostrado efectos significativos con relación a la variable dependiente cónyuge o pareja de hecho.

Tabla 5.4. Efecto de las variables sociodemográficas y socioeconómica en tener pareja.

\begin{tabular}{|c|c|c|c|c|c|}
\hline Variable & B (ET) & Wald & OR & IC95 \% OR & p-valor \\
\hline Edad & $0,30(0,01)$ & 2706,53 & 1,35 & $1,34-1,37$ & $<0,001$ \\
\hline Sexo (mujer vs. hombre) & $0,75(0,04)$ & 330,67 & 2,13 & $1,96-2,31$ & $<0,001$ \\
\hline \multicolumn{6}{|l|}{ Estudios } \\
\hline Ed. primaria & Ref. & & & & \\
\hline Ed. secundaria & $-0,08(0,07)$ & 1,30 & 0,92 & $0,80-1,06$ & 0,255 \\
\hline Ed. superior & $-0,53(0,08)$ & 44,88 & 0,59 & $0,51-0,69$ & $<0,001$ \\
\hline Cursando estudios (sí vs. no) & $-1,24(0,08)$ & 274,80 & 0,29 & $0,25-0,33$ & $<0,001$ \\
\hline Situación (activos $v s$. no activos) & $-0,02(0,07)$ & 0,05 & 0,99 & $0,86-1,13$ & 0,828 \\
\hline Hogar en riesgo de pobreza (sí vs. no) & $0,07(0,05)$ & 1,73 & 1,07 & $0,97-1,19$ & 0,189 \\
\hline \multicolumn{6}{|l|}{ Año } \\
\hline Precrisis & Ref. & & & & \\
\hline Crisis & $-0,25(0,05)$ & 28,58 & 0,78 & $0,71-0,85$ & $<0,001$ \\
\hline Postcrisis & $-0,24(0,05)$ & 22,76 & 0,79 & $0,71-0,87$ & $<0,001$ \\
\hline Hábitat (urbano vs. rural) & $-0,09(0,04)$ & 4,27 & 0,91 & $0,84-1,00$ & 0,039 \\
\hline Constante & $-9,26(0,19)$ & 2432,62 & & & $<0,001$ \\
\hline
\end{tabular}




\subsection{La experiencia en la maternidad/paternidad en los jóvenes. Los elementos que más influencia tienen}

Como viene siendo habitual en todos los análisis de regresión efectuados, a mayor edad la probabilidad de haber completado una transición aumenta. Para el caso de la transición parental, al igual que para la transición conyugal, el hecho de ser mujer aumenta también la probabilidad de ser madre con respecto a los hombres. Es algo conocido, y el análisis de regresión lo confirma, el hecho de que las mujeres son en torno a dos años antes madres que padres los varones, como también se ha constatado en los análisis realizados en el capítulo correspondiente en esta tesis. Ser una persona activa aumenta la probabilidad de ser padre/madre, el pertenecer a un hogar en riesgo de pobreza también aumenta la probabilidad de ser padres frente a los que no tienen este riesgo; este dato habría que tomarlo con cierta cautela, en tanto que la variable riesgo de pobreza del hogar no discrimina entre quienes son y no son responsables de hogar y, en este sentido, es muy probable que quienes son padres sean los responsables de sus propios hogares y ya se ha constatado con anterioridad cómo los hogares regentados por jóvenes tienen peores condiciones económicas que aquellos en los que los responsables son adultos. Tener estudios secundarios o superiores y estar cursando algún tipo de estudios disminuye la probabilidad de ser padre/madre, al igual que en los años de crisis y postcrisis la probabilidad de ser padres también disminuye con respecto a los años anteriores a la crisis. La variable hábitat no está teniendo demasiada influencia en las variables dependientes que se han considerado y que corresponden con las respectivas transiciones; sin embargo, en este caso vivir en un entorno urbano disminuye la probabilidad de ser padre con respecto a vivir en un entorno rural. 
Tabla 5.5. Efecto de las variables sociodemográficas y socioeconómica en ser padre.

\begin{tabular}{lrrrrr}
\hline Variable & B $($ ET) & Wald & OR & IC95\% OR & p-valor \\
\hline Edad & $0,30(0,01)$ & 1933,24 & 1,34 & $1,33-1,36$ & $<0,001$ \\
Sexo (mujer $v s$. hombre) & $0,81(0,05)$ & 295,07 & 2,25 & $2,05-2,47$ & $<0,001$
\end{tabular}

Estudios

Ed. primaria

Ed. secundaria

Ed. superior

Cursando estudios (sí vs. no)

Situación (activos $v s$. no activos)

Hogar en riesgo de pobreza (sí vs. no)

Año

Precrisis

Crisis

Postcrisis

Hábitat (urbano vs. rural)

Constante

Ref.

$\begin{array}{rrrrr}-0,36(0,08) & 21,73 & 0,70 & 0,60-0,81 & <0,001 \\ -1,25(0,09) & 216,18 & 0,29 & 0,24-0,34 & <0,001 \\ -1,45(0,10) & 232,18 & 0,23 & 0,19-0,28 & <0,001 \\ 0,57(0,07) & 60,26 & 1,77 & 1,53-2,05 & <0,001 \\ 0,64(0,06) & 128,51 & 1,90 & 1,70-2,13 & <0,001\end{array}$

Ref.

$\begin{array}{lllll}-0,21(0,05) & 15,22 & 0,81 & 0,73-0,90 & <0,001\end{array}$

$-0,20(0,06) \quad 12,54 \quad 0,82 \quad 0,73-0,91 \quad<0,001$

$\begin{array}{lllll}-0,17(0,05) & 12,21 & 0,84 & 0,77-0,93 & <0,001\end{array}$

$-9,58(0,22) \quad 1965,09 \quad<0,001$

ET: error típico. OR: Odds ratio. IC: intervalo confianza. Modelo: $\chi^{2}(10)=5216,7, \mathrm{p}<0,001 . \mathrm{R}^{2}$ Nagelkerke $=0,387$.

Lo que se ha conseguido con el análisis de regresión logística y la significación estadística de los indicadores que se ofrecen es dar mayor sentido a una buena parte de los resultados ofrecidos en los análisis descriptivos. Es posible resumir los resultados advirtiendo que la edad, lógicamente, es un factor que influye decisivamente en la probabilidad de los eventos de transición, aunque con los matices que se han ofrecido en los capítulos anteriores. En los años de crisis y postcrisis, la probabilidad de cursar algún tipo de estudios aumentó con respecto a los años anteriores a la crisis, así como vivir en un entorno urbano aumenta la probabilidad de estar estudiando con respecto a vivir en un entorno rural; tener estudios secundarios o superiores aumenta la probabilidad de ser activos, por tanto, de completar la transición laboral, el hecho de ser mujer disminuye la probabilidad de ser activo, al igual que pertenecer a un hogar en riesgo de pobreza 
también disminuye esta probabilidad; el nivel de estudios alto y estar estudiando disminuye la probabilidad de estar emancipado, el hecho de ser mujer aumenta la probabilidad de emanciparse con respecto a los hombres, al igual que de tener cónyuge o pareja de hecho y de ser padres; en crisis y postcrisis disminuye la probabilidad de emanciparse, tener pareja y ser padre, en tanto que el tipo de hábitat no mostró significación en la emancipación residencial ni en la variable cónyuge o pareja de hecho, pero sí en ser padre en el sentido de mayor probabilidad de ser padre entre quienes viven en un hábitat rural. 


\section{CAPÍTULO 6. LA HETEROGENEIDAD EN LOS PROCESOS DE TRANSICIÓN A TRAVÉS DEL ÍNDICE DE ENTROPÍA}

En los primeros capítulos, que corresponden con el bloque de análisis de resultados, se han analizado las diferentes variables que tienen influencia en los procesos de transición hacia la vida adulta, habiéndose observado diferencias notables según la edad, el sexo, la formación, etc., si bien siguiendo un discurso deductivo a través de unos indicadores que pueden ser interpretables, como son básicamente frecuencias y porcentajes. En el capítulo inmediatamente anterior se ha elegido un modelo de análisis multivariante en la búsqueda de estas diferencias, y en este último capítulo se ha seleccionado un indicador que de una manera objetiva mida el grado de heterogeneidad de los jóvenes en los procesos de transición hacia la vida adulta y comparar los resultados en diferentes periodos y para diferentes cruces de variables. Se entenderá por heterogeneidad en este análisis el grado de complejidad o simultaneidad de estatus en un grupo de edad. Este indicador es la entropía. A lo largo de la tesis ha sido habitual, como consecuencia del periodo de crisis económica que se está atravesando, el hecho de realizar comparaciones para algunas de las variables que se estudian entre un año que corresponde con un periodo de bonanza económica, el año 2007, con el periodo que corresponde con la salida de la crisis, representado con el año 2014. En el término de la redacción de esta tesis estaban disponibles los datos de la ECV del año 2015, y una vez observado que los datos descriptivos son básicamente los mismos que para el año 2014, se ha decidido fusionar los archivos que corresponden con estos dos años, que corresponderían con el periodo postcrisis. De igual manera, los datos que corresponden con los años 2006 y 2007 ofrecen información descriptiva muy similar, por lo que igualmente se ha decidido fusionar ambos archivos y corresponderían con el periodo precrisis. Esta decisión refuerza los análisis que en adelante se presentarán, al estar apoyados por un número mayor de casos. 
En el apoyo bibliográfico se ha podido comprobar cómo las aportaciones que las investigaciones aportan principalmente como variables básicas en el proceso de transición hacia la vida adulta son el término del periodo formativo, la incorporación al mercado laboral, el hecho de asumir la responsabilidad de un hogar, o emancipación residencial, la decisión de afrontar algún tipo de unión de pareja y el afrontar la paternidad. Es necesario decir en este punto que, como advierte Iacovou (2011), este consenso que existe en Europa con relación a los factores que definen la transición puede ser rebatido en cuanto hay quienes viven toda su vida en el hogar de origen, hay quienes nunca se incorporan al mercado laboral, quienes no viven en pareja y quienes nunca son padres; estas circunstancias cuestionarían la elección de estos elementos como básicos en la incorporación a la adultez. No obstante, se considera necesario buscar el pragmatismo y la operatividad más allá de la estricta exhaustividad, que nos perdería en debates teóricos que no son el objeto de esta tesis, y se asume que desde un punto de vista sociológico la incorporación a la adultez estaría refrendada por los procesos citados, pero con diferencias.

Hasta este punto se ha podido comprobar el alto grado de diferenciación y desigualdad que existe en el colectivo estudiado, con independencia de que se valoren cuestiones de tipo estructural, como el desempleo, el sistema formativo, etc., o estrategias personales encaminadas a minimizar las consecuencias adversas que los elementos estructurales imponen, como la decisión de seguir formándose, el retraso en la emancipación, etc. La constatación de estas diferencias, aunque clara y significativa, quedará reforzada a través del indicador que se presenta a continuación, y que ya ha sido descrito en la parte metodológica de esta tesis.

En este capítulo se presentarán los índices de entropía convertidos a porcentajes y representados gráficamente, donde será posible observar, en primer lugar, el porcentaje 
de entropía para cada cohorte o grupo de edad, obteniendo un primer dato para valorar la heterogeneidad por cohortes, y se construirá una secuencia de transición utilizando el porcentaje de entropía de cada una de las cohortes; en este segundo caso será posible observar la comparación de la heterogeneidad para cada una de las cohortes y el momento de la salida de transición para entrar en la adultez; este momento estaría definido por el ápice de entropía, es decir, la máxima heterogeneidad alcanzada. A partir de este momento se entraría progresivamente en la adultez, periodo este caracterizado por la estabilidad del indicador.

\subsection{La heterogeneidad de la transición antes y en la salida de la crisis}

En el gráfico 6.1 se presenta el porcentaje de entropía antes de la crisis económica y en la salida de la crisis económica. La primera de las lecturas que es posible realizar de los indicadores representados en este gráfico correspondería al aumento progresivo del índice de entropía conforme aumenta la edad; es la consecuencia lógica de que los jóvenes van asumiendo una complejidad en la combinación de estatus o estados que se han descrito, hasta el ápice de entropía, que como se ha dicho representa el momento en el que terminaría la transición y se producirá la incorporación a la adultez. El ápice de entropía para el periodo precrisis está bien definido en la cohorte de 29-31 años, pero no es tan evidente para el periodo postcrisis, donde se produce una continuación del mismo índice entre esta cohorte y los 32-34 años. Aunque no con total claridad, sí es posible interpretar un retraso en la transición en este periodo con relación al anterior. La observación más evidente son las diferencias entre los dos periodos y en las cohortes de los más jóvenes, 17-19 y 20-22 años, con un porcentaje de entropía para los primeros del $17 \%$ y $25 \%$ en precrisis y postcrisis, respectivamente, y del $32 \%$ y $37 \%$ para la cohorte de 20-22 años 
e igualmente en precrisis y postcrisis, respectivamente. La mayor entropía entre los de menor edad en el periodo precrisis permitiría deducir que en una buena coyuntura económica hay mayor facilidad de incorporación al mercado laboral y que los jóvenes comienzan antes a combinar diferentes estados y, por tanto, a aumentar el grado de heterogeneidad. A partir de los 23-25 años aumenta el porcentaje de entropía progresivamente, pero no existen diferencias entre las cohortes de los dos periodos de referencia, salvo lo comentado con relación al ápice de cada secuencia, que haría pensar en un cierto retraso en la transición en el periodo que corresponde con la salida de la crisis económica.

Gráfico 6.1. Porcentaje de entropía antes de la crisis económica y en la salida de la crisis.

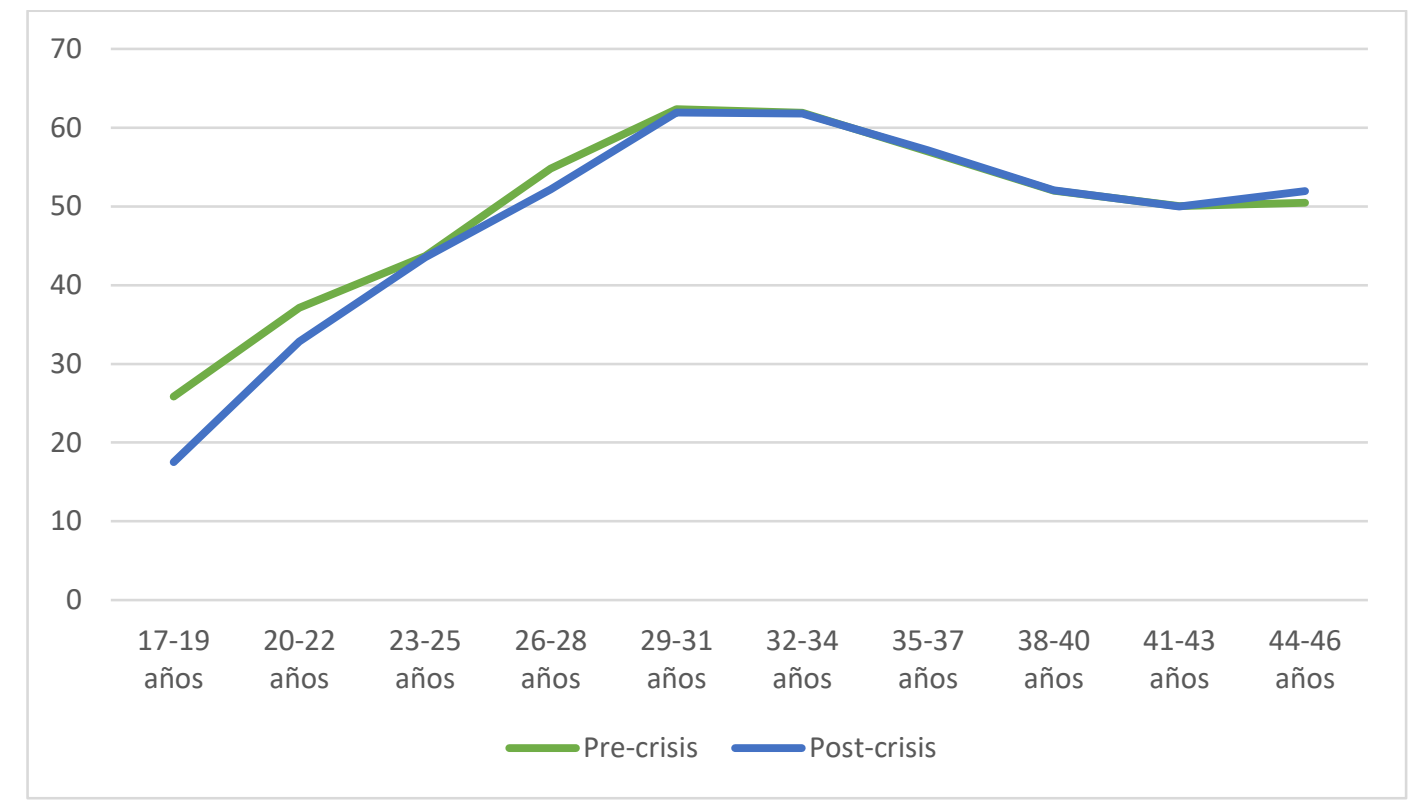

Fuente: elaboración propia con datos de la ECV. 


\subsection{Diferencias por sexo. Los varones, más tiempo jóvenes que las mujeres}

En el gráfico 6.2 se presenta el índice de entropía para los dos periodos de referencia y por sexo. La primera lectura que es posible realizar sobre las secuencias que describe la representación gráfica de los porcentajes de entropía para cada cohorte es la diferencia por sexo en todas las cohortes menos en la de los más jóvenes, 17-19 años, para la cual las diferencias que se observan son por coyuntura económica y no por sexo; tanto varones como mujeres tendrían un porcentaje de entropía de en torno al $25 \%$ en el periodo previo a la crisis económica y del 17,5 \% en el periodo que se ha considerado como el de la salida de la crisis económica. A partir de los 20-22 años, los varones no presentan diferencias entre los dos periodos y el ápice de entropía se sitúa en ambos periodos en el intervalo de 32-34 años con un $55 \%$ de entropía en precrisis y un $58 \%$ en postcrisis. Para las mujeres, las diferencias por coyuntura económica se extienden hasta los 23-25 años y el ápice de entropía se sitúa a los 29-31 años, con un porcentaje de entropía del $66 \%$ para ambos periodos. Lo más relevante del análisis de estos datos está en las diferencias por sexo más que por coyuntura económica, con diferencias por encima de 10 puntos porcentuales más en mujeres que en varones, con la excepción de las cohortes más jóvenes. La diferencia en el ápice de entropía sería de una cohorte antes en las mujeres que en los varones. En resumen, en las mujeres se produce una mayor complejidad en la distribución de estatus en toda la transición hacia la adultez y esta se completaría tres años antes que en los varones, no observándose diferencias por coyuntura económica, salvo en las cohortes de menor edad y en todo caso disminuyendo ligeramente la entropía en postcris. 
Gráfico 6.2. Porcentaje de entropía en el periodo precrisis y postcrisis por sexo.

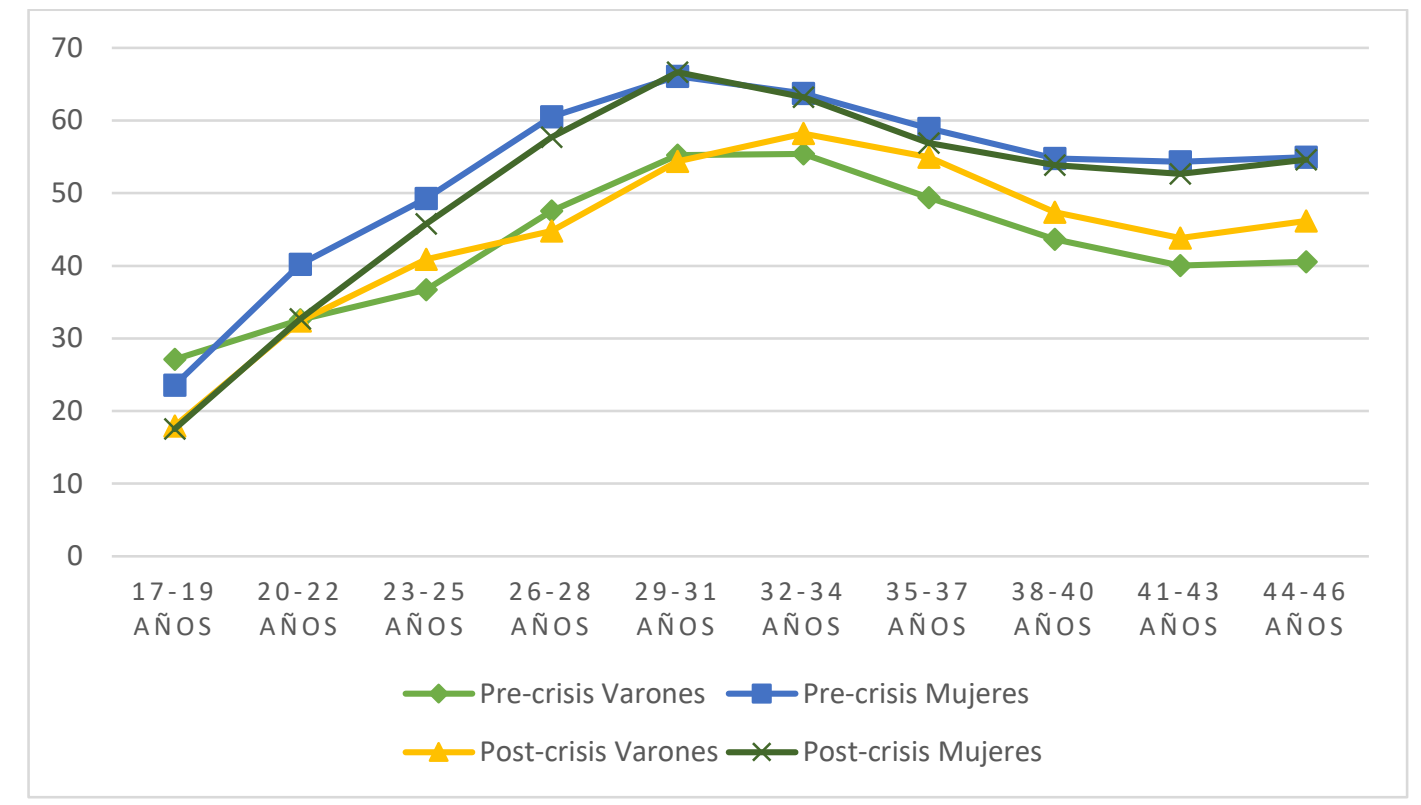

Fuente: elaboración propia con datos de la ECV.

\subsection{El riesgo de pobreza y las diferencias en la transición hacia la adultez}

El nivel de renta es un factor de diferenciación y desigualdad básica en los procesos de transición de los jóvenes hacia la vida adulta, y el riesgo de pobreza y exclusión social está muy relacionado con el nivel de renta personal y del hogar al que se pertenece. Especial interés tiene la transferencia intergeneracional de la pobreza y de las condiciones socioculturales; en los jóvenes que proceden de hogares con dificultades económicas es frecuente que en ellos se reproduzca esta situación. En el capítulo 3 ya se ha hecho referencia a esta circunstancia y se ha presentado un análisis donde es posible constatar con claridad estas situaciones. Resulta adecuado recordar algunas de las aportaciones teóricas donde se ha constatado el retraso en los procesos de emancipación entre los jóvenes que proceden de hogares con unas condiciones socioeconómicas altas respecto a los que proceden de hogares con unas condiciones socioeconómicas bajas en los países 
del sur de Europa, mientras esta situación es contraria entre los países del centro y del norte de Europa, adelantándose los procesos de transición cuanto mejores son las condiciones socioeconómicas (Iacovou, 2011; Sironi y Barban, 2015).

En el gráfico 6.3 se presentan los índices de entropía y las secuencias de transición para los hogares en riesgo y sin riesgo de pobreza en el periodo anterior a la crisis y en el de la salida de la crisis económica. La primera lectura que es posible realizar es el retraso en la salida de la transición entre los que pertenecen a hogares con buenas condiciones económicas frente a aquellos en riesgo de pobreza; la lectura es posible hacerla para ambos periodos, estando el ápice de heterogeneidad entre quienes menos recursos tienen en su hogar de origen a los 29-31 años, frente a los 32-34 cuando en los hogares a los que se pertenece tienen mejores condiciones económicas, con un $64 \%$ y $61 \%$, respectivamente. La entropía es mayor en aquellos que pertenecen a hogares en riesgo de pobreza, con algunas diferencias por edad y periodo; en este sentido, entre los que pertenecen a hogares en riesgo de pobreza las diferencias entre periodos son pequeñas, entre 3 y 4 puntos porcentuales y únicamente entre las cohortes de menor edad, 17-25 años. Entre quienes pertenecen a hogares sin riesgo de pobreza las diferencias son mayores, entre 8 y 12 puntos, pero únicamente en las dos cohortes de los de menor edad, 17-19 y 20-22 años. En resumen, las diferencias no estarían tanto entre periodos, estarían especialmente influenciadas por el riesgo de pobreza, con una mayor heterogeneidad entre quienes son más pobres y un periodo de transición de una cohorte menos. 
Gráfico 6.3. Porcentaje de entropía en el periodo precrisis y postcrisis según se pertenezca a un hogar en riesgo o no de pobreza.

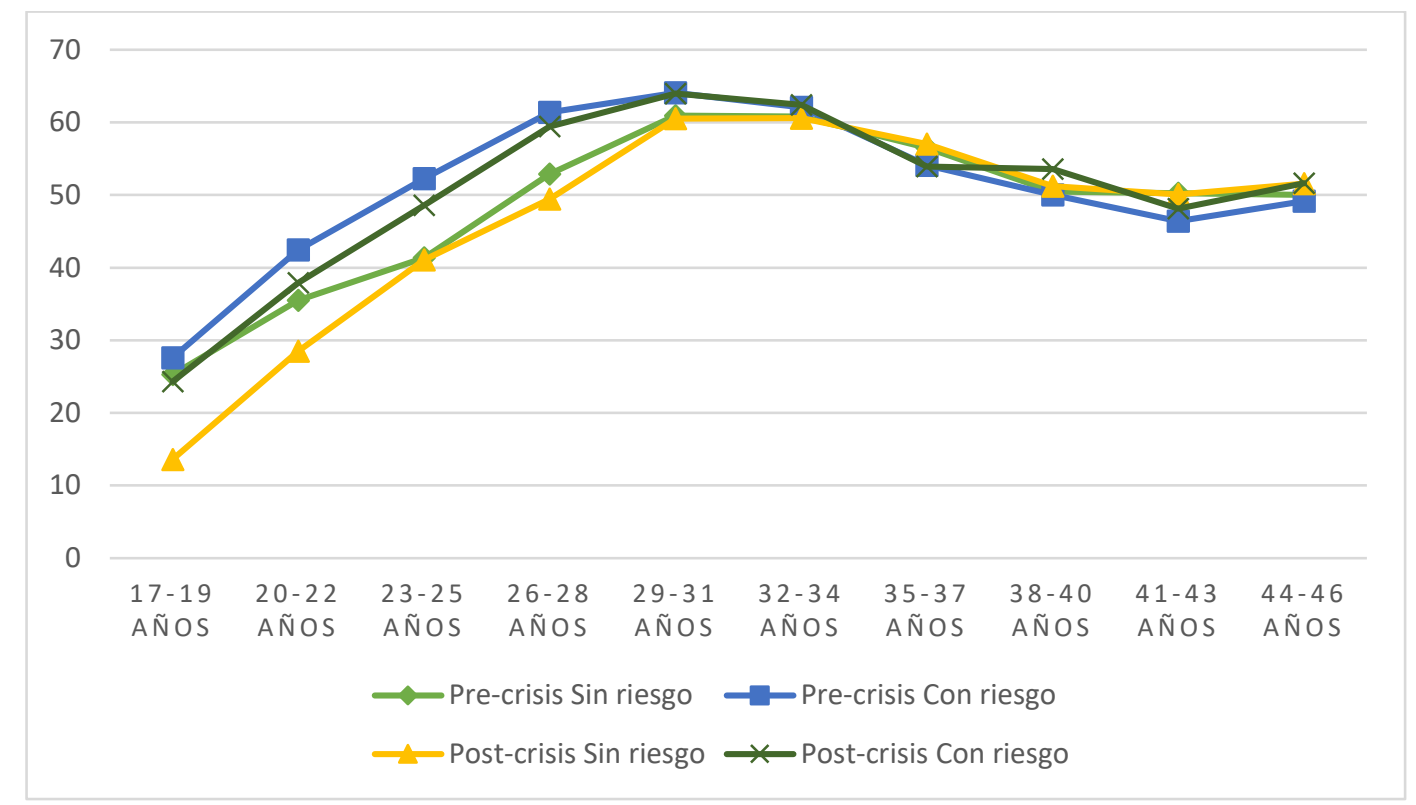

Fuente: elaboración propia con datos de la ECV.

En los gráficos 6.4 a y $6.4 \mathrm{~b}$ se ofrecen los índices de entropía para varones y mujeres, respectivamente, por riesgo de pobreza y en los periodos precrisis y postcrisis. Se advirtió en el apartado metodológico que la elección hasta los 46 años de edad está motivada únicamente con el fin de visualizar con mayor claridad la secuencia de transición, por tanto, lo que sucede en las cohortes por encima de la edad de 34 años excede del análisis que se requiere para esta tesis. Ciertamente, puede suscitar interés la diferencia de entropía a partir de los 34 años de edad entre los periodos de precrisis y postcrisis entre los varones, pero no es una cuestión a valorar en este trabajo de investigación. Lo más destacado para el gráfico que corresponde a los varones es que las diferencias no son tanto por periodo como por riesgo de pobreza, con la excepción del grupo de 17-19 años en postcrisis y sin riesgo de pobreza, en el que disminuye la entropía entre los dos periodos en torno a 15 puntos porcentuales menos de entropía en postcrisis. También se puede observar una diferencia importante, 10 puntos porcentuales, en el grupo de 32-34 años 
entre aquellos que sufren riesgo de pobreza en el sentido de más entropía en el periodo de postcrisis. Excluyendo estas dos excepciones, las diferencias en la heterogeneidad en el proceso de transición son únicamente por pertenecer o no a un hogar en riesgo de pobreza, con un mayor índice de entropía entre los que sufren este riesgo y un adelanto en completar la transición de una cohorte con relación a aquellos que no sufren el riesgo de pobreza; al igual que en el apartado anterior, cuando se han considerado ambos sexos en conjunto, aquellos que sufren riesgo de pobreza culminarían el proceso de transición a los 29-31 años, mientras aquellos varones que no tienen este riesgo lo culminan a los 32-34 años. Para el caso de las mujeres, igualmente, las diferencias más importantes se producen por riesgo de pobreza, si bien en este caso también es posible observar una disminución en el índice de entropía en el periodo de postcrisis tanto en aquellas que tienen riesgo de pobreza como en aquellas que no lo tienen. Lo más significativo es que las mujeres presentan un mayor índice de entropía que los varones en todas las comparaciones y que la edad a la que se produce el ápice de entropía se adelanta una cohorte cuando las mujeres sufren riesgo de pobreza con relación a cuando se ha realizado la comparación por sexo, pero sin tener en cuenta esta variable. Anteriormente, se ha observado cómo el ápice de entropía en las mujeres se producía a los 29-31 años y a los 32-34 años en los varones, se sigue produciendo el ápice de entropía a los 29-31 años en ambos periodos de referencia y para las mujeres que no presentan riesgo de pobreza, pero se adelanta una cohorte en aquellas mujeres que sufren riesgo de pobreza, tanto en precrisis como en postcrisis, hasta los 26-28 años. Nuevamente, las diferencias por sexo, junto al riesgo de pobreza, son los elementos que más influencia tienen en la heterogeneidad de los jóvenes en sus procesos de transición. Las mujeres presentan una mayor heterogeneidad en la sunción de estatus, lo que indica que simultáneamente están asumiendo un mayor número de roles o estatus con relación a los varones, culminan su 
transición antes que estos y, si son pobres, se produce un adelanto extra; la feminización de la pobreza, con peores posibilidades de acceso al mercado laboral, como se ha mostrado en el capítulo correspondiente donde se han descrito los ocupados por sexo, junto a motivos culturales que acentúan la división de roles entre varones y mujeres, asociando ocupaciones de mayor prestigio y recursos económicos a los varones frente a las mujeres, contribuyen a acentuar las dificultades económicas entre las mujeres. Las dificultades en el empleo en el periodo de crisis económica, el retraso en la emancipación residencial, la vida en pareja y la maternidad propician un descenso en el índice de entropía, pero en cualquier caso siempre por encima de los varones si se compara por sexo y también por encima entre aquellos o aquellas que viven en riesgo de pobreza frente a los que no.

Grafico 6.4a. Entropía en varones en pre y post crisis y riesgo de pobreza.

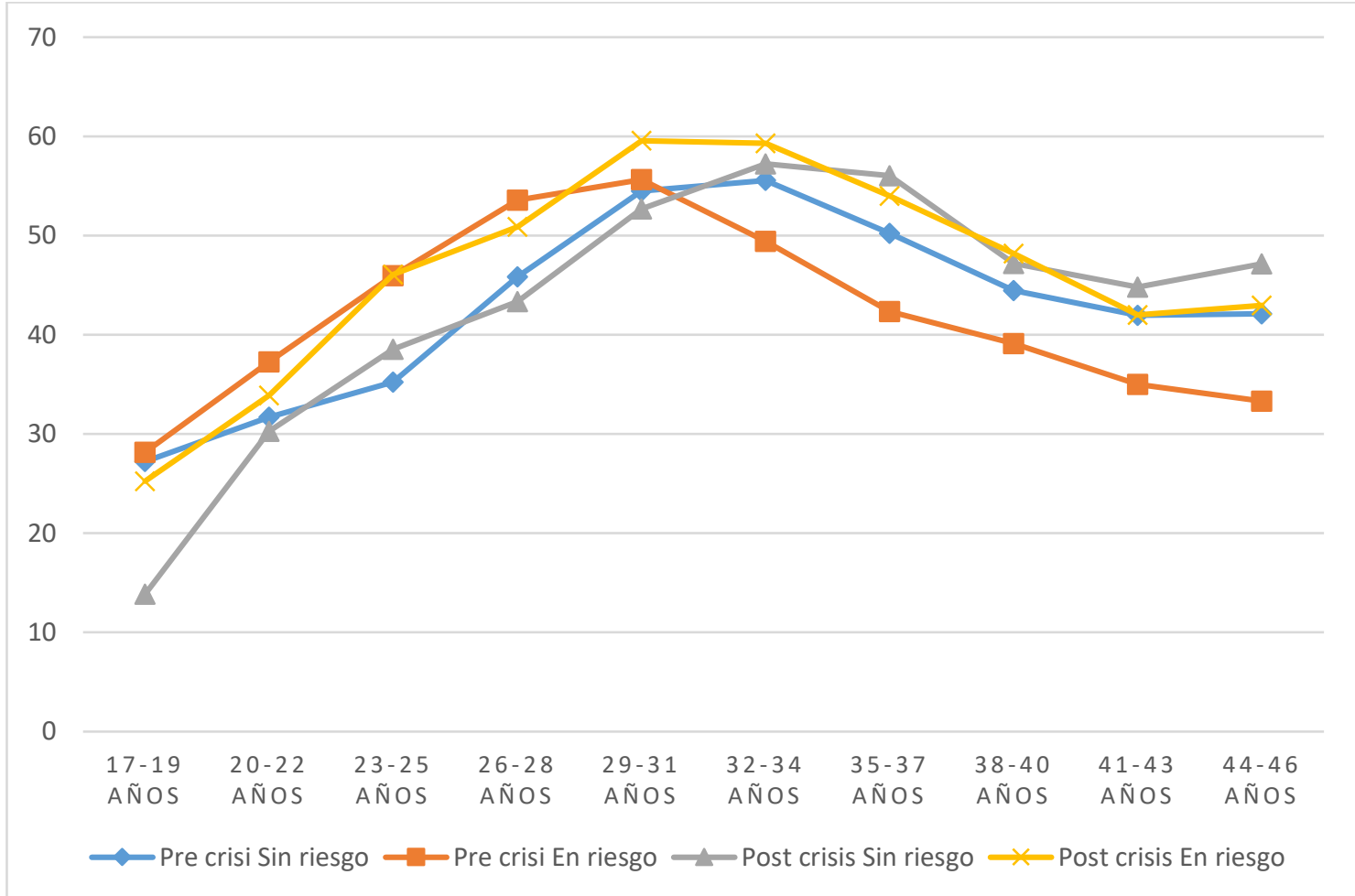


Fuente: Elaboración propia con datos de la ECV años 2006-2007-2014-2015.

Grafico 6.4b. Entropía en mujeres en pre y post crisis riesgo de pobreza.

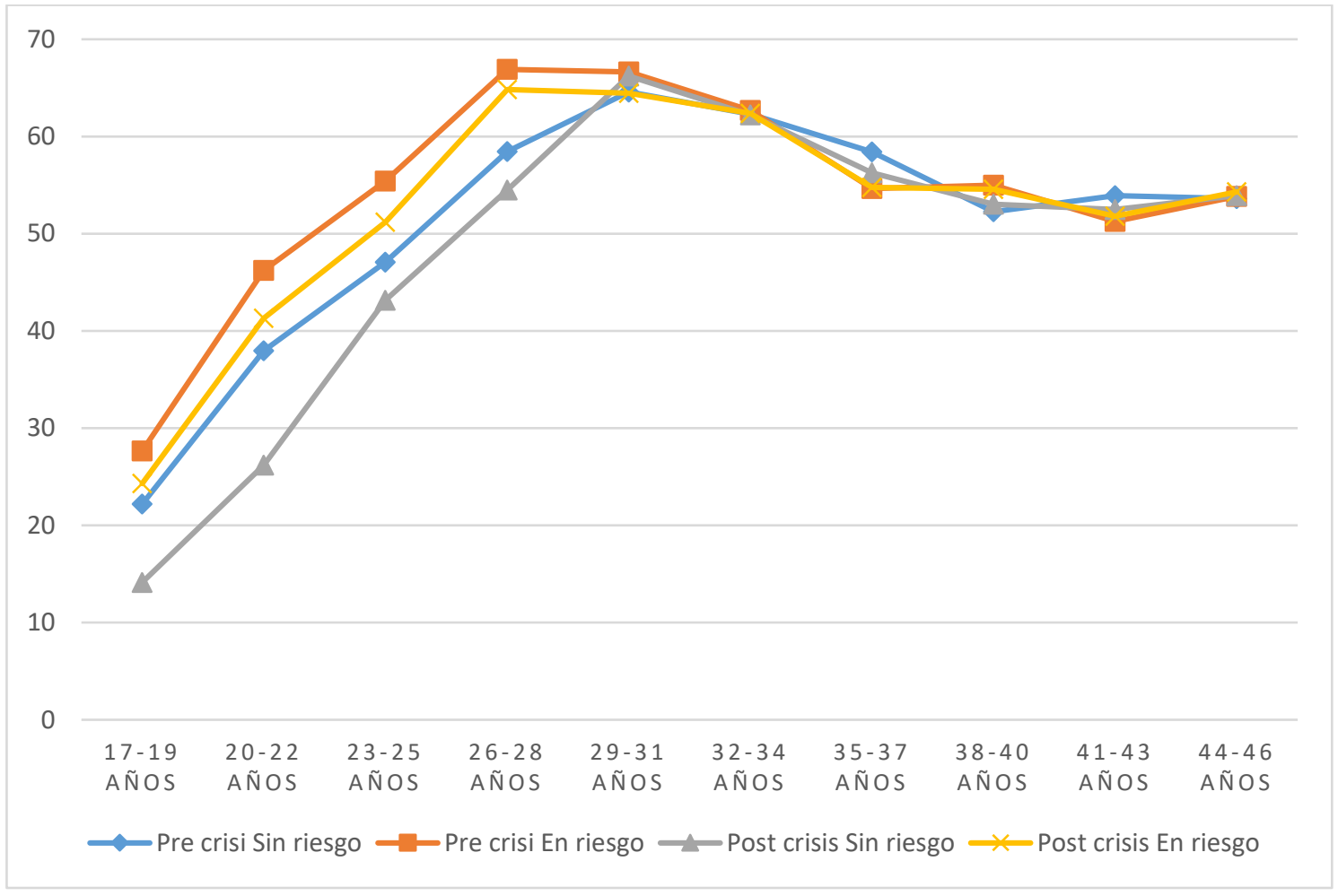

Fuente: Elaboración propia con datos de la ECV años 2006-2007-2014-2015.

\subsection{Heterogeneidad hacia la adultez según el grado de urbanización del hábitat donde se reside}

La ECV ofrece una variable que permite identificar a los casos según se proceda de un hábitat muy urbanizado, medio urbanizado y poco urbanizado. En los capítulos anteriores se ha cruzado esta variable con los estudios terminados, ocupación, emancipación, etc., observándose diferencias: en las zonas rurales, es decir, aquellas con un nivel de 
urbanización bajo, se ha constatado un menor nivel de estudios terminados entre los jóvenes, con menos jóvenes con estudios superiores y más con estudios terminados de inferiores niveles. En este epígrafe, al igual que en los inmediatamente anteriores, se valorará el grado de heterogeneidad en la transición hacia la adultez sirviéndose de base el índice de entropía. A través de las lecturas que es posible hacer de la representación gráfica de este indicador y por edad, será nuevamente posible, por una parte, observar las diferencias por cohortes de edad, las diferencias en momentos de diferente coyuntura económica y, por otra, construir secuencias de transición donde determinar el momento en el que identificar el término de la transición.

En el gráfico 6.4 se representan las secuencias de transición construidas con los índices de entropía en dos periodos de diferente coyuntura económica y para aquellos que residen en un hábitat urbano; con independencia de la variable independiente que se considere, todas las secuencias siguen la misma lógica, conforme aumenta la edad desde las cohortes más jóvenes, aumenta la entropía en la distribución de estatus analizada hasta el ápice que representaría el final de la transición. Las diferencias para aquellos que residen en un hábitat urbano y entre los dos periodos de referencia, únicamente se producirían en las cohortes de menor edad, 17-19 años y 20-22 años, con diferencias de 10 y 5 puntos porcentuales respectivamente para cada intervalo de edad. Para el resto de edades se podría decir que no existen diferencias entre el periodo previo a la crisis económica, 20062007, y el periodo que corresponde con la salida de la crisis, 2014-2015. Con relación al momento del término de la transición, el gráfico muestra, aunque no con toda claridad, cómo la transición habría concluido antes en el periodo previo a la crisis con respecto al periodo que corresponde con la salida de la crisis; sería posible interpretar que se ha producido un retraso de una cohorte de tres años considerando esta variable. La lectura que es posible hacer para aquellos que residen en un hábitat rural es similar a la anterior, 
se observa una mayor entropía, por tanto, heterogeneidad, en las cohortes de menor edad, y a su vez un mayor índice de entropía en precrisis y postcrisis en aquellos que residen en un hábitat rural frente a aquellos que residen en un hábitat urbano. El dato más llamativo del análisis corresponde con los jóvenes que residen en el medio rural pués terminarían la transición antes en el periodo de postcrisis que en el periodo de precrisis en una cohorte de tres años, a los 29-31 años en postcrisis y a los 32-34 años en precrisis.

Gráfico 6.4. Entropía en precrisis y postcrisis cuando se reside un hábitat urbano.

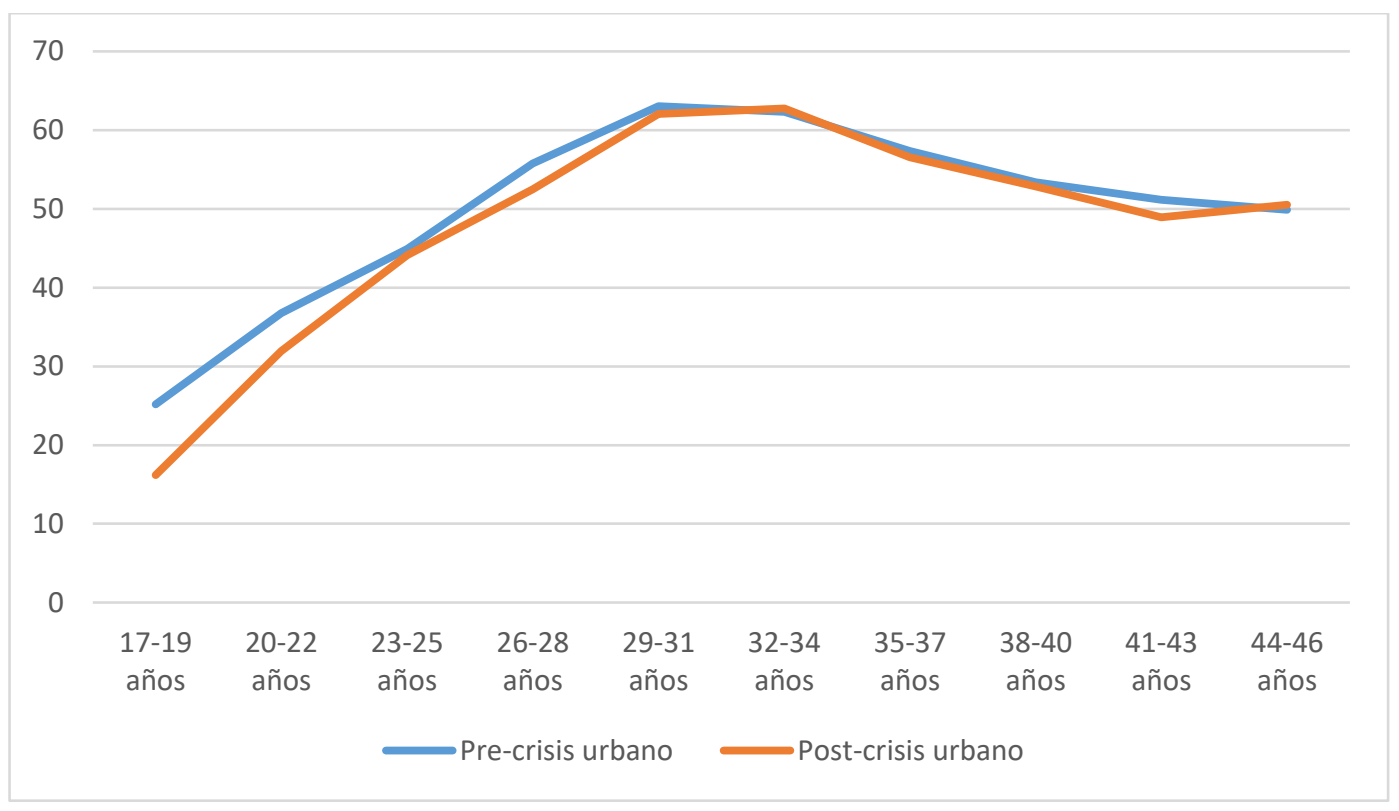

Fuente: elaboración propia con datos de la ECV. 
Gráfico 6.5. Entropía en precrisis y postcrisis cuando se reside en un hábitat rural.

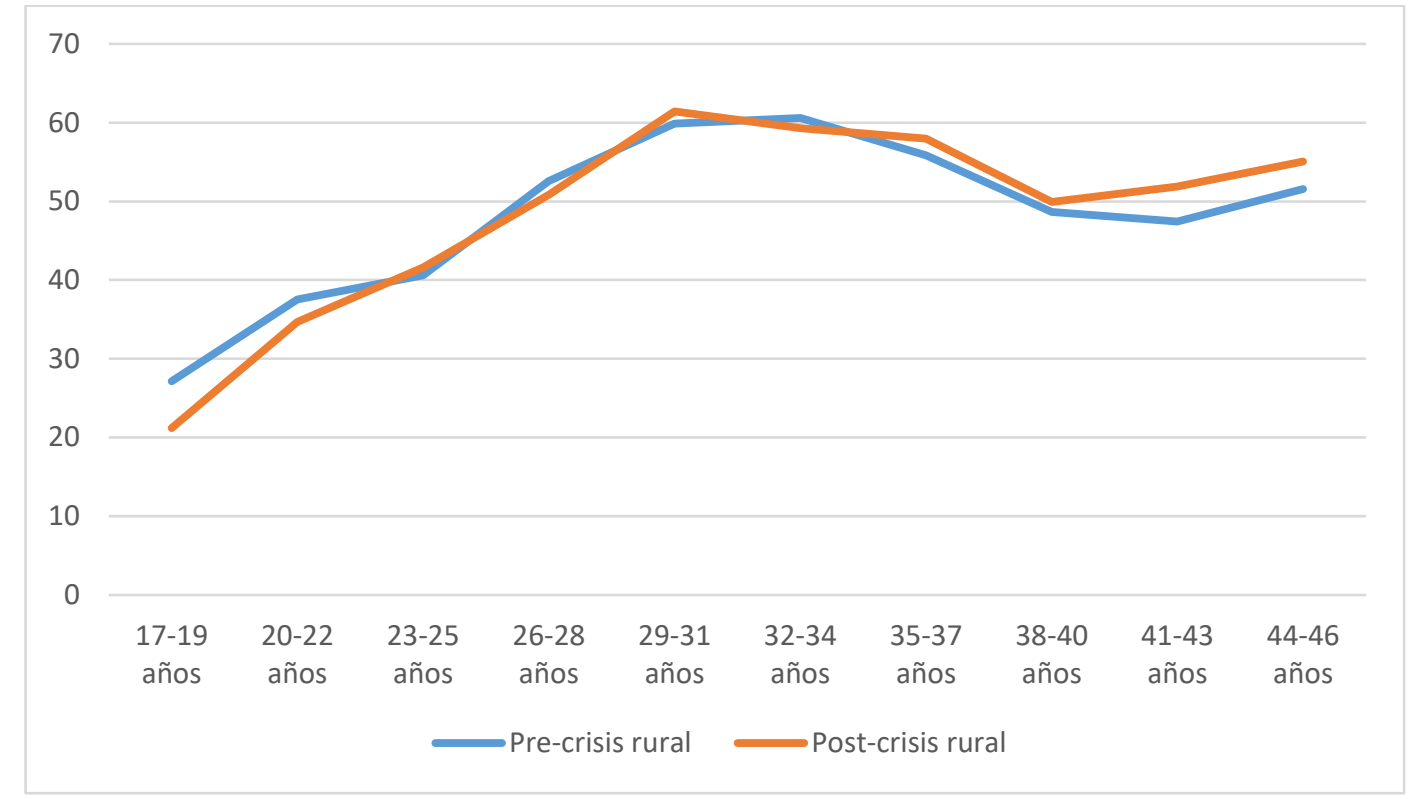

Fuente: elaboración propia con datos de la ECV.

Es posible relacionar el análisis anterior con las informaciones presentadas en los apartados descriptivos en relación con una mayor influencia de la crisis económica en los núcleos más urbanizados. Estos lugares habrían perdido la ventaja en el periodo de crisis respecto a los núcleos rurales con relación a unas mejores condiciones educativas, económicas y, por tanto, mejores facilidades para la emancipación residencial, creación de nuevos hogares, etc. Estas condiciones habrían influido en una tendencia a igualar ambos hábitats en lo que respecta al proceso de transición hacia la adultez. 


\subsection{Las causas de la heterogeneidad. El peso o influencia de cada estado (estudiando, activo, emancipado, en pareja y padre/madre) en el índice de entropía}

En el apartado metodológico de esta tesis se explica con claridad cómo se han construido los indicadores que se ofrecen en la tabla 6.1, únicamente recordar que el interés de esta tesis va más allá de la descripción de las diferencias en los procesos de transición hacia la adultez, también se han buscado cuáles pueden ser algunas de las causas o, como es el caso, cuáles son los estatus o estados que más influencia tienen en el índice de entropía, que es lo mismo que decir en el grado de heterogeneidad del colectivo estudiado por cohortes de edad. En este sentido, la tabla siguiente muestra el peso porcentual de cada estatus en el porcentaje de entropía, que ha sido calculado a través de la diferencia entre la entropía predicha y la entropía observada para cada uno de los estatus e intervalos de edad.

La tabla 6.1 muestra la entropía en porcentaje para el periodo previo a la crisis económica y para el periodo que corresponde con la salida de la crisis y para cada intervalo de edad, además del peso en porcentaje de cada uno de los estados que se vienen a analizando. Entre los 17 y los 19 años el porcentaje de entropía es pequeño, ya se ha comentado reiteradamente a lo largo de este trabajo que se trataría de un colectivo en buena medida aún en formación, si bien se observan diferencias entre los dos periodos que están sirviendo de referencia, en el sentido de un mayor índice de entropía en el periodo previo a la crisis económica, del 25,8 \% frente al 17,5\% en los años que corresponden con la salida de la crisis. Con relación al peso que cada uno de los estatus tiene en estas diferencias, se puede ver en la tabla cómo únicamente los estatus de estudiante y activo tienen relevancia, el resto de estatus no tendría ninguna relevancia en la heterogeneidad de este colectivo ni antes ni después de la crisis económica. El peso que tiene el estatus de estudiante en el índice de entropía en los jóvenes de entre 17-19 años es del 57,1\% 
antes de la crisis y en la salida de la crisis se eleva hasta el 70,3\%, mientras el peso del estatus de activo es del $42,9 \%$ antes de la crisis y del $29,7 \%$ en la salida de la crisis. Los datos apuntan con claridad a esa pérdida de la actividad que se produce en los jóvenes, especialmente entre los de menor edad, a lo largo del periodo de crisis económica.

En la cohorte de 20-22 años los índices de entropía antes y después de la crisis son el $37,1 \%$ y el $32,8 \%$, respectivamente. De nuevo se observa una mayor heterogeneidad en el periodo postcrisis con relación al precrisis y para esta cohorte aparece ya como relevante en las diferencias el estar emancipado con cifras similares entre los dos periodos, en torno al $12 \%$. En esta cohorte siguen existiendo diferencias en el peso que tiene en la heterogeneidad los estatus de estudiante y activo, en ambos periodos el estatus de activo aumenta, disminuyendo el peso del estatus de estudiante, pero sigue teniendo un mayor peso el estatus o estado de estudiante en el periodo postcrisis que en el previo a la crisis, un $28 \%$ y un $40 \%$, respectivamente.

Para el resto de cohortes el porcentaje de entropía es prácticamente idéntico en el periodo postcrisis y en el precrisis, pero existen algunos matices con relación a la influencia de cada estatus en el porcentaje de este indicador; en este sentido, lo más destacado es el bajo peso que tiene el estatus de estudiante en las cohortes de mayor edad, en torno a un $4 \%$, con la excepción de los jóvenes de 23-25 años, donde aún este estado tiene importancia en el periodo postcrisis, con un $13 \%$. Los estatus de cónyuge y padre tienen relevancia en la heterogeneidad a partir de los 26-28 años, con la excepción de la cohorte de 23-25 años, que en el periodo precrisis ya presenta datos a considerar en las diferencias con un $8 \%$.

Sería posible resumir este análisis diciendo que la heterogeneidad entre los jóvenes medida a través del índice de entropía para una distribución de todas las posibles combinaciones de los cinco estados que se han considerado, estudiante, activo, 
emancipado, vida en pareja y padre, aumenta con la edad y en las cohortes de los más jóvenes, 17-22 años, también de un periodo de precrisis a postcrisis; que para las cohortes de los de menor edad únicamente tienen relevancia los estatus de estudiante y activo; que el estatus de emancipado comienza a tener relevancia en el índice de entropía a partir de los 20-22 años y con más claridad a partir de los 23-25 años; que el estatus de cónyuge o cualquier tipo de vida en pareja comienza a tener alguna influencia a partir de los 23-25 años, y más claramente de los 26-28 años, y que el estatus de padre únicamente tiene influencia en las diferencias en las cohortes de mayor edad, y en escasa medida.

Tabla 6.1. Entropía para la distribución de posibles combinaciones con los estatus de estudiante, activo, emancipado, cónyuge y padre. La influencia de cada estatus en la entropía total.

\begin{tabular}{|c|c|c|c|c|c|c|}
\hline Precrisis & $\begin{array}{l}\text { Entropía } 5 \\
\text { estatus }\end{array}$ & Estudiante & Activo & Emancipado & Pareja & Padre \\
\hline 17-19 años & 25,8 & 57,1 & 42,9 & & & \\
\hline 20-22 años & 37,1 & 28,2 & 60,3 & 11,5 & & \\
\hline 23-25 años & 43,7 & 4,8 & 56,7 & 29,8 & 8,6 & \\
\hline 26-28 años & 54,8 & 4,6 & 41,1 & 32,5 & 18,4 & 3,4 \\
\hline 29-31 años & 62,3 & 3,8 & 34,3 & 33,8 & 19,1 & 9 \\
\hline 32-34 años & 61,9 & 3,6 & 31,1 & 39,2 & 18,2 & 8 \\
\hline Postcrisis & $\begin{array}{l}\text { Entropía } 5 \\
\text { estatus }\end{array}$ & Estudiante & Activo & Emancipado & Pareja & Padre \\
\hline 17-19 años & 17,5 & 70,3 & 29,7 & & & \\
\hline 20-22 años & 32,8 & 40,3 & 47 & 12,6 & & \\
\hline 23-25 años & 43,5 & 12,7 & 59,7 & 27,6 & & \\
\hline 26-28 años & 52,1 & 4,8 & 44,9 & 34,3 & 15,6 & 0,4 \\
\hline 29-31 años & 61,9 & 5 & 35,2 & 34,7 & 18,4 & 6,6 \\
\hline 32-34 años & 61,8 & 4,3 & 34,2 & 38,3 & 16 & 7,2 \\
\hline
\end{tabular}

Fuente: elaboración propia con datos de la ECV. 
En la tabla 6.2 se ofrecen los datos que muestran el peso que tiene cada estatus o estado en las diferencias por sexo y por periodo económico. Las lecturas relacionadas con el nivel de heterogeneidad en cada intervalo, por sexo y por periodo ya se han realizado con anterioridad, en este caso se valorará el peso que tiene cada estatus en las diferencias. En la cohorte de los más jóvenes los estatus o estados que intervienen en las diferencias son el estatus de estudiante y el de activo; en el caso de los varones, el peso se reparte casi al $50 \%$ en precrisis, sin embargo, en el periodo de postcrisis el peso que tiene el estar estudiando en el índice de entropía es casi de 40 puntos porcentuales más a favor del estatus de estudiante. Estas diferencias también son importantes entre las mujeres, pero menor que entre los varones. A partir de esta cohorte, empieza a tener alguna importancia en las diferencias el estar emancipado residencialmente, en especial entre las mujeres, y más en el periodo de precrisis que en el de postcrisis; estos datos están claramente en línea con el retraso en la emancipación residencial a lo largo de la crisis económica. Según se avanza en edad, al igual que se ha comentado en la tabla anterior, comienzan a tener relevancia en las diferencias el resto de estados o estatus, como los de tener pareja y ser padres, con datos similares en ambos periodos. Las diferencias, como ha venido siendo habitual en toda la tesis, se producen más por sexo que por periodo; los varones son padres más tarde que las mujeres madres, este dato ya se ha constatado anteriormente y a través de la bibliografía consultada, por tanto, el peso que estos estatus tienen en las diferencias es pequeño y está concentrado en las cohortes de mayor edad. 
Tablas 6.2. El peso de cada estatus en el índice de entropía por sexo y por periodo económico.

\begin{tabular}{|c|c|c|c|c|c|c|}
\hline $\begin{array}{l}\text { PRE } \\
\text { CRISIS } \\
\end{array}$ & & & & & & \\
\hline VARONES & $\begin{array}{l}\text { Entropía } 5 \\
\text { estatus }\end{array}$ & Estudiante & Activo & Emancipado & Cónyuge & Padre \\
\hline 17-19 años & 27 & 55 & 45 & & & \\
\hline 20-22 años & 33 & 26 & 74 & & & \\
\hline 23-25 años & 37 & 7 & 76 & 18 & & \\
\hline 26-28 años & 48 & 4 & 48 & 31 & 16 & 1 \\
\hline 29-31 años & 55 & 5 & 40 & 30 & 19 & 7 \\
\hline 32-34 años & 55 & 5 & 41 & 32 & 17 & 5 \\
\hline MUJERES & $\begin{array}{l}\text { Entropía } 5 \\
\text { estatus }\end{array}$ & Estudiante & Activo & Emancipado & Cónyuge & Padre \\
\hline 17-19 años & 24 & 61 & 38 & 1 & & \\
\hline 20-22 años & 40 & 26 & 47 & 23 & 4 & \\
\hline 23-25 años & 49 & 4 & 48 & 33 & 15 & \\
\hline 26-28 años & 61 & 5 & 38 & 34 & 19 & 4 \\
\hline 29-31 años & 66 & 3 & 33 & 36 & 18 & 10 \\
\hline 32-34 años & 64 & 3 & 31 & 45 & 15 & 6 \\
\hline $\begin{array}{l}\text { POST } \\
\text { CRISIS } \\
\end{array}$ & & & & & & \\
\hline VARONES & $\begin{array}{l}\text { Entropía } 5 \\
\text { estatus }\end{array}$ & Estudiante & Activo & Emancipado & Cónyuge & Padre \\
\hline 17-19 años & 18 & 69 & 31 & & & \\
\hline 20-22 años & 32 & 46 & 50 & 4 & & \\
\hline 23-25 años & 41 & 8 & 66 & 26 & & \\
\hline 26-28 años & 45 & 5 & 55 & 31 & 10 & \\
\hline 29-31 años & 54 & 4 & 43 & 31 & 17 & 4 \\
\hline 32-34 años & 58 & 5 & 39 & 34 & 16 & 6 \\
\hline MUJERES & $\begin{array}{l}\text { Entropía } 5 \\
\text { estatus }\end{array}$ & Estudiante & Activo & Emancipado & Cónyuge & Padre \\
\hline 17-19 años & 18 & 71 & 29 & & & \\
\hline 20-22 años & 33 & 38 & 45 & 17 & & \\
\hline 23-25 años & 46 & 16 & 54 & 27 & 3 & \\
\hline 26-28 años & 58 & 4 & 39 & 36 & 18 & 2 \\
\hline 29-31 años & 67 & 6 & 31 & 37 & 18 & 7 \\
\hline 32-34 años & 63 & 4 & 33 & 43 & 14 & 6 \\
\hline
\end{tabular}

Fuente: Elaboración propia con datos de la ECV años 2006-2007-2014-2015. 


\section{CONCLUSIONES}

Antes de exponer las conclusiones se recuerdan cuáles fueron los objetivos para, a continuación ofrecer las respuestas que se han podido dar a estos objetivos. El objetivo general ha sido valorar la desigualdad y diferenciación entre los jóvenes a través de los procesos de transición y las variables que más influencia tienen en estos. Para ello se plantearon los siguientes objetivos secundarios:

1. Describir y valorar el grado de diferenciación en los jóvenes teniendo en cuenta las variables que más influyen en las diferentes transiciones (escolar, laboral, residencial, vida en pareja y parental) y según variables independientes como edad, sexo, estudios terminados, relación con la actividad, etc.

2. Igualmente describir, valorar y comparar la edad media en la que se producen las transiciones, así como la duración de estas, también según diversas variables independientes, como las comentadas en el punto anterior.

3. Valorar las diferentes influencias de los diversos factores que intervienen en los procesos de transición a través de un análisis de regresión logística multivariante.

4. Valorar las consecuencias de las diferencias descritas en cuanto al comienzo y término de los procesos de transición en diferentes situaciones con coyunturas económicas distintas, por sexo, tipo de hábitat donde se reside o riesgo de pobreza del hogar de origen a través del índice de entropía.

Hay que recordar que el propósito de la tesis no ha sido el análisis con detenimiento de cada una de las cuestiones planteadas: formación, empleo, emancipación residencial, etc. Es servirse de estas variables para constatar las diferencias y desigualdad entre los jóvenes y en su transición hacia la adultez. Tampoco es un análisis estrictamente de transición, se 
valoran las diferencias en estos procesos a través de los hitos que suponen el experimentar cada uno de los eventos, sin otra pretensión que el evidenciar nuevamente las diferencias en el colectivo estudiado y su evolución; quedarían emplazados posteriores estudios longitudinales de transición que ofrezcan tipologías de transición desde un enfoque cualitativo.

Con relación a la primera de las afirmaciones que contenía la hipótesis de partida, según la cual los jóvenes estarían ubicados en la estructura de clase y económica heredada de sus padres y que condicionaría las posibilidades de construir sus propios itinerarios de transición, hay que decir que efectivamente dos de los elementos que más influencia tienes en las diferencias entre los jóvenes son el pertenecer a una hogar en riesgo de pobreza y la reproducción intergeneracional. Por otra parte se ha constatado con claridad cómo el nivel de estudios terminados es otro elemento diferenciador de primer orden y que como se apuntaba en la hipótesis, el nivel de estudios alcanzado discrimina a los jóvenes y que la escuela no compensaría las diferencias asociadas al origen social. Estos elementos de tipo estructural condicionarían igualmente los itinerarios que conducen a la transición laboral, son variados y están influenciados por la estructura económica, en especial los ciclos económicos, tendiendo igualmente hacia la segmentación social de los jóvenes. Aunque no ha formado parte de los objetivos de esta tesis, en los jóvenes se producen elecciones y estrategias para hacer frente a los determinismos estructurales y contextuales que provocan las diferencias y desigualdades, en especial por sexo como se ha comprobado reiteradamente en todo este trabajo; la decisión de prolongar la formación, de retrasar la emancipación residencial, la vida en pareja o la paternidad serían parte de estas estrategias de adaptación, aunque hay que recordar que ninguna estrategia se origina en un vacío social, por lo que la influencia de los elementos estructurales como 
es el contexto, la cultura o la familia serían básicos en las diferencias y la desigualdad entre los jóvenes observada desde sus transiciones y las variables que las definen.

\section{Diferencias formativas, laborales y familiares}

De entre los primeros indicadores que se valoran está la coyuntura económica, valorada fundamentalmente por el nivel de desempleo; se ha constatado cómo el coste de oportunidad al que se hace referencia en el apartado teórico con relación a continuar o no con la formación o incorporase al mercado laboral disminuye en periodos de crisis ante la dificultad de encontrar un empleo, lo que induce a un incremento del tiempo de formación. Por otra parte, el tipo de ocupación o relación con la actividad presenta diferencias en función de las variables que se consideren, siendo la edad y los estudios terminados los principales elementos diferenciadores, aunque también es posible observar diferencias según el grado de urbanización del hábitat donde se reside, con mayores porcentajes de jóvenes ocupados y de jóvenes en formación en los hábitats más urbanizados; para el tipo de ocupación o relación con la actividad las diferencias por sexo son notables en los intervalos de mayor edad, pero no así entre los más jóvenes. Es necesario recordar que la variable ocupación o relación con la actividad que la ECV ofrece está compuesta por diferentes categorías excluyentes entre sí (trabador por cuenta propia, por cuenta ajena, parado, estudiando, jubilado, labores del hogar y otras ocupaciones económicamente inactivas).

Los estudios terminados suponen un elemento diferenciador de primer orden. Los indicadores oficiales muestran una dualidad muy acusada en cuanto a la formación entre los jóvenes españoles, con unos niveles de fracaso escolar de entre los más elevados de los países de la OCDE y, por el contrario, un porcentaje de jóvenes universitarios por encima de la media de entre los países de la Unión Europea. Los indicadores obtenidos 
de la ECV igualmente presentan diferencias dependiendo de las variables que se crucen. La primera diferencia se ha detectado por edad y sexo; es cierto que considerar a los jóvenes de 17-19 años pudiera llevar a errores, en tanto es una edad en la que una buena parte estarían en formación, pero es pertinente constatar el porcentaje de jóvenes de este intervalo que solamente tienen terminada la enseñanza primaria, según los datos obtenidos el $11 \%$, pues difícilmente estos jóvenes superarán la enseñanza secundaria. El $7 \%$ cuando tienen 20-22 años únicamente tienen terminados estudios primarios, aunque algunos de ellos pudieran completar secundaria, es un dato que igualmente indicaría un mal paso por el sistema educativo. Con relación a las diferencias por sexo, las mujeres en todos los intervalos tienen un mayor nivel de estudios que los varones. Para el resto de los análisis relacionados con los estudios terminados, únicamente se han tenido en cuenta el intervalo de entre 25-34 años, entendiendo que ya en esta edad se ha completado la educación formal. Se constatan diferencias con relación a la actividad, con mayor porcentaje de ocupados asalariados o por cuenta propia entre quienes mayor formación tienen; una ligera desventaja en las zonas rurales frente a las urbanas, con mejores niveles formativos en las urbanas, y una clarísima diferencia entre quienes viven en hogares con riesgo de pobreza y quienes viven en hogares sin riesgo de pobreza; en estos últimos, tienen estudios superiores más del $50 \%$ de los jóvenes, mientras entre los que viven en hogares en riesgo de pobreza el porcentaje baja al $25 \%$, con un porcentaje de quienes únicamente poseen estudios primarios del $5 \%$ y del $12 \%$, respectivamente.

Con relación al nivel de estudios terminados y empleabilidad, resulta clara la relación que existe en el sentido de un mayor número de ocupados cuando se tiene un nivel de estudios superior. Sin embargo, es necesario matizar que en periodos donde la coyuntura económica es favorable la formación no condiciona excesivamente la incorporación al mercado laboral en España, pues la diferencia entre el porcentaje de parados con 
formación y sin formación es tan solo de 5 puntos en el año 2004 y de 7 puntos en el año 2007, mientras que en los periodos donde la coyuntura económica es más desfavorable, la formación resulta ser básica para acceder al mercado laboral, como lo muestran los 26 puntos de diferencia que se dan entre los que menos y más formación tienen en el año 2010.

Otro componente estructural que influye en la desigualdad y diferenciación entre los jóvenes es la institución familiar. Se ha analizado la transferencia intergeneracional de las condiciones socioeconómicas y socioculturales de los jóvenes de entre 25 y 34 años y se constata una fuerte relación entre la situación que vivieron cuando estos jóvenes fueron adolescentes en sus hogares de origen y la que poseen en la actualidad, así como la relación de los niveles de estudios de los padres con los que han alcanzado los hijos. En los hogares monoparentales, los rendimientos académicos son mayores cuando son las madres quienes son las responsables que cuando son los padres, con datos perfectamente equiparables a las familias nucleares, incluso mejores. Otro dato de interés sería la disminución en el nivel de estudios terminados cuando el número de menores que conviven son al menos tres, aunque se trate más de una covarianza que de una relación causal, en tanto que el tener más hijos implicaría disponer de menos recursos monetarios por hijo, de modo que la causa sería económica más que de composición del hogar. La cuestión de la transferencia intergeneracional sociocultural y socioeconómica es un hecho constatado que favorece el desigual acceso a la educación, al empleo y a la renta y por consiguiente dificulta los procesos de transición hacia la vida adulta de los jóvenes, acentuándose las diferencias y la desigualdad. Los datos muestran cómo se reproduce la desigualdad entre los jóvenes en función de su origen familiar. Es cierto que tienen mayor formación que sus padres, en cualquier caso, pero es un aumento en todas las categorías, por lo que las diferencias se siguen manteniendo. 
Igualmente se ha analizado la transferencia intergeneracional de la pobreza en los jóvenes de entre 25 y 34 años y que son responsables de un hogar; en primer lugar, se ha constatado la relación que existe entre el nivel de estudios terminados y la situación económica que vivieron en sus hogares de origen, con una relación clara en cuanto a mayor nivel de estudios terminado cuando las condiciones económicas fueron buenas, con más de 30 puntos porcentuales de diferencia entre quienes tienen terminados estudios superiores cuando la situación económica es buena o muy buena, frente a los que peores condiciones económicas tuvieron. Es posible realizar la misma lectura, pero a la inversa, con relación a los estudios primarios, siendo casi inexistentes aquellos que únicamente poseen estudios primarios entre los que pertenecieron a hogares con buenas condiciones económicas y entre el $20 \%$ y el $40 \%$ cuando las condiciones fueron malas o muy malas, respectivamente. Con relación a las condiciones económicas de los hogares de los jóvenes cuando estos son responsables del hogar, se observa nuevamente una tendencia a la reproducción intergeneracional de estas condiciones, con porcentajes mayores de hogares con malas condiciones económicas cuando esta situación se padeció en los hogares de origen. Esta relación no está tan clara para el resto de categorías que definen la situación económica del hogar, se ha observado cómo en las categorías de condiciones moderadas y buenas o muy buenas en los hogares regentados por jóvenes, la influencia de la situación de los hogares de origen es la misma. Esta información estaría indicando que la influencia en las condiciones económicas en los hogares de los jóvenes sería determinante cuando se procede de hogares en malas o muy malas condiciones económicas, pero que para el resto de tipos de origen familiar habría que buscar las diferencias en otro tipo de variables o factores más allá de la situación económica del hogar de origen, como podrían ser el origen sociocultural, tipo de hábitat, comunidad autónoma, etc. Se ha analizado la variable riesgo de pobreza y exclusión social que la ECV ofrece relacionándola con las 
condiciones económicas que los jóvenes responsables de hogar tienen con relación a las condiciones que tuvieron cuando eran adolescentes en su hogar de origen y comparando algunas comunidades autónomas caracterizadas por tener los porcentajes más bajos y más altos de hogares totales en riesgo de pobreza o exclusión social; el grado de reproducción de la pobreza es claro, con porcentajes de hogares pobres entre los jóvenes que son responsables de hogar, descendiendo según las condiciones económicas fueron mejores, de un $44 \%$ de riesgo de pobreza entre quienes pertenecieron a un hogar en muy malas condiciones económicas a un $16 \%$ cuando estas fueron buenas o muy buenas. Las diferencias por comunidades autónomas son llamativas, el País Vasco, Madrid o Cataluña son comunidades con porcentajes de hogares en riesgo de pobreza del 11, 14 y $16 \%$, respectivamente, frente a Andalucía, Castilla-La Mancha y Extremadura, con el 29, 32 y $32 \%$, respectivamente. Es necesario tener en cuenta estos datos para poder realizar un análisis adecuado sobre los hogares en riesgo de pobreza regentados por jóvenes de entre 25 y 34 años de edad, pues aunque la tendencia es hacia mayores porcentajes de hogares de jóvenes con malas condiciones económicas, cuanto mayor porcentaje de hogares en toda la comunidad autónoma está en riesgo de pobreza, se observan datos que pudieran parecer discordantes, como que en el País Vasco, que es una de las comunidades donde menos hogares en riesgo de pobreza hay, el $11 \%$, de entre estos hogares, el $30 \%$ esté regentado por jóvenes, frente al $10 \%$ en Castilla-La Mancha, pero con un porcentaje en esta última de hogares totales en riesgo de pobreza del $32 \%$. En cualquier caso, es necesario considerar la variable lugar de residencia, además del origen familiar, en la valoración de las condiciones económicas de los jóvenes responsables de hogar. Con relación a la variable sexo es necesario advertir de la escasez de casos de mujeres responsables de hogar entre los 24 y 34 años de edad cuando se secciona el archivo de datos utilizado para los análisis, si bien se ha constatado cómo los hogares regentados por 
mujeres, tanto tomados en su totalidad como los que tienen por responsable una mujer joven, están en peores condiciones económicas que aquellos regentados por varones, aunque estas diferencias son menores si se comparan únicamente entre hogares jóvenes varones y mujeres.

Es posible afirmar que la estructura de la población no ha variado sustancialmente en lo que se refiere a ocupaciones profesionales y estatus socioeconómico en los últimos 20 años. Por otra parte, los cambios producidos tienen un sentido positivo, pues el número de mujeres que deciden trabajar fuera de hogar aumenta considerablemente, disminuye el porcentaje de obreros con poca o ninguna cualificación y aumentan ocupaciones de mayor cualificación. En los últimos cinco años lo más significativo es el aumento de parados, pero sigue manteniéndose básicamente la misma estructura de clases que en años anteriores. La cuestión de la transferencia intergeneracional de la pobreza es un hecho constatado que favorece el desigual acceso a la educación, al empleo y a la renta. Los datos muestran cómo se reproduce la desigualdad entre los jóvenes en función de su origen familiar, es cierto que tienen mayor formación que sus padres en cualquier caso, pero es un aumento en todas las categorías, por lo que las diferencias se siguen manteniendo. Estas mejoras manifiestas en el nivel formativo no se ven reflejadas en unas mejores condiciones económicas, pues un alto porcentaje de jóvenes que vivieron en hogares con buenas o muy buenas circunstancias económicas no las disfrutan en estos momentos. Por todo lo expuesto, es necesario considerar el origen familiar como un factor de primer orden en el análisis de la desigualdad y como elemento diferenciador entre los jóvenes a todos los niveles.

La emancipación residencial es en buena medida una decisión personal que corresponde a la voluntad de los individuos, si bien no se puede olvidar que las decisiones no se producen en un vacío social, por lo que en mayor o menor medida los procesos de 
transición han de ser estudiados desde una perspectiva holista. A los 23-25 años el porcentaje de jóvenes emancipados comienza a tener relevancia, con un $16 \%$, hasta llegar a los 32-34 años con un 76 \% de emancipados residencialmente. Son más las mujeres que los varones emancipados, esta información estaría claramente relacionada con las diferencias ya comentadas de un adelanto en las relaciones de vida en pareja y parentales de las mujeres respecto a los varones. Los estudios terminados también serían un factor diferenciador entre los emancipados con una clara tendencia a más emancipados residencialmente, entre el colectivo que es objeto de estudio, cuanto mayor es el nivel de estudios terminados. La relación que tiene estar trabajando y emancipado queda reflejada en el alto porcentaje de emancipados entre quienes son asalariados más trabajadores por cuenta propia, frente al resto de categorías de la variable relación con la actividad, parados, estudiantes, etc.

\section{Pluralidad en las transiciones}

La transición escolar y laboral, según han sido definidas para los análisis de esta tesis, se producirían básicamente en el mismo momento, los jóvenes dejan de estudiar e inmediatamente se convierten en activos laboralmente con independencia de que se esté o no trabajando. Con relación a las diferencias que se han observado en el periodo de precrisis y postcrisis y el porcentaje de jóvenes que está cursando algún tipo de estudios, hay que decir que las diferencias se observan hasta los 23-25 años, aumentando entre 10 y 15 puntos aquellos que deciden prolongar el periodo formativo entre el comienzo y término o en la salida de la crisis económica. Las diferencias por sexo se concentran en las cohortes intermedias, con diferencias entre varones y mujeres de entre 8 y 10 puntos a favor de las mujeres, no habría diferencias ni entre los más jóvenes, 17-19 años, ni entre 
los de mayor edad, 32-34 años. Con relación a la influencia en estar o no en formación y el riesgo de pobreza, cabría resumir el análisis realizado en el sentido de que la crisis económica no habría influido en los jóvenes pertenecientes a hogares pobres en cuanto a su intención de incrementar el periodo formativo, con la única excepción de la cohorte de 17-19 años, en la que sí habrían aumentado ligeramente aquellos que deciden estar en formación. Por el contrario, entre aquellos jóvenes que pertenecen a hogares sin riesgo de pobreza habrían aumentado considerablemente aquellos que deciden seguir formándose entre un periodo previo a la crisis y en la salida de esta. La ausencia de diferencias observadas entre los más jóvenes que viven en el medio rural frente a quienes viven en entornos más urbanizados indicaría unas idénticas posibilidades de formación para los ciclos formativos obligatorios, pero las diferencias observadas en las cohortes intermedias podrían reflejar unas menores oportunidades formativas para los jóvenes del medio rural frente a los que residen en los hábitats más urbanizados.

Con relación a la transición laboral, representada por la variable activo, la crisis económica habría retrasado la incorporación al mercado laboral entre los más jóvenes de los 17 a los 25 años de edad; las altas tasas de desempleo en el periodo de crisis provocan un retraso en la incorporación al mercado laboral entre los jóvenes, incrementándose el porcentaje de los que deciden seguir formándose. En cuanto a las diferencias por sexo, antes de la crisis ya se observan a partir de la cohorte más joven, 17-19 años, unas diferencias de unos 6 puntos, mientras en crisis no existe diferencia entre los varones y las mujeres más jóvenes. A partir de esta cohorte las diferencias se mantienen en torno a esos 6 puntos porcentuales en ambos periodos hasta los 26-28 años, donde las diferencias son escasas, al igual que en las siguientes cohortes inexistentes. Completar la transición laboral no presenta diferencias entre los más jóvenes, pero sí si se compara por periodos, habría más activos tanto sin, como con riesgo de pobreza en el año 2007 frente al año 
2014; en las cohortes intermedias siempre son más activos quienes no presentan riesgo de pobreza y de manera mucho más acentuada en el año 2007 respecto del año 2014. Según el tipo de hábitat no se observan diferencias entre los activos por cohortes en las de menor edad, 17-19 años, y a partir de los 26-28 años, para el resto de cohortes hay diferencias tanto por coyuntura económica como por tipo de hogar, en el sentido de mayor número de activos entre quienes viven en el medio rural en una coyuntura económica favorable.

Las pautas en la emancipación residencial no habrían variado entre los periodos precrisis y postcrisis económica, las diferencias que se observan son por sexo en todos los grupos de edad, con diferencias de 15 puntos más en las mujeres respecto de los varones, menos en las cohortes de menor edad, 17-22 años, donde el porcentaje de emancipados aún es muy bajo. Se ha observado un mayor porcentaje de jóvenes emancipados entre quienes viven en un hogar en riesgo de pobreza, y residir en un hábitat urbano o en uno rural no implicaría diferencias en cuanto a emancipados, como tampoco se han detectado diferencias destacadas entre los años que están sirviendo de referencia.

Con relación a las transiciones de vida en pareja y parental representadas por las variables tener pareja y ser padres, se puede llegar a la misma conclusión que para la emancipación, las diferencias en cuanto a tener cónyuge o pareja de hecho y ser padres están relacionadas con la edad y con el sexo, pero no con la coyuntura económica, la mayor parte de los jóvenes hasta los 20-22 años ni tienen ni viven en pareja ni son padres, a partir de los 23-25 años y de los 26-28 años, respectivamente para varones y mujeres, comenzaría a tener relevancia el porcentaje de jóvenes que viven en pareja o son padres. Las diferencias observadas en la transición hacia la vida en pareja con relación a si se pertenece a un hogar en riesgo de pobreza o no, se centran básicamente entre los 23 y 28 años, con entre 5 y 10 puntos porcentuales más para aquellos que pertenecen a hogares 
en riesgo de pobreza, no observándose diferencias por coyuntura económica. Con relación al tipo de hábitat, únicamente se observan diferencias sustanciales entre los que tienen 29-31 años, con unos 10 puntos porcentuales más con cónyuge o pareja de hecho entre aquellos que viven en el medio rural y con unos 5 puntos porcentuales más jóvenes con pareja de esta misma edad y unos 5 puntos entre los años 2007 y 2014.

\section{Momento de ocurrencia, duración y edad media a la que se producen los eventos de transición}

Teniendo en cuenta las diferencias por sexo y coyuntura económica, para la transición escolar, lo primero que llama la atención, tanto en varones como en mujeres, es lo prolongado de esta, se producen a lo largo de 12 o 13 años, lo que está indicando una diferencia ya sustancial en el colectivo que está siendo objeto de estudio; jóvenes que a los 21 años han culminado su trayectoria escolar junto a jóvenes que la prolongan hasta los 34 años de edad. Las diferencias entre varones y mujeres se producen en el sentido de un adelanto de la transición en los varones respecto de las mujeres de un año, y en las diferencias por año se observa cómo, tanto en varones como en mujeres, la crisis económica ha retrasado en dos años la transición escolar en los varones y en un año en las mujeres. El intervalo de años en los que se produce la transición laboral en el colectivo que se está estudiando es prácticamente idéntico a la transición escolar, es fácil pensar que cuando se terminan los estudios inmediatamente se incorporan al mercado laboral, por lo que los comentarios que se pueden hacer son los mismos que para la transición escolar. El periodo en el que se produce la transición residencial es sustancialmente más corto que las transiciones anteriores e igualmente presenta diferencias por sexo y coyuntura económica; en las mujeres comienza a producirse la transición residencial un 
año antes que entre los varones y se retrasa un año, tanto en varones como en mujeres, entre el año 2007 y el año 2015. La crisis habría retrasado ligeramente el comienzo de la transición residencial. La transición de vida en pareja se comienza a producir dos años antes en las mujeres que en los varones y la crisis económica habría retrasado el comienzo de esta transición dos años para los varones y uno para las mujeres. La transición parental se comienza a producir entre uno y dos años antes en las mujeres que en los varones, para estos últimos no se observa cambio alguno por periodos, pero sí para las mujeres, que retrasarían en uno o dos años el comienzo de esta transición en el año 2015 respecto al 2007 y al 2011.

Teniendo en cuenta el riesgo de pobreza, las diferencias en el momento del evento y su duración son más acusadas que diferenciando únicamente por sexo. Con relación a la transición escolar habría una diferencia en el comienzo de esta transición de hasta tres años antes entre quienes viven en riesgo de pobreza y quienes no. Por otra parte, la crisis económica habría modificado sustancialmente el momento de comienzo de la transición en los hogares sin riesgo de pobreza, retrasando el comienzo y el término de este proceso, pero no habría sufrido cambios significativos el colectivo que vive en hogares en riesgo de pobreza. La transición laboral se produciría en el mismo momento que la escolar, por lo que las pautas de comienzo y término son básicamente las mismas. La transición residencial se comienza a producir dos o tres años antes entre aquellos con malas condiciones económicas respecto de los que disfrutan de buenas condiciones; por otra parte, mientras la crisis económica habría retrasado en un año el comienzo de esta transición para los que tienen buenas condiciones económicas, para aquellos que viven en riesgo de pobreza se produce lo contrario, es decir, se adelanta en uno o dos años el comienzo de la transición residencial, de los 25 a los 24 años, y hasta los 34 años en ambos casos. El análisis que es posible realizar para las transiciones de vida en pareja y 
parental se produce en la misma línea, las transiciones comienzan a producirse dos o tres años antes entre quienes tienen peores condiciones económicas, no modificándose esta tendencia en crisis o salida de la crisis e incluso adelantando en un año la transición, como es el caso de la parental en el año 2015 respecto del 2007 y el 2011; entre los que tienen buenas condiciones económicas se observa un retraso en el comienzo de las transiciones entre el año 2007 y el año 2015, de los 25 años a los 28 años.

Si se tiene en cuenta el grado de urbanización del hábitat en el que se reside, el único dato que se ha observado relevante es el adelanto de la transición escolar de un año en el medio rural respecto del urbano. Para el resto de las transiciones no se observan diferencias en la duración de estos procesos por tipo de hábitat, sí teniendo en cuenta los periodos de referencias, constatándose el retraso de un año en el comienzo de las transiciones en crisis respecto del periodo que representa aún una buena coyuntura económica.

El cambio más evidente con relación a la edad media a la que se producen los eventos es el aumento de casi un año en la edad a la que se producen la transición escolar y la transición laboral. Esta información estaría claramente relacionada con el incremento del tiempo de formación y las dificultades de incorporación al mercado laboral durante los años de crisis económica. Por otra parte, las transiciones residencial, de vida en pareja y parental no experimentan un cambio apreciable, aunque sí una tendencia al retraso en producirse estos sucesos; de las tres transiciones, la transición a la vida en pareja es la que experimentaría un retraso mayor, de medio año. En los apartados anteriores se ha comprobado cómo la crisis económica no ha influido decisivamente en las pautas de emancipación residencial y creación de nuevos núcleos familiares tanto como cabría esperar, que las diferencias entre los jóvenes estarían más centradas en las diferencias por sexo y por pertenecer o no a un hogar en riesgo de pobreza. 
Con relación a las diferencias por sexo, las mujeres tienen una edad media mayor que los varones en 0,3 años para la transición escolar y laboral; la edad media, tanto de las mujeres como de los varones, habría subido un año hasta el 2013, con tendencia a bajar en el año 2015 para ambas transiciones. Con relación a la transición residencial, se observa una diferencia entre ambos sexos en la edad media de 0,5 años más para las mujeres que para los varones en todo el periodo y habrían subido la edad media medio año para ambos sexos, con una edad media de 30,9 años en varones y de 30,5 años en mujeres. Para la edad media en las transiciones de vida en pareja y parental se observa una diferencia entre los varones y mujeres de un año más para los varones y con un aumento en todo el periodo de medio año aproximadamente para ambos sexos.

Como ha sido la tónica general en toda la tesis, el riesgo de pobreza es el elemento que más influencia tiene en las diferencias, también con relación a la edad media a la que se producen las transiciones. Lo más llamativo es la diferencia en las transiciones escolar y laboral, ya en el 2007, año aún con buenas condiciones económicas en España, la diferencia entre la edad media para ambas transiciones fue de un año más entre quienes proceden de un entorno con normales o buenas condiciones económicas y los que sufren malas condiciones económicas, 28,2 años y 27,2 años, respectivamente. La crisis económica ahondaría en esta diferencia, con una edad media en las transiciones escolar y laboral para los que no están en riesgo de pobreza y sí lo están de dos años en 2015: 29,3 años y 27,3 años, respectivamente. En la transición residencial, la de vida en pareja y la parental para aquellos que no presentan riesgo de pobreza se observa en todo el periodo de referencia una diferencia de un año más con respecto a los que sí tienen riesgo de pobreza. A diferencia de las transiciones escolar y laboral, en el periodo de crisis no se incrementan sustancialmente las diferencias en estas transiciones, con una tendencia 
ascendente en la edad media en todas las transiciones y en las dos categorías de unos 0,5 años en la edad media a la que se producen estos sucesos entre el año 2007 y 2015.

La edad media en la que se produce la transición escolar y laboral es de medio año más para quienes viven en un hábitat urbano frente a quienes viven en el medio rural, no presentando diferencias apreciables entre los años que están sirviendo de referencia, si bien desde el comienzo de la crisis, y hasta el momento de la salida de la crisis, representados por los años 2007 y 2015, se produce un aumento de la edad media en ambos tipos de hábitat de entre 0,7 y 0,8 años para las transiciones escolar y laboral. Con relación al resto de las transiciones no se observa una diferencia que merezca atención, pero sí es posible advertir la tendencia a aumentar la edad media en todas estas transiciones desde el año 2007 al año 2015 de entre 0,5 a 0,8 años dependiendo de la transición y la categoría.

Los análisis realizados apuntan claramente hacia un aumento en la edad media en todas las transiciones desde el año 2007 al año 2015. Este aumento dependería de las variables independientes que se consideren y sería especialmente llamativo en las transiciones escolar y laboral, con aumento de un año en la edad media de estas transiciones e incremento de las diferencias cuando se cruza la variable riesgo de pobreza de dos años más de edad media entre quienes no tienen y sí tienen riesgo de pobreza. Por sexo, la edad media de las mujeres es ligeramente mayor que la de los varones en las transiciones escolar y laboral y mucho más acusada si nos referimos al resto de las transiciones, con diferencias en torno a medio año para la transición residencial y de casi un año para la conyugal o vida en pareja. Resulta llamativo el comportamiento de quienes viven en riesgo de pobreza y transiciones escolar y laboral, que no presentan ninguna variación en toda la secuencia, con la misma edad media antes, durante y en la salida de la crisis. 
Por último, se han comparado las edades medias entre comunidades autónomas para las transiciones escolar y laboral, con resultados medios en línea con lo comentado anteriormente, pero con unas diferencias muy notables entre comunidades. Aunque no con exactitud, es posible advertir cómo en las comunidades autónomas más ricas el aumento de la edad media en la transición escolar entre el año 2007 y el año 2015 es de entre 0,7 y 1,3 años, mientras en las comunidades más pobres estaría entre 0,3 y 0,6 años. Se produciría cierta analogía con la variable riesgo de pobreza, que se ha considerado habitualmente en la mayor parte de los análisis, en el sentido de que la crisis económica habría afectado más a las diferentes transiciones a aquellos que habitan en los territorios más ricos.

\section{Factores determinantes de la transición}

Lo que se ha conseguido con el análisis de regresión logística ha sido dar un mayor sentido a una buena parte de los resultados ofrecidos en los análisis descriptivos. Es posible resumir los resultados advirtiendo que la edad, lógicamente, es un factor que influye decisivamente en la probabilidad de los procesos de transición, aunque con los matices que se han ofrecido en los epígrafes anteriores. Ser una persona activa o pertenecer a un hogar en riesgo de pobreza aumenta la probabilidad de ser padre. Tener estudios secundarios o superiores aumenta la probabilidad de cursar algún tipo de estudios, mientras que pertenecer a un hogar en riesgo de pobreza la disminuye. En los años de crisis y postcrisis, la probabilidad de cursar algún tipo de estudios aumentó con respecto a los años anteriores a la crisis. Con respecto al hábitat, vivir en un entorno urbano aumenta la probabilidad de estar estudiando con respecto a vivir en un entorno rural. El hecho de ser mujer disminuye la probabilidad de ser activo con respecto a los 
hombres, por el contrario, tener estudios secundarios o superiores aumenta la probabilidad de ser activo, mientras que estar cursando algún tipo de estudios la disminuye. Pertenecer a un hogar en riesgo de pobreza también disminuye esta probabilidad, mientras que en los años de postcrisis la probabilidad de completar la transición laboral aumenta con respecto a los años anteriores a la crisis. El hecho de ser mujer aumenta la probabilidad de emanciparse con respecto a los hombres, por el contrario, tener estudios superiores disminuye la probabilidad de emanciparse y el hecho de estar cursando algún tipo de estudios la disminuye igualmente. Ser una persona activa y pertenecer a un hogar en riesgo de pobreza aumenta la probabilidad de emancipación, mientras que en los años de crisis y de postcrisis la probabilidad de emanciparse disminuye con respecto a los años anteriores a la crisis. El hecho de ser mujer aumenta la probabilidad de tener pareja con respecto a los varones, mientras que tener estudios superiores y estar cursando algún tipo de estudios la disminuye. En los años de crisis y postcrisis la probabilidad de vivir en pareja disminuyó con respecto a los años anteriores a la crisis. Y por último, el hecho de ser mujer aumenta también la probabilidad de tener hijos respecto a los varones. Ser una persona activa o pertenecer a un hogar en riesgo de pobreza también aumenta la probabilidad de tener hijos. Tener estudios secundarios o superiores y estar cursando algún tipo de estudios disminuye la probabilidad de tenerlos. En los años de crisis y postcrisis la probabilidad de tener hijos disminuyó con respecto a los años anteriores a la crisis. Con respecto al hábitat, vivir en un entorno urbano disminuye la probabilidad de tener hijos con respecto a vivir en un entorno rural. 


\section{La heterogeneidad en la transición y el índice de entropía}

La posibilidad del índice de entropía en la medida de la heterogeneidad entre los jóvenes con relación a la complejidad en la asunción de los roles de adultos, queda explicitada en los indicadores que se han ofrecido en el análisis de resultados correspondiente. En este sentido, la heterogeneidad aumenta progresivamente desde las cohortes más jóvenes hasta las de mayor edad, las mujeres presentan mayores índices de entropía, es decir, de heterogeneidad que los varones, adelantando tres años la salida hacia adultez. Sería posible decir que las mujeres son jóvenes durante menos tiempo que los varones, comienzan su transición en el mismo momento, pero más intensamente que los varones y terminan en torno a tres años antes que estos. Por diferente coyuntura económica, se observa una disminución de la heterogeneidad entre los más jóvenes motivada por las dificultades en el acceso al mercado laboral, lo que repercute en que más jóvenes se encuentren estudiando y no trabajando; aunque los datos no son concluyentes, se observa un cierto alargamiento en la transición hacia la adultez en el periodo que corresponde con la salida de la crisis respecto del periodo previo a la crisis.

En resumen, con relación a las diferencias por sexo, en las mujeres se produce una mayor complejidad en cuanto a la simultaneidad de estatus en toda la transición hacia la adultez, y esta se completaría tres años antes que en los varones, no observándose diferencias por coyuntura económica, salvo en las cohortes de menor edad.

Se produce un retraso en la salida de la transición entre los que pertenecen a hogares con buenas condiciones económicas frente a aquellos en riesgo de pobreza; la lectura es posible hacerla para ambos periodos, estando el ápice de heterogeneidad (que correspondería con el final de la transición) entre quienes menos recursos tienen en su hogar de origen a los 29-31 años, frente a los 32-34 cuando en los hogares a los que se 
pertenece tienen mejores condiciones económicas, con un $64 \%$ y $61 \%$, respectivamente. La entropía es mayor en aquellos que pertenecen a hogares en riesgo de pobreza, con algunas diferencias por edad y periodo; en este sentido, entre los que pertenecen a hogares en riesgo de pobreza las diferencias entre periodos son pequeñas, entre 3 y 4 puntos porcentuales y únicamente entre las cohortes de menor edad, 17-25 años. Entre quienes pertenecen a hogares sin riesgo de pobreza las diferencias son mayores, entre 8 y 12 puntos, pero únicamente en las dos cohortes de los de menor edad: 17-19 y 20-22 años. En resumen, las diferencias no estarían tanto entre periodos, estarían especialmente influenciadas por el riesgo de pobreza, con una mayor heterogeneidad entre quienes son más pobres y un periodo de transición de una cohorte menos.

Las diferencias para aquellos que residen en un hábitat urbano y entre los dos periodos de referencia, únicamente se producirían en las cohortes de menor edad, para el resto se podría decir que no existen diferencias entre el periodo previo a la crisis económica, 20062007, y el periodo que corresponde con la salida de la crisis, 2014-2015. Con relación al momento del término de la transición, se habría producido un retraso de una cohorte de tres años considerando la variable hábitat. Para aquellos que residen en un hábitat rural, la heterogeneidad es mayor en las cohortes de menor edad y terminarían la transición antes en el periodo de postcrisis que en el periodo de precrisis en una cohorte de tres años, a los 29-31 años en postcrisis y a los 32-34 años en precrisis.

Con relación a cuál es el peso en las diferencias de cada estatus, se ha presentado el análisis para el periodo precrisis y postcrisis y por cohortes. La influencia en las diferencias en los más jóvenes está determinada por los estatus de estudiante y activo, con pocas diferencias entre ambos en los años previos a la crisis, pero con peso mucho más importante para el estatus de estudiante en la salida de la crisis. Según se avanza en las cohortes de mayor edad disminuye el peso que tiene el estatus de estudiante, aumenta el 
peso del estatus de activo y a los 20-22 años comienza a tener relevancia el estatus de emancipado, con un $12 \%$ en ambos periodos; para esta cohorte disminuye mucho el peso del estatus de estudiante en precrisis, pero se mantiene muy alto en postcrisis: $28 \% \mathrm{y}$ $40 \%$, respectivamente. En las cohortes que corresponden a edades de entre 26 y 34 años, tienen importancia en las diferencias el estar emancipado, tener cónyuge y ser padre; este último estatus tiene poca relevancia en las diferencias, especialmente en el periodo que corresponde con la salida de la crisis. Sería posible resumir este análisis diciendo que la heterogeneidad entre los jóvenes, medida a través del índice de entropía para una distribución de todas las posibles combinaciones de los cinco estatus que se han considerado (estudiante, activo, emancipado, pareja y padre) aumenta con la edad y en las cohortes de los más jóvenes, 17-22 años, también de un periodo de precrisis a postcrisis; que para estas cohortes, las de menor edad, únicamente tienen relevancia los estatus de estudiante y activo; que el estatus de emancipado comienza a tener relevancia en la heterogeneidad a partir de los 20-22 años y con más claridad a partir de los 23 a los 25 años; que el estatus de pareja comienza a tener alguna influencia a partir de los 23-25 años y más claramente de los 26 a los 28 años y que el estatus de padre únicamente tiene influencia en las diferencias en las cohortes de mayor edad, y en escasa medida.

\section{Discusión final}

La literatura evidencia que los jóvenes estarían ubicados en la estructura de clase y económica heredada de sus padres que condicionaría las posibilidades de construir sus propios itinerarios de transición, hay que decir que efectivamente dos de los elementos que más influencia tienen en las diferencias entre los jóvenes son el pertenecer a una hogar en riesgo de pobreza y la reproducción intergeneracional. Diversos trabajos centran su atención en la influencia de la clase social y el contexto familiar en la manera de afrontar la transición hacia la vida adulta (Becker et al., 2005; Berrington y Falkingham, 
2010; Sironi et al., 2015) constatando la importancia y las diferencias de pertenecer a un hogar de origen con condiciones socioeconómicas mejores o peores, sin embargo hay que recordar las diferencias de los países mediterráneos con respecto al resto, en este caso la salida del hogar se adelanta en las familias con menos recursos y se atrasa entre aquellos jóvenes que pertenecen a familias con más recursos, al contrario que en los países del centro y norte de Europa. Los datos muestran cómo se reproduce la desigualdad entre los jóvenes en función de su origen familiar, es cierto que tienen mayor formación que sus padres en cualquier caso, pero es un aumento en todas las categorías, por lo que las diferencias se siguen manteniendo. Estas mejoras manifiestas en el nivel formativo no se ven reflejadas en unas mejores condiciones a la hora de afrontar las transiciones, pues un alto porcentaje de jóvenes que vivieron en hogares con buenas o muy buenas circunstancias económicas no las disfrutan en estos momentos, los eventos de transición empobrecen a los jóvenes, al menos transitoriamente como también se ha comprobado en las aportaciones de Aassve et al. (2005)

Por otra parte se ha constatado con claridad cómo el nivel de estudios terminado es otro elemento diferenciador de primer orden y que como se apuntaba en la hipótesis, el nivel de estudios alcanzado discrimina a los jóvenes y que la escuela no compensaría las diferencias asociadas al origen social, en Fernández (2003) ya se apunta esta realidad a pesar de los cambios legislativos que se vienen produciendo en España en las últimas décadas. Las altas tasas de fracaso escolar, los problemas de empleabilidad y paradójicamente en otros casos la sobre cualificación son cuestiones que condicionan los procesos de transición y la situación de precariedad de jóvenes españoles (Moreno et al., 2012; Santamaria, 2012; Gentile, 2013) se ha aportado información al respecto observando los cambios producidos en los diferentes periodos económicos, sexo, pobreza y un elemento poco tratado como el tipo de hábitat donde se reside, observando unas 
peores condiciones formativas y laborales en las zonas poco urbanizadas pero produciéndose unas transiciones más rápidas. Aunque se ha constatado el efecto de los periodos de diferente coyuntura económica, las diferencias no estarían tanto entre periodos, estarían especialmente influenciadas por el riesgo de pobreza, con una mayor heterogeneidad entre quienes son más pobres y un periodo de transición más corto.

Las dificultades de acceso al empleo en tiempos de crisis han inducido a los jóvenes, especialmente en los intervalos de menor edad, a prolongar el periodo formativo. El coste de oportunidad al que se hace referencia en el apartado teórico con relación a continuar o no con la formación o incorporase al mercado laboral disminuye en periodos de crisis ante la dificultad de encontrar un empleo, lo que induce a un incremento del tiempo de formación (García, 2009) Aunque el número de ocupados aumenta cuando se tiene un nivel de estudios superior, hay que matizar que en periodos donde la coyuntura económica es favorable la formación no condiciona excesivamente la incorporación al mercado laboral. Los indicadores oficiales muestran una dualidad muy acusada en cuanto a la formación entre los jóvenes españoles, con unos niveles de fracaso escolar de entre los más elevados de los países de la OCDE y, por el contrario, un porcentaje de jóvenes universitarios por encima de la media de entre los países de la Unión Europea.

Una gran parte de los estudios de transición consultados ofrecen diferencias por sexo, algunos de ellos explícitamente entre sus objetivos como La Parra (2000) en España y a nivel Europeo y más recientemente Toulemon (2010) quien ha constatado la evolución hacia una disminución de las diferencias entre hombres y mujeres jóvenes. Las diferencias por sexo aumentan en la Europa del Este y disminuyen en España y Portugal en especial entre las mujeres nacidas en la décadas de los 70. En el presente trabajo se actualizan datos para el caso de España y las diferencias que se observan entre varones y mujeres disminuyen ligeramente en el contexto de crisis económica pero dependen del tipo de 
transición y de la edad, las mujeres prolongan más su periodo formativo, están menos ocupadas y viven en pareja y tienen hijos antes que los varones. En las mujeres se produce una mayor complejidad en cuanto a la simultaneidad de estatus en toda la transición hacia la adultez, y esta se completaría tres años antes que en los varones, no observándose diferencias por coyuntura económica, salvo en las cohortes de menor edad en el sentido de un adelanto de la transición en los varones respecto de las mujeres.

Los efectos de la crisis económica se han sentido en todos los países, si bien los modelos de Estado de bienestar pueden haber contribuido a minimizar los efectos adversos en los procesos de transición (Meda, 2015; Rugg y Quilgars, 2015; Ortega et al., 2016) En España con un Estado de bienestar más débil que en los países del centro y norte de Europa y con políticas positivas hacia los jóvenes de escasa entidad, habrían contribuido a unas mayores dificultades en el acceso al trabajo o a la vivienda. Los análisis realizados apuntan claramente hacia un aumento en la edad media en todas las transiciones desde el año 2007 al año 2015. La pobreza y la inseguridad laboral son circunstancias valoradas por Becker et al. (2005) y Fahmy (2007) donde se ofrecen análisis sobre las consecuencias en los procesos de transición, resulta relevante la comparación de los periodos de diferente coyuntura económica que corroborarían estas aportaciones.

Es posible resumir los resultados advirtiendo que la edad, lógicamente, es un factor que influye decisivamente en la probabilidad de los procesos de transición, aunque con los matices que se han ofrecido en los epígrafes anteriores. Ser una persona activa o pertenecer a un hogar en riesgo de pobreza aumenta la probabilidad de ser padre. Tener estudios secundarios o superiores aumenta la probabilidad de cursar algún tipo de estudios, mientras que pertenecer a un hogar en riesgo de pobreza la disminuye. En los años de crisis y postcrisis, la probabilidad de cursar algún tipo de estudios aumentó con respecto a los años anteriores a la crisis. Con respecto al hábitat, vivir en un entorno 
urbano aumenta la probabilidad de estar estudiando con respecto a vivir en un entorno rural. El hecho de ser mujer disminuye la probabilidad de ser activo con respecto a los hombres, por el contrario, tener estudios secundarios o superiores aumenta la probabilidad de ser activo, mientras que estar cursando algún tipo de estudios la disminuye. Pertenecer a un hogar en riesgo de pobreza también disminuye esta probabilidad, mientras que en los años de postcrisis la probabilidad de completar la transición laboral aumenta con respecto a los años anteriores a la crisis. El hecho de ser mujer aumenta la probabilidad de emanciparse con respecto a los hombres, por el contrario, tener estudios superiores disminuye la probabilidad de emanciparse y el hecho de estar cursando algún tipo de estudios la disminuye igualmente. Ser una persona activa y pertenecer a un hogar en riesgo de pobreza aumenta la probabilidad de emancipación, mientras que en los años de crisis y de postcrisis la probabilidad de emanciparse disminuye con respecto a los años anteriores a la crisis. El hecho de ser mujer aumenta la probabilidad de tener pareja con respecto a los varones, mientras que tener estudios superiores y estar cursando algún tipo de estudios la disminuye.

Serán necesarios nuevos estudios para evaluar de qué manera los jóvenes hacen frente a las dificultades en los procesos de transición desde la perspectivas del curso de vida, Furstenberg (2005) sostiene cómo desde la perspectiva del curso de la vida los sucesos inoportunos e imprevistos, las secuencias de estatus o estados desordenadas o transiciones no normalizadas, tendrían consecuencias para el éxito en los itinerarios de transición y generan estrategias o acciones correctivas que minimizarían las posibles consecuencias negativas de una transición no normalizada. En los jóvenes se producen elecciones y estrategias para hacer frente a los determinismos estructurales y contextuales que provocan las diferencias y desigualdades, en especial por sexo y condiciones económicas de origen, como se ha comprobado reiteradamente en todo este trabajo; la decisión de 
prolongar la formación, de retrasar la emancipación residencial, la vida en pareja o la paternidad serían parte de estas estrategias de adaptación, aunque hay que recordar que ninguna estrategia se origina en un vacío social, por lo que la influencia de los elementos estructurales como es el contexto, la cultura o la familia serían básicos en las diferencias y la desigualdad entre los jóvenes observada desde sus transiciones y las variables que las definen.

En el trabajo que se cocluye se han utilizado datos transversales de varios años que han permitido construir secuencias amplias donde comparar diferentes periodos y observar en el tiempo cómo ha cambiado la estructura de las transiciones hacia la adultez en su descomposición más clásica (escolar, laboral, residencial, vida en pareja y parental) las diferencias observadas teniendo en cuenta las variables independientes que se han considerado (edad, sexo, formación, riesgo de pobreza o grado de urbanización del hábitat donde se reside) revelan un alto grado de desestandarización en las transición, especialmente por razón de sexo y pobreza, que plantean la necesidad de estudios longitudinales que aporten información sobre las estrategias que los jóvenes utilizan para hacer frente a las distorsiones que se producen en la secuencia normalizada de transición y a la reversibilidad o no ocurrencia de algunos de los eventos de transición como señalan (Bois-Reymond y López, 2004; Furstenberg, 2005; Robette, 2010; Iacovou, 2011)

\section{Implicaciones prácticas}

Por último, recordaremos el sentido práctico que se pretende con este estudio, que no es otro que poner de manifiesto las diferencias y desigualdades entre los jóvenes analizando los procesos de transición hacia la adultez, de tal manera que las dificultades que tienen

que hacer frente las personas no deberían encorsetarse en cohortes de edad, pues es necesario tener en cuenta otros factores para poder evaluar con objetividad estas 
necesidades. Desde las administraciones públicas deberían valorarse estas diferencias a la hora de la aplicación de políticas de discriminación positiva hacia un colectivo determinado, pues basar estas políticas únicamente en la edad resultaría injusto a tenor de las grandes diferencias que se han observado. Por haber nacido un día antes o después es posible tener o no acceso a una ayuda a la emancipación residencial, por haber nacido un día antes o después es posible acceder, o no, a un plan de empleo o formativo, por haber nacido un día antes o después puedes, o no, consumir bebidas alcohólicas, o acceder a determinados locales, o consentir relaciones sexuales, o tener responsabilidades penales o no tenerlas, etc. Por muy operativo que sea determinar una edad para este tipo de decisiones legales o administrativas, no se debería caer en el simplismo que esto supone; es necesario articular otros mecanismos que aporten una mayor coherencia y justicia. Deberían ser las necesidades reales las que den acceso a determinados derechos, ayudas o cualesquiera otras atribuciones que los Estados, a través de las administraciones públicas, consideren adecuadas para hacer efectiva la igualdad de derechos y obligaciones de todos los ciudadanos con independencia de la edad. 


\section{REFERENCIAS BIBLIOGRÁFICAS}

Aassve, A., Davia, M. A., Iacovou, M., y Mencarini, L. (2005). Poverty and the transition to adulthood: risky situations and risky events (23). ISER Working Paper Series.

Aguinaga, J., y Comas, D. (2008). La juventud española entre la negación y la mitificación. En S. Campo y J. F. Tezanos (Eds.), La sociedad (pp. 235-239). Madrid: Biblioteca Nueva.

Alaminos, A. (2008). La juventud y sus límites operativos. Revista Obets, número 2.

Albert, C., y Davia, M. A. (2011). Pobreza monetaria, exclusión educativa y privación material de los jóvenes. Revista de Economía Aplicada (56), 59-88.

Albertini, M. (2010). La ayuda de los padres españoles a los jóvenes adultos. El familismo español en perspectiva comparada. Revista de Estudios de Juventud (90), 67-81.

Albertini, M., Martín, K., y Vogel, Cl. (2007). Intergenerational transfers of time and money in European families: common patterns different regimes? Journal of European Social Policy 2007 (17), 319. doi: 10.1177/0958928707081068

Albertini, M., y Radl, J. (2012). Intergenerational transfers and social class: Inter-vivos transfers as means of status reproduction? Acta Sociológica, 55 (2), 107-123.

Alonso, L. E., y Fernández, C. J. (2009). De la norma del consumo al consumo sin norma: Precariedad laboral, especulación inmobiliaria y nuevas formas de consumo en España. En J. F. Tezanos (Ed.), Juventud y exclusión social. (pp. 113-130). Madrid: Editorial Sistema.

Arocena, R., y Sutz, J. (2003). Subdesarrollo e innovación. Navegando contra el viento. Organización de Estados Iberoamericanos para la Educación, la Ciencia y la Cultura (OEI) / Cambridge University Press.

Barbería, J. L. (2009). Generación 'ni-ni': ni estudia ni trabaja. El País, 22/06/2009.

Bataller, J. C., Soler, M. G., Merino, R., y Quesada, M. (2007). Itinerarios y trayectorias: una perspectiva de la transición de la escuela al trabajo. Trayectorias: revista de ciencias sociales de la Universidad Nacional de Nuevo León (22), 9-20. 
Becerra, G. (2011). Las propuestas de Ian Hacking y Judith Butler sobre lo socialmente construido. El caso de la «juventud» en la mirada sociológica. Nómadas. Revista Crítica de Ciencias Sociales y Jurídicas, 32 (4), 45-61.

Beck, U. (1998). La sociedad del riesgo: hacia una nueva modernidad. Barcelona: Paidós.

Beck, U. (2003). Un nuevo mundo feliz: La precariedad del trabajo en la era de la globalización. Barcelona: Paidós, pp. 11, 103-106.

Becker, G. S. (2005). Inversión capital humano e ingresos. En L. Toharia (Ed.), El mercado de trabajo: Teorías y aplicaciones. Madrid: Alianza.

Becker, S. O., Bentolila, S., Fernandes, A., e Ichino, A. (2010). Youth emancipation and perceived job insecurity of parents and children. Journal of Population Economics, 23 (3), 1047-1071.

Bell, D. (1980). The New Class: A Muddled Concept. En Essays and Sociological Journeys 1966-1980 (pp. 144-164). Cambribge: Abt Books.

Benedicto, J. (2008). La juventud frente a la política: ¿desenganchada, escéptica, alternativa o las tres cosas a la vez? Revista de estudios de juventud, (81), 13-28.

Bermúdez-Lobera, J. (2010). Las transiciones a la adultez de los jóvenes que no estudian ni trabajan (ninis) en México. Papeles de Población, vol. 20, núm. 79 (enero-marzo, 2014), 243-279.

Bird, K. y Krüger, H. (2005). The secret of transitions: The interplay of complexity and reduction in life course analysis. Advances in life course research, (10), 173-194.

Blanco, M. M. (2015). El enfoque del curso de vida: orígenes y desarrollo. Revista Latinoamericana de Población (8), 5-31.

Blanes, A., Gil, F., y Pérez, J. (1996): Población y actividad en España: evolución y perspectivas. Colección Estudios e Informes, $n .^{\circ}$ 5, Barcelona: Caja de Ahorros y Pensiones de Barcelona.

Bourdieu, P. (1984). Questions de sociologie. París: Minuit.

Brint, S. (1994). In an Age of Experts: The Changing Role of Professionals in Politics and Public Life. Princeton: Princeton University Press. 
Bruce-Briggs, B. (1979). The New Class? New Brunswick: Transaction Press.

Brunet, I., y Pizzi, A. (2013). El enfoque nominalista de la juventud. Una alternativa crítica a la perspectiva funcionalista. Revista Latinoamericana de Ciencias Sociales, Niñez y Juventud, 11 (1), 51-62.

Brunet, I., y Pizzi, A. (2013). La delimitación sociológica de la juventud. Última Década, n. 38 . CIDPA Valparaíso, 11-36.

Calvo, E. G. (2009). Trayectorias y transiciones: ¿qué rumbos? Revista de Estudios de Juventud, (87), 15-30.

Carbajo, D. (2014). Vivir en la precariedad. Trayectorias y estrategias residenciales de la juventud en la Comunidad Autónoma del País Vasco. Tesis doctoral. Directores: Benjamín Tejerina y Iñaki Martinez, Universidad del País Vasco. Recuperada el día 5/7/2017 en https://addi.ehu.es/bitstream/handle/10810/18295/9082-414-6CarbajoTH.pdf?sequence $=1$

Cardenal de la Nuez, M. E. (2006). El paso a la vida adulta. Dilemas y estrategias ante el empleo flexible. CIS (Centro de Investigaciones Sociológicas). Madrid.

Casal, J., García, M., Merino, M., y Quesada, R. M. (2006) Aportaciones teóricas y metodológicas a la sociología de la juventud desde la perspectiva de la transición. Revista de Sociología. Universidad Autónoma de Barcelona, (79), 21-48.

Castells, M. (1997). La era de la información. Economía, sociedad y cultura, 3 vols. Madrid: Alianza Editorial. [1997, vol. 1; 1998, vols. 2 y 3].

CAUCES (2013). Jóvenes que ni estudian ni trabajan: aprendiendo a conocerlos. Cuadernos del Consejo Económico y Social, n. ${ }^{\circ} 22,29-35$.

Comas, D. (2011). ¿Por qué son necesarias las políticas de juventud? Revista de Estudios de Juventud. Septiembre de 2011, n. ${ }^{\circ} 44$.

Consejo de la Juventud de España (2014). Observatorio de emancipación (Tercer trimestre de 2014). http://www.cje.org/es/publicaciones/novedades/observatorio-deemancipacion-n-7-tercer-trimestre-2014/

Corbetta, P. (2007). Metodología y técnicas de investigación social. Madrid: McGrawHill. 
Dagum, C. (1993). Fundamentos de Bienestar Social de las medidas desigualdad en la distribución de la renta. Cuadernos de Ciencias Económicas y Empresariales, (24), 1136.

Del Campo, S., y Del Mar Rodríguez-Brioso, M. (2002). La gran transformación de la familia española durante la segunda mitad del siglo XX. Reis: Revista Española de Investigaciones Sociológicas, (100), 103-165.

Du Bois-Reymond, M., \& López Blasco, A. (2004). Transiciones tipo yo-yo y trayectorias fallidas: hacia las políticas integradas de transición para los jóvenes europeos. Revista de Estudios de Juventud, 65(04), 11-29.

Echeverría, J. (2006). La movilidad social: pautas y tendencias. En J. J. González y M. Requena (Eds.), Tres décadas de cambio social en España. Madrid: Alianza Editorial.

Elder Jr, G. H. (1999). Children of the Great Depression: Social change in life experience. Westview Press.

Elder Jr., G. H. (1994). Time, human agency, and social change: Perspectives on the life course. Social Psychology Quarterly, 4-15.

Elder, G. H. (1998). The life course as developmental theory. Child development, 69 (1), $1-12$.

Eurobarómetro (2014). European youth 2014. Analytical synthesis. Flash Eurobarometer of the European Parliament (EP EB395).

Fahmy, E. (2007). Poverty and Youth Transitions in Europe: An Analysis of the European Communities Household Panel. En H. Colley, P. Boetzelen, B. Hoskins y T. Parveva (Eds.), Social inclusion for young people: breaking down the barriers. Council of Europe Publishing.

Feixa, C. (2006). Generación XX. Teorías sobre la juventud en la era contemporánea. Revista Latinoamericana de Ciencias Sociales, Niñez y Juventud, 4(2), $21-45$.

Fergurson, C. (productor y director). (2010). Inside job. Estados Unidos: Sony Pictures Classics.

Fernández, M. (2003). Política educativa, igualdad de oportunidades y pensamiento político. Claves de Razón Práctica, (129), 64-69. 
Fernández, M. (2009). La Economía Española Después de la Crisis, Bol. Econ. BDE, Febrero 2009.

Flaquer, L. (2007). Familia y políticas públicas. Anuario de la Facultad de Derecho de la Universidad Autónoma de Madrid, (10).

Furstenberg, F. F. (2005). Non-normative life course transitions: reflections on the significance of demographic events on lives. Advances in Life Course Research, (10), 155-172.

Furstenberg, F. F. (2010). On a new schedule: Transitions to adulthood and family change. The future of children, 20 (1), 67-87.

Fussell, E., Gauthier, A. H., y Evans, A. (2007). Heterogeneity in the transition to adulthood: The cases of Australia, Canada, and the United States. European Journal of Population/Revue Européenne de Démographie, 23 (3-4), 389-414.

García Montalvo, J. (2009). El mercado laboral de los jóvenes en España. En J. F. Tezanos (Ed.), Juventud y exclusión social (pp. 89-101). Madrid: Editorial Sistema.

García, C., Garrido, L., y Toharia, L. (1999). Empleo y paro en España: Algunas cuestiones candentes. En F. Minguelez y C. Prieto (Eds.), Las relaciones de empleo en España. Madrid: Siglo Veintiuno Editores.

Garrido Medina, L., y González, J. J. (2006). Mercado de trabajo, ocupación y clases sociales. En J. J. González y M. Requena (Eds.), Tres décadas de cambio social en España (p. 112). Madrid: Alianza Editorial.

Garrido, L. y Chuliá, E. (2005). Ocupación, formación y el futuro de la jubilación en España. Colección Estudios, n. ${ }^{\circ}$ 173. Madrid: Consejo Económico y Social.

Gentile, A. (2007). Transición a la vida adulta y políticas de juventud: los casos de España y Suecia. VIII Congreso Español de Ciencia Política y de la Administración Política para un mundo en cambio. Valencia.

Gentile, A. (2016). La emancipación juvenil en tiempos de crisis: un diagnóstico para impulsar la inserción laboral y la transición residencial. METAMORFOSIS, 119-124.

Giddens, A. y Bollo Muro, J. (1979). La estructura de clases en las sociedades avanzadas. Madrid: Alianza, pp. 202, 313, 341. 
Gil, V. J., Salas, C. T., y Alegría, J. M. S. (2013). Desigualdad multidimensional en el bienestar a nivel mundial mediante índices de entropía generalizada. En Estado del bienestar: sostenibilidad y reformas (p. 53). Universidad de Sevilla.

Gómez, A. (2003). Filosofía y metodología de las ciencias sociales. Madrid: Alianza Editorial.

Gouldner, A. (1985). El futuro de los intelectuales y el ascenso de la nueva clase. Madrid: Alianza Editorial.

Gutierrez, J. (2013). La paradoja del cambio generacional en la isla de La Gomera: consecuencias demográficas, sociales y económicas. Tesis doctoral. Universidad de la Laguna.

Hareven, T. K. (1995). Historia de la familia y la complejidad del cambio social. Revista de demografía histórica, 13 (1), 99-150.

Hareven, T. K., y Gruyere, A. (2014). La generación de en medio. Comparación de cohortes de ayuda a padres de edad avanzada dentro de una comunidad estadounidense. Desacatos. Revista de Antropología Social, (2), 50-72.

Hessel, S., Sampedro, J. L., y Moreno, T. (2011). ¡Indignaos! Un alegato contra la indiferencia y a favor de la insurrección pacífica (6. ${ }^{\mathrm{a}}$ imp. ed.). Barcelona: Destino. http://www.recp.es/uploads/files/congresos/congreso_08/area6/GT-18/GENTILEALESSANDRO.pdf día 4/7/2017

Iacovou, M. (2011). Leaving home: independence, togetherness and income in Europe. United Nations, Department of Economic and Social Affairs. Population Division.

Iglesias de Ussel, J., y Ayuso Sánchez, L. (2005). La familia, una institución en continuo cambio. En J. Iglesias de Ussel y A. Trinidad Requena (Eds.), Leer la sociedad: una introducción a la sociología general. Madrid: Tecnos.

Inglehart, R. (1991). El cambio cultural en las sociedades industriales avanzadas. Madrid: Centro de Investigaciones Sociológicas.

Jurado, T. (2006). Las nuevas familias españolas. En J. J. González y M. Requena (Eds.), Tres décadas de cambio social en España. Madrid: Alianza Editorial.

Kerbo, H. R., Requena, M., y González, J. J. (2004). Estratificación social y desigualdad: el conflicto de clase en perspectiva histórica, comparada y global. Madrid: McGrawHill. 
La Parra Casado, D. (2000). Desigualdades de género durante la transición a la vida adulta. Papers: revista de sociología, (61), 113-124.

Leccardi, C. (2010). La juventud, el cambio social y la familia: De una cultura "de protección" a una cultura "de negociación". Revista de Estudios de Juventud, (90), 33-42.

Lechuga, M. L. (1998). La distribución Gamma como modelo para analizar la distribución de la renta: Una aplicación a la EPF 1990-1991. Revista de Estudios Regionales, (50), 161-186.

Livi Bacci, M. (2001): A Concise History of World Population (3. ${ }^{\mathrm{a}}$ ed.), Oxford: Blackwell.

López, A., y Segado, S. (2009). Jóvenes, accidentes debidos al tráfico y riesgos laborales: estrategias para mejorar las condiciones de seguridad y salud en el trabajo. Madrid: INJUVE.

Lugo, M. A. (2005). Medidas de desigualdad para variables educativas. Sistemas de Información de Tendencias Educativas en América Latina. http://www.siteal.iipe-oei.org Boletín n. 4.

MacInnes, J., y Pérez, J. (2005). The reproductive revolution. XXV Conferència Internacional de Població, IUSSP. Tours, 18-23 de juliol de 2005. Centre d'Estudis Demogràfics.

MacInnes, J., y Pérez, J. (2008). La tercera revolución de la modernidad; la revolución reproductiva. Reis: Revista Española de Investigaciones Sociológicas, (122), 89-118.

Macionis, J., y Plummer, K. (1999). Sociología. Madrid: Prentice Hall.

Macunovich, D. J. (2012). The role of demographics in precipitating economic downturns. Journal of Population Economics, 25(3), 783-807.

Macy, M. (1988). New Class Dissent among Social-Cultural Specialists. Sociological Forum 3, 325-356.

Martín Criado, E. (1998). Producir la juventud. Madrid: Ediciones Istmo.

Martínez García, J. S. (2013). Fracaso escolar, PISA y la difícil ESO. RASE: Revista de la Asociación de Sociología de la Educación, 2(1), 56-85. 
Meil, G. (2010). Padres e hijos en la España actual. Colección estudios sociales, 19. Barcelona: Fundación La Caixa.

Merino, R. (2006). Participación y asociacionismo de los jóvenes en Europa. Tendencias sociales y retos sociopolíticos. Revista internacional de sociología, 64(43), 193-215.

Merino, R., Casal, J., y García, M. (2006). ¿Vías o itinerarios en el sistema educativo? La comprensividad y la formación profesional a debate. Revista de Educación, 340, 10651083.

Ministerio de Educación Cultura y Deporte (2012). Panorama de la Educación. Indicadores de la OCDE 2012, informe español.

Ministerio de Educación Cultura y Deportes (2012). Sistema Estatal de Indicadores de la Educación.

Morales, A. F., y Costa, M. (1998). Descomposición de los índices de Gini y entropía generalizada: desigualdad y nivel de estudios en España e Italia (1991). Estadística Española, 40 (143), 233-256.

Moreno A. (2005). Empleo de la mujer y familia en los regímenes de bienestar del sur de Europa en perspectiva comparada: permanencia del modelo de varón sustentador. Reis: Revista Española de Investigaciones Sociológicas, (112), 131-164.

Moreno, A. (2007). Modelos familiares y empleo de la mujer en el estado de bienestar español. Estudios de progreso. Madrid: Fundación Alternativas.

Moreno, A. (2011). La reproducción intergeneracional de las desigualdades educativas: límites y oportunidades de la democracia. Revista de Educación. Número extraordinario 2011, 183-206.

Moreno, A. (2013). Situación demográfica, económica y laboral de las personas jóvenes. Informe 2012, Juventud en España. Madrid: Instituto de la Juventud.

Moreno, A., López, A., y Segado, S. (2012). La transición de los jóvenes a la edad adulta. Crisis económica y emancipación tardía. Barcelona: Obra Social La Caixa.

Pérez Camarero, S., Calderón, M. J., Hidalgo, A., y Ianova, A. (2010). Efectos de la crisis económica sobre la juventud española. Manuscrito sin publicar. http://www.congosto.ccbierzo.net/portalBierzo/portalJuventud/RecursosWeb/DOCUM ENTOS/1/0_14033_1.pdf 
Prieto, C. (1999). Crisis de empleo: ¿crisis del orden social? En F. Mínguez y C. Prieto (Eds.), Las relaciones de empleo en España. Madrid: Siglo Veintiuno Editores.

Ramos da Silva, A. C. (2006). Welfare arrangements, safety nets and familial support for the elderly in Portugal (Doctoral dissertation, The London School of Economics and Political Science (LSE)).

Requeijo, J. (2002). Economía mundial. Madrid: McGraw-Hill.

Reygadas, L. (2004). Las redes de la desigualdad: un enfoque multidimensional. Política y Cultura, (22), 7-25.

Ritzer, G. (2001). Teoría sociológica clásica. Madrid: McGraw-Hill.

Ritzer, G., y Casado Rodríguez, M. T. (2001). Teoría sociológica moderna. Madrid: McGraw-Hill.

Robette, N. (2010). The diversity of pathways to adulthood in France: Evidence from a holistic approach. Advances in Life Course Research, 15 (2), 89-96.

Rodríguez, C. (1994). Ciclos demográficos, una perspectiva socioeconómica. Valladolid: Secretariado de Publicaciones, Universidad de Valladolid.

Sánchez, M. T., y Sotomayor, E. V. (2009). Escenarios tendenciales en el nuevo siglo. En J. F. Tezanos (Ed.), Juventud y exclusión social. Madrid: Editorial Sistema.

Santamaría López, E. (2012). Jóvenes y precariedad laboral: trayectorias laborales por los márgenes del empleo. Zerbitzuan: Gizarte zerbitzuetarako aldizkaria= Revista de servicios sociales, (52), 129-139.

Santos, A.; Muñoz, D.; Gentile, A.; Moreno, (2016). Emancipación juvenil residencial, modelos de Estado de bienestar y políticas de vivienda. ZERBITZUAN, 59: 107-127 y Youth and Policy, 104: 5-16.

Saraví, G. (2004). Entre la evasión y la exclusión social: jóvenes que no estudian ni trabajan. Una exploración del caso argentino. Nueva Sociedad, (189), 69-84.

Segalen, M. (2006). Antropología histórica de la familia. Madrid: Taurus (colecc. universitaria).

Silver, H. (2007). The process of social exclusion: the dynamics of an evolving concept. doi: $10.2139 /$ ssrn. 1087789 
Sironi, M., Barban, N., e Impicciatore, R. (2015). Parental social class and the transition to adulthood in Italy and the United States. Advances in Life Course Research, (26), 89104.

Sistema Estatal de Indicadores de la Educación (2012). Ministerio de Educación Cultura y Deportes.

Souto Kustrín, S. (2007). Juventud, teoría e historia: la formación de un sujeto social y de un objeto de análisis. HAOL, (13), 171-192. ISSN 1696-2060.

Tejerina, B., Perugorría, I., y Simó, C. (2013). Crisis y empleo juvenil en Europa, una perspectiva del Sur ¿una solución europea? Monografía del Consejo de la Juventud de España. Madrid.

Tezanos, J. F. (2001). El trabajo perdido: ¿hacia una civilización postlaboral? Madrid: Biblioteca Nueva.

Tezanos, J. F. (2009). Las generaciones perdidas. Tendencias de precariedad laboral y exclusión social en los jóvenes. En J. F. Tezanos (Ed.), Juventud y exclusión social. Madrid: Editorial Sistema.

Theil, H. (1972). Statistical decomposition analysis; with applications in the social and administrative sciences. Amsterdam: North Holland Publ.

Tian, F. F. (2016). Transition to adulthood in China in 1982-2005: a structural view. Demographic Research, 34, 451.

Toharia, L. (2002). La incidencia familiar del paro. En L. Garrido Medina y E. Gil Calvo (Eds.), Estrategias familiares. Madrid: Alianza Universidad.

Torres, A., y Lapa, T. (2010). Familia y jóvenes en Europa. Convergencia y diversidad. Revista de Estudios de Juventud, (90), 11-32.

Torres, J. (1999). Nuevas expresiones de la desigualdad social. Estudios Regionales, (54), 147-160.

Toulemon, L. (2009). Transition to adulthood in Europe: Is there convergence between countries and between men and women? European Commission Directorate-General Employment, Social Affairs and Equal Opportunities. Unit E1 - Social and Demographic Analysis, December 2009. 
Ulrich, K. (2008). New Directions in Life Course Research. Yale University, Center for Research on Inequalities and the Life Course. ciqle@yale.edu www.yale.edu/ciqle

Urcola, M. (2003). Algunas apreciaciones sobre el concepto sociológico de juventud. Invenio, 6 (11), 41-51.

Vieira, J. M. (2013). Possibilidades de aplicação da análise de entropia nas Ciências Sociais e na Demografia. Idéias-Revista do Instituto de Filosofia e Ciências Humanas da UNICAMP.

Vieira, J., y Miret, P. (2010). Transición a la vida adulta en España: una comparación en el tiempo y en el territorio utilizando el análisis de entropía. Reis: Revista Española de Investigaciones Sociológicas, (131), 75-107.

Vitali, A. (2010). Regional differences in young Spaniards' living arrangement decisions: A multilevel approach. Advances in life course research, 15 (2), 97-108. 


\section{BASES DE DATOS}

Banco de España. http://www.bde.es/bde/es/

Centro de Investigaciones Sociológicas. http://www.cis.es/cis/opencms/ES/index.html

Eurostat. http://ec.europa.eu/eurostat/web/main/home

INJUVE. http://www.injuve.es/

Instituto Nacional de Estadística. http://www.ine.es/

Ministerio de Educación Cultura y Deporte de España. www.mecd.gob.es 
